Aus der Abteilung Molekulare Neurobiologie

(Leiter: PD Dr. rer. nat. N. Brose)

des Max-Planck-Instituts für Experimentelle Medizin

in Göttingen

\title{
$\alpha$-Synuclein: Synaptische Funktion und Rolle bei der \\ Pathogenese der Parkinson-Syndrome
}

\author{
INAUGURAL - DISSERTATION \\ zur Erlangung des Doktorgrades \\ der Medizinischen Fakultät \\ der Georg-August-Universität zu Göttingen
}

vorgelegt von

Dr. rer. nat. Oliver M. Schlüter

aus

Göttingen

Göttingen 2001 
Dekan: Prof. Dr. med. M. Droese

\author{
I. Berichterstatter: PD Dr. N. Brose \\ II. Berichterstatter/in: Prof. Dr. med. W. Paulus
}

Tag der mündlichen Prüfung: 14. Juni 2002 


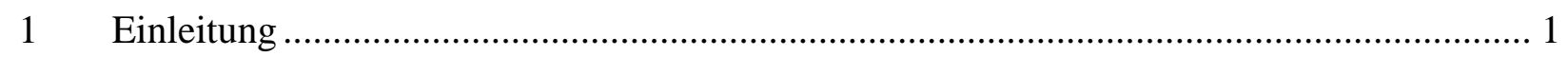

1.1 Anatomische und funktionelle Grundlagen.

1.2 Dopaminerge Systeme ........................................................................................

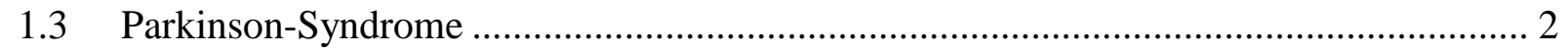

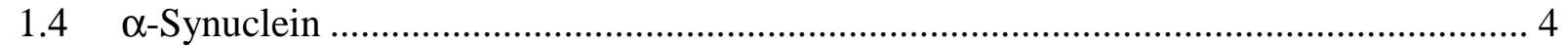

2 Zielsetzung ..........................................................................................................................

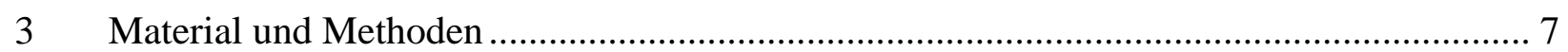

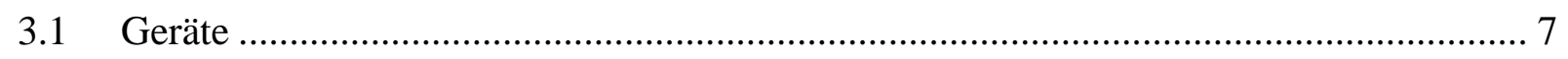

3.2 Computerprogramme und Internetzugänge …………………………………………….... 8

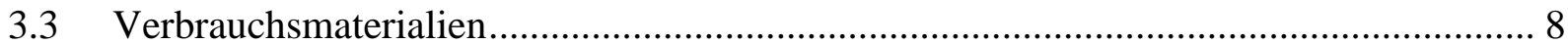

$3.4 \quad$ Chemikalien................................................................................................. 9

$3.5 \quad$ Chemikalien für die Zellkultur ................................................................................... 11

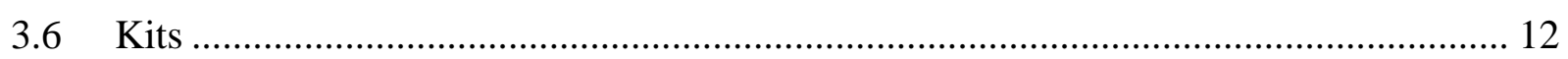

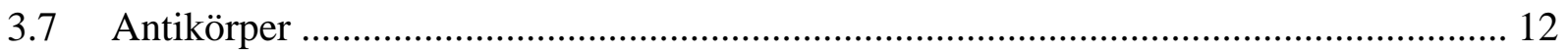

3.8 Plasmidvektoren ...................................................................................... 14

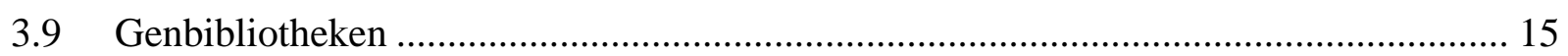

3.10 Synthetische Oligonukleotide ........................................................................................ 15

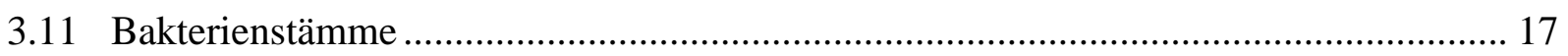

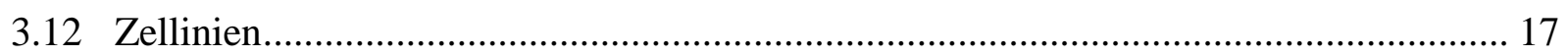

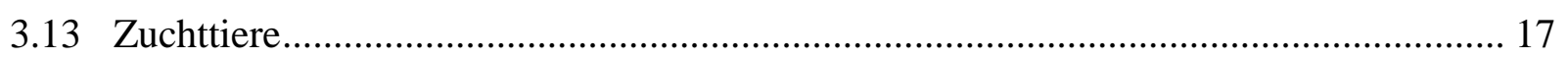

3.14 Medien und Lösungen .................................................................................................... 17

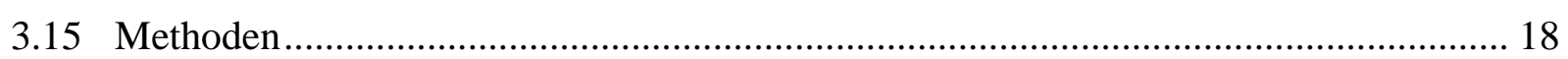

3.15 .1 DNA-Amplifikation über die Polymerasekettenreaktion ................................... 18

3.15.2 Polymerasekettenreaktion für die Genotypisierung................................................. 19

3.15.3 Subklonierung von Plasmid-DNA ...................................................................... 19

3.15.3.1 Herstellung elektrokompetenter Bakterien.................................................. 19

3.15.3.2 Transformation von Bakterien.................................................................... 19

3.15.3.3 Blau-weiß-Selektionstest........................................................................ 19

3.15.3.4 Testung auf gewünschte Klone über radioaktive Sonden ................................. 20

3.15.3.5 Testung auf gewünschte Klone über PCR .................................................... 20

3.15.4 Präparation von DNA …………............................................................................. 20

3.15.4.1 Phenol/Chloroform-Extraktion ………………………………………………… 20

3.15.4.2 DNA-Präzipitation ........................................................................................ 20 
3.15.4.3 Isolierung von DNA-Fragmenten aus Agarosegelen....................................... 20

3.15.4.4 Plasmidschnellpräparation ...........................................................................2 21

3.15.4.5 Plasmidpräparation hoher Reinheit ..................................................................... 21

3.15.4.6 Präparation genomischer DNA aus Gewebeproben ......................................... 21

3.15 .5 Kurzlyseprotokoll für genomische DNA von Gewebeproben .............................. 21

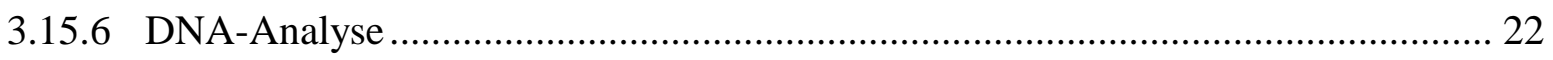

3.15.6.1 Konzentrationsbestimmung.............................................................................. 22

3.15.6.2 Restriktionsverdau von DNA .................................................................. 22

3.15.6.3 DNA-Sequenzierung …………............................................................. 22

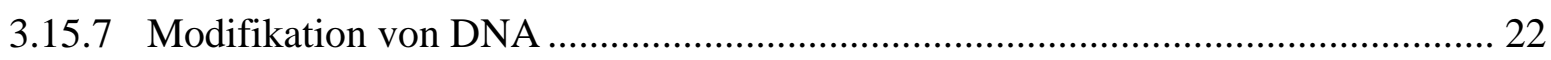

3.15 .7 .1 Dephosphorylierung der 5'-Enden von DNA ............................................ 22

3.15.7.2 Ligation von DNA ……………………………………………………………………. 22

3.15.7.3 Zielgerichtete Mutationen, eingefügt über die Polymerase-Kettenreaktion..... 23

3.15.7.4 Auffüllen und Verdau von überstehenden Enden nach Restriktionsverdau..... 23

3.15.7.5 Radioaktive Markierung von DNA ……………………….................................. 24

0.15 .8 DNA-Gelelektrophorese ............................................................................. 24

3.15 .9 DNA-Transfer auf Nylonmembranen nach Southern........................................... 24

$\$ .15 .10$ Hybridisierung ............................................................................................. 24

3.15.11 Klonierung aus Phagen-Genbibliotheken ......................................................... 25

3.15.11.1 Screening einer Phagen-Genbibliothek ……………………………………..... 25

3.15.11.2 Phagenamplifikation....................................................................................... 25

3.15.11.3 Präparation von $\lambda$-Phagen-DNA …............................................................ 25

3.15.11.4 Subklonierung der genomischen Klone .................................................. 26

3.15 .12 Sequenzanalyse und Datenbanksuche ........................................................ 26

3.15 .13 Gewinnung von Gewebehomogenaten ........................................................ 26

3.15.14 Subzelluläre Fraktionierung ........................................................................ 26

3.15.15 Proteinpräzipitation ..................................................................................... 27

3.15.16 Präparation von GST-Fusionsproteinen ……………........................................ 27

3.15.16.1 Überexpression von Fusionsproteinen in E. coli............................................. 27

3.15.16.2 Reinigung von Fusionsproteinen..................................................................... 27

3.15.16.3 Proteolytische Spaltung von Fusionsproteinen ............................................... 27

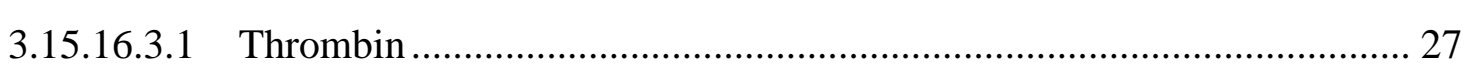

3.15.16.3.2 TEV-Protease ……............................................................................ 28 
3.15.16.4 Gelfiltrationschromatographie................................................................. 28

3.15.17 Immunisierung von Kaninchen ................................................................... 28

3.15.18 Messung der Neurotransmitteraufnahme ........................................................ 28

3.15.18.1 Synaptosomaler Transport............................................................................. 28

3.15.18.2 Vesikulärer Transport.............................................................................. 29

3.15.19 Nitrosylierung von Tyrosinresten in Gewebehomogenaten .................................... 29

3.15.20 Methoden zur Proteinanalyse ............................................................................... 29

3.15.20.1 Konzentrationsbestimmung von Proteinen ..................................................... 29

3.15.20.2 SDS-Polyacrylamidgelelektrophorese ....................................................... 30

3.15.20.3 Proteingelfärbung mit Coomassie Brilliant blue ………………..................... 30

3.15.20.4 Immunoblotanalyse ............................................................................... 30

3.15.20.4.1 Protein-Transfer nach Western ....................................................... 30

3.15.20.4.2 Immunodetektion von Proteinbanden........................................................ 31

3.15.20.4.3 Quantifizierung von Proteinbanden .......................................................... 31

3.15.21 Methoden für die Immunzytochemie ........................................................... 31

3.15.21.1 Fixierung von Mausgewebe ……………………....................................... 31

3.15.21.2 Fixierung von neuronalen Primärkulturen ………………………………….... 32

3.15.21.3 Bereitstellung von Gewebeschnitten ........................................................ 32

3.15.21.4 Gelatinebeschichtung von Objektträgern ..................................................... 32

3.15.21.5 Immunofärbung von Gewebeschnitten und Primärkulturen ............................. 32

3.15.22 Heterologe Expression in 293-Zellen ............................................................... 33

3.15.22.1 Einfrieren und Auftauen von eukaryontischen Zellen................................. 33

3.15.22.2 Passagierung von eukaryontischen Zellen..................................................... 33

3.15.22.3 Kultivierung von 293-Zellen ........................................................................ 33

3.15.22.4 Transfektion über Calciumphosphat-Kopräzipitate ..................................... 33

3.15.22.5 Gewinnung von Zellhomogenaten ............................................................. 34

3.15 .23 Erstellung hippokampaler Primärkulturen ...................................................... 34

3.15.23.1 Vorbereitung der Deckgläschen für die Kultur .............................................. 34

3.15.23.2 Hippokampuspräparation ............................................................................ 34

3.15.23.3 Neuronenkultur......................................................................................... 34

3.15.23.4 Astrozytenkultur ......................................................................................... 35

3.15.24 Herstellung rekombinanter embryonaler Mausstammzellen ............................... 35

3.15.24.1 Kultivierung von E14.1-Zellen................................................................. 35 
3.15.24.2 Kultivierung von embryonalen Mausfibroblasten ............................................. 35

3.15.24.3 Transfektion von E14.1-Zellen...................................................................... 36

3.15.24.3.1 Vorbereitung des Rekombinationsvektors ........................................... 36

3.15.24.4 Selektion von homolog rekombinierten E14.1-Zellen ................................... 36

3.15.24.5 Isolierung der resistenten Klone ............................................................ 36

3.15.24.6 Vorbereitung für die Blastozysten-Injektion ................................................... 36

3.15.24.7 DNA-Isolierung aus in 96-Lochplatten kultivierten E14.1-Zellen................... 36

3.15.25 Pharmakologische Behandlung von Mäusen.................................................... 37

3.15.25.1 Quantifizierung der Neurotransmitter ........................................................ 37

3.15.25.1.1 Catecholamine ............................................................................. 37

3.15.25.1.2 Aminosäuren................................................................................ 37

3.15.25.1.3 Proteinbestimmung nach Lowry.................................................... 38

$4 \quad$ Ergebnisse ............................................................................................................. 39

$4.1 \quad$ Klonierung und Charakterisierung von Synuclein-Isoformen aus Mensch und Ratte ... 39

$4.2 \quad$ Klonierung eukaryontischer Expressionskonstrukte ……………….............................. 41

4.3 Einfügung der Missense-Mutationen der familiären Parkinson-Syndrome .................... 41

$4.4 \quad$ Erstellung bakterieller Expressionsvektoren .................................................................. 41

$4.5 \quad$ Klonierung von Vektoren zur Herstellung transgener Mäuse ………………………….. 42

$4.6 \quad$ Klonierung und Charakterisierung des Maus- $\alpha$-Synuclein-Gens.................................... 43

$4.7 \quad$ Klonierung eines Rekombinationsvektors für das $\alpha$-Synuclein-Gen ........................... 43

$4.8 \quad$ Antikörperherstellung und -charakterisierung ............................................................. 44

$4.9 \quad$ Verteilung von $\alpha$ - und $\beta$-Synuclein im Mausgehirn ……....................................... 46

$4.10 \quad$ Subzelluläre Verteilung von $\alpha$ - und $\beta$-Synuclein........................................................ 49

4.11 Erzeugung von Maus- $\alpha$-Synuclein-Nullmutanten ................................................... 51

4.12 Charakterisierung der Maus- $\alpha$-Synuclein-Nullmutanten ....................................... 51

4.13 Pharmakologisches Tiermodell eines Parkinson-Syndroms...................................... 57

4.14 Untersuchung der C57B16/J/ola/hsd-Mauslinie .......................................................60

4.15 Untersuchung der Modulation des synaptischen Dopamintransports durch $\alpha$-Synuclein

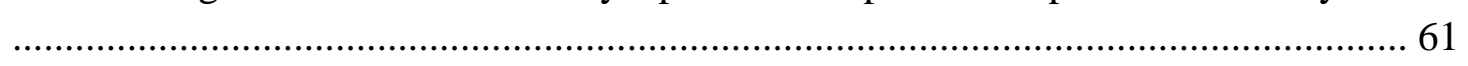

4.16 Herstellung und Analyse transgener, $\alpha$-Synuclein überexprimierender Mäuse ............. 63

4.17 Untersuchung neurologischer Ausfälle durch Mutationen der familiären ParkinsonSyndrome ................................................................................................................... 67

$4.18 \quad$ Symptomverstärkung in doppelt-transgenen Mäusen .................................................... 67 
4.19 Symptomatik bei Imitierung eines konstitutiv phosphorylierten Serin-87 _...................68

4.20 Vergleich der Expressionsstärke mit der Schwere der neurologischen Ausfälle ........... 69

4.21 Einfluß der $\alpha$-Synuclein-Mutanten auf das dopaminerge System................................ 69

$4.22 \quad$ In-vitro-Nitrosylierung von $\alpha$-Synuclein................................................................. 73

$5 \quad$ Diskussion ................................................................................................. 74

$5.1 \quad$ Physiologische Funktion von $\alpha$-Synuclein ……………………….............................. 74

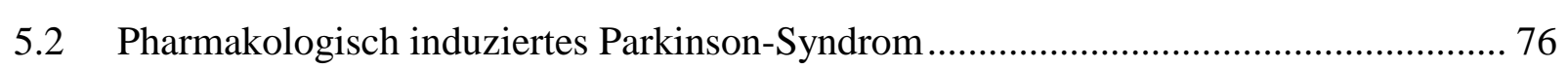

$5.3 \quad$ Rolle von $\alpha$-Synuclein in der Pathogenese der Parkinson-Syndrome........................... 78

$6 \quad$ Zusammenfassung ............................................................................................... 82

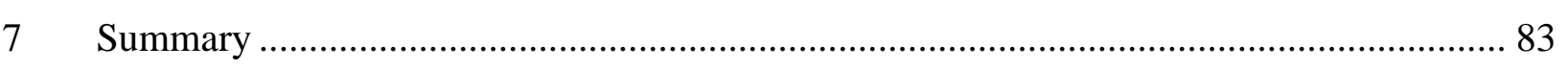

$8 \quad$ Literaturverzeichnis..................................................................................................... 84 


\section{Abkürzungen und Anglizismen}

Viele wissenschaftliche Begriffe entstammen dem englischen Wortschatz und können nur schwer ins Deutsche übersetzt werden. Die hieraus verwendeten Begriffe und Abkürzungen sind im folgenden erläutert:

$3^{\prime}$ oder $5^{\prime}$

AMBA

APS

AS

ATP

BSA

cAMP

cDNA

cfu

CTAB

C-terminal

dCTP

DMEM

DMF

DNA

dNTP

D-PBS

DTT

ECL

EDTA

EST

g

GAPDH

GDI

GDP

GST

GTP

HEPES

HRP

IgG

insert

IP-3
Bezeichnug des DNA-Strangendes, das die 3'- bzw. 5'-Hydroxylgruppe des Zuckers des DNA-Rückgrats trägt.

Acrylamid-/Bisacrylamid-Lösung

Ammoniumperoxodisulfat

Aminosäure

Adenosintriphosphat

Rinderserumalbumin

zyklisches Adenosin-3', 5'-Monophosphat

komplementäre DNA, die durch revers transkribierte mRNA erhalten wird

colony forming units

Cetyl-Trimethylammoniumbromid

am Carboxylende eines Proteins gelegen

desoxy-Cytidintriphosphat

Dulbecco's modified eagle medium

Dimethylformamid

Desoxyribonukleinsäure

äquimolare Desoxyribonukleotidtriphosphatmischung

Dulbecco's PBS

Dithiothreitol

enhanced chemoluminescence

Ethylendiamintetraessigsäure

expressed sequence tag

Erdbeschleunigung

Glycerinaldehyd-3-Phosphatdehydrogenase

GDP dissociation inhibitor

Guanosin-5'-Diphosphat

Glutathion-S-Transferase

Guanosin-5'-Triphosphat

N-2-Hydroxyethylpiperazin-N-2-Ethansulfonsäure

Meerrettich-Peroxidase

Immunglobulin $\mathrm{G}$

in einen Vektor klonierte DNA-Sequenz

Inositol-3-Phosphat 


\begin{tabular}{|c|c|}
\hline IPTG & Isopropyl- $\beta$-thiogalactopyranosid \\
\hline $\mathrm{kb}$ & 1000 Basenpaare \\
\hline $\mathrm{K}_{\mathrm{D}}$ & Dissoziationskonstante \\
\hline $\mathrm{kD}$ & Kilodalton \\
\hline KO & knockout $=$ Nullmutante \\
\hline lift & $\begin{array}{l}\text { durch Auflegen einer Nylonmembran auf Agar adsorbieren z.B. Phagen } \\
\text { an dieser }\end{array}$ \\
\hline mRNA & messenger- oder Boten-RNA \\
\hline Munc & mammalian unc (uncoordinated movements) homolog \\
\hline $\mathrm{NACP}$ & non- $A_{\beta}$ component of $A D$ amyloid protein \\
\hline NEB & New England Biolabs GmbH \\
\hline NMDA & N-Methyl-D-Aspartat \\
\hline Northernblot & über Kapillarwirkung erzielter RNA-Transfer vom Gel auf Membranen \\
\hline NSF & N-ethylmaleimide-sensitive factor \\
\hline N-terminal & am Aminoende eines Proteins gelegen \\
\hline OD & optische Dichte \\
\hline PAGE & Polyacrylamidgelelektrophorese \\
\hline PBS & phosphatgepufferte physiologische Kochsalzlösung \\
\hline PCR & Polymerasekettenreaktion \\
\hline PET & Positronen-Emissions-Tomographie \\
\hline pfu & plaque forming units \\
\hline Pfu & Pyrococcus furiosus, thermophiler Bakterienstamm \\
\hline $\mathrm{pH}$ & negativer dekadischer Logarithmus der Protonenkonzentration \\
\hline PMSF & Phenyl-Methylsulfonyl-Fluorid \\
\hline PNS & post nuclear supernatant \\
\hline $\begin{array}{l}\text { post nuclear } \\
\text { supernatant }\end{array}$ & $\begin{array}{l}\text { Überstand einer Zentrifugation bei 1000x g eines Gewebehomogenates, } \\
\text { durch die Zellkerne und Kern-haltige Zellen sedimentiert werden }\end{array}$ \\
\hline Primer & $\begin{array}{l}\text { synthetisch hergestellte einzelsträngige DNA, die z.B als Starter- } \\
\text { moleküle für PCR-Reaktionen verwendet werden }\end{array}$ \\
\hline Rim & Rab3 interacting molecule \\
\hline RNA & Ribonukleinsäure \\
\hline rpm & revolutions per minute (Umdrehungen pro Minute) \\
\hline SCAMP & secretory carrier membrane protein \\
\hline SDS & Sodiumdodecylsulfat \\
\hline SDS-PAGE & SDS-Polyacrylamidgelelektrophorese \\
\hline SNAP & soluble NSF-attachement protein \\
\hline SNAP-25 & synaptosome-associated protein of $25 \mathrm{kD}$ \\
\hline SNARE & SNAP-Rezeptor \\
\hline Southernblot & über Kapillarwirkung erzielter DNA-Transfer vom Gel auf Membranen \\
\hline
\end{tabular}


In dieser Arbeit als Bezeichnung für kurze an ein Protein angefügte Aminosäurensequenzen, über die dieses affinitätschromatographisch gereinigt werden kann oder die als Antigen für die Immunodetektion dienen

Taq

TCA

TEMED

TEV

$\mathrm{U}$

UCHL

UTR

Westernblot

wt

$\mathrm{X}-\mathrm{Gal}$

ZNS
Thermus aquaticus, thermophiler Bakterienstamm

Trichloressigsäure

$\mathrm{N}, \mathrm{N}, \mathrm{N}$ ', N'-Tetramethylethylendiamin

tobacco envelope virus

Unit

Ubiquitin-Carboxylterminale-Hydrolase

5' oder 3' gelegener nicht translatierter Sequenzabschnitt der mRNA

durch ein elektrisches Feld erzielter Protein-Transfer vom Gel auf Membranen

Wildtyp

5-Brom-4-Chlor-3-Indolyl- $\beta$-Galactosid

Zentralnervensystem 


\section{$1 \quad$ Einleitung}

\subsection{Anatomische und funktionelle Grundlagen}

Das Zentralnervensystem besteht aus schätzungsweise $10^{11}$ Neuronen, die miteinander über Neurotransmitter kommunizieren. Als Neurotransmitter dienen die Aminosäuren Glutamat und Glycin, GABA sowie Monoamine, insbesondere Dopamin, Serotonin und Histamin. Glutamat wirkt über seine Rezeptoren erregend auf die nachgeschalteten Nervenzellen, während GABA und Glycin inhibierend wirken.

Systematisch unterteilt man das Gehirn von kaudal nach rostral in Rautenhirn, Mittelhirn, Zwischenhirn und Endhirn. Das Endhirn enthält als oberstes Integrationszentrum zentralnervöser Prozesse die Großhirnrinde und als akzessorisches Zentrum sowohl motorischer als auch mentaler Aktionen Anteile der Basalganglien. Die Basalganglien bestehen aus Nucleus caudatus, Putamen, dem dem Zwischenhirn angehörenden Globus pallidus und dem dem Mittelhirn angehörenden Nucleus subthalamicus sowie der Substantia nigra. Funktionell und zytologisch werden der Nucleus caudatus und das Putamen als Striatum zusammengefaßt. Die Substantia nigra besteht aus der Zona compacta, die große Neuromelanin-haltige Neurone des dopaminergen Systems enthält, und der Zona reticulata, die zytologisch dem Globus pallidus gleicht.

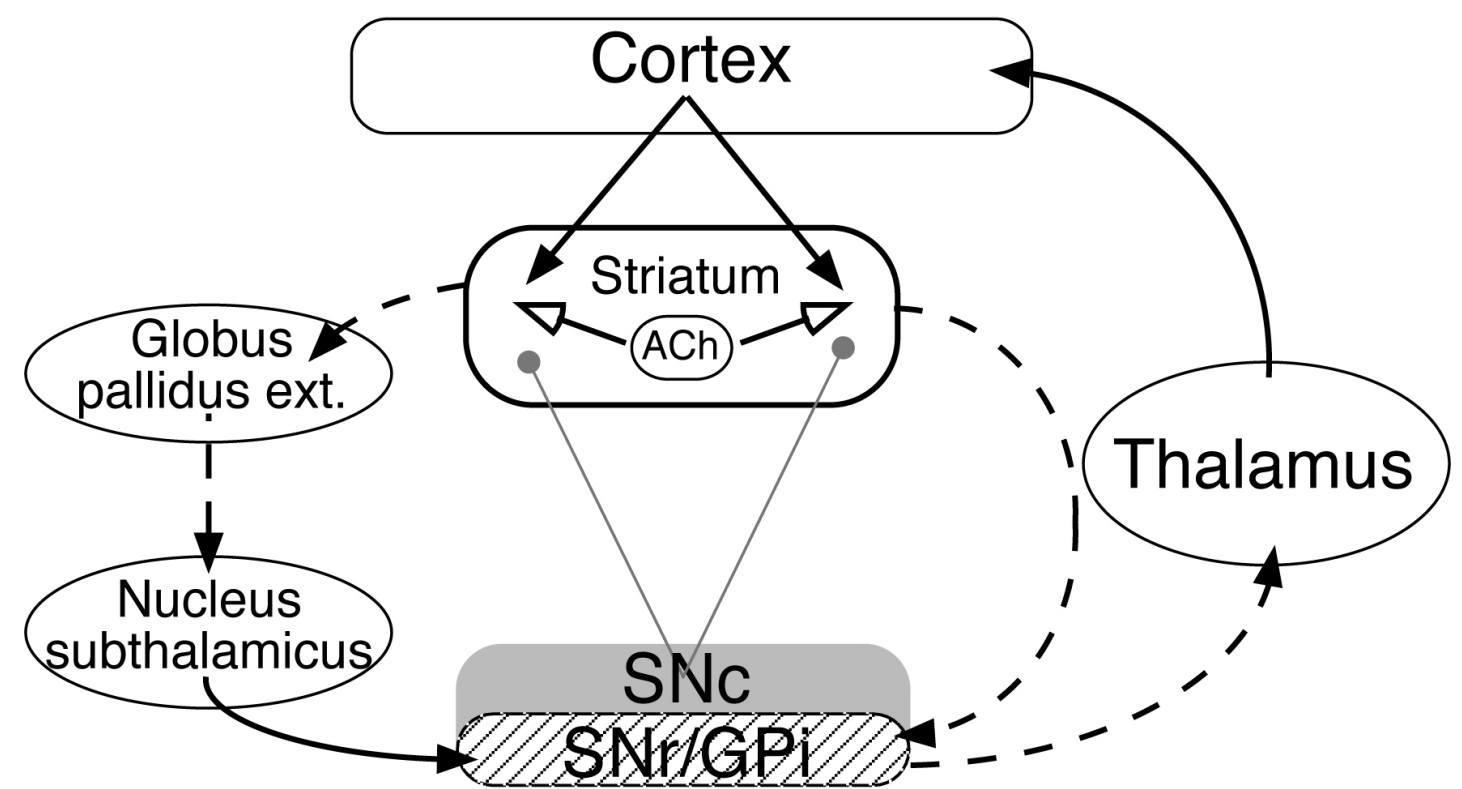

Abb. 1: Schematische Darstellung der neuronalen Verschaltung in den Basalganglien. Glutamaterge Neurone des Cortex innervieren zwei Haupttypen von inhibitorischen Neuronen im Striatum. Der eine Typ koexprimiert die Neuropeptide Dynorphin und Substanz P und projiziert direkt auf den Globus pallidus internus (GPi) und die Substantia nigra pars reticulata (SNr) (direkter Weg). Die andere Gruppe der GABAergen Neurone exprimiert Enkephalin und projiziert über den indirekten Weg über den Globus pallidus externus und den Nucleus subthalamicus auf den Globus pallidus internus bzw. die Substantia nigra pars reticulata. Von diesen wird der Thalamus gehemmt, von dem glutamaterge Neurone zurück in den Cortex projizieren. Die GABAergen Neurone im Striatum werden weiterhin von lokalen cholinergen Neuronen (ACh) stimuliert bzw. von dopaminergen Neuronen aus der Substantia nigra pars compacta inhibiert. GABAerge Wege sind durch gestrichelte Pfeile, glutamaterge durch durchgezogene Pfeile, dopaminerge durch graue Pfeile und cholinerge durch Pfeile mit offener Spitze dargestellt. 
Als akzessorisches motorisches Zentrum unterstützen die Basalganglien die Willkürmotorik über Steuerung des Muskeltonus von Agonisten und Antagonisten (Abb. 1). So führen Erkrankungen der Basalganglien zu hypo- oder hyperkinetischen Syndromen, wie etwa den ParkinsonSyndromen, der Chorea Huntington, dem Hemiballismus und anderen. Die Eingangsstruktur bildet das Striatum, dessen Haupt-Innervation glutamaterg aus dem prämotorischen Cortex auf das Putamen erfolgt. Die Ausgangsstruktur bilden der Globus pallidus internus und die Substantia nigra pars reticulata, von denen GABAerge Bahnen zum Hirnstamm und dem Thalamus ziehen. Vom Putamen ziehen zwei Bahnen über verschiedene Stationen zum Thalamus. Der direkte Weg führt GABAerg zum Globus pallidus internus und über ihn zur Anregung des Thalamus, während der indirekte Weg GABAerg zum Globus pallidus externus und Nucleus subthalamicus und glutamaterg zum Globus pallidus internus zieht und dadurch zur Inhibition des Thalamus führt. Der direkte und indirekte Weg steuert Agonisten und Antagonisten der Muskeln und wirkt daher synergistisch. Der direkte und der indirekte Weg werden über dopaminerge Fasern aus der Substantia nigra moduliert, die je nach Dopaminrezeptorsubtyp inhibierend oder stimulierend wirken.

\subsection{Dopaminerge Systeme}

Das dopaminerge System wird in vier Bahnen unterteilt. Der nigrostriatale Trakt zieht von Neuromelanin-haltigen Neuronen der Substantia nigra pars compacta zum Striatum. Wie oben erwähnt, wirkt er modulatorisch auf die akzessorische motorische Funktion der Basalganglien. Reduktion der dopaminergen Zellen und Dopaminantagonisten führen zu Hypokinese, Rigor und Tremor.

Der mesokortikale Trakt entstammt dem ventralen mesenzephalen Tegmentum und innerviert den anteromedialen Frontalkortex. Erkrankungen dieses Systems führen möglicherweise zu kognitiven Störungen bei Parkinson-Syndromen.

Der mesolimbische Trakt zieht vom ventralen mesenzephalen Tegmentum zum limbischen System. Er reguliert Stimmung, Affekt und Antrieb, und indirekte Dopaminagonisten wie Kocain führen hier zu Halluzinationen. Die Wirksamkeit von Neuroleptika bei der Behandlung von Psychosen wird durch einen Effekt auf dieses System erklärt.

Tuberoinfundibuläre Bahnen innervieren die Hypophyse aus dem Hypothalamus. Sie führen zur Hemmung der Prolaktin-Freisetzung. Daher können Dopaminantagonisten wie Bromocriptin zum Abstillen verwendet werden. Neuroleptika wirken ebenfalls auf diese Bahnen und können als unerwünschte Wirkung zu Laktation führen.

\subsection{Parkinson-Syndrome}

In Parkinson-Syndromen kommt es zu einer Degeneration dopaminerger Neurone in der Zona compacta der Substantia nigra (SNC). Beim idiopathischen Parkinson-Syndrom, dem Morbus Parkinson, sind die ventrolateralen Anteile, die zum Putamen ziehen, besonders stark betroffen. Charakteristisch für Parkinson-Syndrome sind eosinophile intrazytoplasmatische Einschlußkörperchen, die Lewy-Körper, die in dopaminergen Neuronen der Substantia nigra, aber auch in anderen Neuronen vorkommen. Lewy-Körper kommen aber auch bei anderen neurodegenerativen Erkrankungen, insbesondere einer Unterform des Morbus Alzheimer vor (Lang und 
Lozano 1998; Lowe et al. 1990). Eine infektiöse Form der Parkinson-Syndrome, die Encephalitis lethargica, und eine familiäre Form, das juvenile autosomal rezessive Parkinson-Syndrom, zeigen keine Einschlußkörperchen. Allen Formen gemeinsam ist eine Reduktion der Neurone in der Substantia nigra, die zu einer dopaminergen Minderinnervation des Striatums führt. Ab einem Verlust von ca. $60 \%$ der Neuromelanin-haltigen Neurone oder einer Dopaminreduktion von ca. $80 \%$ im Striatum kommt es zu den charakteristischen Symptomen, wie Tremor, Rigor und Bradykinese (Bernheimer et al. 1973; Fearnley und Lees 1991; McGeer et al. 1988). Die idiopathische Form ist mit $80 \%$ der Fälle auch die häufigste. Sie beginnt im allgemeinen zwischen dem 50- und 60sten Lebensjahr. Die jährliche Inzidenz liegt bei 20 pro 100.000 Einwohnern mit einer Prävalenz von 100 bis 200 pro 100.000. Damit ist der Morbus Parkinson die zweithäufigste neurodegenerative Erkrankung nach dem Morbus Alzheimer. Früher war die Mortalität von Parkinson-Patienten dreifach gegenüber gleichaltrigen Personen erhöht. Nach Einführung der Dopaminsubstitutionstherapie war sie nicht mehr signifikant erhöht. Problematisch bleibt insbesondere nach mehrjähriger Therapiedauer die hohe Rate der Pflegebedürftigkeit.

Neben der Substantia nigra sind auch andere pigmentierte Hirnareale betroffen. Hierunter fallen der noradrenerge Locus coeruleus, der serotonerge Nucleus raphe dorsalis und der dorsale motorische Vaguskern. Bei Parkinson-Patienten mit kognitiven Störungen findet man im Nucleus basalis Meynert einen über 70 \%igen Verlust cholinerger Neurone. Dieser Kern ist insbesondere beim Morbus Alzheimer betroffen.

Obwohl die Parkinson-Erkrankung schon 1817 erstmals von James Parkinson beschrieben wurde, ist erst in den letzten Jahren über die Ätiologie etwas bekannt geworden. Eine toxische Genese wurde vermutet, nachdem Drogenabhängige durch die Injektion von mit 1-Methyl-4Phenyl-1,2,3,6-Tetrahydro-Pyridin (MPTP) verunreinigten Meperidin-Analoga ein ParkinsonSyndrom entwickelten (Langston et al. 1983). MPTP wird in Gliazellen über die Monoaminoxidase B in das L-Methyl-Phenyl-Pyridinium-Ion $\left(\mathrm{MPP}^{+}\right)$oxidiert und über den Dopamintransporter selektiv in dopaminerge Neuronen aufgenommen (Javitch et al. 1985; Markey et al. 1984). $\mathrm{MPP}^{+}$inhibiert effektiv den Komplex I der mitochondrialen Atmungskette (Nicklas et al. 1985; Ramsay et al. 1986). So wurde in Parkinson-Patienten eine verminderte Aktivität der mitochondrialen NADH-Dehydrogenase in der SNC nachgewiesen. Neben der verminderten ATPSynthese deuten erhöhte Eisen- und reduzierte Glutathion- und Ferritin-Spiegel auf eine erhöhte Anfälligkeit gegenüber oxidativen Entgleisungen hin (Dexter et al. 1990; Jellinger et al. 1993; Sian et al. 1994).

Eine genetische Ursache des Morbus Parkinson konnte bisher zwar nicht bewiesen werden, doch fand sich bei PET-Zwillingsstudien eine hohe Konkordanz für verminderte striatale Dopaminlevel im präklinischen Stadium (Piccini et al. 1999).

Die sehr viel selteneren familiären Formen der Parkinson-Syndrome können in zwei Gruppen aufgeteilt werden. Die erste wird autosomal-dominant vererbt und durch Mutationen im $\alpha-$ Synuclein- oder dem UCHL 1-Gen charakterisiert. Beide bisher im $\alpha$-Synuclein-Gen identifizierten Mutationen führen zu einem einzelnen Aminosäurenaustausch, Alanin-30 zu Prolin (A30P) bzw. Alanin-53 zu Threonin (A53T) (Krüger et al. 1998; Polymeropoulos et al. 1997). Der Erkrankungsbeginn (im Mittel 45 Jahre) liegt wesentlich früher als beim Morbus Parkinson. Der Aminosäurenaustausch von Isoleucin-93 zu Methionin im UCHL 1-Gen reduziert die enzymatische Aktivität dieses Proteins und führt ebenfalls zu einem L-DOPA-sensitiven Parkinson-Syndrom (Leroy et al. 1998). Der Erkrankungsbeginn der beiden betroffenen 
Geschwister lag bei 50 Jahren. Die Penetranz dieser Erkrankung ist jedoch nicht vollständig, wie der Erbgang über den nicht erkrankten Vater zeigt. UCHL 1 kann wie auch $\alpha$-Synuclein in Lewy-Körpern nachgewiesen werden (Lowe et al. 1990). Das Protein selber ist eines der häufigsten neuronalen Proteine und macht ca. $2 \%$ des Proteingewichtes des menschlichen Gehirns aus (Wilkinson et al. 1992; Wilkinson et al. 1989). Zwei weitere autosomal dominant vererbte Loci an den chromosomalen Positionen 2p13 und 4p15 wurden bisher identifiziert, wobei die betroffenen Gene noch nicht bekannt sind (Farrer et al. 1999; Gasser et al. 1998).

Der Erbgang der zweiten Gruppe erfolgt autosomal rezessiv. Diese Erkrankung ist durch einen frühen Beginn, eine langsame Progredienz, Empfindlichkeit gegenüber L-DOPA und die Abwesenheit von Lewy-Körpern charakterisiert (Matsumine et al. 1998). Das identifizierte Gen liegt an der chromosomalen Position 6q27 und kodiert für das Protein Parkin (Kitada et al. 1998). Bei den betroffenen Patienten waren unterschiedliche Exone deletiert.

\section{$1.4 \quad \alpha-S y n u c l e i n$}

Die Synuclein-Proteinfamilie wird im Menschen von vier verschiedenen Genen an den chromosomalen Positionen 4q21.3 für $\alpha$-, 5q35 für $\beta$ - und 10q23.2 für $\gamma$-Synuclein kodiert (Jakes et al. 1994; Lavedan et al. 1998; Polymeropoulos et al. 1997). Zusätzlich gibt es noch das Retina-spezifische Paralog Synoretin (Surguchov et al. 1999). Die drei Paraloge $\alpha-, \beta$ - und $\gamma-$ Synuclein sind zwischen 127 und 140 Aminosäuren lang und zu 55-62 \% identisch. N-terminal sind sie durch eine unvollendete Aminosäurenwiederholung (fünf bis sieben Wiederholungen) charakterisiert (Goedert 2001). Der C-Terminus des löslichen Proteins ist negativ geladen. Die Klonierung der Proteine erfolgte unabhängig in verschiedenen biologischen Zusammenhängen. $\gamma$-Synuclein wurde 1988 zunächst aus dem elektrischen Organ des Zitterrochens isoliert und später aus der Ratte kloniert (Maroteaux und Scheller 1991; Maroteaux et al. 1988). Die damals identifizierte synaptische und nukleäre Lokalisation gaben dem Protein seinen Namen Synuclein. Das $\beta$-Ortholog wurde bei der Suche nach Phosphoproteinen im Rinderhirn als PhosphoNeuroprotein 14 (PNP-14) entdeckt (Nakajo et al. 1993; Nakajo et al. 1990). Bei der Charakterisierung von Alzheimer-Plaques wurde in diesen später das humane $\alpha$-Ortholog als weitere Komponente neben $A_{\beta}$ identifiziert und als NACP bezeichnet (Ueda et al. 1993). Das $\alpha-$ Synuclein-Ortholog Synelfin der Zebrafinken wurde im Zusammenhang von veränderten Protein-Expressionsmustern während der kritischen Phase des Lernens von Balzliedern durch männliche Vögel gefunden (George et al. 1995). Dieses regulierte Expressionsmuster veranlaßte die Autoren, Synuclein eine Funktion in der synaptischen Plastizität zuzuschreiben.

$\alpha$-Synuclein ist ein sehr häufiges präsynaptisches Protein, das ca. $1 \%$ des gesamten löslichen Gehirnproteins ausmacht (Iwai et al. 1995). Während $\alpha$-Synuclein bevorzugt im Endhirn exprimiert wird, ist die Verteilung von $\beta$-Synuclein homogener (Irizarry et al. 1996; Iwai et al. 1995; Nakajo et al. 1994). $\gamma$-Synuclein wurde durch subtraktive Hybridisierung aus Spinalganglien kloniert und wird bevorzugt in diesen und dem Rückenmark exprimiert (Akopian und Wood 1995; Buchman et al. 1998a; Buchman et al. 1998b). In der Präsynapse liegen $\alpha$ - und $\beta$-Synuclein hauptsächlich zytosolisch vor, wie durch subzelluläre Fraktionierungen und Immunogold-Färbungen gezeigt werden konnte (Clayton und George 1999; Iwai et al. 1995; Kahle et al. 2000; Nakajo et al. 1994; Shibayama-Imazu et al. 1993). In vitro bindet $\alpha$-Synuclein an Vesikel, die einen hohen Anteil saurer Phospholipide enthalten (Davidson et al. 1998). Durch 
die Bindung verändert das Protein seine Struktur von ungefaltet in $\alpha$-helikal, wobei insbesondere der N-terminus beteiligt ist (Clayton und George 1998; Davidson et al. 1998; Weinreb et al. 1996). Interessanterweise nimmt $\alpha$-Synuclein in Lewy-Körper-Filamenten eine für Amyloid typische gekreuzte $\beta$-Faltblatt-Struktur an, die für die Aggregation notwendig ist (Conway et al. 2000; Serpell et al. 2000).

Über die physiologische Funktion von Synuclein ist trotz intensiver Forschung noch wenig bekannt. Neben dem indirekten Hinweis auf eine Beteiligung bei der synaptischen Plastizität wurde eine Funktion in der Signaltransduktion vermutet. In diesem Zusammenhang wurden $\alpha$ und $\beta$-Synuclein als potente Inhibitoren der Phospholipase D2 isoliert (Jenco et al. 1998). Phospholipase D2 ist nahe der Plasmamembran lokalisiert und hydrolysiert Phosphatidylcholin in Cholin und Phosphatidylsäure, die als sekundäre Botenmoleküle wirken (Colley et al. 1997; Exton 1997). Eine Phosphorylierung von $\alpha$-Synuclein durch G-Protein-gekoppelte Rezeptorkinasen (GRKn) am Serin-129 und durch Mitglieder der Src-Tyrosinkinase-Familie am Tyrosin-125 deutet in die gleiche Richtung (Ellis et al. 2001; Pronin et al. 2000). Eine physiologische Bedeutung konnte jedoch bisher für keinen dieser Prozesse nachgewiesen werden. 


\section{Zielsetzung}

Das erste Synuclein-Ortholog wurde zwar bereits 1988 kloniert, doch fand das Molekül bis 1997 wenig Aufmerksamkeit. Erst mit der Identifikation seiner Rolle bei Parkinson-Syndromen wurde die Forschung über dieses Protein intensiviert.

Vier Paraloge wurden bisher in der Synuclein-Familie identifiziert. Über die physiologische Funktion dieser Proteinfamilie ist jedoch noch wenig bekannt. Ziel dieser Arbeit war es, anhand der Charakterisierung von $\alpha$-Synuclein Hinweise auf die physiologische Funktion zu erhalten und die Rolle in der Pathogenese tierexperimenteller Parkinson-Modelle zu untersuchen.

Hierzu wurden Antikörper zur spezifischen Detektion der einzelnen Paraloge benötigt, die über rekombinante Proteine hergestellt werden sollten. Die Untersuchung der Gewebeverteilung und subzellulären Verteilung der beiden hirnspezifischen Paraloge $\alpha$ - und $\beta$-Synuclein sollte vergleichend in Mäusen erfolgen. Da nur in Mäusen bisher eine gezielte Mutagenese möglich ist, war beabsichtigt, dieses Tiermodell für die funktionelle Charakterisierung $\mathrm{zu}$ verwenden. Über homologe Rekombination sollte die $\alpha$-Synuclein-Expression ausgeschaltet und der Effekt dieser Mutation auf die synaptische Funktion untersucht werden. Hierzu war in erster Linie eine Analyse mit biochemischen und morphologischen Methoden beabsichtigt, die je nach Phänotyp durch elektrophysiologische Studien ergänzt würden.

Für die Untersuchungen der Rolle von $\alpha$-Synuclein in der Pathogenese von ParkinsonSyndromen war die Analyse von zwei tierexperimentellen Modellen geplant. Einerseits war beabsichtigt, ein pharmakologisches Modell zu verwenden, in dem der Einfluß von $\alpha$-Synuclein auf die MPTP-Toxizität analysiert werden sollte, andererseits sollten die $\alpha$-Synuclein-Mutationen der familiären Formen der Parkinson-Syndrome in Mäusen transgen exprimiert werden.

Hierbei stand die Frage im Vordergrund, inwieweit neurochemische Veränderungen wie der striatale Dopaminverlust und Einschlußkörperchen der Parkinson-Syndrome in Mäusen induziert werden können. 


\section{Material und Methoden}

\subsection{Geräte}

Agarosegelsysteme

Cryostat, Jung CM 3000

DNA-Sequencer 373 Stretch

E. coli Pulser

Epifluoreszenzmikroskop, Axiophot

Fastproteinliquidchromatographie

(FPLC) Anlage

Filmentwickler Curix 60

Fluo-Link

Flüssigkulturenschüttler Innova 4000

Fujix BAS 5000

Gefriermikrotom CM 1325

Gen-Pulser Elektroporationssystem II

Hi Load 16/60 Superdex 75-Chromatographiesäule

Konfokales Mikroskop MRC 1024

Mehrkanalpipette, 12-Pette, 10 - $200 \mu 1$

Mehrkanalpipette, zwölffach, $1-10 \mu \mathrm{l}$

Mikroplattenreplikator

Mikrotiterplattenlesegerät Thermomax

PCR-Maschine DNA Engine Tetrad

PCR-Maschine Uno II

pH-Meter

Potter Elvehjem, $15 \mathrm{ml}$

Potter Elvehjem, $2 \mathrm{ml}$

Potter Elvehjem, 30 und $60 \mathrm{ml}$

Präparierbesteck

Proteingelsysteme, Mini-PROTEAN II

Spektralphotometer

Sterilwerkbänke

Thermomixer 5436
Life-Technologies Gibco-BRL GmbH, EggensteinLeopoldshafen und Konstruktionen der Institutswerkstatt

Leica, Bensheim

Applied Biosystems, Weiterstadt

Bio-Rad Laboratories GmbH, München

Zeiss GmbH, Jena

Pharmacia Biotech GmbH, Freiburg

Agfa-Gevaert GmbH, Martsel, Belgien

Biometra, Göttingen

New Brunswick Sience GmbH, Nurtingen

Raytest Isotopenmeßgeräte $\mathrm{GmbH}$, Straubenhardt

Leica, Bensheim

Bio-Rad Laboratories GmbH, München

Pharmacia Biotech GmbH, Freiburg

Bio-Rad Laboratories GmbH, München

Costar GmbH, Bodenheim

Südlaborbedarf GmbH, Gauting

Merk eurolab GmbH, Hannover und Konstruktionen der Institutswerkstatt

Molecular Devices, MWG-Biotech AG, Ebersberg

MJ Research, Waltham, USA

Biometra, Göttingen

Knick, Schütt GmbH, Göttingen

Wheaton, Schütt, Göttingen

Glas-Col, Schütt, Göttingen

B. Braun Biotech International GmbH, Melsungen martin, Karl Grosse GmbH, Braunschweig

Bio-Rad Laboratories GmbH, München

Beckmann Instruments $\mathrm{GmbH}$, München und Pharmacia Biotech GmbH, Freiburg

Haereus GmbH, Hanau

Eppendorf, Hamburg 
Tischzentrifuge, Biofuge 13

Ultra Turrax, T8

Ultrafine Juwelier Pinzette $11 \mathrm{~cm}$

Ultraschallbad

Ultraschall-Homogenisator Labsonic U

Videogeldokumentationsanlage

Zentrifuge, 5403

Zentrifuge, Megafuge 3.0R

Zentrifuge, Optima TLX und Optima Beckmann Instruments GmbH, München L60

Zentrifuge, RC-5B Plus
Haereus GmbH, Hanau

IKA, Schütt GmbH, Göttingen

Medicon Instrumente, Tuttlingen

Branson, Schütt GmbH, Göttingen

B. Braun Biotech International $\mathrm{GmbH}$, Melsungen

Intas $\mathrm{GmbH}$, Göttingen

Eppendorf, Hamburg

Haereus GmbH, Hanau

\subsection{Computerprogramme und Internetzugänge}

Excel

LaserGene Navigator

MacBas Version 2.3

National Center for Biotechnology

Information (NCBI)

OligoOrder Vers. 1.0.1

Swiss Institute for Experimental

Cancer Research (ISREC)

Research Collaboratory for http://www.rcsb.org/pdb

Structural Bioinformatics (RCSB)

WebLab Viewer Lite Vers. 3.2
Microsoft, Seattle, USA

DNA-Star Inc., Madison, USA

Raytest Isotopenmeßgeräte $\mathrm{GmbH}$, Straubenhardt

http://www.ncbi.nlm.nih.gov/

Applied Biosystems, Weiterstadt

http://www.isrec.isb-sib.ch/

Molecular Simulations Inc., San Diego, USA

\subsection{Verbrauchsmaterialien}

Bio Spin P30, Chromatographiesäule

Biomax-5K, Ultrafiltrationseinheit

Column PD-10, Sephadex G-25 M

ECL-Röntgenfilme

Elektroporationsküvetten $1 \mathrm{~mm}$ oder $4 \mathrm{~mm}$ Elektrodenabstand

Fettmarkerstift für die Immunzytochemie

Hybond- ${ }^{+}$Nylon-Membranen

Kunststoffgefäße

Nitrocellulose Transfermembran, Protran $0,2 \mu \mathrm{m}$

Nitrocellulose-Filter

$137 \mathrm{~mm}$ ) Typ HA, 0,45 $\mu \mathrm{m}$
Bio-Rad Laboratories GmbH, München

Millipore $\mathrm{GmbH}$, Eschborn

Pharmacia Biotech GmbH, Freiburg

Amersham-Buchler GmbH \& Co., Braunschweig

Bio-Rad Laboratories GmbH, München

DAKO Diagnostika GmbH, Hamburg

Amersham-Buchler GmbH \& Co., Braunschweig

Brandt, Costar, Falcon, Greiner, Sarstedt

Schleicher \& Schuell, Dassel

Millipore GmbH, Eschborn 
Phase Lock Gel I heavy

Reaktionsgefäße

Röntgenfilme

SuperFrost Plus Objektträger

Verstärkerfolie für Autoradiographiekassetten

Whatman 3MM Chr

GF/B-Filter, $25 \mathrm{~mm}$ Durchmesser

Nitrocellulosefilter Hybond ECL, 0,45 $\mu \mathrm{m}$
5 Prime - 3 Prime, Boulder, Colorado, USA

Eppendorf, Hamburg

Kodak, Integra Biosciences GmbH, Fernwald

Menzel-Gläser, Braunschweig

Du Pont de Nemours GmbH, Bad Homburg

Whatman International Ltd, Maidstone, England Whatman International Ltd, Maidstone, England Amersham Pharmacia Biotech, Buckinghamshire, England

Sterilfiltrationsaufsätze Millex $\quad(0,2 \mu \mathrm{m}$ Millipore $\mathrm{GmbH}$, Eschborn

\subsection{Chemikalien}

$\left[\alpha-{ }^{32} \mathrm{P}\right] \mathrm{dCTP}$

$\left[{ }^{3} \mathrm{H}\right]$-Dopamin

2,2,2-Tribromethanol

Agarose

Alkalische Phosphatase

AMBA

Ammoniumperoxodisulfat

Ampicillin

Bacto-Agar

Bacto-Hefeextrakt

Bacto-Trypton

Coomassie Blue R250

DNA-Längenstandard $\lambda B s t$ E II

dNTP

DTT

ECL-Reagenzien

Einbettmedium

Ethidiumbromid

Extran

Ficoll 400

Folin \& Ciocalteu's Phenol Reagenz

Freund'sches Adjuvans

GBR12909

Gelatine
Amersham-Buchler GmbH \& Co., Braunschweig Amersham-Buchler GmbH \& Co., Braunschweig Sigma-Aldrich GmbH, Deisenhofen

Life-Technologies Gibco-BRL GmbH, Eggenstein-Leopoldshafen

Boehringer Mannheim GmbH

Bio-Rad Laboratories GmbH, München

Bio-Rad Laboratories GmbH, München

BioMol Feinchemikalien GmbH, Hamburg

Difco Laboratories GmbH, Augsburg

Difco Laboratories GmbH, Augsburg

Difco Laboratories GmbH, Augsburg

BioMol Feinchemikalien GmbH, Hamburg

New England Biolabs, Schwalbach

Pharmacia Biotech GmbH, Freiburg

Sigma-Aldrich GmbH, Deisenhofen

Amersham-Buchler GmbH \& Co., Braunschweig

Jung, Leica, Nussloch

Sigma-Aldrich GmbH, Deisenhofen

Merck, Darmstadt

Pharmacia Biotech GmbH, Freiburg

Sigma-Aldrich GmbH, Deisenhofen

Sigma-Aldrich GmbH, Deisenhofen

Sigma-Aldrich GmbH, Deisenhofen

DIFCO Laboratories GmbH, Augsburg 
Glutathion-Agarose-Matrix

IPTG

Klenow-DNA-Polymerase

Lachsspermien-DNA

Lysozym

Methamphetamin

Molekulargewichtsstandard für SDS-

PAGE "low" und "high"

MPTP

Mung-Bean-DNA-Polymerase

Natriumperoxynitrit

$\mathrm{Ni}^{2+}$-NTA-Agarose-Matrix

N-Lauroylsarkosin

N-Propylgallat

PBS-Puffertabletten

PEG 8000

Pfu-Polymerase

Phenol, puffergesättigtes Phenol

Polyvinylpyrrolidon

Ponceau S

PowerScript DNA Polymerase Mix

Proteaseinhibitor-Cocktail-Tabletten

Proteaseinhibitoren: Aprotinin, Leupeptin, Pepstatin A, PMSF

Proteinase $\mathrm{K}$

Quick clone cDNA aus Menschengehirn

Quick clone cDNA aus Rattengehirn

Reserpin

Restriktionsendonukleasen

RNase DNase free

SDS

Szintillationsflüssigkeit: Rotiszint eco plus

T4 DNA Polymerase, 3'-5' ssDNA

Exonuklease-, keine 5'-3' Exonukleaseaktivität

T4 DNA-Ligase

Taq-Polymerase

TEMED
Sigma-Aldrich GmbH, Deisenhofen

BioMol Feinchemikalien GmbH, Hamburg

New England Biolabs, Schwalbach

Sigma-Aldrich GmbH, Deisenhofen

Sigma-Aldrich GmbH, Deisenhofen

Sigma-Aldrich GmbH, Deisenhofen

Bio-Rad Laboratories GmbH, München

Sigma-Aldrich GmbH, Deisenhofen

New England Biolabs, Schwalbach

Cayman Chemical, Ann Arbor, USA

Qiagen, Hilden

Sigma-Aldrich-GmbH, Deisenhofen

Sigma, Deisenhofen

Sigma-Aldrich GmbH, Deisenhofen

Sigma-Aldrich GmbH, Deisenhofen

Stratagene GmbH, Heidelberg

Life-Technologies Gibco-BRL GmbH, Eggenstein-Leopoldshafen

Sigma-Aldrich GmbH, Deisenhofen

Sigma-Aldrich GmbH, Deisenhofen

PAN Systems GmbH, Aidenbach

Boehringer Mannheim GmbH

Boehringer Mannheim GmbH

Boehringer Mannheim GmbH

Clontech, Palo Alto, USA

Clontech, Palo Alto, USA

Sigma-Aldrich GmbH, Deisenhofen

Boehringer Mannheim GmbH oder New England Biolabs, Schwalbach

Boehringer Mannheim GmbH

Boehringer Mannheim $\mathrm{GmbH}$

Roth, Karlsruhe

Boehringer Mannheim GmbH

Boehringer Mannheim $\mathrm{GmbH}$

Sigma-Aldrich GmbH, Deisenhofen

Bio-Rad Laboratories GmbH, München 


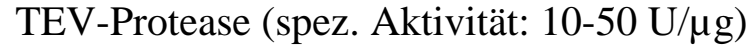

Tris (Tris-Hydroxymethyl-Aminomethan)

Triton X-100

Trockenmilchpulver

Tween 20

X-Gal

Ziegenserum

$\beta$-Mercaptoethanol
Life-Technologies Gibco-BRL GmbH, Eggenstein-Leopoldshafen

Sigma-Aldrich GmbH, Deisenhofen

Boehringer Mannheim GmbH

Glücksklee Magermilchpulver, Nestle Deutschland AG, Frankfurt/Main

Sigma-Aldrich GmbH, Deisenhofen

BioMol Feinchemikalien GmbH, Hamburg

Life-Technologies Gibco-BRL GmbH, Eggenstein-Leopoldshafen

Sigma-Aldrich GmbH, Deisenhofen

Alle nicht aufgeführten Chemikalien wurden von den Firma Merck GmbH (Darmstadt) in p.A. Qualität bezogen.

\subsection{Chemikalien für die Zellkultur}

2-Mercaptoethanol "cell culture tested"

Albumin, Rind

B27-Supplement

Cystein

DMEM mit 4,5 g/l D-Glucose

DMEM/25mM HEPES

DMEM-Pulvermedium mit L-Glutamin, 4,5 g/l D-Glucose, ohne Natriumpyruvat

D-PBS

\section{ESGRO-LIF}

Sigma-Aldrich GmbH, Deisenhofen

Sigma-Aldrich GmbH, Deisenhofen

Life-Technologies Gibco-BRL GmbH, Eggenstein-Leopoldshafen

Sigma-Aldrich GmbH, Deisenhofen

Life-Technologies Gibco-BRL GmbH, Eggenstein-Leopoldshafen

Life-Technologies Gibco-BRL GmbH, Eggenstein-Leopoldshafen

Life-Technologies Gibco-BRL GmbH, Eggenstein-Leopoldshafen

Life-Technologies Gibco-BRL GmbH, Eggenstein-Leopoldshafen

Life-Technologies Gibco-BRL GmbH, Eggenstein-Leopoldshafen

Fötales Rinderserum (embryonale Stamm- HyClone, Erembodegen-Aalst, Belgien zellkultur)

Fötales Rinderserum (FBS) für die Seromed, Berlin Neuronenkultur, Hitze-inaktiviert für $30 \mathrm{~min}$ bei $56^{\circ} \mathrm{C}$

Fötales Rinderserum, hitzeinaktiviert

Gangciclovir

Glutamax-Stammlösung
Life-Technologies Gibco-BRL GmbH, Eggenstein-Leopoldshafen

Roche AG, Basel, Schweiz

Life-Technologies Gibco-BRL GmbH, Eggenstein-Leopoldshafen 
HBSS (Hanks Balanced Salt Solution)

Kollagen

L-Glutamin, 100x

MEM nichtessentielle Aminosäuren, 100x

Mineralöl

MITO

Mitomycin C

Neomycin (G418-Sulfat)

Neurobasal

Papain

Penicillin/Streptomycin, 500x: $50000 \mathrm{IU} / \mathrm{ml}$ Penicillin, $50 \mathrm{mg} / \mathrm{ml}$ Streptomycin

Trypsin Inhibitor

Trypsin-EDTA, 1x

Life-Technologies Gibco-BRL GmbH, Eggenstein-Leopoldshafen

Collaborative Biomedical Products; Becton Dickinson Labware, Bedford, USA

Life-Technologies Gibco-BRL GmbH, Eggenstein-Leopoldshafen

Life-Technologies Gibco-BRL GmbH, Eggenstein-Leopoldshafen

Sigma-Aldrich GmbH, Deisenhofen

Collaborative Biomedical Products; Becton Dickinson Labware, Bedford, USA

Sigma-Aldrich GmbH, Deisenhofen

Life-Technologies Gibco-BRL GmbH, Eggenstein-Leopoldshafen

Life-Technologies Gibco-BRL GmbH, Eggenstein-Leopoldshafen

Worthington Biomedical Corporation, Lakewood, USA

Boehringer Mannheim GmbH

Sigma-Aldrich GmbH, Deisenhofen

Life-Technologies Gibco-BRL GmbH, Eggenstein-Leopoldshafen

\subsection{Kits}

BCA Protein Assay-Kit

Plasmid Mini, Midi und Maxi-Kits

Prime-It II - Random Primer Labeling-Kit

Qiaex II-Kit

QIAquick PCR Purification-Kit

TOPO-Quick Ligation Kit
Pierce, Rockford, Illinois, USA

Qiagen AG, Hilden

Stratagene GmbH, Heidelberg

Qiagen AG, Hilden

Qiagen AG, Hilden

Invitrogen, Karlsruhe

\subsection{Antikörper}

Es wurden zusätzlich zu den neu erstellten die unten angegebenen primären Antikörper verwendet. Die Bezugs- oder Literaturquelle ist angegeben.

Aktin AC-40

Amphiphysin

APP

Complexin 1 und 2
$\mathrm{P} 924$

U955

P942
Sigma-Aldrich GmbH, Deisenhofen

Synaptic Systems, Göttingen

Prof. T. C. Südhof, Dallas, USA

Synaptic Systems, Göttingen 


\begin{tabular}{|c|c|c|}
\hline CSP & $\alpha \mathrm{CSP}$ & Dr. B. Stahl, Göttingen \\
\hline Doc2A & Maus anti Doc2A & Transduction Laboratories, Lexington, USA \\
\hline Dopamintransporter & M369 & Transduction Laboratories, Lexington, USA \\
\hline Dynamin & E765 & (Robinson et al. 1993) \\
\hline GAPDH & $6 \mathrm{G} 5$ & Biotrend GmbH, Köln \\
\hline GDI & $\mathrm{Cl} 81.3$ & (Chou und Jahn 2000) \\
\hline Hexahistidin & $\begin{array}{l}\text { Maus anti Peptide } \\
\text { „RGSHHHH““ }\end{array}$ & Qiagen AG, Hilden \\
\hline Mint & P932 & Prof. T.C. Südhof, Dallas, USA \\
\hline mSEC7 & SA3613 & H. Koch, Göttingen \\
\hline Munc13-1 & $3 \mathrm{H} 5$ & (Betz et al. 1998) \\
\hline Munc18 & $\mathrm{I} 370$ & Prof. T.C. Südhof, Dallas, USA \\
\hline Neuroligin I & $4 \mathrm{C} 12$ & (Song et al. 1999) \\
\hline NMDA-R1 & $\mathrm{Cl} 54.1$ & (Brose et al. 1994) \\
\hline NSF & $\mathrm{I} 372$ & (McMahon und Südhof 1995) \\
\hline $\begin{array}{l}\text { p116 der vesikulären } \\
\text { ATPase }\end{array}$ & 587 & Synaptic Systems, Göttingen \\
\hline Presenilin I Schleife & $\alpha \mathrm{PSI}$ & Prof. T. C. Südhof, Dallas, USA \\
\hline Rab3A & 583 & Synaptic Systems, Göttingen \\
\hline Rab3A & $\mathrm{Cl} 42.2$ & (Matteoli et al. 1991) \\
\hline Rab3B & U954 & (Schlüter 2000) \\
\hline $\mathrm{Rab} 3 \mathrm{C}$ & P180 & (Castillo et al. 1997) \\
\hline Rabaptin & R321 & Dr. Y. Wang, Dallas, USA \\
\hline Rabphilin & $\mathrm{I} 734$ & (Li et al. 1994) \\
\hline Rim & Maus anti Rim & Transduction Laboratories, Lexington, USA \\
\hline SCAMP & P936 & Synaptic Systems, Göttingen \\
\hline$\alpha \mathrm{SNAP}$ & I373 & Prof. T. C. Südhof, Dallas, USA \\
\hline SNAP-23 & P914 & Synaptic Systems, Göttingen \\
\hline SNAP-25 & $\mathrm{Cl} 72.2$ & Prof. R. Jahn, Göttingen \\
\hline Synapsin I und II & E028 & (Rosahl et al. 1995) \\
\hline Synaptobrevin 1 & P938 & Synaptic Systems, Göttingen \\
\hline Synaptobrevin 2 & $\mathrm{Cl} 69.1$ & (Edelmann et al. 1995) \\
\hline Synaptogyrin & P925 & Synaptic Systems, Göttingen \\
\hline Synaptojanin & P923 & Synaptic Systems, Göttingen \\
\hline Synaptophysin I & $\mathrm{Cl} 17.2$ & Prof. Dr. R. Jahn \\
\hline Synaptophysin II & $\alpha p 37$ & (Fykse et al. 1993) \\
\hline Synaptotagmin I & V216 & (Perin et al. 1990) \\
\hline Synaptotagmin II & $\mathrm{I} 735$ & (Rosahl et al. 1995) \\
\hline Syntaxin 1 & $\mathrm{Cl} 78.2$ & Prof. R. Jahn, Göttingen \\
\hline
\end{tabular}




\begin{tabular}{|c|c|c|}
\hline Syntaxin $1 b$ & P941 & Synaptic Systems, Göttingen \\
\hline Tyrosin Hydroxylase & Maus anti TH & Boehringer Mannheim GmbH \\
\hline $\begin{array}{l}\text { Vesikuläre } \\
\text { transporter } 2\end{array}$ & $\alpha$ VMAT-2 & Prof. E. Weihe, Marburg \\
\hline$\alpha-, \beta$-Synuclein & Q698 & Dr. R. Janz, Houston, Texas, USA \\
\hline$\alpha$ SNAP & $\mathrm{I} 373$ & (McMahon und Südhof 1995) \\
\hline$\alpha-$ Synuclein & $\alpha \operatorname{Syf}$ & Transduction Laboratories, Lexington, USA \\
\hline$\alpha$-Tubulin & $\mathrm{DM} 1 \alpha$ & Sigma-Aldrich GmbH, Deisenhofen \\
\hline$\beta$-Tubulin & TUB2.1 & Sigma-Aldrich GmbH, Deisenhofen \\
\hline Tyrosinhydroxylase (TH) & $\alpha \mathrm{TH}$ & Boehringer Mannheim GmbH \\
\hline
\end{tabular}

Zur Detektion wurden folgende sekundäre Antikörper verwendet:

Affinitätsgereinigter Kaninchen-anti-Maus-IgG (H+L) Antikörper

Affinitätsgereinigter Ziege-anti-Kaninchen-IgG (H\&L) konjugiert mit Cy2, $\lambda_{\max } 489 \mathrm{~nm}, \varepsilon_{\max }: 505 \mathrm{~nm}$

Affinitätsgereinigter Ziege-anti-Maus-IgG (H\&L) konjugiert mit Cy3.29, $\lambda_{\max }: 552 \mathrm{~nm}, \varepsilon_{\max }: 565 \mathrm{~nm}$

Affinitätsgereinigter Ziege-anti-Maus-IgG (H\&L) konjugiert mit $\mathrm{Cy} 2$

Affinitätsgereinigter Ziege-anti-Kaninchen-IgG (H\&L) konjugiert mit Cy3.29

Affinitätsgereinigter Ziege-anti-Maus-IgG (H\&L) konjugiert mit Cy5.29, $\lambda_{\max }: 650 \mathrm{~nm}, \varepsilon_{\max }: 667 \mathrm{~nm}$

Affinitätsgereinigter Ziege-anti-Maus (H\&L) konjugiert mit HRP

Affinitätsgereinigter Ziege-anti-Kaninchen (H\&L) konjugiert mit HRP

Affinitätsgereinigter Ziege-anti-Ratte-IgG (H\&L) konjugiert mit Cy2
Jackson ImmunoResearch Lab., West Grove, USA

Rockland, Gilbertsville, USA

Rockland, Gilbertsville, USA

Rockland, Gilbertsville, USA

Rockland, Gilbertsville, USA

Rockland, Gilbertsville, USA

Bio-Rad Laboratories GmbH, München

Bio-Rad Laboratories GmbH, München

Rockland, Gilbertsville, USA

\subsection{Plasmidvektoren}

pcDNA3: 5,4 kb (Invitrogen, Groningen, Niederlande). Eukaryontischer Expressionsvektor mit Ampicillin-Resistenz-Gen, einem CMV ,promotor/enhancer“ Element, einer BGH Polyadenylierungskassette, einem SV40 Replikationsstartelement und einer NeomycinresistenzExpressionskassette $\left(\mathrm{Neo}^{\mathrm{R}}\right)$ zur Selektion von stabilen Transfektanten.

pBluescript II SK+: 2,9 kb (Stratagene GmbH, Heidelberg). Klonierungsvektor mit AmpicillinResistenz-Gen mit hoher Kopienzahl und der Möglichkeit zur Testung von rekombinanten Klonen über $\beta$-Galaktosidase-Expressionstest.

pTK-Neo 3a: ca. 8 kb (Rosahl et al. 1993). Klonierungsvektor zur Klonierung von Rekombinationsvektoren für die homologe Rekombination. In den Mehrfachklonierungsbereich von 
pBluescript II wurden zwei Thymidinkinase-(TK) und eine Neomycinresistenz-Expressionskassette $\left(\mathrm{Neo}^{\mathrm{R}}\right)$ mit RNA-Polymerase II-Promotor kloniert. Als singuläre Restriktionsschnittstellen sind zwischen TK und Neo ${ }^{\mathrm{R}}$ SalI und ClaI und 3' von der Neo ${ }^{\mathrm{R}}$ BamHI, SpeI, NotI und SacII vorhanden.

pGEX-KG: 5,0 kb (Guan und Dixon 1991). Bakterieller Expressionsvektor mit AmpicillinResistenz-Gen zu Expression von N-terminalen Glutathion-S-Transferase-Fusionsproteinen (GST).

NHispBSK.1: 2,9 kb (Schlüter 2000). In Vektor pBlueScript SK+ (Stratagene GmbH, Heidelberg) wurde über die Restriktionsenzyme HinDIII und BamHI eine Oligonukleotidpaar kloniert, das die Kozak-Nukleotidsequenz „CCACC“, gefolgt vom Startcodon „ATG“ und die Codons für die Aminosäuresequenz „RGSHHHHHH“ kodierte.

pCR-Script II: 2,9 kb (Schlüter 2000). Im Vektor pCR-Script (Stratagene GmbH, Heidelberg) wurde die zusätzliche SmaI-Restriktionsschnittstelle durch SpeI ersetz. Bei der Klonierung von PCR-Fragmenten mit glatten Enden konnte die SrfI-Restriktionsschnittstelle sowohl mit SmaI als auch mit SrfI während der Ligation geschnitten werden.

pTSC21: 9,1 kb (Dr. M. Goedert, MRC Laboratory of Molecular Biology, Cambridge, England). pUC18-Vektor, der das Maus-Thy1-Gen enthält. Die kodierenden Bereiche der Exone zwei bis vier wurden ausgeschnitten und eine einzige Klonierungsstelle für das Restriktionsenzym XhoI eingefügt. Das Gen kann über die Restriktionsenzyme EcoRI oder NotI und PvuI aus dem Vektor herausgeschnitten werden.

\subsection{Genbibliotheken}

pVP16-3 cDNA-Bibliothek aus Ratte (E18)

Dr. Massaya Okamoto, Southwestern Medical Center, Dallas, USA

Lambda FIX II genomische Phagenbibliothek aus der Mauslinie 129SvJ

Stratagene GmbH, Heidelberg

\subsection{Synthetische Oligonukleotide}

Oligonukleotide wurden vom institutseigenen Oligosyntheselabor hergestellt und sind anhand der Synthesenummer bezeichnet.

288: CCTGTCCGGTGCCCTGAATGAA

428: $\quad$ GAGCGCGCGCGGCGGAGTTGTTGAC

439: CGCGAATTCATTGGGGAAAACAGGAGG

440: CGCGAATTCCACTGTTGTCACTCCATG

670: CGCATCGATAGATCTCGTGGCTGAACTTGAGC

672: CGCATCGATTCCAGGAAGAAATATCAGATATC

739: GCTGAGGGAAGGAAAAGGCTGAAGCC

741: CCCCTCGAGTTCAGAGGGCCCTCAG

786: CGAATTCTAATGGATGTGTTCATGAAAGGACTTTCAAAGGC 
787: CGCAAGCTTTTAGGCTTCAGGCTCATAGTCTTGGTAGC

801: CGCAAGCTTTTAGGCTTCAGGTTCGTAGTCTTGATACC

817: CGCAAGCTTCCACCATGGATGTGTTCATGAAAGGACTTTC

818: CGCCTCGAGAATCCGAAGTCCGAGTATCAGAACC

832: CGCCTCGAGTTAGGCTTCAGGCTCATAGTCTTGG

887: GCCGATCCCCTCAGAAGAAC

946: CCACCATGGACGTCTTCAAGAAAGGC

947: CCTTCTAGTCACCTCCACTCTTGGCC

948: GGAGGGAGTGGTCCATGGTGTGACAACAGTGGCTGAGAAGACC

949: GGTCTTCTCAGCCACTGTTGTCACACCATGGACCACTCCCTCC

1103: TCTCTGGTGTGGCATCTGGGCTCGT

1106: GTTGGTTGGAGGTGCGGTGCGTGAGG

1120: CGAATTCGCGATCGCTTAGGCTTCAGGTTCGTAGTCTTGATACC

1121: GGGTGTGGCAGAAGCCCCGGGAAAGAC

1122: GTCTTTCCCGGGGCTTCTGCCACACCC

1123: GGCGCGCCACCATGGATGTATTCATGAAAGGACTTTC

1241: GCGGATCCGATGTGTTCATGAAAGGACTTTCAAAGG

1242: GCGGATCCGACGTGTTCATGAAGGGCCTGTCC

1243: ATCATGGACCCTTCGCCTCTGGTTCGTATTCCTG

1244: GGAAGATCTGACGTCTTCAAGAAAGGCTTCTCC

1333: GGCACCTAGAGGATCTCGACTAGTGG

1334: GGACCTCGACGCTTAGGCTTCAGG

1383: TGGAGCCTACATAGAGAACACCCTC

1643: CGCAAGCTTAGGCTTCAGGTTCGTAGTCTTGA

1646: GCTCTAGAAAACCTGTATTTTCAGGGCATGGATGTATTCATGAAAGGACTTT CA

2033: GATCCTGACAATGAGGCCTATGAAATGCCTGATGAGGAAGGGTATCAAGAC TACGAACCTGAAGCCTA

2034: AGCTTAGGCTTCAGGTTCGTAGTCTTGATACCCTTCCTCATCAGGCATTTCAT AGGCCTCATTGTCAG

2035: GAGGGAGCAGGGGACATTGCAGCTGCCACTGGC

2036 GCCAGTGGCAGCTGCAATGTCCCCTGCTCCCTC

2199: GTGGATCTCAAGCCCTCAAGG (Thyl fwd. sequencing primer)

2200: TGAGATATTTGAAGGACTTGG (Thy1 rev. sequencing primer)

T1818 CGGAATTCGGATCCTTACGCCTCTGGCTCGTATTCC

T1819 GCATATGGACGTGTTCATGAAGGGCC 


\subsection{Bakterienstämme}

Klonierungen und Überexpressionen wurden mit den folgenden Escherichia-coli-Bakterienstämmen (E. coli) durchgeführt:
XL1-Blue
Stratagene GmbH, Heidelberg
BL21(DE3)pLysS
Novagen, Madison, USA
XL1-Blue MRA(P2)
Stratagene GmbH, Heidelberg

\subsection{Zellinien}

293 Zellen: Diese Zellinie wurde durch Transfektion von menschlichem embryonalen Nierengewebe mit Adenovirus Typ 5 DNA-Fragmenten immortalisiert (Graham et al. 1977).

MEF: Embryonale Primärkulturen aus Mausfibroblasten (GenomeSystems, St. Louis, USA).

E14.1: Omnipotente embryonale Mausstammzellinie aus der Mauslinie 129SV (Hooper et al. 1987). Freundlicherweise von Prof. Dr. K. Rajewsky, Köln, zur Verfügung gestellt.

\subsection{Zuchttiere}

Die Mauslinie C57B16/J wurden vom Tierzuchtbetrieb Elevage Janvier, Le Genest St Isle, Frankreich, und die Mauslinie C57B16/J/ola/hsd von Harlan Winkelmann, Borchen, bezogen und im institutseigenen Tierhaus gezüchtet. Erstere wurde für die Blastozystengewinnung und Verpaarungen der chimären Mäuse und Rückkreuzungen verwendet. Die Mauslinie FVB wurde im institutseigenen Tierhaus gezüchtet und für die Gewinnung befruchteter Eizellen für die Erstellung trangener Mäuse verwendet.

Wistar-Ratten für die Gewinnung von Gewebeproben, Chinchilla-Kaninchen für die Immunisierung und NMRI-Mäuse als Ammen für Embryotransfers wurden ebenfalls aus den institutseigenen Tierställen bezogen.

\subsection{Medien und Lösungen}

Falls nicht anders angegeben, beziehen sich die Konzentrationsangaben auf wäßrige Lösungen, die mit Hilfe von vollentsalztem Wasser $\left(\mathrm{H}_{2} \mathrm{O}\right)$ hergestellt wurden.

Ampicillin-Stammlösung, $\quad 20 \mathrm{mg} / \mathrm{ml}$

200x:

Denaturierungslösung:

1,5 M NaCl; 0,5 M NaOH.

Denhardt's Lösung, 50x:

$1 \%$ Rinderserumalbumin; $1 \%$ Ficoll 400; $1 \%$ Polyvinylpyrrolidon

Homogenisationspuffer

320 mM Saccharose; 10 mM HEPES/NaOH, pH 7,4; 0,1 mM EDTA 
Hybridisierungslösung:

IPTG-Stammlösung, 1000x:

LB-Kulturschalen:

LB-Medium:

LB-Selektionsmedium:

LB-Top-Agar:

Neutralisierungslösung:

PBS:

Prähybridisierungslösung:

SDS-Probenpuffer

SM-Puffer

SSC, 20x:

TAE, 50x:

TBS, 10x:

TE-Puffer:

X-Gal-Stammlösung, 1000x:
Prähybridisierungslösung mit radioaktiv markierter DNASonde

$30 \mathrm{mg} / \mathrm{ml}$

$15 \mathrm{~g} / \mathrm{l}$ Bacto-Agar in LB-Medium, autoklaviert. Bei Selektionsmedien erfolgte die Zugabe der Antibiotika nach Abkühlung auf $50^{\circ} \mathrm{C}$.

$10 \mathrm{~g} / \mathrm{l} \mathrm{NaCl} ; 10 \mathrm{~g} / \mathrm{l}$ Bacto-Trypton; $5 \mathrm{~g} / \mathrm{l}$ Hefeextrakt; autoklaviert.

LB-Medium mit Antibiotikazugabe direkt vor Gebrauch.

LB-Medium mit 0,7 \% Agarose

1,5 M NaCl; $1 \mathrm{M}$ Tris/HCl, pH 7,4; 1 mM EDTA

$8 \mathrm{~g} / \mathrm{l} \mathrm{NaCl}, 0,2 \mathrm{~g} / \mathrm{l} \mathrm{KCl}, 1,44 \mathrm{~g} / 1 \mathrm{Na}_{2} \mathrm{HPO}_{4} * 7 \mathrm{H}_{2} \mathrm{O}, 0,24 \mathrm{~g} / \mathrm{l}$ $\mathrm{KH}_{2} \mathrm{PO}_{4} * \mathrm{H}_{2} \mathrm{O}, \mathrm{pH} 7,4$

$50 \%$ Formamid; 5x Denhardt's; 1,5\% SDS; 5x SSC; $0,1 \mathrm{mg} / \mathrm{ml}$ denaturierte Lachsspermien-DNA (Denaturierung durch fünfminütiges Kochen direkt vor Gebrauch der Lösung). $50 \mathrm{mM}$ Tris/HCl, pH 6,8; 3,3\% SDS; $30 \%$ Glycerin; 0,03\% Bromphenolblau; $50 \mathrm{mM}$ DTT

$5,8 \mathrm{~g} / \mathrm{l} \mathrm{NaCl} ; 2 \mathrm{~g} / \mathrm{l} \mathrm{MgSO}{ }_{4} * \mathrm{H}_{2} \mathrm{O} ; 50 \mathrm{ml} / 11 \mathrm{M}$ Tris/HCl, $\mathrm{pH}$ 7,$5 ; 5 \mathrm{ml} / 12 \%$ Gelatine, autoklaviert

$3 \mathrm{M} \mathrm{NaCl} ; 0,3 \mathrm{M} \mathrm{Na}_{3}$-Citrat

$242 \mathrm{~g}$ Tris; 57,1 ml Eisessig; $100 \mathrm{ml} \mathrm{0,5} \mathrm{M} \mathrm{EDTA} \mathrm{pH} \mathrm{8,0}$

$0,2 \mathrm{M}$ Tris/HCl, $\mathrm{pH} 7,4 ; 1,4 \mathrm{M} \mathrm{NaCl}$

$10 \mathrm{mM}$ Tris/HCl, $\mathrm{pH} 8 ; 1 \mathrm{mM}$ EDTA.

$50 \mathrm{mg} / \mathrm{ml}$ in DMF

\subsection{Methoden}

\subsubsection{DNA-Amplifikation über die Polymerasekettenreaktion}

(Saiki et al. 1988)

Für die Amplifikation von DNA wurden verschiedene Matrizen verwendet: $1 \mu 1 \mathrm{cDNA}$ aus Ratten- oder Menschengehirn, $1 \mu 1$ genomische Maus-DNA oder 1 pg Plasmid-DNA. Für die Gen-Klonierung wurden die Pfu-Polymerase oder die Polymerasenmischung PowerScript verwendet, wobei sich erste durch eine geringere Fehlerrate und zweite durch erhöhte Produktmenge auszeichneten. Die verwendeten Primer wurden auf eine optische Dichte bei $260 \mathrm{~nm}$ von 5 eingestellt. Ein typischer PCR-Ansatz hatte folgende Komponenten:

$\begin{array}{ll}1 \mu \mathrm{l} & \text { Matrizen-DNA } \\ 5 \mu \mathrm{l} & \text { 10x Reaktionspuffer } \\ 10 \mu \mathrm{l} & 5 x \text { Enhancer (nur PowerScript) } \\ 1 \mu \mathrm{l} & 50 \mathrm{mM} \mathrm{MgCl}_{2} \text { (nur PowerScript) }\end{array}$




$\begin{array}{ll}1,4 \mu \mathrm{l} & \text { Primer } 1 \\ 1,4 \mu \mathrm{l} & \text { Primer } 2 \\ 1 \mu \mathrm{l} & 40 \mathrm{mM} \mathrm{dNTP} \\ 0,5 \mu \mathrm{l} & \text { Pfu }(5 \mathrm{U} / \mu \mathrm{l}) \text { bzw. } 1 \mu \mathrm{l} \text { PowerScript }(2,5 \mathrm{U} / \mu \mathrm{l}) \\ \text { ad } 50 \mu \mathrm{l} & \mathrm{H}_{2} \mathrm{O} .\end{array}$

Initial erfolgte eine Denaturierung für 5 min bei $94^{\circ} \mathrm{C}$. Die Zyklenzahl betrug 30 bis 45 Zyklen, wobei die Synthesezeit der letzten 20 Zyklen um je $10 \mathrm{~s}$ verlängert wurde. Die Schmelzzeit betrug $30 \mathrm{~s}$, -temperatur $94^{\circ} \mathrm{C}$, die Hybridisierungszeit $30 \mathrm{~s}$ und die Synthesetemperatur $72^{\circ} \mathrm{C}$. Die Synthesezeit betrug zu Beginn 2 min pro 1000 bp. Die Hybridisierungstemperatur wurde 2 bis $10^{\circ} \mathrm{C}$ unterhalb der mit dem Programm OligoOrder bestimmten Schmelztemperatur gewählt.

\subsubsection{Polymerasekettenreaktion für die Genotypisierung}

Der Reaktionsansatz enthielt in $10 \mu \mathrm{l}$ TNK-Puffer (Blanchard et al. 1993) 0,5 $\mu 1100 \mathrm{mM}$ dNTP und 0,2 U Taq-Polymerase verschiedener Hersteller. Die Primer wurden mit Hilfe des OligoOrder-Programms gewählt, so daß der GC-Gehalt ca. 50-60 \%, die Länge 17-26 Basen und die Schmelztemperatur 59-64 ${ }^{\circ} \mathrm{C}$ betrug. Die Endkonzentration betrug 0,25 pMol. Die Zyklenparameter wurden wie oben angegeben eingestellt.

TNK-Puffer, 10x: $100 \mathrm{mM}$ Tris/HCl pH8,5; $15 \mathrm{mM} \mathrm{MgCl}_{2} ; 500 \mathrm{mM} \mathrm{KCl;} 50 \mathrm{mM} \mathrm{NH}_{4} \mathrm{Cl}$

\subsubsection{Subklonierung von Plasmid-DNA}

\subsubsection{Herstellung elektrokompetenter Bakterien}

Ein Liter LB-Medium wurden 1:100 mit einer Übernachtkultur angeimpft und bei $37^{\circ} \mathrm{C}$ im Schüttelinkubator bei $300 \mathrm{rpm}$ kultiviert. Nach Erreichen der exponentiellen Wachstumsphase bei einer optischen Dichte $\left(\mathrm{OD}_{600}\right)$ von 0,5 bis 0,7 wurden die Bakterien durch Zentrifugation (15 min, 4000x g, $4^{\circ} \mathrm{C}$ ) geerntet. Die Bakterien wurden nachfolgend mit einem Liter, 0,5 1 und 0,25 1 eiskalter, steriler $10 \%$ iger Glycerinlösung gewaschen. Nach der letzten Zentrifugation wurde das Bakterienpellet in $4 \mathrm{ml} 10 \%$ iger Glycerinlösung resuspendiert und in Aliquots auf in einem Trockeneis/Isopropanol-Bad vorgekühlte Reaktionsgefäße verteilt. Über mehrere Monate behielten die Bakterien eine Transformationseffizienz von bis $\mathrm{zu} 10^{9} \mathrm{cfu} / \mu \mathrm{g}$ pBluescript II SK bei Lagerung bei $-80^{\circ} \mathrm{C}$.

\subsubsection{Transformation von Bakterien}

Ein Aliquot der elektrokompetenten Zellen wurde auf Eis aufgetaut. 20 bis $40 \mu$ l Bakteriensuspension wurden mit bis zu $5 \mu$ l Plasmidlösung in $\mathrm{H}_{2} \mathrm{O}$ in eine Elektroporationsküvette mit $0,1 \mathrm{~cm}$ Elektrodenabstand gefüllt. Die Elektroporation erfolgte bei $1,8 \mathrm{kV}$ im E.-coli-Pulser. Unmittelbar anschließend wurden die Zellen in $300 \mu \mathrm{l}$ LB-Medium aufgenommen und auf LBSelektionsplatten ausgestrichen und über Nacht bei $37^{\circ} \mathrm{C}$ inkubiert.

\subsubsection{Blau-weiß-Selektionstest}

Die Mehrfachklonierungsstelle in den Vektoren pBluescript II SK und pCR-Script war im lacZGen enthalten. Bakterienkolonien, die Vektoren mit in die Mehrfachklonierungstelle eingefügter DNA enthielten, ließen sich durch $\beta$-Galaktosidase-Expressionstests als weiße Kolonien identi- 
fizieren. Vor Ausstreichen der transformierten Bakterien wurden die LB-Selektionsplatten mit $30 \mu 1$ IPTG-Stammlösung und $30 \mu 1 \mathrm{X}$-Gal-Stammlösung ausgestrichen.

\subsubsection{Testung auf gewünschte Klone über radioaktive Sonden}

Die transformierten Bakterien wurden auf Nylonfiltern auf Selektionsplatten ausplattiert und über Nacht bei $37^{\circ} \mathrm{C}$ inkubiert. Der Filter wurde auf ein Filterpapier gelegt und eine Kopie durch Auflegen eines zweiten Nylonfilters erhalten (replica). Nach Markierung der Orientierung wurde die Kopie auf die Selektionsplatte gelegt und für weitere $4 \mathrm{~h}$ bei $37^{\circ} \mathrm{C}$ inkubiert. Zur Lysierung der Bakterien wurde der Originalfilter 5 min auf ein mit $10 \%$ iger SDS-Lösung getränktes Filterpapier gelegt. Die Denaturierung der DNA erfolgte nach Transfer für $5 \mathrm{~min}$ auf ein mit Denaturierungspuffer getränktes Filterpapier. Anschließend wurde der Filter 5 min auf einem mit Neutralisierungspuffer getränktem Filterpapier inkubiert und die DNA auf dem noch feuchten Filter bei $1 \mathrm{~J} / \mathrm{cm} 2$ im Fluo-Link vernetzt. Bakterienreste wurden mit 2x SSC abgewaschen. Die Hybridisierung der Bakterienlifts erfolgte wie weiter unten beschrieben.

\subsubsection{Testung auf gewünschte Klone über PCR}

Einzelkolonien der LB-Selektionsplatten wurden in $100 \mu \mathrm{l}$ LB-Selektionsmedium in 96Lochplatten für mehrere Stunden bei $37^{\circ} \mathrm{C}$ inkubiert. Der PCR-Reaktionsansatz wurde in 96Loch-PCR-Reaktionsplatten vorgelegt und die Reaktion nach Zugabe von ca. $1 \mu$ l Bakterienlösung über einen Miktroplattenreplikator gestartet. Der PCR-Reaktionsansatz enthielt einen Vektor-spezifischen und einen insert-spezifischen Primer.

\subsubsection{Präparation von DNA}

\subsubsection{Phenol/Chloroform-Extraktion}

Zur Denaturierung von Proteinen wurde die DNA-Lösung mit gleichem Volumen Phenol/Chloroform-Mischung versetzt. Zur Phasentrennung wurde der Ansatz 5 min bei $15000 \mathrm{rpm}$ in der Tischzentrifuge zentrifugiert. Die obere wäßrige Phase wurde mit gleichem Volumen Chloroform extrahiert und nach Trennung die Phasen durch erneute Zentrifugation getrennt. Die DNA aus der oberen wäßrige Phase wurde gefällt.

Phenol/Chloroform-Mischung: Puffergesättigtes Phenol / Chloroform im Volumenverhältnis von $1: 1$

\subsubsection{DNA-Präzipitation}

Die DNA-Lösung wurde auf eine NaCl-Konzentration von $200 \mathrm{mM}$ eingestellt und mit zwei Volumina Ethanol gefällt. Die DNA wurde $10 \mathrm{~min}$ bei $15000 \mathrm{rpm}$ in der Tischzentrifuge abzentrifugiert, der Überstand verworfen und das Pellet in $\mathrm{H}_{2} \mathrm{O}$ gelöst, so daß eine DNAKonzentration von 0,5 bis $1,5 \mu \mathrm{g} / \mu 1$ resultierte.

\subsubsection{Isolierung von DNA-Fragmenten aus Agarosegelen}

Die Gelbanden wurden unter der UV-Handlappe $(312 \mathrm{~nm})$ ausgeschnitten und mit Hilfe des Qiaex II Kits nach Herstellerangaben isoliert. Transgene Vektoren wurden anschließend noch mit Phenol/ $\mathrm{ChCl}_{3}$ extrahiert, die DNA in $5 \mathrm{mM}$ Tris/ $\mathrm{HCl}(\mathrm{pH} 7,5)$ aufgenommen und steril filtriert.

Gelstücke mit DNA-Fragmenten größer als $20 \mathrm{~kb}$ wurden mit zwei Volumen puffergesättigtem Phenol versetzt und eingefroren. Die Proben tauten während der zehnminütigen Zentrifugation in 
der Tischzentrifuge bei 15000 rpm zur Phasentrennung auf. Die DNA aus der oberen wäßrigen Phase wurde mit Chloroform extrahiert und gefällt und anschließend in $30 \mu 1 \mathrm{H}_{2} \mathrm{O}$ gelöst.

\subsubsection{Plasmidschnellpräparation}

(Del Sal et al. 1988)

Zur Testung auf den gewünschten Klon nach Ligation wurden $1 \mathrm{ml}$ für Plasmide mit hoher Kopienzahl oder $5 \mathrm{ml}$ LB-Selektionsmedium für Plasmide mit niedriger Kopienzahl in Reaktionsgefäßen bzw. $15 \mathrm{ml}$ Röhrchen mit Einzelkolonien angeimpft und über Nacht bei $37^{\circ} \mathrm{C}$ inkubiert. Die Bakterien wurden $1 \mathrm{~min}$ in Reaktionsgefäßen in der Tischzentrifuge bei $10000 \mathrm{rpm}$ bzw. $10 \mathrm{~min}$ bei $3500 \mathrm{rpm}$ in der Schwingrotorzentrifuge geerntet. Das Pellet wurde in $200 \mu \mathrm{l}$ STET aufgenommen und nach Zugabe von $4 \mu$ l Lysozymlösung 5 min unter Schütteln bei Raumtemperatur inkubiert. Die Proben wurden anschließend für $1 \mathrm{~min}$ bei $100^{\circ} \mathrm{C}$ behandelt. Zelltrümmer und denaturierte Proteine wurden $5 \mathrm{~min}$ bei $15000 \mathrm{rpm}$ in der Tischzentrifuge abzentrifugiert und mit einem Zahnstocher entfernt. Die DNA wurde durch Zugabe von $8 \mu 1$ 5 \%ige CTAB-Lösung präzipitiert und $10 \mathrm{~min}$ bei $15000 \mathrm{rpm}$ in der Tischzentrifuge abzentrifugiert. Nach Abnahme des Überstandes wurde die DNA in $300 \mu 1$ 1,2 M NaCl-Lösung unter kräftigem Schütteln gelöst und nach Zugabe von $750 \mu$ l Ethanol gefällt. Die DNA wurde wie oben erwähnt abzentrifugiert, der Überstand verworfen und nach Trocknung bei Raumtemperatur in 20 bis $30 \mu \mathrm{l} \mathrm{H}_{2} \mathrm{O}$ gelöst. 3 bis $5 \mu \mathrm{l}$ der Präparation wurden einem analytischen Restriktionsverdau unter Zugabe von $1 \mu 1$ RNAse pro Ansatz unterzogen, um den gewünschten Klon zu identifizieren.

STET: $\quad 8 \%$ Sucrose; $0,1 \%$ Triton X-100; 50 mM EDTA; 50 mM Tris/HCl, pH 8

Lysozymlösung: $50 \mathrm{mg} / \mathrm{ml}$ Lysozym

\subsubsection{Plasmidpräparation hoher Reinheit}

Für die DNA-Sequenzierung und Transfektion bzw. Mikroinjektion eukaryontischer Zellen wurde Plasmid-DNA hoher Reinheit benötigt. Hierfür wurden die Mini- und Midi-Kits von der Firma Qiagen verwendet und nach Herstellerangaben vorgegangen.

\subsubsection{Präparation genomischer DNA aus Gewebeproben}

$5 \mathrm{~mm}$ Schwanzspitze von Mäusen wurden in $200 \mu \mathrm{l}$ SNET mit Proteinase K über Nacht bei $55^{\circ} \mathrm{C}$ lysiert. Die DNA wurde mit $400 \mu 1$ Phenol/Chloroform-Gemisch extrahiert. Der Ansatz wurde in ein Phase Lock Gel I heavy-Gefäß überführt und die Phasentrennung nach 10minütiger Zentrifugation bei $15000 \mathrm{rpm}$ in der Tischzentrifuge erreicht. Die wäßrige Phase wurde mit $400 \mu \mathrm{l}$ Chloroform extrahiert und die Phasen durch kurze Zentrifugation getrennt. Die DNA wurde gefällt und in $50 \mu 1 \mathrm{H}_{2} \mathrm{O}$ über Nacht gelöst.

SNET: $\quad 20 \mathrm{mM}$ Tris/HCl pH 8,0; 5 mM EDTA; $1 \%$ SDS; $400 \mathrm{mM} \mathrm{NaCl}$

Proteinase K: $100 \mu \mathrm{g} / \mathrm{ml}$ frisch eingewogen

\subsubsection{Kurzlyseprotokoll für genomische DNA von Gewebeproben}

Jackson Laboratory, Main Harbor, USA

$2 \mathrm{~mm}$ Schwanzspitzen von Mäusen wurden in 1,2 $\mathrm{ml}$ fassende collection tubes überführt und in $200 \mu \mathrm{l}$ PBND mit $5 \mu 110 \%$ iger Proteinase K-Lösung über Nacht bei $55^{\circ} \mathrm{C}$ lysiert. Der Ansatz 
wurde 10 min im kochenden Wasserbad inkubiert. Ca. $1 \mu \mathrm{l}$ der Lösung wurde für PCR-Reaktionen verwendet.

PBND: $10 \mathrm{mM}$ Tris/HCl, $\mathrm{pH}$ 8,3; $50 \mathrm{mM} \mathrm{KCl;} \mathrm{2,5} \mathrm{mM} \mathrm{MgCl}_{2} ; 0,1 \mathrm{mg} / \mathrm{ml} \mathrm{Gelatine;} \mathrm{0,45} \mathrm{\%} \mathrm{(v/v)}$ Nonidet P40; 0,45 \% (v/v) Tween 20; autoklaviert.

\subsubsection{DNA-Analyse}

\subsubsection{Konzentrationsbestimmung}

Die Konzentration von Plasmid-DNA nach Isolierung über das Plasmid Mini- oder Midi-Kit wurde über die Absorption bei $260 \mathrm{~nm}$ im Photometer bestimmt. Dabei entspricht eine DNAKonzentration von $50 \mu \mathrm{g} / \mathrm{ml}$ einer optischen Dichte von eins. Ansonsten wurde die DNAKonzentration nach Agarosegelelektrophorese im Vergleich zu der Intensität der Ethidiumbromid gefärbten Banden des Längenstandards $\lambda$ BstE II ermittelt.

\subsubsection{Restriktionsverdau von DNA}

Für analytische Zwecke wurden 0,5 bis $2 \mu \mathrm{g}$ Plasmid-DNA in $25 \mu \mathrm{l}$ Gesamtvolumen über eine Stunde mit 1 bis $5 \mathrm{U}$ eines oder mehrerer Restriktionsendonukleasen verdaut. Der Inkubationspuffer und die Inkubationstemperatur wurden nach Empfehlung des Enzymherstellers gewählt. Die Fragmente wurden durch Agarosegelelektrophorese aufgetrennt und das Restriktionsmuster mit Hilfe der Videogeldokumentationsanlage dokumentiert.

Für präparative Zwecke wurden bis zu $10 \mu \mathrm{g}$ Plasmid-DNA in 50 bis $100 \mu \mathrm{l}$ Gesamtvolumen verdaut. Die Isolation des Vektors (Fragment, das die Anteile des Plasmides enthält, die für die Propagation in Bakterien notwendig sind) erfolgte nach Auftrennung durch Agarosegelelektrophorese mit Hilfe des Qiaex II-Kits oder, falls nur Fragmente kleiner 20 bp abgetrennt wurden, durch Fällung. Die übrigen Fragmente wurden mit Hilfe des Qiaex II-Kits gereinigt.

\subsubsection{DNA-Sequenzierung}

DNA-Sequenzierungen wurden nach einer modifizierten Didesoxy-Methode durchgeführt (Sanger et al. 1977). Die Sequenz aller subklonierten PCR-Produkte, von Teilen aller Rekombinationsvektoren und aller Expressionskonstrukte wurde über die DNA-Sequenzierung überprüft. Plasmid-DNA wurde auf eine Konzentration von $100 \mathrm{ng} / \mu \mathrm{l}$ und PCR-Produkte auf 10-30 ng/ $\mu \mathrm{l}$ eingestellt. Die Sequenzierung erfolgte über das institutseigene Sequenzierlabor.

\subsubsection{Modifikation von DNA}

\subsubsection{Dephosphorylierung der 5'-Enden von DNA}

Nach Restriktionsverdau der Plasmid-DNA wurde der Ansatz vierfach mit $\mathrm{H}_{2} \mathrm{O}$ verdünnt. Nach Zugabe des 10fach konzentrierten Inkubationspuffers des Herstellers und $1 \mathrm{U}$ pro $\mu \mathrm{g}$ DNA alkalischer Phosphatase wurde der Ansatz 2-4 h bei $37^{\circ} \mathrm{C}$ inkubiert. Die Proteine wurden über Phenol/Chloroform-Extraktion entfernt und die DNA anschließend in $\mathrm{H}_{2} \mathrm{O}$ aufgenommen.

\subsubsection{Ligation von DNA}

20 bis 100 ng Vektor-DNA wurden mit ca. der dreifachen molaren Menge der einzufügenden DNA (insert) in einem Endvolumen von $30 \mu \mathrm{l}$ vermischt. Die Reaktion erfolgte im mitgelieferten Puffer mit $1 \mathrm{U}$ T4-DNA-Ligase über Nacht bei $16^{\circ} \mathrm{C}$. 
Bei der Ligation von nicht kohesiven Enden (blunt end) wurde die Reaktion für 2-4 h bei Raumtemperatur durchgeführt. Ein Teil des Ansatzes wurde in Bakterien transformiert.

Die Ligation von PCR-Produkten mit nicht kohesiven Enden erfolgte in den Vektor pCRScript II. 25 ng Vektor-DNA verdaut mit SmaI wurden mit ca. der fünffachen molaren Menge über das Qiaex II- oder QIAquick PCR Purification-Kit-gereinigte PCR-Produkt in einem Endvolumen von $10 \mu \mathrm{l}$ vermischt. Nach Zugabe von NEB-Puffer A, 0,5 $\mu 110 \mathrm{mM}$ ATP, $2 \mathrm{U}$ SmaI oder SrfI und $1 \mu 1$ T4 DNA-Ligase wurde die Ligation für $2 \mathrm{~h}$ bei Raumtemperatur durchgeführt und ein Aliquot transformiert.

Die Ligation von PCR-Produkten nach Amplifikation mit der Power-Script-PolymeraseMischung erfolgte nach Herstellerangaben mit dem TOPO-Ligations-Kit. $1 \mu \mathrm{l}$ des $8 \mu$ l-Ansatzes wurden in elektrokompetente Bakterien transformiert.

\subsubsection{Zielgerichtete Mutationen, eingefügt über die Polymerase-Kettenreaktion}

(Higuchi 1990)

Zwei Primerpaare, die den gewünschten Genabschnitt flankieren, wurden erstellt. Im Bereich der einzufügenden Mutation wurden zwei gegenläufige Primerpaare generiert, die die Mutation und eine stille Mutation zur Einfügung einer neuen Markierungs-Restriktionsschnittstelle enthielten. Anschließend wurden zwei Polymerase-Kettenreaktionen mit je einem Mutationsprimer und einem flankierenden Primer durchgeführt. Die Sequenz dieser Produkte überlappt sich um ca. 30 bp. Die Produkte wurden 1:100 verdünnt, in einer neuen Reaktion ohne Primer eingesetzt und über 5-10 Zyklen verschmolzen. Anschließend wurden die flankierenden Primer zugefügt und das gewünschte mutierte Produkt amplifiziert, isoliert und in den gewünschten Vektor kloniert. Der Erfolg konnte über die eingefügte Markierungsschnittstelle überprüft werden.

\subsubsection{Auffüllen und Verdau von überstehenden Enden nach Restriktionsverdau}

Restriktionsenzyme wie z.B. KpnI produzieren 3'-überhängende Enden. Für die Ligation mit nicht kohesiven DNA-Fragmenten wurde die DNA nach Restriktionsverdau gefällt und in $50 \mu 1$ Endvolumen im mitgelieferten Inkubationspuffer mit $2 \mathrm{U}$ T4-DNA-Polymerase und 0,1 mM dNTP für $1 \mathrm{~h}$ bei $37^{\circ} \mathrm{C}$ inkubiert.

Restriktionsenzyme wie z.B. EcoRI produzieren 5'-überhängende Enden. Diese wurden mit 2 U Klenow-DNA-Polymerase und $1 \mathrm{mM}$ dNTP innerhalb von $1 \mathrm{~h}$ bei $37^{\circ} \mathrm{C}$ aufgefüllt.

Die Entfernung von 5'-überhängenden Enden erfolgte mit der Mung-Bean-Exonuklease nach Herstellerangaben.

Für die partielle Auffüllung von 5'-überhängenden Enden wurden nur die entsprechenden Nukleotide in den Reaktionsansatz gegeben. Das verbleibende 5'-überhängende Ende wurde dann mit Hilfe der Mung-Bean-Exonuklease entfernt.

Falls die DNA nach Modifizierung noch einem weiteren Restriktionsverdau unterzogen wurde, wurde die DNA vorher mit Phenol/Chloroform extrahiert und in dem entsprechenden Puffer wieder gelöst.

Die erhaltenen Fragmente wurden über Agarosegelelektrophorese aufgetrennt. 


\subsubsection{Radioaktive Markierung von DNA}

(Feinberg und Vogelstein 1983)

Die Markierung wurde nach Vorschrift des Prime-IT II Random Primer labeling-Kits durchgeführt und nicht inkorporierte Nukleotide über Bio Spin P30-Säulen abgetrennt.

\subsubsection{DNA-Gelelektrophorese}

Standardmäßig wurden für Plasmid-DNA 1 \%ige Gele und für die Analyse von PCR-Produkten bei der Genotypisierung 1,5\%ige Gele verwendet. Die Analyse von DNA-Fragmenten kleiner als 500 bp wurde mit Hilfe einer Agarosekonzentration von $2 \%$ durchgeführt. Die Agarose wurde unter Kochen in 1x TAE gelöst. Nach Abkühlung auf ca. $50^{\circ} \mathrm{C}$ wurde Ethidiumbromid in einer Endkonzentration von $0,5 \mu \mathrm{g} / \mathrm{ml}$ zugefügt, das Gel in den Gelträger der Elektrophoresekammer gegossen und der Probenkamm eingesetzt. Die DNA-Proben wurden mit ca. 0,2 Volumen des Probenpuffers versetzt, bei 150 bis $250 \mathrm{~V}$ im Gel aufgetrennt und die Fragmente auf dem UV-Leuchttisch (254 nm) sichtbar gemacht.

6x Probenpuffer: $\quad$ 0,25\% Bromphenolblau, $40 \%$ Saccharose.

\subsubsection{DNA-Transfer auf Nylonmembranen nach Southern}

(Southern 1975)

Für Hybridisierungen wurde die DNA auf einen Nylonträger transferiert. Nach Agarosegelelektrophorese wurde das Gel 20 min im Denaturierungspuffer inkubiert. Das Gel wurde auf zwei Lagen in Denaturierungspuffer getränktem Whatman 3MM-Filterpapier aufgelegt, deren Enden in Tanks mit reichlich Denaturierungspuffer eintauchten. Auf das Gel wurde eine feuchte Nylonmembran, gefolgt von zwei Lagen feuchtem Filterpapier und einem Stapel trockener Papierhandtücher, gelegt. Der Aufbau wurde mit einem Gewicht von ca. 200 bis $500 \mathrm{~g}$ beschwert, um eine bessere Kapillarwirkung der Handtücher zu bewirken. Nach zwölfstündigem Transfer wurde die Nylonmembran 5 min im Neutralisierungspuffer und 5 min in 2x SSC inkubiert. Die DNA wurde durch UV-Licht $(1 \mathrm{~J} / \mathrm{cm} 2)$ im Fluo-Link kovalent an die Membran gebunden.

Für den zweistündigen Transfer von Plasmid-DNA wurde das Gel auf einen Streifen Frischhaltefolie ohne Denaturierungspuffer-Reservoir gelegt.

\subsubsection{Hybridisierung}

Nylonmembranen nach Southernblot, Bakterienlifts oder Phagenlifts wurden 2 bis $4 \mathrm{~h}$ bei $42^{\circ} \mathrm{C}$ im Prähybridisierungspuffer inkubiert. Die Lösung wurde durch Hybridisierungspuffer ersetzt und über Nacht bei $42^{\circ} \mathrm{C}$ unter Schwenken inkubiert. Die Membran wurde zweimal 20 min bei $60^{\circ} \mathrm{C}$ in reichlich Waschlösung I und $20 \mathrm{~min}$ bei $60^{\circ} \mathrm{C}$ in reichlich Waschlösung II gewaschen. Die luftgetrocknete Membran wurde anschließend auf einem Röntgenfilm bei $-70^{\circ} \mathrm{C}$ oder einer Expositionsplatte des FujiBas 5000 exponiert.

Waschlösung I: $\quad 2 x \mathrm{SSC} ; 0,1 \% \mathrm{SDS}$

Waschlösung II: $\quad 0,1 x$ SSC; $0,1 \%$ SDS 


\subsubsection{Klonierung aus Phagen-Genbibliotheken}

\subsubsection{Screening einer Phagen-Genbibliothek}

Mit Hilfe von DNA-Sonden können über Hybridisierung einzelne Klone einer Genbank identifiziert werden. Überlappende Klone umspannen das gesamte Gen bzw. die cDNA.

$50 \mathrm{ml}$ LB-Medium mit 0,2\% Maltose und $10 \mathrm{mM} \mathrm{MgSO}_{4}$ wurden mit einer Kolonie Bakterien (XL1-Blue MRA(P2)) über Nacht bei $37^{\circ} \mathrm{C}$ inkubiert. Die Bakterien wurden pelletiert und nach einmaligen Waschen in SM-Puffer aufgenommen, so daß die Suspension eine optische Dichte bei $600 \mathrm{~nm}$ von eins hatte. Zur Titerbestimmung wurde eine Verdünnungsreihe der Bibliothek von $10^{-3}$ bis $10^{-6}$ hergestellt. $40 \mu$ l Phagenverdünnung wurden mit $400 \mu$ l Bakterien 20 min bei $37^{\circ} \mathrm{C}$ inkubiert mit $8 \mathrm{ml} 50^{\circ} \mathrm{C}$ warmem Top-Agar vermischt und auf vorgewärmte LBKulturschalen (15 cm Durchmesser) ausgegossen. Nach Erhärten des Agars wurden die Kulturschalen ca. $10 \mathrm{~h}$ bei $37^{\circ} \mathrm{C}$ inkubiert, bis die Lysehöfe konfluent wurden.

Die Genbibliothek wurde mit einem Titer von 50.000 pfu pro Platte auf ca. 20 Platten ausplattiert. Von den erkalteten Platten wurden doppelte Filter-Replikate (Phagenlifts) erstellt. Die Phagen auf den Nylonmembranen wurden denaturiert (5 min Denaturierungslösung) und nach Neutralisation (5 min Neutralisierungslösung) und Waschen der Filter (zweimal 5 min 2x SSC) wurde die DNA $2 \mathrm{~h}$ im Vakuumofen an der Membran fixiert. Die gesuchten Plaques wurden durch Hybridisierung mit einer radioaktiven Sonde identifiziert und herausgestanzt. Es wurden nur die Signale als positiv bewertet, die auf beiden Duplikaten vorkamen. Die Phagen wurden aus dem Agarblöckchen in SM-Puffer ausgeschwemmt und Einzelplaques durch erneutes Ausplattieren isoliert.

\subsubsection{Phagenamplifikation}

Die Einzelplaques wurden durch Ausplattieren mit 50000 pfu amplifiziert und mit 4 ml SMPuffer über $5 \mathrm{~h}$ heruntergewaschen. Nach Zugabe von $50 \mu \mathrm{l}$ Chloroform konnte die Lösung für einige Wochen bei $4^{\circ} \mathrm{C}$ gelagert werden.

\subsubsection{Präparation von $\lambda$-Phagen-DNA}

Für die Isolation von $\lambda$-Phagen-DNA wurden 20 bis $100 \mu l$ des Amplifikates mit $400 \mu 1$ Bakterien versetzt und dieser Ansatz in $50 \mathrm{ml} \mathrm{LB}$ mit $0,2 \%$ Maltose und $10 \mathrm{mM} \mathrm{Mg} \mathrm{SO}_{4}$ über Nacht bei $37^{\circ} \mathrm{C}$ inkubiert. Je nach Phagen/Bakterien-Verhältnis fand eine vollständige Lyse statt. Diese wurden nach Zugabe von $750 \mu$ l Chloroform und Inkubation für $30 \mathrm{~min}$ bei $37^{\circ} \mathrm{C}$ bei $3500 \mathrm{rpm}$ in der Megafuge für $10 \mathrm{~min}$ abzentrifugiert. Die Isolation der DNA erfolgte nach einem Protokoll der Firma Qiagen, Hilden: Nach Zugabe von $100 \mu 1$ Puffer L1 wurde 30 min $37^{\circ} \mathrm{C}$ und nach weiteren $10 \mathrm{ml}$ Puffer L2 $60 \mathrm{~min}$ bei $0^{\circ} \mathrm{C}$ inkubiert. Nach Zentrifugation für $10 \mathrm{~min}$ bei 10000x g wurde das Sediment in $3 \mathrm{ml} \mathrm{L3}$ aufgenommen, $3 \mathrm{ml}$ L4 hinzugefügt und $20 \mathrm{~min}$ auf Eis inkubiert. Nach Zugabe von $3 \mathrm{ml}$ Puffer L5 wurde der Ansatz 30 min bei 15000x g zentrifugiert. Die Zentrifugation wurde mit dem Überstand wiederholt und die DNA aus diesem über das Qiagen Midi-Kit nach Herstellerangabe isoliert.

Puffer L1: $300 \mathrm{mM} \mathrm{NaCl;} 100 \mathrm{mM}$ Tris/HCl, pH 7,5; $10 \mathrm{mM}$ EDTA; 0,2 mg/ml BSA; $20 \mathrm{mg} / \mathrm{ml}$ RNAse A; $6 \mathrm{mg} / \mathrm{ml}$ DNAse I

Puffer L2: $30 \%$ Polyethylenglykol (PEG 6000); $3 \mathrm{M} \mathrm{NaCl}$

Puffer L3: 100 mM NaCl; 100 mM Tris/HCl, pH 7,5; 25 mM EDTA 
Puffer L4: $4 \%$ SDS

Puffer L5: 3 M Natriumacetat, $\mathrm{pH}$ 5,5

\subsubsection{Subklonierung der genomischen Klone}

Mit Hilfe der Restriktionsendonuklease NotI und Trennung durch Agarosegelelektrophorese wurde die klonierte genomische DNA isoliert und in das Plasmid pBluescript II kloniert.

\subsubsection{Sequenzanalyse und Datenbanksuche}

Die computergestützte Sequenzanalyse erfolgte mit dem Programmpaket Lasergene. Proteinstrukturanalyse, Suche nach verwandten Proteinen und Literaturdatenbanksuche erfolgte über die Internetzugänge bei NCBI und ISREC.

\subsubsection{Gewinnung von Gewebehomogenaten}

Ratten oder Mäuse wurden durch Genickbruch getötet, die Gewebe entnommen und im Homogenisationspuffer auf Eis gelagert. Gehirnregionen wurden unter dem Binocular auf einem eiskalten mit Homogenisationspuffer getränktem Filterpapier präpariert. Die Hippokampusregionen wurden analog der Vorschrift von Hörtnagl, gewonnen (Hörtnagl et al. 1991).

Homogenisationspuffer: 0,32 M Saccharose; 20 mM HEPES/NaOH, pH 7,4; 0,1 mM EDTA; 1x Proteaseinhibitor-Mix.

Proteaseinhibitor-Mix (1000x): $1 \mathrm{mg} / \mathrm{ml}$ Aprotinin in $\mathrm{H}_{2} \mathrm{O} ; 1 \mathrm{mg} / \mathrm{ml}$ Leupeptin in $\mathrm{H}_{2} \mathrm{O} ; 1 \mathrm{mg} / \mathrm{ml}$ Pepstatin in Ethanol; 200 mM PMSF in Ethanol.

\subsubsection{Subzelluläre Fraktionierung}

(Huttner et al. 1983; Jones und Matus 1974)

30 Cortices von Mäusen (6-8 Wochen alt) wurden in eiskaltem Homogenisationspuffer gesammelt. Das Gewebe wurde in $80 \mathrm{ml}$ Homogenisationspuffer mit 12 Hüben bei $900 \mathrm{rpm}$ im Potter-Elvehjem homogenisiert. Die Kerne und Zelltrümmer wurden bei 800x g für $10 \mathrm{~min}$ abzentrifugiert (P1). Aus dem Überstand (S1) wurden Synaptosomen durch 15minütige Zentrifugation bei 9200x g angereichert (P2). Der Überstand wurde $1 \mathrm{~h}$ bei 100.000x g zentrifugiert. Dieses Pellet (P3) enthielt hauptsächlich Mikrosomen, Lysosomen und auch synaptische Vesikel. Der Überstand (S3) war angereichert mit löslichen Proteinen aus dem Zytosol. Das Pellet P2 wurde mit Homogenisationspuffer gewaschen und erneut abzentrifugiert (P2'). Dieses Pellet enthielt die unreine Synaptosomenfraktion und wurde in $13 \mathrm{ml}$ Homogenisationspuffer resuspendiert. Die Synaptosomen wurden durch Zugabe von neun Volumina $\mathrm{H}_{2} \mathrm{O}$ und Homogenisation mit fünf Hüben bei $1500 \mathrm{rpm}$ im Potter-Elvehjem lysiert. Der Ansatz wurde 20 min bei 25000x g zentrifugiert, wobei das Pellet (LP1) mit Plasmamembranen aus aufgebrochenen Nervenendigungen angereichert war. Aus dem Überstand wurde durch Zentrifugation für $1 \mathrm{~h}$ bei 100.000x g die unreine synaptische Vesikelfraktion (LP2) gewonnen. Der Überstand (LS2), der mit synaptischen zytosolischen Proteinen angereichert war, wurde im Biomax-5K ultrafiltriert oder durch TCA gefällt. Das Pellet LP1 wurde in $45 \mathrm{ml} \mathrm{1,2} \mathrm{M} \mathrm{Sucroselösung}$ aufgenommen und aufgeteilt in drei Zentrifugenröhrchen mit $15 \mathrm{ml} \mathrm{0,8} \mathrm{M} \mathrm{Sucrose} \mathrm{und} \mathrm{0,3} \mathrm{M}$ Sucrose überschichtet. Die Fraktion der synaptischen Plasmamembranen wurde nach Zentri- 
fugation für $150 \mathrm{~min}$ bei $19000 \mathrm{rpm}$ im SW28-Rotor (Beckmann Instruments, München) als Bande zwischen den untersten Schichten isoliert mit zwei Volumen $\mathrm{H}_{2} \mathrm{O}$ verdünnt und 20 min bei 37000x g abzentrifugiert (SPM).

1,2 M Sucroselösung: 1,2 M Sucrose, 5 mM HEPES/NaOH; pH 7,4

\subsubsection{Proteinpräzipitation}

Proteine wurden durch die Zugabe von 0,25 Volumenanteilen $50 \%$ TCA ausgefällt und 10 min bei maximaler Umdrehung in der Tischzentrifuge oder $30 \mathrm{~min}$ bei $20.000 \mathrm{x} \mathrm{g}$ in der SorvallZentrifuge abzentrifugiert. Um überschüssige TCA zu entfernen, wurde das Pellet mit Diethylether gewaschen und erneut abzentrifugiert. Nach TCA-Fällung wurde die Probe in der Regel in SDS-Probenpuffer aufgenommen.

\subsubsection{Präparation von GST-Fusionsproteinen}

\subsubsection{1 Überexpression von Fusionsproteinen in E. coli}

LB-Medium wurde 1:100 mit einer Übernachtkultur des gewünschten pGEX-KG-Konstruktes in BL21(DE3)pLysS angeimpft und unter starkem Schütteln bei $37^{\circ} \mathrm{C}$ inkubiert. Nach Erreichen der exponentiellen Wachstumsphase $\left(\mathrm{OD}_{600}=0,5-0,8\right)$ wurde die Expression durch Zugabe von IPTG induziert. Die Expressionszeit, IPTG-Menge und Inkubationstemperatur wurden in Vorversuchen für jedes Konstrukt optimiert. Die Bakterien wurden geerntet und eingefroren.

\subsubsection{Reinigung von Fusionsproteinen}

Eingefrorene Bakterienpellets wurden in $10 \mathrm{ml}$ Lysepuffer pro Liter Kultur resuspendiert. Nach Zugabe von $70 \mu \mathrm{g} / \mathrm{ml}$ Lysozym und $1 \mathrm{mM}$ PMSF wurde der Ansatz $30 \mathrm{~min}$ auf Eis inkubiert und die Bakterien durch vier Ultraschallpulse über 30 s (output level 6, duty 50\%) aufgeschlossen. Nach Zugabe der gleichen Menge PMSF und einer Spatelspitze DNAse wurde der Ansatz 20 min auf Eis inkubiert und anschließend $20 \mathrm{~min}$ bei $16.500 \mathrm{rpm}$ im SS34-Rotor zentrifugiert. Der Überstand wurde mit $1 \mathrm{ml}$ Glutathion-Agarose pro Liter Kultur $1 \mathrm{~h}$ bei $4^{\circ} \mathrm{C}$ unter Schwenken inkubiert. Das Säulenmaterial wurde $5 \mathrm{~min}$ bei $3500 \mathrm{rpm}$ in der Megafuge abzentrifugiert und mindestens dreimal mit $50 \mathrm{ml}$ Lysepuffer gewaschen. Die Elution erfolgte durch proteolytische Abspaltung des Tags. Die Protease Thrombin wurde über Gelfiltrationschromatographie von und die TEV-Protease über $\mathrm{Ni}^{2+}$-NTA-Agarose abgetrennt. Die Fraktionen wurden durch SDS-PAGE analysiert und bei Bedarf gegen $\mathrm{H}_{2} \mathrm{O}$ über Nacht bei $4^{\circ} \mathrm{C}$ dialysiert.

Lysepuffer: $\quad 50 \mathrm{mM}$ Tris/ $\mathrm{HCl} \mathrm{pH} 7,5,300 \mathrm{mM} \mathrm{NaCl}$

\subsubsection{Proteolytische Spaltung von Fusionsproteinen}

\subsection{Thrombin}

Die Glutathion-Agarose wurde dreimal mit 10fachem Volumen Thrombinpuffer gewaschen. Der Thrombinverdau erfolgte in zweifachen Bettvolumen mit 0,1 U Thrombin pro Liter Kultur für 30 min bei Raumtemperatur. Die Glutathion-Agarose wurde 1 min bei 1000 x g sedimentiert und der Überstand abgenommen und EGTA zu einer Endkonzentration von $5 \mathrm{mM}$ zugegeben. Der Verdau wurde noch zweimal wiederholt und die gesammelten Überstände auf Eis gelagert. Die 
Überstände wurden in Biomax-5K-Ultrafiltrationseinheiten durch Zentrifugation auf 0,5 ml pro Liter Kultur konzentriert.

Thrombinpuffer: $\quad 50 \mathrm{mM}$ Tris/HCl, $\mathrm{pH} 7,5 ; 150 \mathrm{mM} \mathrm{NaCl} ; 2,5 \mathrm{mM} \mathrm{CaCl}_{2}$.

\subsection{TEV-Protease}

Die Glutathion-Agarose wurde dreimal mit 10fachem Volumen TEV-Puffer gewaschen. Die Spaltung mit TEV-Protease erfolgte in zweifachem Bettvolumen mit $10 \mathrm{U}$ pro Liter Kultur für eine Stunde bei $30^{\circ} \mathrm{C}$. Der Verdau wurde analog zum Thrombinverdau zweimal wiederholt und die Überstände auf Eis gesammelt. Die Protease wurde durch Zugabe von $50 \mu 1 \mathrm{Ni}^{2+}$-NTAAgarose und Inkubation für eine Stunde bei $4{ }^{\circ} \mathrm{C}$ gebunden. Der Überstand wurde analog dem Thrombinverdau konzentriert.

TEV-Puffer: $50 \mathrm{mM}$ Tris/HCl, $\mathrm{pH}$ 8,0; 0,5 mM EDTA.

\subsubsection{Gelfiltrationschromatographie}

Die Gelfitrationschromatographie wurde an einer FPLC-Anlage auf einer Hi Load 16/60 Superdex 75-Säule durchgeführt. Die Proben wurden in einem Volumen von bis zu $1 \mathrm{ml}$ über eine Schleife aufgetragen und bei einer Flußgeschwindigkeit vom Laufpuffer von $1 \mathrm{ml} / \mathrm{min}$ aufgetrennt. Die Säulenelution wurde über einen UV-Detektor registriert und der erste Gipfel gesammelt. Eine Kontrolle der Fraktionen erfolgte über SDS-PAGE.

Laufpuffer: $20 \mathrm{mM}$ Tris/HCl, pH 7,4; $100 \mathrm{mM} \mathrm{NaCl} ; 30$ min unter Vakuum entgast.

\subsubsection{Immunisierung von Kaninchen}

Die Immunisierung von Kaninchen wurde durch die Applikation von Immunogen mit Adjuvantien an mehreren Stellen subkutan durchgeführt. Vor der Immunisierung wurden $5 \mathrm{ml}$ Präimmunserum abgenommen. $300 \mu \mathrm{g}$ rekombinantes Protein in $500 \mu \mathrm{l}$ PBS wurde mit gleichem Volumen kompletten Freund'schen Adjuvans' versetzt. Die Emulsion wurde durch mehrmalige Passage durch eine Kanüle $(20 \mathrm{G})$ homogenisiert. Die folgenden drei Immunisierungen mit inkomplettem Freund'schem Adjuvans erfolgten im Wochenabstand. Einen Tag nach der letzten Immunisierung wurde $10 \mathrm{ml}$ Blut gewonnen. Nach der Gerinnung wurde der Blutkuchen abzentrifugiert und das Serum getestet. In Wochenabständen wurden weitere Seren gewonnen und getestet. Mögliche Boosterimmunisierungen konnten den Titer erhöhen. Bei gutem Titer wurden die Kaninchen ausgeblutet und die Seren in Aliquots eingefroren gelagert.

\subsubsection{Messung der Neurotransmitteraufnahme}

\subsubsection{Synaptosomaler Transport}

(Teng et al. 1997)

Es wurde die rohe Synaptosomenfraktion P2 der subzellulären Fraktionierung von MausStriatum verwendet. 300 bis $350 \mu \mathrm{g}$ Gesamtprotein in $120 \mu 1$ Reaktionsvolumen wurden 10 min bei $32^{\circ} \mathrm{C}$ in KRH-Puffer mit oder ohne Modulatoren vorinkubiert. Für die Leerwertbestimmung enthielt die Lösung 0,1 mM des Dopamintransporterblockers GBR12909. Die synaptosomale Aufnahme wurde durch die Zugabe von $0,05 \mu \mathrm{Ci}\left[{ }^{3} \mathrm{H}\right]$-Dopamin mit einer finalen Dopaminkonzentration von $0,27 \mu \mathrm{M}$ gestartet. Nach 10 -minütiger Inkubation bei $32^{\circ} \mathrm{C}$ wurde die 
Reaktion durch Zugabe von $3 \mathrm{ml}$ eiskaltem KRH-Puffer gestoppt und die Proben durch mit 0,05\%-igem Polyethylenimid vorbehandelte Whatman GF/B-Filter filtriert. Die Filter wurden dreimal mit $3 \mathrm{ml} \mathrm{KRH-Puffer} \mathrm{gewaschen} \mathrm{und} \mathrm{die} \mathrm{gebundene} \mathrm{Radioaktivität} \mathrm{im} \mathrm{Szintillations-}$ zähler bestimmt. Leerwerte wurden subtrahiert und die Aufnahme bezogen auf die eingesetzte Proteinmenge und Zeiteinheit berechnet.

\subsubsection{Vesikulärer Transport}

(Hell et al. 1988; Teng et al. 1997)

Es wurde die rohe synaptische Vesikelfraktion LP2 der subzellulären Fraktionierung von MausVorderhirnen verwendet. 25 bis $50 \mu \mathrm{g}$ Gesamtprotein wurden 5 min bei $32^{\circ} \mathrm{C}$ in KHE-Puffer mit oder ohne Modulatoren vorinkubiert. Als Modulatoren wurden $20 \mu \mathrm{g}$ rekombinante $\alpha$-SynucleinKonstrukte verwendet. Die Reaktion wurde durch Zugabe von $1 \mu \mathrm{Ci}\left[{ }^{3} \mathrm{H}\right]$-Dopamin $(0,2 \mu \mathrm{M}$ finale Dopaminkonzentration) und 1,8 mM ATP gestartet. Leerwerte wurden in Anwesenheit von $50 \mu \mathrm{M}$ Reserpin bestimmt. Alle Ansätze enthielten $1 \%(\mathrm{v} / \mathrm{v})$ Ethanol in einem Ansatzvolumen von $170 \mu \mathrm{l}$. Nach 5 min wurde die Reaktin durch Zugabe von $3 \mathrm{ml}$ eiskaltem Puffer gestoppt und die Proben durch Nitrocellulosefilter $(0,45 \mu \mathrm{m}$ Porengröße) filtriert. Die Filter wurden dreimal mit $3 \mathrm{ml}$ Puffer gewaschen und die gebundene Radioaktivität im Szintillationszähler bestimmt. Leerwerte wurden subtrahiert und die Aufnahme bezogen auf die eingesetzte Proteinmenge und Zeiteinheit berechnet.

KRH-Puffer: $125 \mathrm{mM} \mathrm{NaCl}, 5 \mathrm{mM} \mathrm{KCl}, 1,5 \mathrm{mM} \mathrm{MgSO}_{4}, 1,25 \mathrm{mM} \mathrm{CaCl}_{2}, 1,5 \mathrm{mM} \mathrm{KH}_{2} \mathrm{PO}_{4}$, $10 \mathrm{mM}$ D-Glucose, 0,1 mM EDTA, 0,1 mM Pargyline, 0,1 mM Ascorbinsäure, $25 \mathrm{mM}$ HEPES-NaOH pH7,4; vor Gebrauch mit $\mathrm{O}_{2}$ gesättigt.

KHE-Puffer: $100 \mathrm{mM}$ Kaliumtartrat, $25 \mathrm{mM}$ HEPES-KOH pH7,4, $50 \mu \mathrm{M}$ EGTA, $100 \mu \mathrm{M}$ EDTA, $2 \mathrm{mM} \mathrm{MgSO}$, 1,7 mM Ascorbinsäure.

\subsubsection{Nitrosylierung von Tyrosinresten in Gewebehomogenaten}

Postnukleäre Überstände von Gehirnkortex zusammen mit Zwischenhirn wurden gewonnen. Die Zugabe von 18,9 $\mu$ l Peroxynitritlösung erfolgte unter kräftigem Schütteln zu $300 \mu$ PNS mit einer Proteinkonzentration von $4 \mathrm{mg} / \mathrm{ml}$. Die Reaktion wurde fünf Minuten bei Raumtemperatur inkubiert. Der Leerprobe wurde die gleiche Menge 0,3 M NaOH zugegeben. Anschließend wurden die Proben mit Probenpuffer versetzt und über Immunoblotanalyse analysiert.

Peroxynitritlösung: $33 \mathrm{mM}$ Peroxynitrit in 0,3 M NaOH . Lagerung in Aliquots bei $-70^{\circ} \mathrm{C}$. Konzentrationsbestimmung über den Extinktionskoeffizienten $\varepsilon_{302}=1,670 \mathrm{M}^{-1} \mathrm{~cm}^{-1}$.

\subsubsection{Methoden zur Proteinanalyse}

\subsubsection{Konzentrationsbestimmung von Proteinen}

Proteinkonzentrationen wurden über das BCA-Kit der Firma Pierce bestimmt. 1 bis $5 \mu 1$ Probe wurden in $50 \mu \mathrm{H} \mathrm{H}_{2} \mathrm{O}$ aufgenommen. $10 \mu \mathrm{l}$ wurden mit $200 \mu \mathrm{l}$ BCA-Reagenz 30 min bei $60^{\circ} \mathrm{C}$ in einer 96-Lochplatte inkubiert. Nach 10minütigem Abkühlen der Platte wurde die Absorption bei $570 \mathrm{~nm}$ im Thermomax microplate reader gemessen. Die Konzentration wurde anhand einer Eichgeraden ermittelt, die über Standardproteinkonzentrationen mit BSA ermittelt wurden. 


\subsubsection{SDS-Polyacrylamidgelelektrophorese}

(Laemmli 1970)

Proteine wurden in diskontinuierlichen $1 \mathrm{~mm}$ dicken SDS-Polyacrylamidgelen nach der Proteingröße aufgetrennt. Das Sammel- und Trenngel wurden über Nacht polymerisiert. Bis zu $80 \mu \mathrm{g}$ Gesamtprotein in SDS-Probenpuffer wurden $10 \mathrm{~min}$ auf 50 bis $60^{\circ} \mathrm{C}$ erhitzt und in die Probentaschen gefüllt. Die Elektrophorese wurde in Mini-PROTEAN II-Gelkammern bei $15 \mathrm{~mA}$ pro Gel im Laufpuffer durchgeführt, bis die Bromphenolblau-Bande das Ende des Gels erreicht hatte. Anschließend wurden die Gele gefärbt oder die Proteine auf Nitrocellulose transferiert.

Laufpuffer:

3 g/l Tris; 14,4 g/l Glycin; 2g/l SDS

Sammelgelpuffer: $\quad$ 0,5 M Tris/HCl, $\mathrm{pH} 6,8 ; 0,4 \%$ SDS

Trenngelpuffer: $\quad 1,5 \mathrm{M}$ Tris/ $\mathrm{HCl}, \mathrm{pH} 8,8 ; 0,4 \%$ SDS

AMBA: $\quad 30 \%$ ige Acrylamid/N,N'-Methylen-bis-Acrylamid-Lösung im Mischungsverhältnis $37,5 \mathrm{zu} 1$

Sammelgel: $\quad$ für ca. 6 Gele: $5 \mathrm{ml} \mathrm{H} \mathrm{H}_{2} \mathrm{O} ; 1 \mathrm{ml}$ AMBA; $2 \mathrm{ml}$ Sammelgelpuffer; $20 \mu \mathrm{l}$ TEMED; $48 \mu 110 \%$ APS

Trenngel (5-15\%): für 4 Gele: 10-5 ml $\mathrm{H}_{2} \mathrm{O} ; 5-10 \mathrm{ml}$ AMBA; $5 \mathrm{ml}$ Trenngelpuffer; $25 \mu \mathrm{l}$ TEMED; $60 \mu 110 \%$ APS

\subsubsection{Proteingelfärbung mit Coomassie Brilliant blue}

SDS-Polyacrylamidgele wurden $15 \mathrm{~min}$ in $50^{\circ} \mathrm{C}$ warmer Färbelösung inkubiert. Anschließend wurden sie in reichlich $\mathrm{H}_{2} \mathrm{O} 10 \mathrm{~min}$ bei voller Intensität in der Mikrowelle gekocht. Anschließend wurde das Wasser mehrmals gewechselt, bis der Hintergrund entfärbt wurde. Zur Beschleunigung der Entfärbung wurde Entfärbelösung verwendet.

Färbelösung: $\quad$ 0,15 \% Coomassie Brilliant Blue R250; 10 \% Eissessig; 25 \% Isopropanol

Entfärbelösung: 30 \% Methanol; 10 \% Eisessig

\subsubsection{Immunoblotanalyse}

(Towbin et al. 1979)

\subsection{Protein-Transfer nach Western}

Proteine wurden aus SDS-Polyacrylamidgelen auf Nitrocellulosemembranen über ein elektrisches Feld transferiert. Dabei wurde die Nitrocellulosemembran auf das Gel gelegt und mit Filterpapieren und Schwämmen in einem Rahmen fixiert. Der Transfer erfolgte in einer Tankblotkammer, gefüllt mit Transferpuffer, über Nacht bei $40 \mathrm{~mA}$.

Die Proteinbanden auf den Nitrocellulosemembranen wurden durch Inkubation mit PonceauSLösung sichtbar gemacht. Die Hintergrundfärbung wurde mit $\mathrm{H}_{2} \mathrm{O}$ abgewaschen.

Transferpuffer: $\quad 3 \mathrm{~g} / \mathrm{l}$ Tris; $14,4 \mathrm{~g} / \mathrm{l}$ Glycin; $20 \%$ Methanol

Ponceau S-Lösung: $\quad$ 0,1 \% Ponceau S; 5 \% Eisessig 


\subsection{Immunodetektion von Proteinbanden}

Proteine auf Nitrocellulosemembranen wurden mit spezifischen Antikörpern markiert und mit sekundären Antikörpern detektiert. Nitrocellulosemembranstreifen wurden in $5 \%$ Trockenmilchpulver in TBS-T 30 min unter Schütteln inkubiert. Nach kurzem Waschen mit TBS-T wurden sie mit der Antikörperlösung für $1 \mathrm{~h}$ inkubiert. Überschüssige Antikörper wurden durch zweimaliges Waschen für jeweils 10 min entfernt. Anschließend erfolgte die Inkubation mit der Detektionsantikörperlösung für ebenfalls $1 \mathrm{~h}$. Nach gründlichem Waschen (dreimal für mehr als jeweils $10 \mathrm{~min}$ ) wurden die Signale detektiert. Signale von HRP-konjugierten Sekundärantikörpern wurden nach Herstellerangaben über das ECL-Kit, und von jodinierten, radioaktiven Sekundärantikörpern über Exposition auf Detektionsplatten des FujiBas 5000 visualisiert. Bei der Verwendung von murinen Primärantikörpern wurde vor der Inkubation mit den radioaktiven Sekundärantikörpern analog mit einer Brückenantikörperlösung inkubiert.

TBS-T:

TBS; $0,1 \%$ Tween 20

Antikörperverdünnungslösung: $1 \%$ Ziegenserum in TBS-T

Antikörperlösung:

Primärantikörper wurden 1:1000 bis 1:10000 in Antikörperverdünnungslösung verdünnt.

Brückenantikörperlösung: Kaninchen-anti-Maus-IgG 1:3000 in Antikörperverdünnungslösung verdünnt.

Detektionsantikörperlösung: HRP konjugierte Sekundärantikörper 1:5000 in Antikörperverdünnungslösung verdünnt bzw. $9 \mu$ l jodinierte, radioaktive Sekundärantikörper pro $10 \mathrm{ml}$ Antikörperverdünnungslösung.

\subsection{Quantifizierung von Proteinbanden}

Signale auf Detektionsplatten des FujiBas 5000 wurden mit der „Profile-Option“ des Programmes MacBas ausgewertet. Dazu wurde ein Rahmen um die Gelspur der zu detektierenden Bande gezogen, die Nullinie bestimmt und die Fläche unter dem Bandengipfel gemessen. Die Mittelwerte und Standardabweichung von Bandenintensitäten von drei verschiedenen Mäusen jeder Analysegruppe wurden berechnet und signifikante Unterschiede über Student's Ttest mit dem Programm Excel bestimmt.

\subsubsection{Methoden für die Immunzytochemie}

\subsubsection{Fixierung von Mausgewebe}

Mäuse wurden über intraperitoneale Applikation von 0,6 ml Avertin pro mouse (Körpergewicht 30 g) narkotisiert. Nach negativem Zwischenzehenreflex wurde die Maus auf der Unterlage fixiert, der Thorax beidseits parasternal eröffnet und der linke Ventrikel des Herzens punktiert. Nach Fixierung der Punktionskanüle und kleiner Inzision im rechten Herzohr wurde das Tier mit $20 \mathrm{ml}$ PBS gefolgt von $20 \mathrm{ml}$ Fixierlösung perfundiert. Das Gehirn wurde präpariert und 30 min in Fixierlösung inkubiert. Anschließend wurde das Gewebe dreimal mit reichlich eiskaltem PBS gewaschen und in $10 \mathrm{ml}$ eiskalte Gefrierschutzlösung überführt. Nach Absinken der Gewebe (ca. 24 bis $36 \mathrm{~h}$ ) wurden diese in Einbettmedium auf Trockeneis eingefroren und bei $-20^{\circ} \mathrm{C}$ gelagert. 
Avertin:

Fixierlösung:

$1 \mathrm{~g} \mathrm{2,2,2-Tribrom-Ethanol;} 180 \mu \mathrm{l}$ Amylalkohol; 71,5 $\mathrm{ml} \mathrm{H}_{2} \mathrm{O}$; bei $42^{\circ} \mathrm{C}$ lichtgeschützt gelöst.

$4 \%$ Paraformaldehyd in PBS. Das Paraformaldehyd wurde in $\mathrm{H}_{2} \mathrm{O}$ unter Erwärmen und der Zugabe von $20 \mu 15 \mathrm{M} \mathrm{NaOH}$ pro $100 \mathrm{ml}$ gelöst. Nach Zugabe der PBS-Tabletten wurde die Lösung filtriert und innerhalb von zwei Tagen verbraucht.

Gefrierschutzlösung: 30 \% Sucrose in PBS.

\subsubsection{Fixierung von neuronalen Primärkulturen}

Die Deckgläschen wurden einmal mit $500 \mu \mathrm{l}$ PBS gewaschen und 20 min mit $500 \mu 1$ Fixierlösung fixiert. Nach zweimaligem Waschen mit je $500 \mu 1$ PBS wurden die Deckgläschen in PBS bei $4^{\circ} \mathrm{C}$ bis zur weiteren Bearbeitung aufbewahrt.

\subsubsection{Bereitstellung von Gewebeschnitten}

5 bis $15 \mu \mathrm{m}$ dicke Gewebeschnitte wurden bei -20 bis $-25^{\circ} \mathrm{C}$ Kammer- und Objekttemperatur im Kryostaten angefertigt. Die Schnitte wurden vom Messer auf SuperFrost Plus-Objektträger gezogen und über Nacht getrocknet. Die Objektträger wurden bei $-20^{\circ} \mathrm{C}$ gelagert und vor der Weiterbearbeitung von überschüssigem Einbettmedium befreit.

20 bis $30 \mu \mathrm{m}$ dicke Gewebeschnitte wurden bei $-25^{\circ} \mathrm{C}$ Objekttemperatur im Gefriermikrotom angefertigt. Die Schnitte wurden bei $-20^{\circ} \mathrm{C}$ in Kryoschutzlösung aufbewahrt. Vor der Immunofärbung wurden die Schnitte mit reichlich PBS gewaschen.

Kryoschutzlösung: $50 \% 50$ mM Natriumphosphatpuffer, $\mathrm{pH} 7,3 ; 30 \%$ Ethylenglycol; $20 \%$ Glycerin

\subsubsection{Gelatinebeschichtung von Objektträgern}

Die Objektträger wurden $20 \mathrm{~min}$ bei $50^{\circ} \mathrm{C}$ im Ultraschallbad bei voller Intensität mit ca. $2 \%$ Extran-Lösung in Leitungswasser gewaschen. Anschließend wurden sie gründlich unter fließendem Leitungswasser und anschließend deionisiertem Wasser gespült. Die Beschichtung wurde für $2 \mathrm{~min}$ in frischer ca. $40^{\circ} \mathrm{C}$ warmer Eintauchlösung durchgeführt. Anschließend wurden die Objektträger $30 \mathrm{~min}$ bei $40^{\circ} \mathrm{C}$ im Vakuumofen getrocknet und konnten über Monate verwendet werden.

Eintauchlösung: $1 \%$ Gelatine; $0,1 \%$ Chromkaliumsulfat. Die Gelatine wurde bei $50^{\circ} \mathrm{C}$ gelöst und anschließend Chromkaliumsulfat zugefügt. Nach Filtration war die Lösung warm gebrauchsfertig.

\subsubsection{Immunofärbung von Gewebeschnitten und Primärkulturen}

(Mandell et al. 1990)

Schnitte auf Objektträgern wurden mit einem Fettmarkerstift umfahren und die Inkubation der Lösungen erfolgte in einer feuchten Kammer auf dem Objektträger. Die Gewebeschnitte wurden 30 min mit GSDB inkubiert. Der primäre Antikörper wurde in GSDB verdünnt und die Schnitte über Nacht bei $4^{\circ} \mathrm{C}$ darin inkubiert. Nach zweimaligem Waschen mit Waschlösung wurden die Schnitte in GSDB mit dem Fluoreszenzfarbstoff-markierten Detektionsantikörper für mindestens $5 \mathrm{~h}$ bei Raumtemperatur oder über Nacht bei $4^{\circ} \mathrm{C}$ inkubiert. Nach dreimaligem Waschen mit 
Waschlösung und PBS für mindestens je 10 min wurden die Schnitte im leicht angetrockneten Zustand mit Antibleichmittel eingedeckelt.

Gewebeschnitte vom Kryomikrotom wurden in 24-Lochplatten analog inkubiert und anschließend auf mit Eintauchlösung vorbehandelte Objektträger gezogen. Die Eindeckelung erfolgte wie oben beschrieben.

Deckgläschen mit neuronalen Primärkulturen wurden in 12-Lochplatten inkubiert und mit Antibleichmittel auf Objektträger überführt.

GSDB: $\quad 450 \mathrm{mM} \mathrm{NaCl} ; 17 \%$ Ziegenserum; 0,3\% Triton X-100; $20 \mathrm{mM}$ Natriumphosphatpuffer, $\mathrm{pH} 7,4$

Waschlösung: $\quad 450 \mathrm{mM} \mathrm{NaCl} ; 0,3 \%$ Triton X-100; 20 mM Natriumphosphatpuffer, pH 7,4

Antibleichmittel: 1,5\% N-Propylgallat; $60 \%$ Glycerin; in PBS

\subsubsection{Heterologe Expression in 293-Zellen}

\subsubsection{Einfrieren und Auftauen von eukaryontischen Zellen}

Zellen einer konfluent bewachsenen 6-Lochplatte wurden in 5 Aliquots eingefroren. Dazu wurden die Zellen mit D-PBS gewaschen und 5 min mit 1x Trypsin-EDTA bedeckt. Nach Zugabe von 2,5 $\mathrm{ml}$ Medium wurden die Zellen vereinzelt, mit 2,5 $\mathrm{ml} \mathrm{2x}$ Einfriermedium vermischt und in einer Styroporbox bei $-80^{\circ} \mathrm{C}$ eingefroren. Langzeitlagerung erfolgte in flüssigem Stickstoff.

Die Zellen wurden rasch bei $37^{\circ} \mathrm{C}$ aufgetaut und mit $10 \mathrm{ml}$ Medium verdünnt. Sie wurden anschließend abzentrifugiert ( 5 min 800x g) und in frischem Medium auf eine Zellkulturschale mit $25 \mathrm{~cm}^{2}$ Fläche ausgesät.

Einfriermedium, 2x: $20 \%$ DMSO; $20 \%$ fötales Kälberserum; 60 \% Medium

\subsubsection{Passagierung von eukaryontischen Zellen}

Konfluente Zellrasen wurden mit D-PBS gewaschen und 5 min bei $37^{\circ} \mathrm{C}$ mit $1 \mathrm{x}$ Trypsin-EDTA inkubiert. Nach Zugabe von 4- bis 10fachem Volumen Medium wurden die Zellen durch Aufund Abpipettieren vereinzelt. Die Zellen wurden auf die drei- (E14.1-, Glia- und MEF-Zellen) bis 10fache (293-Zellen) Kulturfläche ausgesät.

\subsubsection{Kultivierung von 293-Zellen}

293-Zellen wurden in $10 \mathrm{~cm}$-Rundschalen mit $10 \mathrm{ml} 293$-Medium bei $37^{\circ} \mathrm{C}, 5 \% \mathrm{CO}_{2}$ und Wasserdampf-gesättigter Atmosphäre in Begasungsbrutschränken inkubiert. Sie wurden passagiert, sobald die Schale konfluent bewachsen war.

293-Medium: DMEM-Medium mit 4,5 g/l D-Glucose; $10 \%$ hitzeinaktiviertes fötales Rinderserum; 2 mM L-Glutamin

\subsubsection{Transfektion über Calciumphosphat-Kopräzipitate}

(Chen und Okayama 1987)

Das Medium einer semikonfluenten $10 \mathrm{~cm}$-Rundschale wurde $12 \mathrm{~h}$ vor Transfektion gewechselt. $\mathrm{Zu} 20 \mu \mathrm{g}$ Plasmid-DNA in $50 \mu \mathrm{l} \mathrm{H}_{2} \mathrm{O}$ wurden $500 \mu \mathrm{l}$ HBS-Puffer gegeben. Der Ansatz wurde 
mit $32 \mu 12 \mathrm{M} \mathrm{CaCl}_{2}$ versetzt, sorgfältig geschüttelt und tropfenweise auf die Zellen pipettiert. Einen halben Tag später wurden die Zellen mit D-PBS gewaschen und in frischem Medium weiter kultiviert.

HBS-Puffer: 10 mM HEPES/NaOH, pH 7,15; $137 \mathrm{mM} \mathrm{NaCl} ; 5 \mathrm{mM} \mathrm{KCl} ; 1 \mathrm{mM} \mathrm{MgCl} 2 ; 0,7 \mathrm{mM}$ $\mathrm{Na}_{2} \mathrm{HPO}_{4}$; durch Filter mit $0,22 \mu \mathrm{m}$ Porengröße filtriert. Der $\mathrm{pH}-$ Wert wurden in engen Grenzen variiert und der Puffer mit der höchsten Transfektionseffizienz verwendet.

\subsubsection{Gewinnung von Zellhomogenaten}

Fünf Tage nach Transfektion wurden die Zellen mit Homogenisationspuffer gewaschen und in 2x $1 \mathrm{ml}$ Homogenisationspuffer von der $10 \mathrm{~cm}$-Rundschale geschabt. Nach Homogenisation (zehn Hübe) wurden der PNS gewonnen.

\subsubsection{Erstellung hippokampaler Primärkulturen}

\subsubsection{Vorbereitung der Deckgläschen für die Kultur}

Glas-Deckgläschen wurden über Nacht in 1 N Salzsäure gewaschen. Die Salzsäure wurde mit reichlich Wasser ausgewaschen und die Deckgläschen nach mehrmaligem Schwenken in 70 \%igem Ethanol in 95\%-igem Ethanol gelagert. Die feuchten Deckgläschen wurden in die 12Lochkulturschalen überführt, getrocknet, mit Kollagen/Poly-D-Lysin-Lösung bestrichen und unter einer UV-Lampe sterilieriert.

Kollagen/Poly-D-Lysin-Lösung: $\quad 0,1 \mathrm{mg} / \mathrm{ml}$ Poly-D-Lysin, 0,2 mg/ml Kollagen, 0,1 mM Essigsäure.

\subsubsection{Hippokampuspräparation}

Am Embryonaltag 19 (E19) wurde die Muttermaus durch Genickbruch getötet und der Uterus mit der Feten entnommen. Die Feten wurden bis zur Präparation in eiskaltem PBS gelagert. Für die Präparation wurde der Fetus aus dem Uterus entnommen und durch Dekapitation getötet. Die Haut wurde mit einer Pinzette abgezogen und der Schädelknorpel nach zwei lateralen Inzisionen am Foramen magnum bei den Augenbulbi beginnend abgezogen. Das Gehirn wurde mit einem Spatel entnommen und in eiskaltem HBSS präpariert. Die Großhirnhemisphären wurden vom Zwischenhirn getrennt. Die Hirnhäute wurden vom Bulbus olfactorius beginnend an einem Stück abgezogen. Der Hippokampus wurde herausgeklappt und zwischen CA1-Region und enterorhinalem Cortex abgetrennt. Die Fimbrien wurden entfernt und der Hippokampus in $1 \mathrm{ml}$ Enzymlösung überführt.

Enzymlösung: 0,2 mg/ml Cystein, $1 \mathrm{mM} \mathrm{CaCl} 2,0,5 \mathrm{mM}$ EDTA, $25 \mathrm{U} / \mathrm{ml}$ Papain in DMEM, 20 min mit Carbogen begast.

\subsubsection{Neuronenkultur}

Der Hippokampus wurde eine Stunde bei $37^{\circ} \mathrm{C}$ in Enzymlösung inkubiert. Die Lösung wurde abgenommen und durch $1 \mathrm{ml}$ Inhibitionslösung ersetzt. Nach 5-minütiger Inkubation bei $37^{\circ} \mathrm{C}$ wurde die Lösung abgenommen und der Hippokampus in $200 \mu 110 \%$ FBS mit einer gelben Spitze der Pipettierhilfe trituriert. Nach einminütigem Absetzen der Zellen wurde der Überstand in ein neues Gefäß überführt und die sedimentierten Zellen erneut mit $200 \mu 110 \%$ FBS mit vier 
Hüben trituriert. Der Vorgang wurde noch einmal wiederholt und die gesammelten Zellen in $600 \mu \mathrm{l}$ der Überstände in der Neubauer-Zählkammer gezählt. 20000 Zellen wurden auf Deckgläschen mit konfluenten Astrozytenrasen in einer 12-Lochschale in 1,5 ml NBA kultiviert.

10\% FBS: $\quad 10 \%$ FBS, 1x MITO, $100 \mathrm{U} / \mathrm{ml}$ Penicillin, $100 \mu \mathrm{g} / \mathrm{ml}$ Streptomycin in DMEM.

Inhibitionslösung: 2,5 mg/ml Albumin, $2,5 \mathrm{mg} / \mathrm{ml}$ Trypsin-Inhibitor in $10 \%$ FBS.

NBA: $\quad 1 \mathrm{x}$ B27 Supplement, 1x Glutamax-Supplement, $100 \mathrm{U} / \mathrm{ml}$ Penicillin, $100 \mu \mathrm{g} / \mathrm{ml}$ Streptomycin in Neurobasal A.

\subsubsection{Astrozytenkultur}

Die nach Hippokampuspräparation übrig gebliebene Großhirnhemisphäre wurde in $1 \mathrm{ml}$ Emzymlösung analog inkubiert, mit Inhibitionslösung versetzt und in insgesamt $1 \mathrm{ml} 10 \%$ FBS trituriert. Die Zellen aus dem Überstand wurden in $10 \mathrm{ml} 10 \%$ FBS in einer $75 \mathrm{~cm}^{2}$ Gewebekulturflasche kultiviert. Nach Erreichen eines konfluenten Zellrasens wurde die Kulturflasche auf einem Laborschüttler über Nacht inkubiert. Nach zweimaligem Waschen mit $10 \%$ FBS und erneutem Schütteln wurden die Astrozyten trypsiniert, trituriert und ausgezählt. 5000 bis 10000 Zellen wurden pro Deckgläschen in einer 12-Lochkulturschale ausgesät und in 1,5 $\mathrm{ml} 10 \%$ FBS kultiviert. Nach Erreichen eines konfluenten Zellrasens wurde die Zellteilung durch Zugabe von $20 \mu$ l FUDR gestoppt.

FUDR: $\quad$ 8,1 mM 5-Fluoro-2'-Deoxyuridin, 20,4 mM Uridin in DMEM.

\subsubsection{Herstellung rekombinanter embryonaler Mausstammzellen}

(Hooper et al. 1987)

\subsubsection{Kultivierung von E14.1-Zellen}

Die E14.1-Zellen wurden auf Mitose-gehemmten embryonalen Mausfibroblasten (MEF) kultiviert. Das Medium wurde jeweils gewechselt, wenn es sich deutlich gelb färbte. Die übrigen Arbeitsschritte und Kultivierungsbedingungen erfolgten analog der Kultivierung von 293-Zellen.

Medium:

DMEM-Pulvermedium und 2,3 $\mathrm{g} \mathrm{NaHCO}_{3}$ in $11 \mathrm{H}_{2} \mathrm{O}$ gelöst und durch Sterilfiltereinheiten filtriert. Pro $500 \mathrm{ml}$ wurden $6 \mathrm{ml}$ Amino Acids, $6 \mathrm{ml}$ frischer Mercaptoethanol-Lösung, 1,2 ml 500x Penicillin/Streptomycin, $50 \mathrm{ml}$ fötales Rinderserum (HyClone) und $60 \mu 1$ ESGRO-LIF zugefügt.

Mercaptoethanol-Lösung: $14 \mu 1$ 2-Mercaptoethanol auf $20 \mathrm{ml}$ D-PBS.

\subsubsection{Kultivierung von embryonalen Mausfibroblasten}

MEF-Zellen wurden in dem selben Medium wie E14.1-Zellen über ca. 10 Passagen kultiviert. Die übrigen Bedingungen waren analog der Kultivierung von 293-Zellen.

Zur Vorbereitung der MEF für die Kokultur mit E14.1-Zellen wurde nach Erreichen einer 70 \%igen Konfluenz die Zellteilung durch Mitomycin gestoppt. Die Zellen wurden dafür auf mit Gelatine beschichteten Kulturschalen kultiviert (Schalen $1 \mathrm{~h}$ mit Gelatine-Lösung behandelt). Die MEF wurden $2 \mathrm{~h}$ mit $10 \mathrm{mg} / \mathrm{ml}$ Mitomycin im Medium kultiviert und anschließend viermal 
mit $10 \mathrm{ml}$ D-PBS gewaschen und entweder in der Schale weiterkultiviert oder auf Mehrlochkulturschalen ausgesät.

Gelatine-Lösung: $\quad 0,1 \%$ Gelatine in D-PBS.

Mitomycin-Stammlösung, $50 \mathrm{x}: 2 \mathrm{~g}$ Mitomycin C in $4 \mathrm{ml}$ D-PBS.

\subsubsection{Transfektion von E14.1-Zellen}

Die ES-Zellen wurden in einer $25 \mathrm{~cm}^{2}$-Kulturflasche angezogen, bis eine Konfluenz von $80 \%$ erreicht wurde. Sie wurden vereinzelt, sorgfältig mit D-PBS gewaschen und in 0,8 ml D-PBS resuspendiert. Nach Zugabe des Rekombinationsvektors wurden die Zellen verteilt auf zwei Elektroporationsküvetten $(0,4 \mathrm{~cm}$ Elektrodenabstand) mit $500 \mathrm{mF}$ und $23 \mathrm{~V}$ elektroporiert. Anschließend wurden sie verteilt auf fünf $5 \mathrm{~cm}$-Rundschalen kultiviert.

\subsection{Vorbereitung des Rekombinationsvektors}

$400 \mu \mathrm{g}$ des Rekombinationsvektors wurden zur Linearisierung mit NotI verdaut. Die Proteine wurden zweimal mit Phenol/Chloroform und Chloroform extrahiert. Die gefällte DNA wurde mit eiskaltem $70 \%$ Ethanol gewaschen, unter der Sterilwerkbank getrocknet und in $1 \mathrm{ml}$ D-PBS gelöst.

\subsubsection{Selektion von homolog rekombinierten E14.1-Zellen}

Am Tag 1 nach Transfektion wurde das Medium morgens gewechselt. Am Abend wurde die Selektion mit Medium, dem $190 \mu \mathrm{g} / \mathrm{ml}$ Neomycin zugesetzt wurden, über acht Tage begonnen. Die Selektion mit $2 \mathrm{mM}$ Ganciclovir erfolgte zusätzlich von Tag 3 bis Tag 5. Während der Selektion wurde das Medium zweimal täglich gewechselt. Am Tag 9 und 10 wurden resistente Einzelklone isoliert und in 96-Lochkulturschalen kultiviert. Nach ca. drei Tagen wurden die Stammzellen auf zwei 96-Lochkulturschalen passagiert. Nach Erreichen der Konfluenz wurde eine Platte für die DNA-Analyse verwendet und die zweite eingefroren.

\subsubsection{Isolierung der resistenten Klone}

Am 9. und 10. Tag der Selektion wurden die resistenten Klone isoliert. Die Zellen wurden mit DPBS gewaschen und mit DMEM/25 mM HEPES bedeckt. Die Klone wurden unter dem Mikroskop mit einer ausgezogenen Pasteurpipette angesaugt und in $50 \mu 1$ 1x Trypsin-EDTA in einer 96-Lochplatte ("U"-förmige Mulden) überführt. Alternativ konnte auch eine $100 \mu 1$ Pipettierhilfe verwendet werden. Nachdem über ca. 20 min Kolonien isoliert wurden, wurden diese 5 min bei $37^{\circ} \mathrm{C}$ inkubiert und nach Zugabe von $100 \mu \mathrm{l}$ Medium vereinzelt und auf mit $100 \mu 1$ Medium bedeckten MEF in 96-Lochplatten ausgesät.

\subsubsection{Vorbereitung für die Blastozysten-Injektion}

Rekombinante Klone wurden über 24-, 12- und 6-Lochplatten expandiert und in fünfmal $1 \mathrm{ml}$ Volumen eingefroren. Für die Blastozysteninjektion wurden sie in 12-Lochplatten kultiviert. Am Tag der Injektion wurden die Zellen vereinzelt und als Suspension dem institutseigenen Mikroinjektionslabor bereitgestellt.

\subsubsection{DNA-Isolierung aus in 96-Lochplatten kultivierten E14.1-Zellen}

Die konfluent gewachsenen Zellklone wurden zweimal mit D-PBS gewaschen und in jeweils $50 \mu \mathrm{l}$ Lysispuffer über Nacht bei $60^{\circ} \mathrm{C}$ lysiert. Die DNA wurde durch Zugabe von $100 \mu 1$ 
eiskalter Fällungslösung und Inkubation für 30 min bei Raumtemperatur gefällt. Der Überstand wurde dekantiert und die DNA dreimal mit eiskaltem $70 \%$ Ethanol gewaschen. Nach Trocknen der DNA wurde sie über Nacht in $50 \mu 1 \mathrm{H}_{2} \mathrm{O}$ gelöst.

Die Analyse der rekombinanten Klone erfolgte über PCR oder über Restriktionsanalyse und radioaktiver Hybridisierung nach Transfer über Southernblot.

\subsubsection{Pharmakologische Behandlung von Mäusen}

Die verwendeten $\alpha$-Synuclein-Maus-Nullmutanten und Wildtyp-Kontrolltiere waren Geschwistertiere aus Verpaarungen heterozygoter Elterntiere. Die Toxinbehandlung wurde an männlichen Tieren im Alter von acht bis 15 Wochen durchgeführt. Als Kontrollen dienten die weiblichen Geschwistertiere, denen die gleichen Mengen der Trägersubstanz physiologischer Kochsalzlösung injiziert wurden. Die Tiere wurden einzeln in Käfigen mit freiem Zugang zu Wasser und Futter für die Zeitdauer zwei Tage vor Behandlung und bis zur Analyse gehalten.

Die Injektionen von 200 bis $300 \mu$ l Volumen erfolgten mit den in physiologischer Kochsalzlösung gelösten Methamphetaminhydrochlorid oder MPTP-Hydrochlorid intraperitoneal. 20 oder $30 \mathrm{mg} / \mathrm{kg}$ Körpergewicht MPTP bzw. $5 \mathrm{mg} / \mathrm{kg}$ Körpergewicht Methamphetamin wurden pro Injektion verabreicht. Bei Mehrfach-Injektionen erfolgten diese im Abstand von jeweils zwei Stunden. Für die Analyse wurden die Tiere fünf bzw. zehn Tage nach der letzten Injektion getötet und das Striatum der Mäuse präpariert. Aus je einem Striatum wurde der postnukleäre Überstand für die Proteinquantifizierung isoliert und ein Striatum bzw. ein Stück des Gehirnkortex für die Bestimmung der Neurotransmitter verwendet.

\subsubsection{Quantifizierung der Neurotransmitter}

Die Neurotransmitteranalytik wurde von Dr. Francesco Fornai und Mitarbeitern (Universität Pisa) durchgeführt.

Ein Striatum bzw. ein Stück Cortex wurden in 0,6 ml eiskaltem P-Puffer im Sonicator homogenisiert. $50 \mu \mathrm{l}$ des Homogenats wurden für die Proteinbestimmung nach Lowry entnommen. Das restliche Homogenat wurde $10 \mathrm{~min}$ bei $8000 \mathrm{x} \mathrm{g}$ abzentrifugiert und der Überstand abgenommen.

P-Puffer: $\quad$ 0,1 M Perchlorsäure, $10 \mathrm{ng} / \mathrm{ml}$ Dihydroxybenzylamin

\subsection{Catecholamine}

$20 \mu 1$ des klaren Überstandes wurden auf eine HPLC-Säule injiziert. Die Trennung erfolgte bei einer Flußgeschwindigkeit von $1 \mathrm{ml} / \mathrm{min}$ auf einer C18-Säule mit einem Citrat-Phosphat-Puffer als mobile Phase. Die Detektion erfolgte mit Hilfe zweier elektrochemischer Detektoren. Die Quantifizierung erfolgte über eine Standardkurve erstellt mit geeichten Komponenten.

Citrat-Phosphat-Puffer: 0,04 M Citronensäure, 0,06 M Na $\mathrm{NPO}_{4}, 0,1 \mathrm{mM}$ EDTA, 0,6 mM Natriumheptansulfonat, $10 \%$ Methanol.

\subsection{Aminosäuren}

Der klare Überstand wurde mit gleichem Volumen Li-S-Puffer (Beckman, München) verdünnt und $50 \mu \mathrm{l}$ in das Analysegerät (Beckman System 6300) injiziert. Die Analyse erfolgt voll 
automatisch an einer Lithium-Ionenaustauschersäule. Das Eluat wurde mit Ninhydrin gemischt und die Absorption bei $570 \mathrm{~nm}$ bestimmt. Die Quantifizierung erfolgte über die mitgelieferten Standardsubstanzen.

\subsection{Proteinbestimmung nach Lowry}

(Lowry et al. 1951)

Die Proteinbestimmung wurde mit einer nach dem Protokoll von Lowry et al. (1951) abgewandelten Methode durchgeführt. $50 \mu \mathrm{l}$ des Homogenates für die Neurotransmitterbestimmung wurden mit $200 \mu 11 \mathrm{~N} \mathrm{NaOH}$ vermischt. $10 \mu \mathrm{l}$ dieses Gemisches wurden für die Proteinbestimmung in einer Mikrotiterplatte verwendet. Nach Zugabe von $200 \mu$ Lösung A wurde der Ansatz 10 min bei Raumtemperatur inkubiert. Die Farbreaktion entstand dann nach Zugabe von $20 \mu \mathrm{l}$ Lösung B und wurde in einem Mikrotiterplattenlesegerät vermessen. Die Proteinkonzentration wurde anhand einer Eichgeraden mit Standardproteinkonzentrationen verdünnt in $1 \mathrm{~N} \mathrm{NaOH}$ bestimmt.

Lösung A: $\quad 20 \mathrm{~g} / 1 \mathrm{Na}_{2} \mathrm{CO}_{3} ; 100 \mathrm{mg} / \mathrm{l} \mathrm{CuSO} \mathrm{C}_{4} ; 100 \mathrm{mg} / \mathrm{l} \mathrm{NaKTartrat;}$ 0,1 N NaOH.

Lösung B: 1x Folin \& Ciocalteu's Phenol Reagenz 


\section{$4 \quad$ Ergebnisse}

Der erste Teil der Ergebnisse beschreibt die Klonierung der verwendeten DNA-Konstrukte und die Generierung und Charakterisierung von Antikörpern gegen die Synuclein-Paraloge. Mit den Antikörpern wurde die Verteilung von $\alpha$ - und $\beta$-Synuclein im Gehirn und in subzellulären Kompartimenten untersucht. Diese Ergebnisse bildeten die Grundlage für die Erstellung und Analyse der $\alpha$-Synuclein-defizienten Mäuse.

In einem weiteren Schritt wurden die Mausnullmutanten in einem pharmakologischen Modell der Parkinson-Syndrome untersucht. Über die Generierung und Analyse transgener Mäuse, die die Mutanten der Parkinson-Syndrome auslösenden Formen des humanen $\alpha$-Synuclein exprimieren, wurde deren Einfluß auf die Pathogenese charakterisiert.

\subsection{Klonierung und Charakterisierung von Synuclein-Isoformen aus Mensch und Ratte}

Die für die Klonierung der gewünschten Expressionskonstrukte benötigten cDNA-Sequenzen wurden über PCR gewonnen. Primer wurden anhand der veröffentlichten Sequenzen in GenBank (human $\alpha$-Synuclein: L36675; Ratte $\alpha$-Synuclein: AF007758; Ratte $\beta$-Synuclein: Q63754; Ratte $\gamma$-Synculein: NM 031688) entworfen.

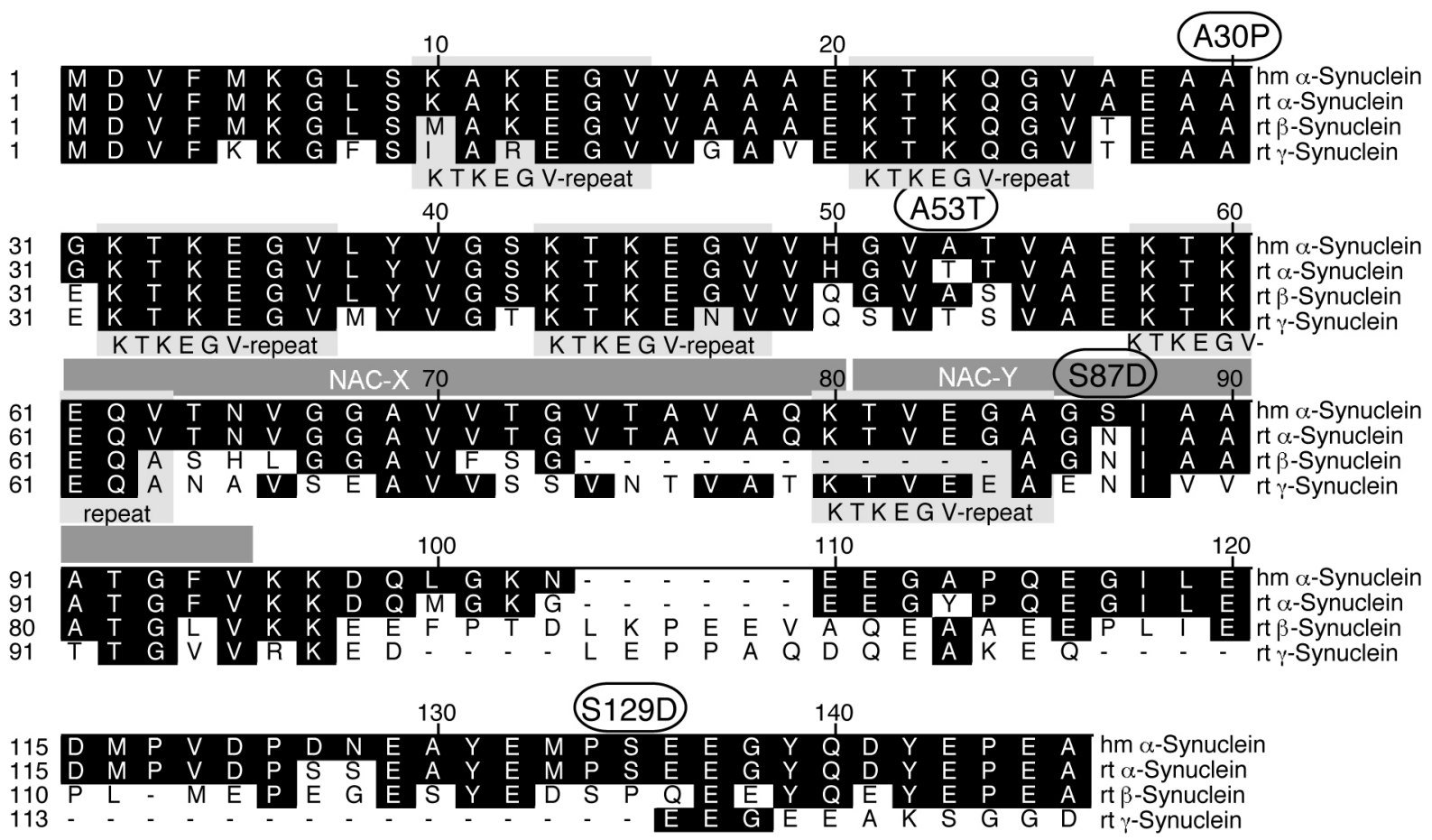

Abb. 2: Die cDNAs von $\alpha$-Synuclein aus Ratte (rt) und Mensch (hm) und die Ratten-Paraloge $\beta$ - und $\gamma$-Synuclein wurden über PCR aus cDNA-Bibliotheken amplifiziert und sequenziert. Die daraus übersetzten Aminosäuresequenzen wurden verglichen. Mit der humanen $\alpha$-Synuclein-Sequenz identische Aminosäuren sind schwarz unterlegt. In hellgrau sind die charakteristischen Wiederholungen von sechs Aminosäuren mit der consensusSequenz „KTKEGV“ dargestellt (Maroteaux et al., 1988). Der Bereich der aus Alzheimer-Plaques isolierten Peptide NAC-X und Y ist in dunkel grau eingezeichnet (Ueda et al. 1993). Die Positionen für die Aminosäurenaustausche, die zu familiären Parkinson-Syndromen (A30P, A53T) oder zur Imitierung konstitutiv phosporylierterer Serine (S87D, S129D) führen, sind hervorgehoben. pI (hm $\alpha$-Synuclein) $=4,58$; pI (rt $\alpha-$ Synuclein $)=4,66$; pI $(\beta-$ Synuclein $)=4,34 ; \mathrm{pI}(\gamma-$ Synuclein $)=4,63$. 
Die Menschen- und Ratten-cDNA für $\alpha$-Synuclein wurde mit Hilfe der Primer 786 und 801 bzw. 786 und 787 aus den entsprechenden Gesamthirn-cDNAs amplifiziert und über die Restriktionsschnittstellen EcoRI und HinDIII in den Vektor pGEX-KG kloniert (phSyf.1: OliverS240997-B 05, -B 06; LrSyf.15: OliverS170997-B 25, -B 28). Die $\beta$ - und $\gamma$-Isoformen aus Ratte wurden mit Hilfe der Primer T1818 und T1819 bzw. 946 und 947 aus einer embryonalen cDNA-Bibliothek bzw. der entsprechenden Gesamthirn-cDNA amplifiziert. Die Klonierung des mit EcoRI verdauten PCR-Produktes von $\beta$-Synuclein erfolgte in den mit SmaI und EcoRI geschnittenen Vektor pGEX-KG (LbSyn.5: !3403239.SEQ). Das PCR-Produkt von $\gamma$-Synuclein wurde in den Vektor pCR-Script II kloniert (g-Synu.22: OliverS011098-B 02).

$\alpha$-Synuclein war 140 Aminosäuren lang und die Sequenzen aus Ratte und Mensch zu 95\% identisch (Abb. 2). Der auffälligste Unterschied in der Rattensequenz war das Threonin an der Position 53, da diese Aminosäure in der humanen Sequenz zu einer familiären Form der Parkinson-Erkrankung führt. Wie der Vergleich mit der genomischen Sequenz der Maus und den Datenbankeinträgen ergab, enthielt die Maussequenz an der Position 53 ebenfalls ein Threonin und unterschied sich von der Rattensequenz durch einen anderen Aminosäurenaustausch (D121G; AF044672). Die $\beta$ - (134 Aminosäuren) und $\gamma$-Paraloge (123 Aminosäuren) waren zu 61,2 bzw. 55,3\% identisch mit dem Ratten- $\alpha$-Synuclein. Alle drei Isoformen enthielten, die für Synucleine charakteristische Wiederholung von sechs Aminosäuren mit der Konsensus-Sequenz „KTKEGV“ (Abb. 2; Maroteaux et al. 1988). Die größte Sequenzübereinstimmung war im Bereich der N-terminalen Hexa-Wiederholungs-Regionen, wobei die sechste Wiederholung im $\beta$-Synuclein fehlte.

Die Wiederholung dieses Sequenzmotivs ist einmalig, wie ein Vergleich mit den bisher veröffentlichten Proteinsequenzen zeigte. Mit Hilfe der Prosite-Datenbank wurde getestet, welche Proteine ein ähnliches Sequenzmotiv K-T-[KR]-[EQ]-[GQ]-V enthielten. Der Vergleich ergab insgesamt sieben Proteine aus Säugetieren. RhoB und C gehören zur Familie kleiner GTPbindender Proteine, p21/H-Ras-1, p21B/K-Ras-2b und N-Ras sind an der Signaltransduktion zum Zellzyklus beteiligt, Hsp-27 ist ein Chaperon und IP-3-Kinase ein Inositolphosphat phosphorylierendes Enzym. Eine Röntgenstruktur ist nur von RhoA und p21/H-Ras bekannt (Franken et al. 1993; Wei et al. 1997). In beiden liegt das entsprechende Sequenzmotiv in einer Schleife an der Außenseite des Proteins. Das Valin gehört jeweils zur der dem Loop folgenden $\alpha-$-Helix.

Die C-Termini aller Synucleine enthielten eine Vielzahl negativ geladener Aminosäuren. Das Ratten- $\alpha$-Synuclein enthielt in diesem Abschnitt insgesamt 14 Aspartat- oder Glutamatreste, denen nur drei positiv geladene Lysine entgegenstanden. Der isoelektrische Punkt des gesamten Proteins lag mit 4,66 relativ niedrig. Das Serin-121 in der $\alpha$-Synuclein-Sequenz aus Ratte war in der humanen Sequenz noch durch ein zusätzliches Aspartat ersetzt, so daß der isoelektrische Punkt mit 4,58 noch niedriger war. Die negative Ladung des C-Terminus von $\beta$-Synuclein war noch ausgeprägter. Insgesamt 19 sauren Aminosäuren standen nur drei Lysine gegenüber. Der isoelektrische Punkt lag dadurch bei 4,34. $\gamma$-Synuclein hatte einen isoelektrischen Punkt vergleichbar mit dem vom $\alpha$-Synuclein. 


\subsection{Klonierung eukaryontischer Expressionskonstrukte}

Eukaryontische Expressionskonstrukte wurden für die Charakterisierung der SynucleinAntikörper benötigt. Die Klonierung der $\alpha$-Synuclein-cDNAs aus Mensch und Ratte erfolgte nach Amplifikation mit den Primerpaaren 817/818 und 817/832 über die Restriktionsschnittstellen XhoI und HinDIII in den Vektor pcDNA3 (Lhsyfpc3.1: OliverS061197-A 01; LrSyfpc3.2: OliverS211197-A 05).

Zur Charakterisierung der Isoformenspezifität der Antikörper wurde N-terminal die Markersequenz „MRGSHHHHHH“ angefügt, die durch einen spezifischen Antikörper ( $\alpha$ His) detektiert werden konnte und zur Kalibrierung diente. Die Amplifikation der $\alpha$-SynucleinKonstrukte aus Ratte erfolgte mit dem Primerpaar 1241/787, die von $\beta$-Synuclein mit dem Primerpaar 1242/1243 und die von $\gamma$-Synuclein mit dem Primerpaar 1244/947. Die PCRProdukte für $\alpha$ - und $\beta$-Synuclein wurden mit BamHI und die für $\gamma$-Synuclein mit BglII verdaut und in den mit BamHI/EcoRV geschnittenen Vektor NHispBSK.1, der die erwähnte Markersequenz enthielt, kloniert (Schlüter 2000). Die vollständigen Konstrukte wurden über die Restriktionsschnittstelle HinDIII in den entsprechend vorbereiteten eukaryontischen Expressionsvektor pcDNA3 subkloniert (pcDNA3His $\alpha$ Syf.6: OliverS171198-B 09; pcDNA3HisbSyf.2: OliverS271098-B 05; pcDNA3HisgSyf.8: OliverS051198-B 16).

\subsection{Einfügung der Missense-Mutationen der familiären Parkinson- Syndrome}

Über die Primerpaare 1123/1122 und 1121/1120 wurden zwei überlappende PCR-Produkte aus dem Plasmid LhSyfpc3.1 amplifiziert, die für den Aminosäurenaustausch A30P kodierten. Zur Markierung wurde zusätzlich die Restriktionsschnittstelle SmaI eingefügt. Die Amplifikation der hybridisierten überlappenden PCR-Produkte über das Primerpaar 1123/1120 und Klonierung in den Vektor pCR-Script II ergab die gewünschte mutierte humane $\alpha$-Synuclein cDNA (L1123.21: OliverS090698-A 33).

Die Sequenz für den Aminosäurenaustausch A53T und die zusätzlichen Restriktionsschnittstelle für NcoI wurde analog über die Primerpaare 817/949 und 948/818 eingefügt. Die mit den Primern 817/818 amplifizierte mutierte humane cDNA wurde ebenfalls in den Vektor pCRScript II kloniert (LA53T.13: OliverS030398-A 13).

\subsection{Erstellung bakterieller Expressionsvektoren}

Über Bakterien erfolgte die Überexpression von Synuclein-Konstrukten, die gereinigt für die Immunisierung von Kaninchen und Studien der vesikulären Neurotransmitteraufnahme benötigt wurden. Zusätzlich zu den oben beschriebenen Konstrukten im bakteriellen Expressionsvektor pGEX-KG wurden Konstrukte erstellt, die die humane Sequenz mit dem Aminosäurenaustausch A53T bzw. N-Terminal die Erkennungssequenz für die TEV-Protease enthielten (Dougherty et al. 1988). Alle bakteriellen Expressionskonstrukte waren N-terminal an GST fusioniert.

Durch die Amplifikation des humanen $\alpha$-Synuclein A53T mit dem Primerpaar 786/801 und Subklonierung über die Restriktionsschnittstellen EcoRI und HinDIII in den Vektor pGEX-KG 
entstand das entsprechende bakterielle Expressionskonstrukt (L786.19: OliverS030398-A 25, !0202259.SEQ).

Wie unten gezeigt, enthielt $\alpha$-Synuclein eine interne Thrombin-Erkennungssequenz. Um nach Abspaltung des GST $\alpha$-Synuclein in voller Länge zu erhalten, wurde vor die kodierende Sequenz eine TEV-Protease-Erkennungssequenz eingefügt. Nach Abspaltung des GST verblieb somit nur ein zusätzliches Glycin N-terminal. Die Einfügung der Erkennungsstelle in das humane $\alpha$ Synuclein erfolgte über den Primer 1646. Die Amplifikation zusammen mit dem Primer 1643 und Subklonierung über die Restriktionsschnittstellen XbaI und HinDIII in pGEX-KG ergab die TEV-Expressionskonstrukte für $\alpha$-Synuclein, $\alpha$-Synuclein A30P und $\alpha$-Synuclein A53T (TEV haSyf.1: OliverS221299-B 08, -01; TEV Syf A30P.2: OliverS221299-B 09; TEV Syf A53T.1: OliverS221299-B 10).

Mehrere Studien haben eine Phosphorylierung von $\alpha$-Synuclein an zwei Serinen und Tyrosin125 gezeigt (Ellis et al. 2001; Okochi et al. 2000; Pronin et al. 2000). Über eine physiologische Bedeutung dieser Phosphorylierung ist bisher nichts bekannt. Durch den Austausch von Serin gegen Aspartat kann eine konstitutiv aktive Phosphorylierung imitiert werden. Um die Funktion des phosphorylierten $\alpha$-Synuclein zu untersuchen, wurden Konstrukte erstellt, deren Serin an der dominanten Phosphorylierungsstelle durch Aspartat ersetzt wurde (Okochi et al. 2000).

Das hybridisierte Primerpaar 2033/2034 kodierte für den C-Terminus von $\alpha$-Synuclein mit dem Aminosäurenaustausch S129D und wurde über die Restriktionsschnittstellen XbaI und HinDIII in die entsprechenden bakteriellen Expressionskonstrukte TEV haSyf.1, TEV Syf A30P.2 und TEV Syf A53T.1 eingefügt (TEV hSyf S129D.1: OliverS14062000-B 02; TEV A30P S129D.1: OliverS14062000-B 03; TEV A53T S129D.1: OliverS14062000-B 04).

\subsection{Klonierung von Vektoren zur Herstellung transgener Mäuse}

Mit Hilfe der transgenen Technologie können Proteine heterolog exprimiert werden und so deren Einfluß auf den Organismus in Abhängigkeit von eingefügten Mutationen, vom Expressionsmuster und der Expressionsstärke untersucht werden. Das Thy1-Gen steuert eine breite neuronale Expression und je nach Kopienzahl des transgenen Konstruktes ist eine Überexpression möglich.

Es wurden Mäuse generiert, die entweder das humane $\alpha$-Synuclein, die Mutante $\alpha$-Synuclein A30P oder die Mutante $\alpha$-Synuclein A53T transgen exprimierten (Abb. 16). Um zusätzlich den Einfluß eines konstitutiv phosporylierten Serin-87 zu untersuchen, wurde die Mutante $\alpha-$ Synuclein A30P S87D transgen exprimiert.

Die Klonierung des aus dem Plasmid LhSyfpc3.1 über XbaI und HinDIII ausgeschnittenen humanen $\alpha$-Synuclein-Konstruktes erfolgte nach Auffüllung der überstehenden Enden in die XhoI-Restriktionsschnittstelle des transgenen Vektors (pTSC21-hSyf.1: OliverS1311000-B07, OliverS31052001-A 01).

Die cDNA für $\alpha$-Synuclein A30P wurde über die Restriktionsschnittstellen SpeI und PvuI aus dem Plasmid L1123.21 ausgeschnitten und analog in den transgenen Vektor kloniert (LpTA30P2.2: OliverS121198-B 29, OliverS171198-B 10).

Um mögliche Einflüsse von nicht kodierenden Bereichen der cDNA-Konstrukte zu minimieren, wurden die flankierenden Bereiche des Plasmids LA53T.13 entsprechend verändert. Hierzu wurde das die A53T kodierende BspHI/BamHI-Fragment zusammen mit dem die N-terminalen 
Aminosäuren kodierenden Xhol/BspHI-Fragment aus dem Plasmid L1123.21 in das mit XhoI und BamHI geschnittene Vektorrückgrat des Plasmids L1123.21 kloniert. Die Klonierung in den transgenen Vektor erfolgte wie oben beschrieben (L533.7: OliverS041298-B 01, -03).

Die Erstellung der Mutation S87D erfolgte über PCR mit den Primerpaaren 1123/2036 und 2035/1120 aus dem Plasmid L1123.21. Die Amplifikation der hybridisierten Fragmente ergab die cDNA für $\alpha$-Synuclein A30P S87D, die in den Vektor pCR-Script II kloniert wurde. Die Klonierung des Klons mit der analogen Orientierung wie L1123.21 erfolgte wie beschrieben in den transgenen Vektor (hSyf A30P S87D.32: OliverS110700-B 24, -29).

\subsection{Klonierung und Charakterisierung des Maus- $\alpha-S y n u c l e i n-G e n s$}

Über homologe Rekombination lassen sich zielgerichtet Mutationen ins Maus-Genom einfügen. Genetisch veränderte omnipotente Stammzellen überführen diese Mutationen in Mäuse (Capecchi 1989). Um eine Deletion ins Maus-Synuclein-Gen einzufügen, wurden genomische Sequenzabschnitte des Maus- $\alpha$-Synuclein-Gens benötigt. Mit Hilfe einer das 5'-Ende der Ratten$\alpha$-Synuclein-cDNA repräsentierenden Sonde (amplifiziert über die Primer 439 und 440) wurden genomische Klone aus einer genomischen Bank isoliert, die das 5'-Ende des Maus- $\alpha$-SynucleinGens enthielten. Die Charakterisierung der Klone erfolgte über Restriktionskartierung und Sequenzierung. Die etwa $21 \mathrm{~kb}$ großen genomischen Inserts enthielten die ersten beiden kodierenden Exone (Aminosäuren 1-40 und 41-54) und 5'-nicht-kodierende Exone (Abb.2; GenBank acc.\#AF277451).

Der Sequenzvergleich mit der EST-Datenbank ergab zwei Gruppen von EST-Klonen, die über den 5'-Bereich des ersten kodierenden Exons hinausreichten aber die gleichen kodierenden Abschnitte enthielten. Die beiden Gruppen von EST-Klonen ergaben sich somit aus zwei mRNA-Transkripten mit alternativem ersten Exon (im folgenden Exon 1a und 1b bezeichnet). Drei EST-Klone stammten von Exon 1a ab (AI893265, W39982, W75614), wohingegen die anderen neun EST-Klone dem Exon 1b entstammten (W41663, W98185, AI322484, AI304140, AA238977, AA014832, AA013645, AA013580, AA003289). Die Exone lagen ca. 900 bp auseinander, wobei Exon 1b vom Exon 21100 bp entfernt lag. Der Abstand von 900 Basenpaaren ließ vermuten, daß in der Maus zwei alternative Transkriptionsstarts enthalten waren, oder noch ein weiteres nicht-kodierendes Exon weiter 5' liegen könnte. Die alternativen Transkripte deuten auf Regulationsmechanismen der $\alpha$-Synucleinexpression auf Ebene der mRNA-Stabilität, -Lokalisation oder -Translation hin.

\subsection{Klonierung eines Rekombinationsvektors für das $\alpha$-Synuclein- Gen}

Unter Verwendung der genomischen Klone wurde ein homologer Rekombinationsvektor konstruiert, in dem das Exon 2 (Aminosäuren 1-40) durch einen Selektionsmarker (NeomycinResistenz-Expressionskassette) ersetzt war (Abb. 3). Hierzu wurde das $8 \mathrm{~kb}$-Fragment des genomischen Klones \#2 über die Restriktionsschnittstellen PstI und NotI in den mit SpeI und NotI vorbereiteten Vektor pTKNeo3A (Rosahl et al. 1995) kloniert. Über die Primer 670 und 672 wurde der 1,5 kb große zweite Rekombinationsarm aus dem genomischen Klon \#2 amplifiziert 
und über die Restriktionsschnittstelle ClaI in den Vektor eingefügt. Für die Analyse rekombinanter Klone wurde über den Primer 670 eine BglII-Restriktionsschnittstelle eingefügt.

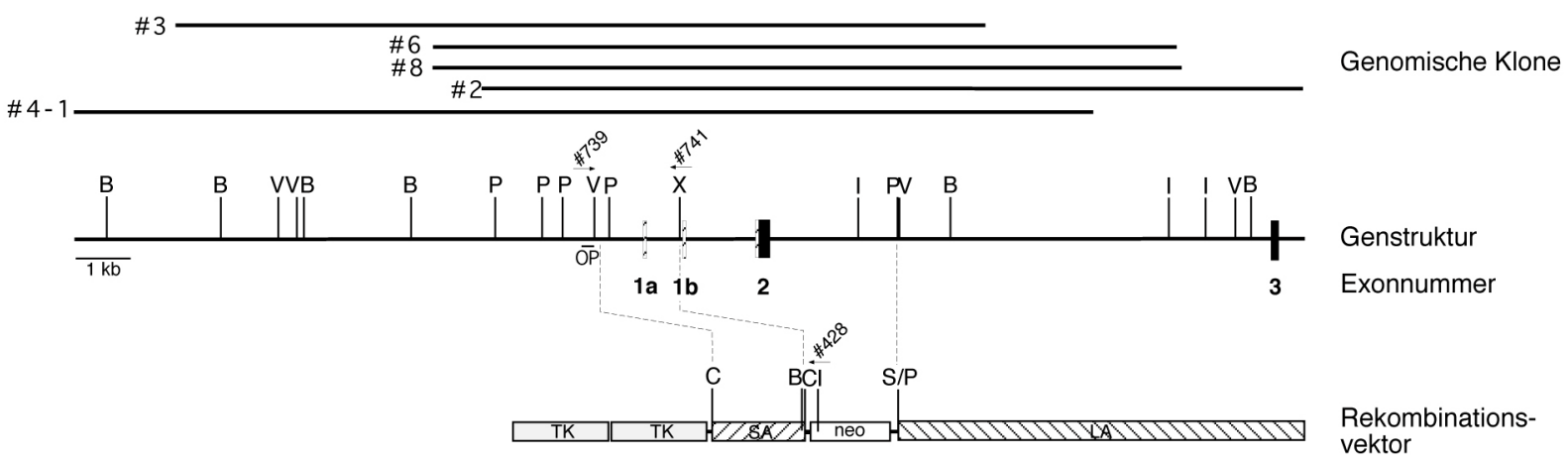

Abb. 3: Darstellung der Struktur eines Anteils des murinen $\alpha$-Synuclein-Gens, die sich aus der Analyse der genomischen Klone ergab, und der Rekombinationsstrategie für die Erzeugung von $\alpha$-Synuclein-Mausnullmutanten. Es sind die Erkennungsstellen für die Restriktionsenzyme BglII (B), ClaI (C), EcoRI (I), EcoRV (V), SpeI (S), PstI (P) und XhoI (X), die Position der nichtkodierenden (gestreifter Kasten) und kodierenden (gefüllter Kasten) Exone und die Genotypisierungsprimer eingezeichnet. Im Rekombinationsvektor sind die eingefügten genomischen Sequenzen als gestreifte Kästchen (LA und SA) und die Selektionsmarker (neo: Neomycinresistenz-Expressionskassette, TK: Thymidin-Kinase) als offene Kästchen dargestellt. Durch die homologe Rekombination wurde das Exon 2, das für die Aminosäuren 1-40 kodiert, und flankierende Bereiche durch ein Neomycinresistenzgen ersetzt.

\subsection{Antikörperherstellung und -charakterisierung}

Für die Herstellung von Antikörpern gegen $\alpha$-Synuclein wurden die bakteriellen Expressionskonstrukte phSyf.1 (humanes $\alpha$-Synuclein) und L786.19 (humanes $\alpha$-Synuclein A53T) und gegen $\beta$-Synuclein das Expressionskonstrukt LbSyn.5 verwendet. Die Proteine wurden im Bakterienstamm B121DE3 überexprimiert und aus dem Überstand der aufgeschlossenen Zellen über Glutathion-Agarose-Säulenchromatographie gereinigt. Die Abspaltung des Synucleins von der Säule erfolgte über Thrombin-Verdau. Nach Ultrafiltration des Eluats wurde das Thrombin über Gelfiltration abgetrennt und die beiden erhaltenen Proteine der Größe 18 und 19 kDa nach SDS-PAGE und Westernblot mikrosequenziert. Die N-terminale Mikrosequenzierung ergab für die 19 kDa-Bande die Sequenz „GSPGISGGGGGGGILM....“, die der Brückensequenz des Vektors pGEX-KG nach Thrombinverdau entsprach und für die $18 \mathrm{kDa}$-Bande die Sequenz „GLSKAKEGVVAAA.....“, die nach dem ersten Lysin in der $\alpha$-Synuclein-Sequenz folgte. Der N-Terminus des 18 kDa-Proteins war durch Thrombin-Spaltung innerhalb der SynucleinSequenz entstanden. Die Effizienz der internen Spaltung war geringer als die in der Brückensequenz. Es entstand jedoch immer ein signifikanter Anteil des verkürzten $\alpha$-Synuclein, der bei der Immunisierung nicht störte. Die Proteine wurden mit Freund'schem Adjuvans gemischt Hasen subkutan injiziert. Für $\alpha$-Synuclein wurden das Serum U1126, für $\beta$-Synuclein die Seren U1127 und U1128 und für $\alpha$-Synuclein A53T das Serum S053 erhalten.

Für die Charakterisierung der Antiköper wurden die cDNA-Sequenzen der drei klonierten Rattenisoformen in 293-Zellen exprimiert. Durch die enthaltenen N-terminalen Markersequenzen konnten die Konzentrationen der heterolog exprimierten Proteine in den Zelllysaten so eingestellt werden, daß jeweils die gleiche Menge der drei Isoformen auf einer Gelspur aufgetragen wurden. Die Quantifizierung erfolgte über Immunoblotanalyse mit $\alpha$ His6 Antikörpern und iodinierten sekundären Antikörpern. Um gleiche Gesamtproteinmengen pro Spur zu erhalten, wurden die 
Lysate mit den höchsten Expressionsraten entsprechend mit Lysaten untransfizierter Zellen verdünnt.
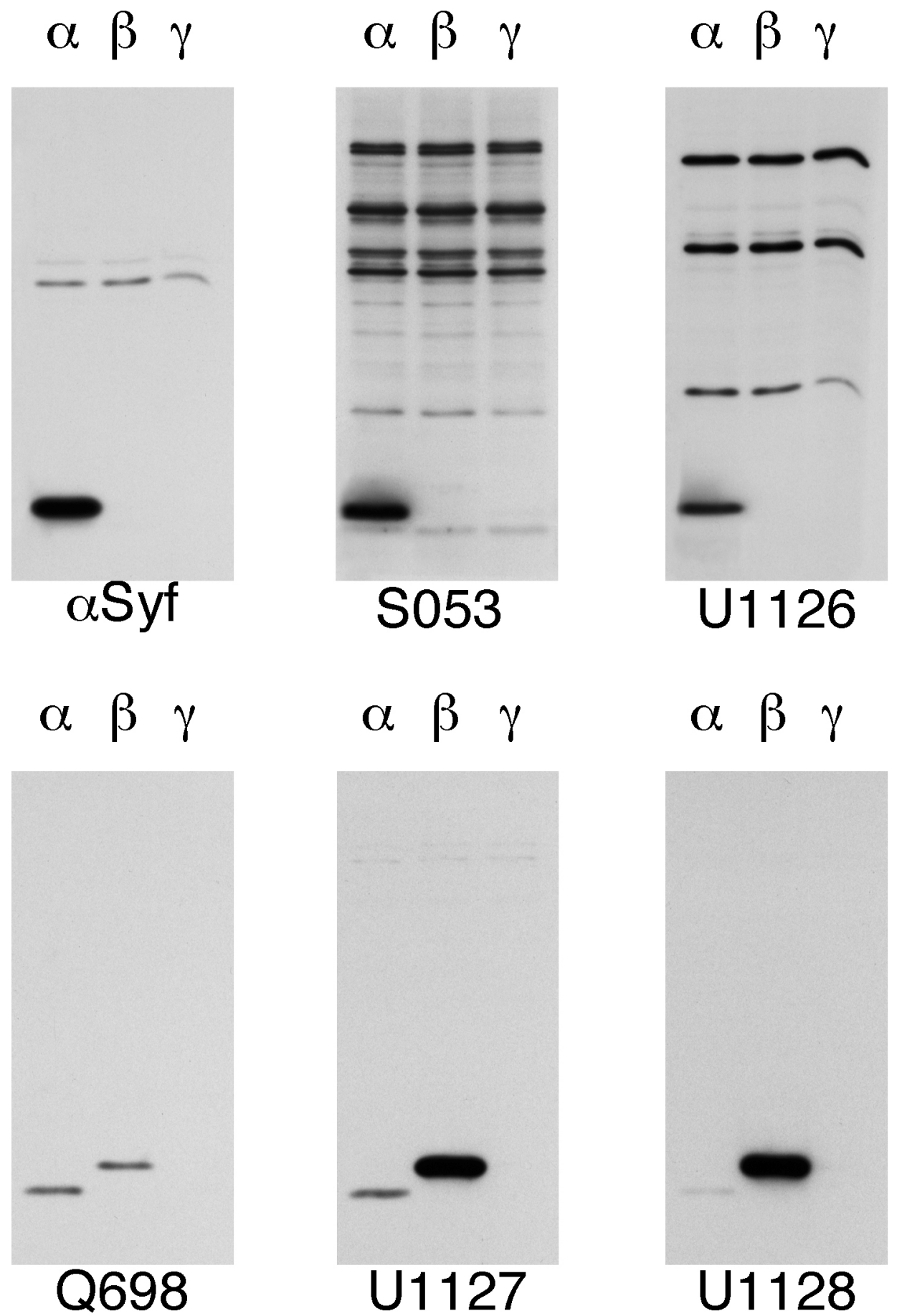

Abb. 4: Die drei Ratten-Synuclein-Paraloge wurden mit N-terminalem Polyhistidin-Tag in 293-Zellen transient exprimiert. Fünf Tage nach Transfektion wurden postnukleäre Überstände gewonnen und mit untransfizierten Zellen auf gleiche Synuclein-Konzentration verdünnt. $20 \mu \mathrm{g}$ Gesamtprotein wurden gelelektrophoretisch (12\% SDSPAGE) aufgetrennt und über Immunoblotanalyse und ECL-Detektion mit mononklonalen ( $\alpha$ Syf) und polyklonalen Antikörpern (S053, U1126, Q698, U1127 und U1128) gerichtet gegen die Synuclein-Paraloge analysiert.

Der kommerzielle monoklonale Antikörper $\alpha$ Syf wie auch das Antiserum S053 waren spezifisch für $\alpha$-Synuclein (Abb. 4). Insbesondere S053 detektierte auch höhermolekulare Banden, die von Proteinen der 293-Zellen stammten. Die relativen Affinitäten der Antikörper wurden über Quantifizierung der Signalstärken mit iodinierten Sekundärantikörpern bestimmt. Hierbei zeigten 
die Antikörper $\alpha$ Syf und S053 eine 20- bis 40fach höhere Affinität zu $\alpha$-Synuclein im Vergleich zu $\beta$-Synuclein. Die Affinität des Antiserums U1126 war 5- bis 10fach geringer und auch die Spezifität der Detektion von $\alpha$-Synuclein gegenüber $\beta$-Synuclein war nur 15 fach höher. Eine vergleichbare Affinität gegenüber $\alpha$-Synuclein hatte das Serum Q698, das $\alpha$ - und $\beta$-Synuclein nahezu gleich gut detektierte. $\gamma$-Synuclein wurde von keinem der verwendeten Antikörper detektiert. Die beiden Antiseren U1127 und U1128 detektierten $\beta$-Synuclein mit einer vergleichbaren Affinität wie S053 $\alpha$-Synuclein. Die Spezifität war jedoch geringer, da beide $\beta$-Synuclein nur 10- bis 15 fach stärker banden als $\alpha$-Synuclein. Da sich die Migrationsstrecken in der SDSPAGE von $\alpha$ - und $\beta$-Synuclein unterschieden, war in der Immunoblotanalyse eine eindeutige Unterscheidung dieser beiden Isoformen möglich.

Die Antikörper wurden zur Charakterisierung von Maus-Modellen der Parkinson-Syndrome verwendet. Zunächst wurde getestet, ob sie die charakteristischen Einschlußkörperchen, die Lewy-Körper, detektieren würden. Der Antikörper Q698 markiert pathomorphologische Veränderungen, die $\alpha$-Synuclein enthalten (Abb. 6). Lewy-Körper und Lewy-Neuriten konnten mit diesem Antikörper in Paraffinschnitten aus dem Gehirn von Patienten mit einer LewyKörper-Variante des Morbus Alzheimer angefärbt werden. Im Gegensatz zu Färbungen mit Antikörpern gegen Ubiquitin, waren die gefärbten Einschlußkörperchen schon bei geringer Vergrößerung deutlich sichtbar.

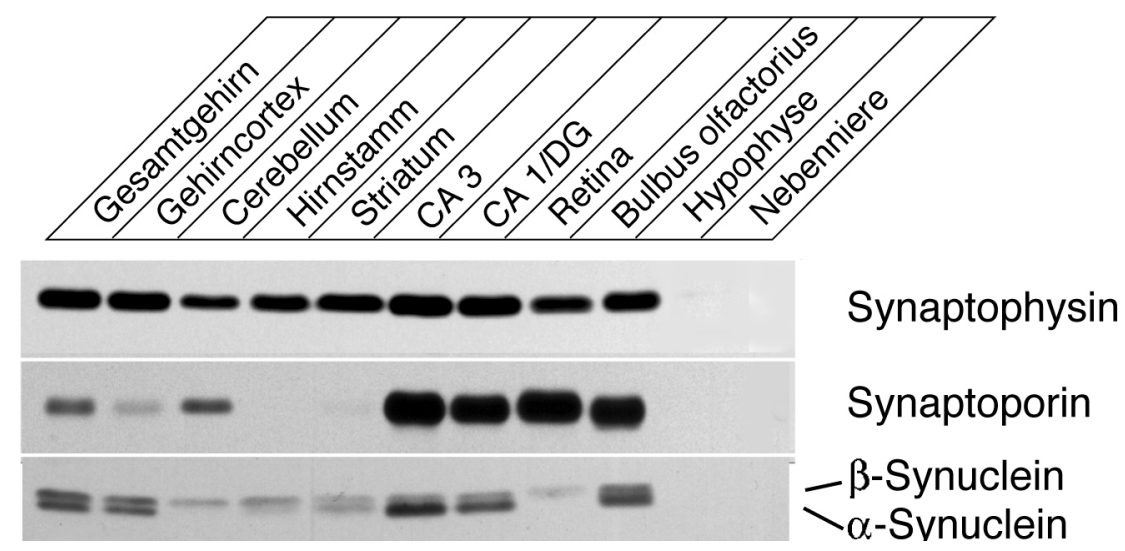

Abb. 5: Immunoblotanalyse mit ECL-Detektion der Verteilung der angegebenen Proteine in verschiedenen Hirnregionen. $30 \mu \mathrm{g}$ Gesamtprotein von postnukleären Überständen pro Gelspur (12\% SDS-

PAGE) wurden aufgetrennt und auf Nitrocellulosemembranen transferiert. Verwendete Antikörper: Q698 $(\alpha-\quad$ und $\beta$-Synuclein), C17.2 (Synaptophysin I), $\alpha$ p37 (Synaptophysin II).

\subsection{Verteilung von $\alpha$ - und $\beta$-Synuclein im Mausgehirn}

$\alpha$ - und $\beta$-Synuclein werden hauptsächlich im ZNS exprimiert, wohingegen $\gamma$-Synuclein im peripheren Nervensystem überwiegt. Um die Verteilung von $\alpha$ - und $\beta$-Synuclein im Mausgehirn $\mathrm{zu}$ untersuchen und die relativen Mengen zu bestimmen, wurden verschiedene Hirnregionen präpariert und die postnukleären Überstände gewonnen. Die Proben wurden durch SDS-PAGE aufgetrennt und die Verteilung durch Immunoblotanalyse untersucht (Abb. 5). Die Detektion erfolgte durch das Antiserum Q698, welches beide Isoformen in vergleichbarer Affinität band. Zum Vergleich wurden die beiden Synaptophysin-Isoformen I und II untersucht, von denen die erste in ungefähr gleichen Konzentrationen im gesamten Gehirn vorkam und die zweite insbesondere im Hippokampus, der Retina und dem Bulbus olfactorius angereichert war (Fykse et al. 1993). Die Gesamtmengen im Gehirn von $\alpha$ - und $\beta$-Synuclein waren ähnlich hoch. $\beta$-Synuclein war homogener als $\alpha$-Synuclein verteilt und geringfügig im Hirnkortex und im Bulbus olfactorius angereichert. $\alpha$-Synuclein zeigte eine heterogene Verteilung, wobei die rostralen Hirnabschnitte höhere Mengen aufwiesen, während etwa im Cerebellum und Hirnstamm nur geringe Mengen nachweisbar waren. Im Cortex und Striatum waren die Mengen von 
$\alpha$ - und $\beta$-Synuclein ähnlich hoch. Auffällig war, daß die $\alpha$-Synuclein-Mengen im Striatum deutlich geringer waren als z.B. im Hippokampus. Die höchsten Konzentrationen von $\alpha-$ Synuclein waren in der CA3-Region des Hippokampus nachweisbar. Dies zeigte sich auch in der Immunfluoreszenzanalyse, in der die Moosfaserterminalen dieser Region besonders stark angefärbt waren (Abb. 10). In der Retina war $\alpha$-Synuclein nicht nachweisbar.
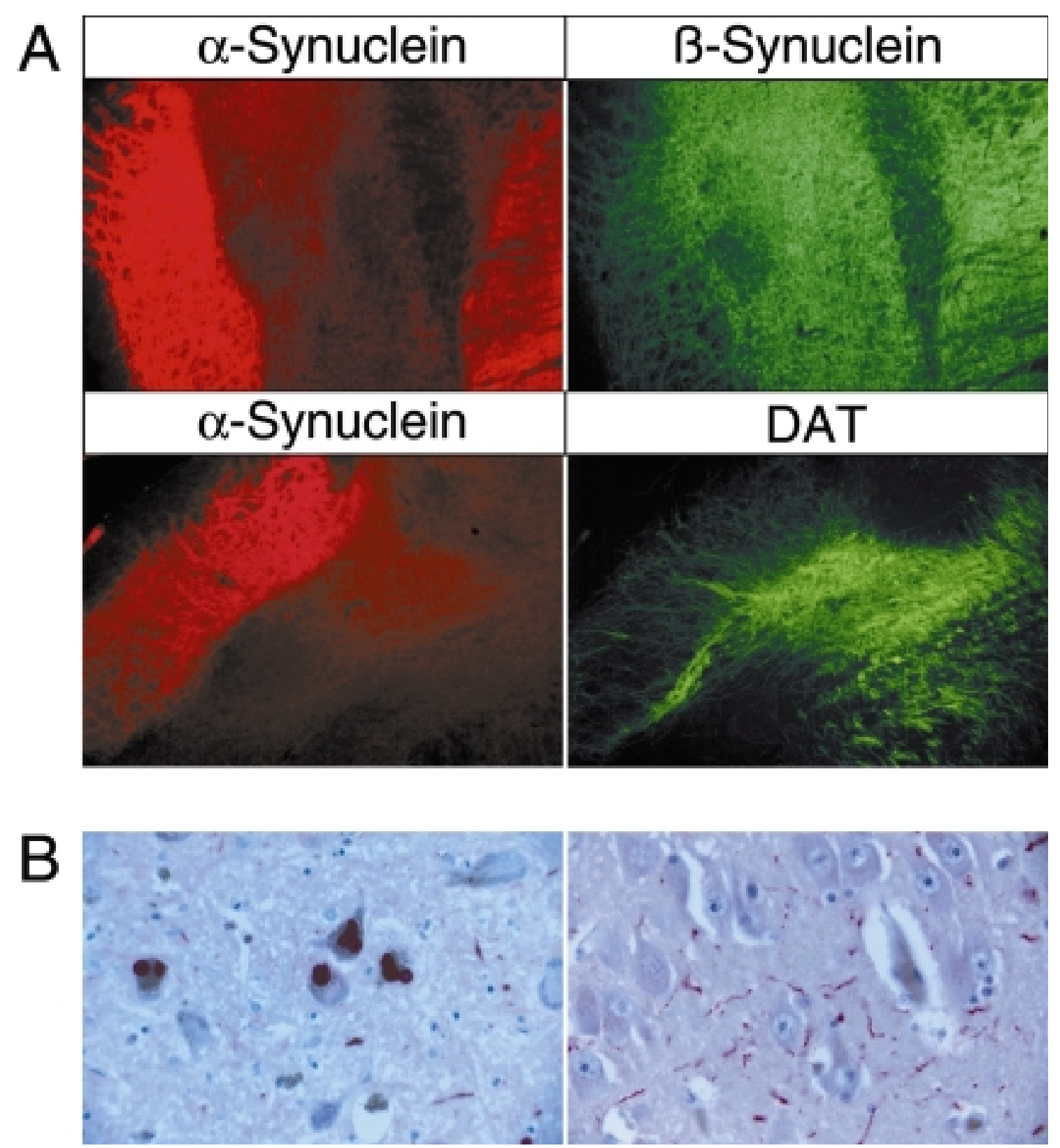

Abb. 6: A: Immunfluoreszenzanalyse aus dem Mittelhirn der Maus. $20 \mu \mathrm{m}$ dicke Gefrierschnitte wurden mit den Antikörpern gegen $\alpha$-Synuclein ( $\alpha$ Syf), $\beta$-Synuclein (U1128) und DAT (M369) inkubiert. Fluoreszenzsignale der sekundären Antikörper GaM-Cy3, GaR-Cy2 und GaRt-Cy2 wurden im Fluoreszenzmikroskop mit einer 100-fachen Vergrößerung detektiert. B: Immunhistochemische Färbung von Paraffin-Schnitten aus dem Mittelhirn von Patienten mit einer Lewy-Körper-Variante des Morbus-Alzheimer. Anfärbung von Lewy-Körpern und Lewy-Neuriten in rot über den Synuclein-Antikörper Q698 (Färbungen freundlicherweise von Dr. M. Neumann (Göttingen) zur Verfügung gestellt).

Die homogenere Verteilung von $\beta$-Synuclein bestätigte sich auch in der Immunfluoreszenzanalyse, die eine viel höhere räumliche Auflösung erreicht als sie mit der quantitativen Bestimmung der Proteine in Westernblots möglich ist (Abb. 6, 10). $\alpha$ - und $\beta$-Synuclein schienen 
in den meisten Synapsen koexprimiert zu werden, wobei sich jedoch die relativen Mengen drastisch unterschieden. $\beta$-Synuclein war im Hippokampus in den synpatischen Strata moleculare, lacunosum moleculare und lucidum angereichert. Im Cortex und Mittelhirn war seine Verteilung homogen. Die Mengen von $\alpha$-Synuclein waren in den Strata moleculare und lacunosum moleculare am geringsten. Hier waren nur die Synapsen des Tractus perforans angefärbt. Im Cortex war die IV. Schicht prominent gefärbt und hob sich von den anderen Schichten ab. Im Mittelhirn war nur die Region der Substantia nigra reticulata angefärbt. Die Verteilung von $\alpha$ - und $\beta$-Synuclein im Striatum war homogen.
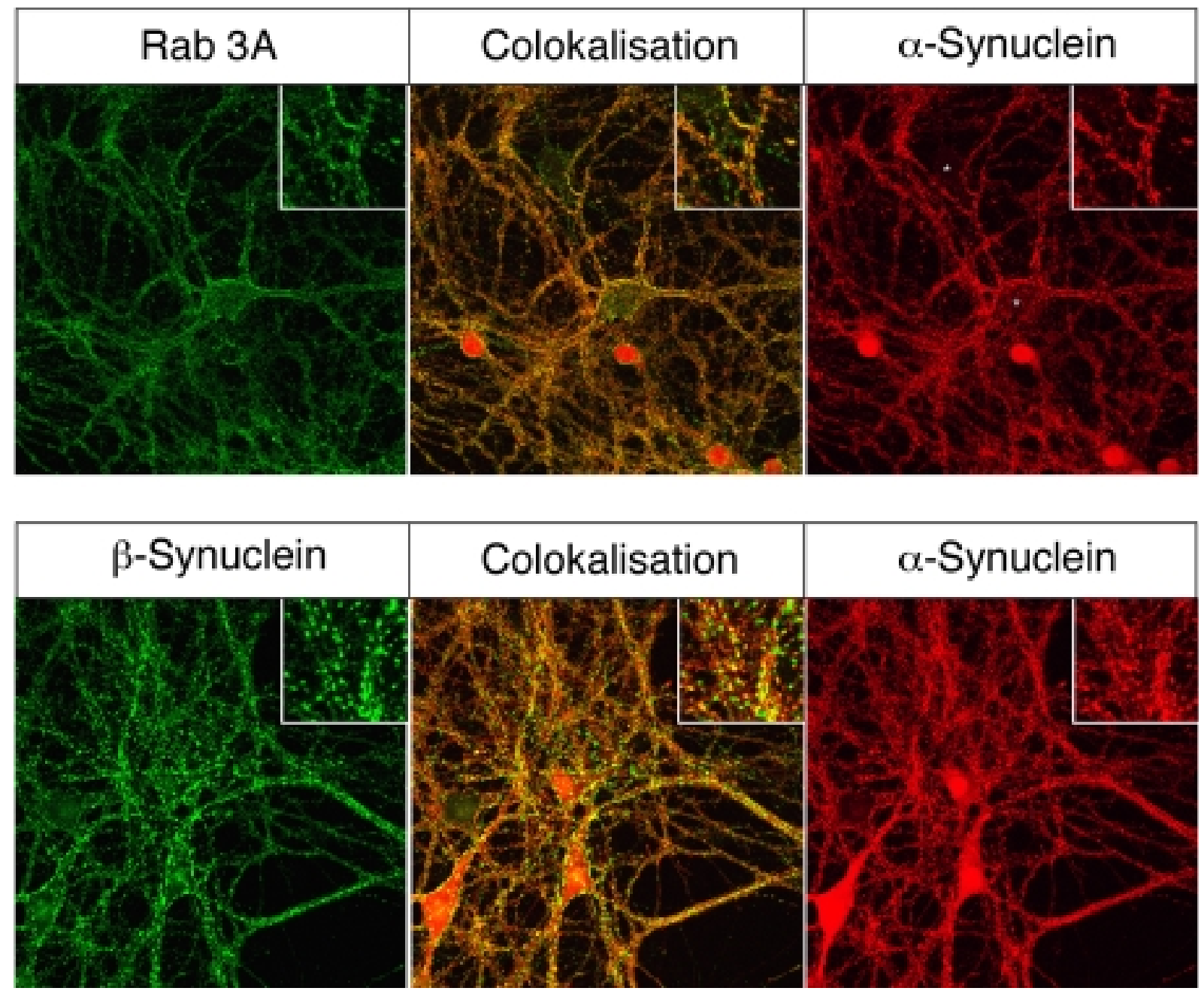

Abb. 7: Immunfluoreszenzanalyse hippokampaler Primärkulturen aus Mäusen. Neuronen wurden nach 12 Tagen in Kultur fixiert und mit Antikörpern gegen $\alpha$-Synuclein ( $\alpha$ Syf), $\beta$-Synuclein (U1128) und Rab3A (583) markiert. Fluoreszenzsignale der sekundären Antikörper GaM-Cy3 und GaR-Cy2 wurden im konfokalen Mikroskop mit 400facher Vergrößerung detektiert. Kolokalisationen sind in der Überlagerung der Einzelsignale in der mittleren Spalte in gelb dargestellt. 800fach vergrößerte Detailaufnahmen sind jeweils in der rechten oberen Ecke lokalisiert.

In neuronalen Primärkulturen aus dem Maus-Hippokampus zeigten die Antiseren gegen $\alpha$ - und $\beta$-Synuclein eine typische punktförmige synaptische Färbung (Abb. 7). $\alpha$ - und $\beta$-Synuclein waren in den meisten Synapsen kolokalisiert. Eine signifikante Anzahl von Synapsen enthielt nur $\beta$-Synuclein. Bei dem Vergleich der $\alpha$-Synuclein-Verteilung mit Rab3A, einem unbiquitär im Gehirn exprimierten synaptischen Protein, waren in den meisten Synapsen beide Proteine vorhanden. Die $\alpha$-Synuclein-Antiseren färbten in den meisten Neuronen zusätzlich Zellkerne an. Lediglich einige große Neurone enthielten kein nukleäres $\alpha$-Synuclein. Die auffällige nukleäre Färbung war in den gefärbten Hirnpräparaten nicht vorhanden. 


\subsection{Subzelluläre Verteilung von $\alpha$ - und $\beta$-Synuclein}

Mit Hilfe der subzellulären Fraktionierung wurde die Verteilung von Proteinen innerhalb von Zellkompartimenten untersucht. Hierzu wurden Mäusegehirne homogenisiert (Fraktion H) und durch differentielle Zentrifugationsschritte die Zellkerne und -trümmer (Fraktion P1) abgetrennt und eine relativ unreine Synaptosomenfraktion (P2) gewonnen. Der Überstand wurde durch Ultrazentrifugation in die zytosolische Fraktion (S3) und die Mikrosomenfraktion (P3) aufgetrennt. Die synaptischen Vesikel wurden aus den Synaptosomen durch hypotonen Schock entlassen. Die leeren Synaptosomen wurden abzentrifugiert (Fraktion LP1) und aus ihnen die synaptischen Plasmamembranen durch Dichtegradientenzentrifugation angereichert (SPM). Im Pellet nach Ultrazentrifugation des Überstandes der leeren Synaptosomen reicherten sich die synaptischen Vesikel an (Fraktion LP2). Der letzte Überstand enthielt das stark verdünnte synaptische Zytosol, das durch Ultrafiltration oder Fällung konzentriert wurde (LS2).

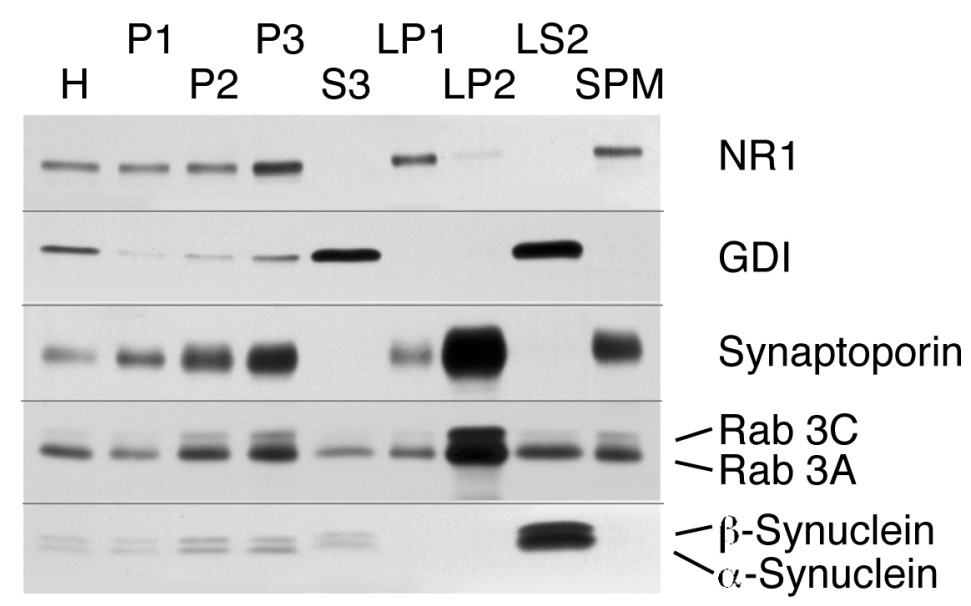

Abb. 7: Immunoblotanalyse mit ECL-Detektion von subzellulären Fraktionierungen aus Mausgehirngewebe. Gehirnkortices wurden homogenisiert $(\mathrm{H})$ und in Zellkernsediment (P1), rohe Synaptosomenfraktion (P2), Mikrosomenfraktion (P3) und Zytosol (S3) fraktioniert. Aus den Synaptosomen wurden eine rohe synaptische Plasmamembranfraktion (LP1), eine rohe synaptische Vesikelfraktion (LP2), synaptische Zytosolfraktion (LS2) und eine synaptische Plasmamembranfraktion mit angereicherten aktiven Zonen und postsynaptischen Verdichtungen (SPM) erhalten. Die Fraktionen wurden über SDS-PAGE und Transfer auf Nitrocellulosemembranen aufgetrennt und mit den folgenden Antikörpern analysiert: C154.1 (NR1), $\alpha$ p37 (Synaptophysin II), C142.1 (Rab3A und C), C181.1 (GDI) und Q698 ( $\alpha$ - und $\beta$-Synuclein).

Die Anreicherung der einzelnen Kompartimente in den Fraktionen wurde durch Markerproteine analysiert. Das synaptische Vesikelprotein Synaptophysin II war in der Fraktion LP2 angereichert (Abb. 8). Die NMDA-Rezeptor-Untereinheit 1 (NR1) ist sowohl in synaptischen Plasmamembranen als auch intrazellulären postsynaptischen Vesikeln vorhanden. Dies spiegelte sich in der Anreicherung in den Fraktionen SPM und P3 wider. GDI ist ein zytosolisches Protein, welches in den löslichen Fraktionen S3 und LS2 vorkam. Die Abwesenheit in den Membranfraktionen P3 und LP2 zeigte eine quantitative Abtrennung an. Ebenfalls waren die Transmembranproteine Synaptophysin II und NR1 nicht in den löslichen Fraktionen nachweisbar. Rab3A und $\mathrm{C}$ sind synaptische Proteine, die sowohl an synaptische Vesikel binden als auch gelöst im synaptischen Zytosol vorkommen.

$\alpha$ - und $\beta$-Synuclein waren stark in der synaptischen Zytosolfraktion LS2 angereichert. Durch die starke Anreicherung konnten sie als Markerproteine dieser Fraktion verwendet werden. Die synaptischen Membranfraktionen enthielten kein Synuclein. In vitro wurde eine Bindung von $\alpha$-Synuclein an Membranen mit sauren Phospholipiden gezeigt (Davidson et al. 1998). Es ist 
somit möglich, daß unter bestimmten physiologischen Bedingungen dieses Protein vom zytosolischen Kompartment an Membranen wechselt, der Großteil liegt jedoch gelöst vor.

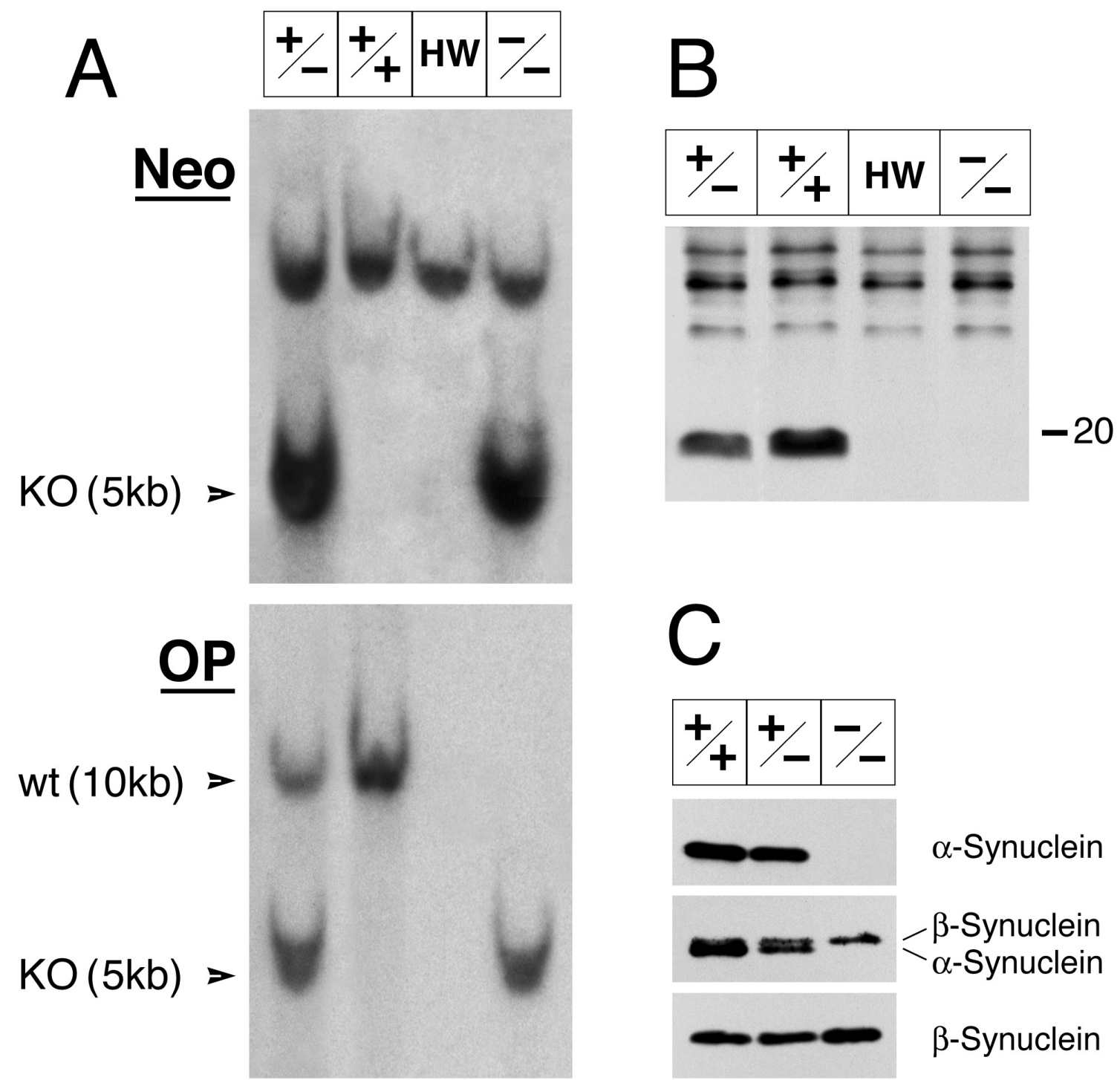

Abb. 9: Southern- und Immunoblotanalyse der $\alpha$-Synuclein-Mausnullmutanten und der Mauslinie C57B16/J/ola/hsd. A: Southernblot-Analyse heterozygot mutierter (+/-), Wildtyp-Mäuse (+/+), der C57B16/J/ola/hsdLinie (HW) und homozygoter Nullmutanten $(-/-)$. Genomische DNA wurde mit BglII verdaut und auf Nylonmembranen transferiert. Diese wurden mit einer Sonde für den Neomycinselektionsmarker (Neo) hybridisiert, die die spezifische Bande bei $\sim 5 \mathrm{~kb}$ und eine kreuzhybridisierende Bande bei $\sim 10 \mathrm{~kb}$ detektiert. Die Signalstärken der kreuzhybridisierenden Banden zeigen gleiche DNA-Mengen pro Spur an. Die Hybridisierung mit einer Sonde, die aus einem genomischen Abschnitt benachbart aber außerhalb des rekombinierten Bereichs erstellt wurde, markierte das Wildtyp-Allel bei $\sim 10$ und das rekombinierte Allel bei $\sim 5 \mathrm{~kb}$. Das Fehlen eines Signals in der C57B16/J/ola/hsd-Linie deutete auf eine Deletion des $\alpha$-Synuclein-Gens hin. B, C: Repräsentative Immunoblotanalyse mit ECL-Detektion von heterozygoten und homozygoten $\alpha$-Synuclein-Nullmutanten, Wildtyp-Geschwistertieren und der C57B16/J/ola/hsd-Linie. $30 \mu \mathrm{g}$ Gesamthirnhomogenate wurden über SDS-PAGE (12\%) aufgetrennt und nach Transfer auf Nitrocellulosemembranen mit zwei $\alpha$-Synuclein-spezifischen Antiseren (S053 in Abschnitt B und $\alpha$ Syf in Abschnitt C oben), einem Antikörper, der beide Paraloge detektiert (U1126 Abschnitt C Mitte) und einem $\beta$-Synuclein-spezifischen Antiserum (U1128 Abschnitt C unten) analysiert. Die höhermolekularen Banden in Abschnitt B waren in allen Spuren gleich stark. 


\subsection{Erzeugung von Maus- $\alpha-S y n u c l e i n-N u l l m u t a n t e n$}

Der Rekombinationsvektor wurde in omnipotente Mausstammzellen tranfiziert, welche dann auf homolog rekombinierte Klone selektioniert wurden (Abb. 3). Die PCR-Analyse mit dem Primerpaar 739/428 der doppelt resistenten Klone ergab in 15,6\% von insgesamt 384 analysierten Klonen ein PCR-Produkt der erwarteten Größe von 1,5 kb. Die Restriktionsanalyse des PCRProduktes zeigte, daß die Rekombination an der richtigen Stelle stattgefunden hatte. Zwei der Klone (\#42 und \#116) wurden expandiert, und in C57B16/J-Blastozysten injiziert. Chimäre Männchen wurden mit C57B16/J-Weibchen verpaart. Die Verpaarung der heterozygoten agoutifarbenen Nachkommen ergab homozygote und heterozygote Nullmutanten sowie WildtypMäuse, deren Anzahl nach der Mendel'schen Regel verteilt war. Die Genotypisierung erfolgte über Southernblot- und PCR-Analyse (Abb. 9). Mit den Primerpaaren 739 und 741 wurde ein 1,5 kb großes und mit den Primerpaaren 1103 und 1106 ein 0,2 kb großes Fragment aus dem wtAllel amplifiziert. Das über das Primerpaar 739 und 428 amplifizierte 1,5 kb große Fragment war spezifisch für das homolog rekombinierte Allel, da der Primer 739 außerhalb des rekombinierten Bereichs band. Im weiteren erfolgte die Genotypisierung jedoch mit dem Primerpaar 288/887, mit dem ein 0,7 kb großes Fragment aus dem Selektionsmarkerbereich amplifiziert wurde.

Die erfolgreiche Deletion des Synuclein-Gens wurde über Immunoblot-Analyse mit verschiedenen Antikörper gegen $\alpha$-Synuclein bestätigt (Abb. 9). Die homozygoten $\alpha$-SynucleinNullmutanten waren überlebensfähig und ohne offensichtliche Verhaltensveränderungen. Sie konnten als homozygote Linie gehalten werden.

Um den genetischen Hintergrund so einheitlich wie möglich zu halten, wurde die F1-Generation sechsmal in die C57B16/J-Mauslinie zurückgekreuzt. Während dieser Prozedur fiel auf, das in Mäusen vom Lieferanten Harlan-Winkelmann (Mauslinie C57B16/J/ola/hsd) $\alpha$-Synuclein fehlte (Abb. 9). Das Fehlen eines Hybridisierungssignals bei der Southernblot-Analyse mit einer $\alpha-$ Synuclein-spezifischen Sonde deutete auf eine Deletion im $\alpha$-Synuclein-Gen hin. Die Größe der Deletion blieb unbekannt. Durch die Deletion waren die $\beta$-Synuclein-Mengen nicht beeinflußt.

\subsection{Charakterisierung der Maus- $\alpha-S y n u c l e i n-N u l l m u t a n t e n$}

Die Maus- $\alpha$-Synuclein-Nullmutanten wurden detailliert morphologisch und biochemisch untersucht. In diesen Experimenten wurden die Nullmutanten im Vergleich zu Geschwistertierkontrollen analysiert, um mögliche genetische Hintergrundeffekte weitestgehend auzuschließen. Die Charakterisierung der Gehirnarchitektur erfolgte anhand von Gefrierschnitten, die mit Antikörpern gegen verschiedene synaptische und Struktur-Proteine gefärbt wurden. Es ergaben sich dabei keine Unterschiede $\mathrm{zu}$ den wt-Kontrolltieren. Insbesondere die Verteilung von $\beta$-Synuclein, Tyrosinhydroxylase (TH) und Dopamintransporter (DAT) waren im Hippokampus, der Region höchster $\alpha$-Synuclein-Mengen, und dem Striatum unverändert (Abb. 10, 12). 

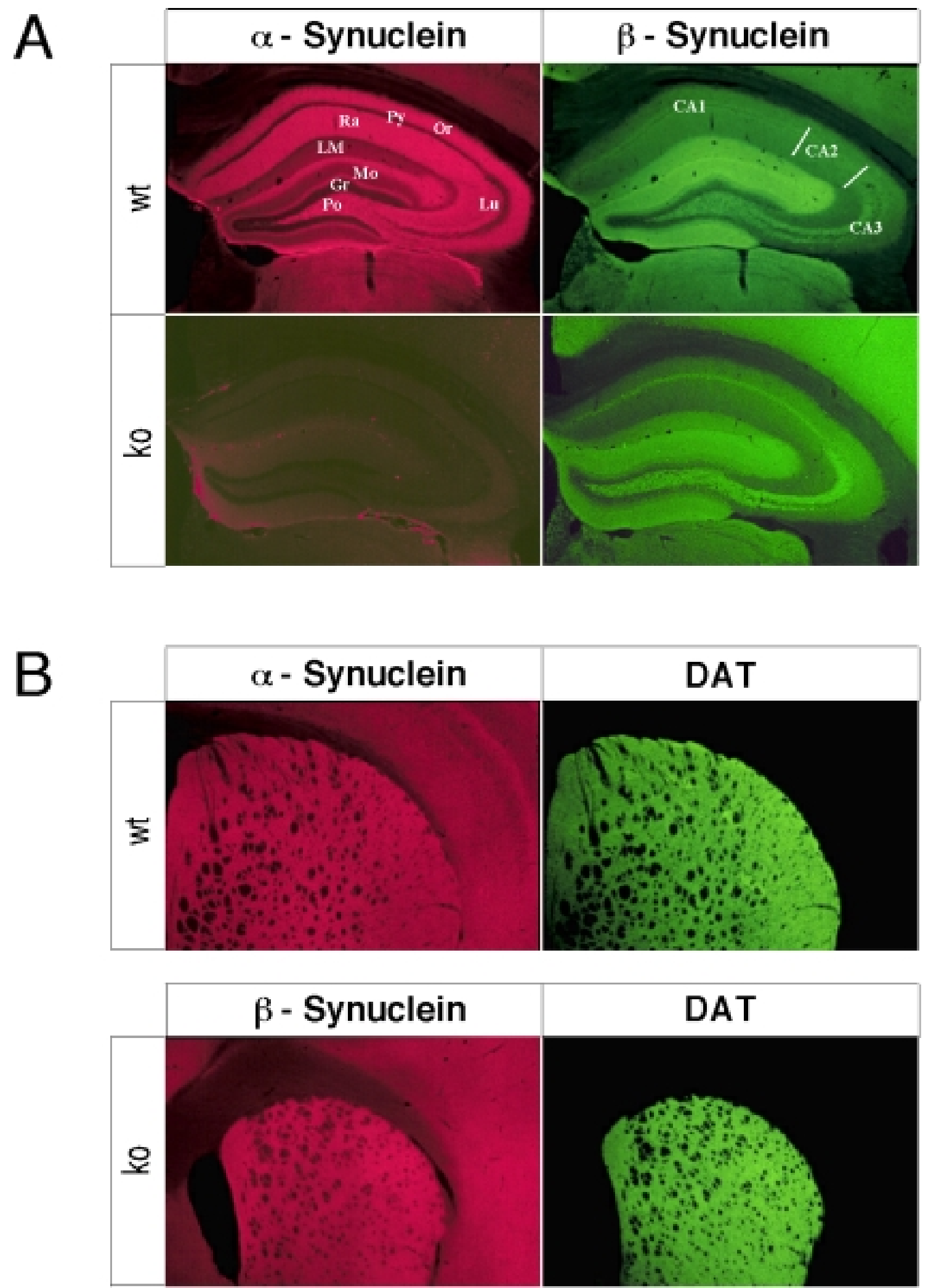

Abb. 10: Vergleichende Immunfluoreszenzanalyse des Hippokampus und Striatum von $\alpha$-Synuclein-Nullmutanten und Wildtyp-Mäusen. A: $20 \mu \mathrm{m}$ dicke Gefrierschnitte des Hippokampus wurden mit Antikörpern gegen $\alpha-(\alpha$ Syf) und $\beta$-Synuclein (U1128) doppelt gefärbt. Die Sekundärantiköper wurden im Fluoreszenzmikroskop mit einer 50fachen Vergrößerung detektiert. Die Hippokampusregionen CA1 bis -3 und die Schichten Stratum oriens (Or), Stratum pyramidale (Py), Stratum radiatum (Ra), Stratum lacunosum moleculare (LM), Stratum moleculare (Mo), Stratum granulosum (Gr), Stratum lucidum (Lu) und die polymorphe Synapsenschicht (Po) sind markiert. B: Analoge Proben aus dem Striatum wurden zusätzlich mit einem Antikörper gegen DAT (M369) markiert. 


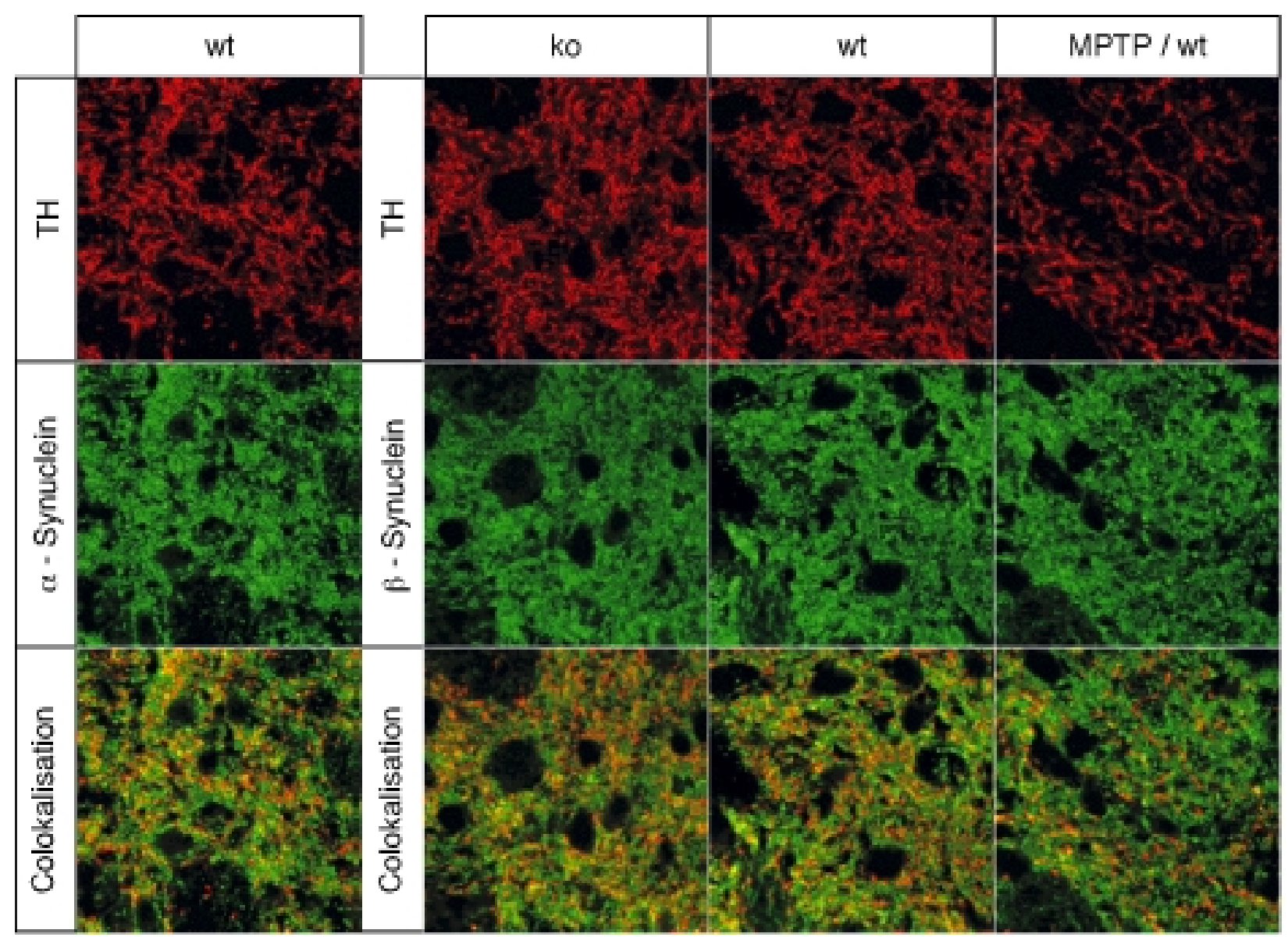

Abb. 11: Vergleichende konfokale Fluoreszenzanalyse von $\alpha$-Synuclein-Nullmutanten und von Wildtyp-Mäusen mit und ohne MPTP-Behandlung. $10 \mu \mathrm{m}$ dicke Gefrierschnitte wurden mit den bezeichneten Antikörpern doppelt gefärbt ( $\alpha$-Synuclein: U1126; $\beta$-Synuclein: U1128; TH: $\alpha \mathrm{TH})$. Fluoreszenzsignale der sekundären Antkörpern wurden mit 400facher Vergrößerung detektiert. Kolokalisation ist in gelb gefärbt. Die mit $30 \mathrm{mg} / \mathrm{kg} \mathrm{MPTP}$ behandelte Maus wurde fünf Tage nach i.p.-Injektion analysiert und zeigte eine Reduktion der TH-Immunofärbung.

$\alpha$-Synuclein war im präsynaptischen Zytosol angereichert. Insofern stellte sich die Frage, ob die Deletion von $\alpha$-Synuclein einen Einfluß auf die Verteilung anderer synaptischer Proteine hatte. Hierfür wurden die Mengen von mehr als 40 neuronalen Proteinen über Immnunoblot-Analyse quantifiziert. Wenn möglich wurden die Mengen eines Proteins mit verschiedenen Antikörpern bestimmt. Die Mengen aller getesteten Proteine, einschließlich der getesteten 15 synaptischen Vesikelproteine, waren unverändert (Tab. 1; Abb. 13). Insbesondere waren die Mengen von Markern dopaminerger Neuronen (Tyrosinhydroxylase, vesikulärer Monoamintransporter 2 (VMAT 2) und Dopamintransporter) im Gesamtgehirn bzw. im Striatum unverändert. Auch die Mengen von $\beta$-Synuclein unterschieden sich in den Gesamtgehirnhomogenaten nicht von Kontrolltieren. Wurden jedoch die Mengen im Striatum untersucht, so zeigte sich eine geringfügige, statisch signifikante, Heraufregulation von ca. $11 \%$ in den $\alpha$-Synuclein-Nullmutanten und von ca. $18 \%$ in der Mauslinie mit der chromosomalen Deletion. 


\begin{tabular}{|c|c|c|c|}
\hline Protein & $\alpha-S y n u c l e i n-/-$ & $+/+$ & Antikörper \\
\hline Aktin & $94 \pm 3$ & $100 \pm 5$ & AC-40 \\
\hline Amphiphysin & $105 \pm 15$ & $100 \pm 14$ & P924 \\
\hline APP & $99 \pm 6$ & $100 \pm 10$ & U955 \\
\hline Complexin 1 & $109 \pm 6$ & $100 \pm 6$ & P942 \\
\hline Complexin 2 & $107 \pm 5$ & $100 \pm 5$ & P942 \\
\hline CSP & $101 \pm 14$ & $100 \pm 4$ & $\alpha \mathrm{CSP}$ \\
\hline DOC2A & $105 \pm 3$ & $100 \pm 3$ & $\alpha \mathrm{DOC} 2$ \\
\hline Dynamin & $103 \pm 8$ & $100 \pm 8$ & E765 \\
\hline GDI & $109 \pm 10$ & $100 \pm 5$ & $\mathrm{Cl} 81.2$ \\
\hline Mint & $95 \pm 5$ & $100 \pm 5$ & P932 \\
\hline Munc13-1 & $99 \pm 10$ & $100 \pm 12$ & $3 \mathrm{H} 5$ \\
\hline Munc18 & $109 \pm 6$ & $100 \pm 9$ & $\mathrm{I} 370$ \\
\hline Neuroligin I & $100 \pm 14$ & $100 \pm 8$ & $4 \mathrm{C} 12$ \\
\hline NMDA-R1 & $99 \pm 3$ & $100 \pm 4$ & Cl54.1 \\
\hline $\mathrm{NSF}$ & $95 \pm 7$ & $100 \pm 8$ & $\mathrm{I} 372$ \\
\hline p116 & $94 \pm 6$ & $100 \pm 9$ & 587 Str. \\
\hline Presinilin I Schleife & $103 \pm 5$ & $100 \pm 6$ & $\alpha$ PSI \\
\hline Rab3A & $97 \pm 6$ & $100 \pm 8$ & $\mathrm{Cl} 42.2$ \\
\hline Rab3B & $104 \pm 7$ & $100 \pm 12$ & U954 \\
\hline Rab3C & $100 \pm 5$ & $100 \pm 3$ & $\mathrm{P} 180$ \\
\hline Rabaptin & $99 \pm 5$ & $100 \pm 7$ & R321 \\
\hline Rabphilin & $100 \pm 7$ & $100 \pm 6$ & $\mathrm{I} 734$ \\
\hline RIM & $109 \pm 5$ & $100 \pm 6$ & $\alpha$ RIM Str. \\
\hline SCAMP & $98 \pm 5$ & $100 \pm 2$ & P936 \\
\hline mSEC7 & $104 \pm 4$ & $100 \pm 7$ & SA3613 \\
\hline aSNAP & $102 \pm 6$ & $100 \pm 3$ & I373 \\
\hline SNAP-23 & $103 \pm 3$ & $100 \pm 6$ & P914 \\
\hline SNAP-25 & $98 \pm 4$ & $100 \pm 2$ & $\mathrm{Cl} 172.2$ \\
\hline Synapsin Ia & $103 \pm 5$ & $100 \pm 5$ & E028 \\
\hline Synapsin Ib & $98 \pm 6$ & $100 \pm 5$ & E028 \\
\hline Synaptobrevin 1 & $99 \pm 7$ & $100 \pm 11$ & P938 \\
\hline Synaptobrevin 2 & $98 \pm 2$ & $100 \pm 4$ & $\mathrm{Cl} 69.1$ \\
\hline Synaptojanin & $102 \pm 3$ & $100 \pm 6$ & P923 \\
\hline Synaptogyrin & $101 \pm 5$ & $100 \pm 8$ & P925 \\
\hline Synaptophysin I & $95 \pm 4$ & $100 \pm 4$ & C7.2 \\
\hline Synaptophysin II & $95 \pm 7$ & $100 \pm 3$ & $\alpha p 37$ \\
\hline Synaptotagmin I & $\begin{array}{l}111 \pm 6 \\
94 \pm 10\end{array}$ & $\begin{array}{c}100 \pm 7 \\
100 \pm 11 \\
\end{array}$ & $\begin{array}{c}\mathrm{V} 216 \\
\text { V216 Str. }\end{array}$ \\
\hline $\begin{array}{c}\text { Syntaxin } \\
\text { Syntaxin 1b }\end{array}$ & $\begin{array}{l}94 \pm 7 \\
97 \pm 6 \\
\end{array}$ & $\begin{array}{l}100 \pm 3 \\
100 \pm 2 \\
\end{array}$ & $\begin{array}{l}\mathrm{C} 178.2 \\
\mathrm{P} 941 \\
\end{array}$ \\
\hline$\alpha$-Synuclein & $\begin{array}{c}15 \pm 2 \\
3 \pm 1 \\
\end{array}$ & $\begin{array}{l}100 \pm 25 \\
100 \pm 13\end{array}$ & $\begin{array}{l}\text { S053 } \\
\alpha \text { Syf }\end{array}$ \\
\hline$\beta$-Synuclein & $\begin{array}{l}107 \pm 7 \\
105 \pm 4 \\
\end{array}$ & $\begin{array}{l}100 \pm 8 \\
100 \pm 6 \\
\end{array}$ & $\begin{array}{l}\text { U1127 } \\
\text { U1128 } \\
\end{array}$ \\
\hline$\alpha$-Tubulin & $97 \pm 6$ & $100 \pm 2$ & DM1a \\
\hline$\beta$-Tubulin & $97 \pm 6$ & $100 \pm 6$ & Tub2.1 \\
\hline $\mathrm{TH}$ & $110 \pm 8$ & $100 \pm 8$ & $\alpha \mathrm{TH}$ \\
\hline
\end{tabular}

Tab. 1: Quantifizierung der Proteinmengen im Gehirn von $\alpha$-Synuclein-Nullmutanten im Vergleich zu WildtypGeschwistertieren. Postnukleäre Überstände aus dem Frontalhirn bzw. Striatum (Str.) von jeweils fünf Tieren jeder Gruppe wurden über SDS-PAGE aufgetrennt und über radioaktive Immunoblotanalyse mit den angegebenen Antikörpern quantifiziert. Angegeben sind die Mittelwerte \pm Standardabweichung. 
Die unveränderte Menge der synaptischen Vesikelproteine in $\alpha$-Synuclein-Nullmutanten ist ein Indiz unveränderter Anzahl synaptischer Vesikel, wie der Vergleich mit quantitativer Auswertung morphologischer Daten in anderen Nullmutanten zeigte (Rosahl et al. 1995). Analog weist die unveränderte Menge von Proteinkomponenten der aktiven Zone (Munc13-1 und RIM) auf eine unveränderte Anzahl und Größe von Synapsen hin. Analog kann aus den Ergebnissen der Quantifizierung von VMAT 2 und DAT im Striatum auf eine unveränderte Anzahl dopaminerger synaptischer Vesikel und Axone im nigrostriatalen System geschlossen werden.

\begin{tabular}{|l|c|c|}
\hline & wt $[\mathbf{n m o l} / \mathbf{m g}]$ & ko $[\mathbf{n m o l} / \mathbf{m g}]$ \\
\hline Taurin & $111,68 \pm 5,85$ & $119,01 \pm 5,71$ \\
\hline Aspartat & $23,85 \pm 2,97$ & $19,36 \pm 1,84$ \\
\hline Glutamat & $109,43 \pm 7,31$ & $97,37 \pm 4,08$ \\
\hline Glycin & $8,57 \pm 0,34$ & $7,65 \pm 0,54$ \\
\hline GABA & $7,78 \pm 0,83$ & $8,61 \pm 1,26$ \\
\hline
\end{tabular}

\begin{tabular}{|l|c|c|}
\hline & wt $[\mathbf{n g} / \mathbf{m g}]$ & ko $[\mathbf{n g} / \mathbf{m g}]$ \\
\hline Dopamin & $112,00 \pm 3,43$ & $107,41 \pm 3,39$ \\
\hline DOPAC & $7,90 \pm 0,71$ & $7,17 \pm 0,61$ \\
\hline HVA & $8,02 \pm 0,94$ & $9,02 \pm 0,43$ \\
\hline Serotonin & $3,91 \pm 0,33$ & $4,22 \pm 0,42$ \\
\hline 5-HIAA & $1,76 \pm 0,12$ & $1,77 \pm 0,24$ \\
\hline
\end{tabular}

Tab. 2: Striatale Neurotransmittermengen in $\alpha$-Synuclein-Nullmutanten (ko) und Wildtyp-Geschwistertieren (wt). Obere Tabelle mit Werten von jeweils acht Tieren und untere Tabelle mit Werten von jeweils 24 Tieren. Angegben ist der Mittelwert der chromatographischen Bestimmung \pm des Standardfehlers.

Weiterhin wurden die Mengen verschiedener Neurotransmitter im Striatum analysiert (Tab. 2). Es ergaben sich keine signifikanten Unterschiede. Insbesondere die Mengen von Dopamin und Serotonin waren unverändert, im Gegensatz zu einer bereits veröffentlichten Studie von $\alpha-$ Synuclein-Mausnullmutanten, die eine Dopaminreduktion von ca. $18 \%$ nachwiesen (Abeliovich et al. 2000).

Zusammengenommen zeigten diese Befunde, daß die Deletion von $\alpha$-Synuclein eine normale neuronale Funktion zuließ und morphologische und biochemische Veränderung des Gehirns nicht detektierbar waren. 

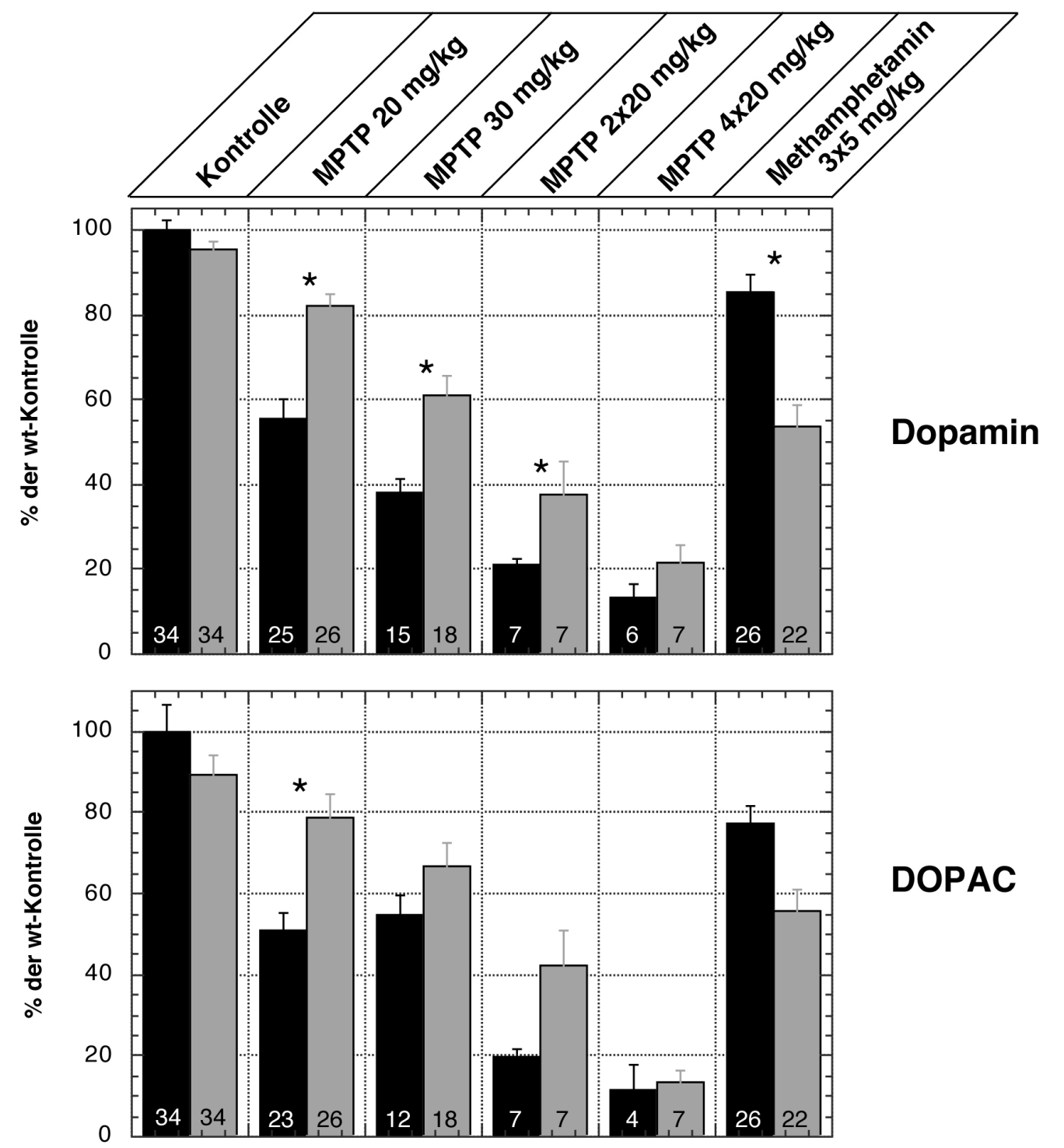

DOPAC

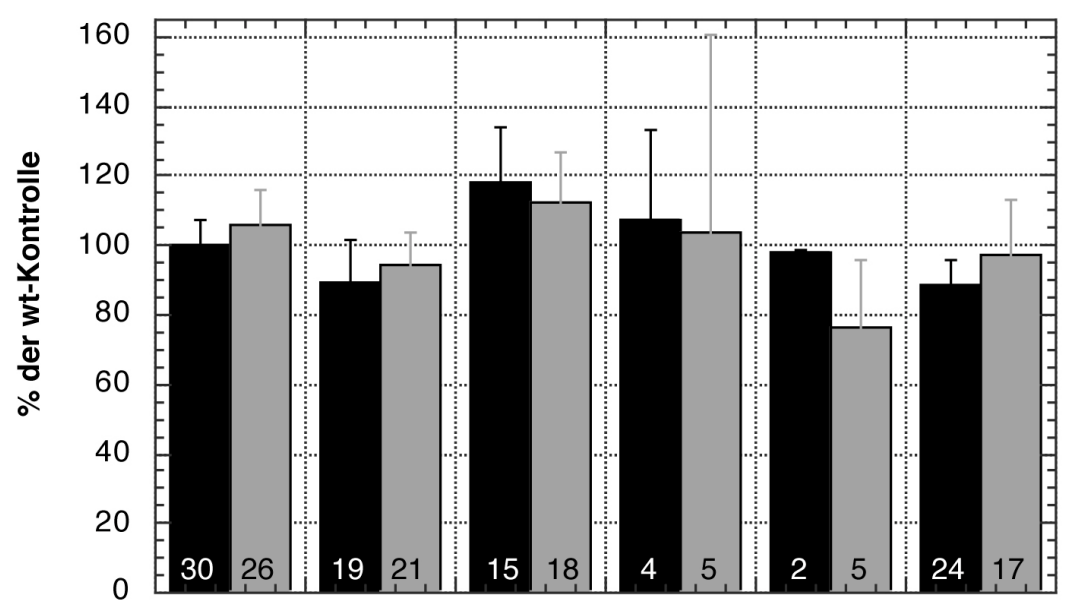

Serotonin

Abb. 12: Striatale Dopamin-, DOPAC- und Serotonin-Mengen in Wildtyp-Mäusen und $\alpha$-Synuclein-Nullmutanten in Abhängigkeit von MPTP oder Methamphetamin. Mäusen wurden im Abstand von je zwei Stunden die angegebenen Dosen MPTP oder Methamphetamin i.p. injiziert. Kontrolltiere erhielten das gleiche Volumen der Trägersubstanz. Die Neurotransmitter-Mengen wurden fünf Tage nach Applikation aus deproteinierten Striatumextrakten über HPLC ermittelt. Aufgetragen sind die relativen Werte bezogen auf die Wildtyp-Kontrolltiere aus vier kumulierten Experimenten. Die Anzahl der analysierten Tiere ist am Fuß jedes Balkens dargestellt. Werte sind als Mittelwerte \pm Standardfehler dargestellt. Statistisch signifikante Unterschiede (ANOVA: $\mathrm{p}<0,05$ ) sind mit einem Sternchen markiert. schwarze Balken: Wildtyp; graue Balken: $\alpha-$ Synuclein-Nullmutanten. 


\subsection{Pharmakologisches Tiermodell eines Parkinson-Syndroms}

In Mäusen kommt keine der Parkinson-Erkrankung ähnliches Syndrom vor. Allerdings löst MPTP eine Vielzahl von Veränderungen aus, die der Parkinson-Erkrankung gleichen. Um den Einfluß von $\alpha$-Synuclein auf die Pathogenese dieser Erkrankung zu untersuchen, wurde angenommen, daß die idiopathische Form prinzipiell dem gleichen pathogenetischen Mechanismus folgt, wie die durch das Toxin MPTP ausgelöste Erkrankung. $\alpha$-Synuclein-Nullmutanten und Wild-Typ-Geschwistertiere bekamen verschiedene Dosen dieses Toxins injiziert. Methamphetamin behandelte Mäuse dienten als Kontrolle, da beide Toxine eine akute Dopaminfreisetzung induzieren, jedoch unterschiedliche chronische Effekte aufweisen (Giovanni et al. 1994a; Giovanni et al. 1994b; Hogan et al. 2000; O'Dell et al. 1993; Sirinathsinghji et al. 1988; Sonsalla et al. 1992; Sulzer und Rayport 1990). Daher konnten die Effekte von MPTP und Methamphetamin möglicherweise helfen, zwischen akuten, durch Dopaminfreisetzung verursachten, und chronischen pathologischen Effekten zu unterscheiden. Die verabreichten MPTPMengen reichten von relativ milden Dosen (eine i.p.-Injektion von $20 \mathrm{mg} / \mathrm{kg}$ ) bis zu hohen Dosen (vier i.p.-Injektionen von $20 \mathrm{mg} / \mathrm{kg}$ im Abstand von je $2 \mathrm{~h}$ ) mit signifikanter akuter Mortalität. Die verwendeten Methamphetamin-Mengen mit drei i.p.-Injektionen von $5 \mathrm{mg} / \mathrm{kg}$ waren eher moderat. Die Tiere wurden fünf oder zehn Tage nach Behandlung getötet, einem Zeitpunkt, an dem die akuten Effekte beider Toxine vorüber waren (Fornai et al. 1997a; Fornai et al. 1999; Heikkila et al. 1984; Sonsalla et al. 1989).

Erste Hinweise auf eine mögliche Protektion der $\alpha$-Synuclein-Nullmutanten gegenüber der MPTP-Toxizität ergaben sich aus der erhöhten Letalität in der Wild-Typ-Gruppe. Vier der 57 behandelten Tiere verstarben innerhalb der ersten $24 \mathrm{~h}$, wohingegen alle der 58 behandelten Nullmutanten überlebten. Es konnten keine wesentlichen Verhaltensveränderungen zwischen den beiden Gruppen festgestellt werden. In beiden induzierte MPTP eine kurze Aktivitätssteigerung, die von einer katatonischen Phase gefolgt war. Nach Applikation der höchsten MPTP-Dosis waren die Wildtyp-Tiere unfähig sich fortzubewegen, wohingegen die Nullmutanten im Beobachtungszeitraum von fünf Minuten kurze Distanzen zurückgelegt hatten.

Nach Applikation von Methamphetamin vollführten sowohl die Nullmutanten als auch die Wildtyp-Geschwistertiere stereotype Verhaltensmuster, wie Lecken, Nagen und Fellpflege, die besonders nach der dritten Applikation evident waren.

Bei der Analyse wurden zuerst die Gehirne der MPTP-behandelten Mäuse morphologisch untersucht. In Gefrierschnitten wurde immunzytochemisch TH angefärbt (Abb. 11). Die Reduktion der TH-positiven Terminalen in den MPTP-behandelten Tieren variierte stark zwischen einzelnen analysierten Mäusen, wohingegen in den Methamphetamin behandelten Tieren keine Reduktion deutlich wurde. Alternativ wurden die Mengen an Dopamin und seiner Metaboliten im Striatum als Funktion der Behandlung untersucht (Abb. 12). Als Kontrolle dienten die Konzentrationen von Serotonin, das ebenfalls durch MPTP und Methamphetamin akut freigesetzt wird, dessen Mengen jedoch keiner chronischen Veränderung unterliegen. Mit steigenden MPTP-Dosen zeigte sich eine deutliche Reduktion des striatalen Dopamins. Diese verringerte sich um bis zu $90 \%$ bei der höchsten angewendeten Dosis. Im Vergleich dazu veränderten sich die Serotonin-Konzentrationen nicht, so daß die Reduktion auf chronische Effekte zurückzuführen war. Die $\alpha$-Synuclein-Nullmutanten waren signifikant gegenüber der MPTPBehandlung geschützt. Bei der Behandlung mit der geringsten MPTP-Dosis war dieser Effekt 
besonders deutlich. Hier wiesen die Nullmutanten eine Dopamin-Reduktion von lediglich ca. $15 \%$ verglichen zu $45 \%$ bei den Wildtyp-Geschwistertieren auf. Das gleiche Ergebnis zeigte sich bei DOPAC, einem Dopamin-Metaboliten.
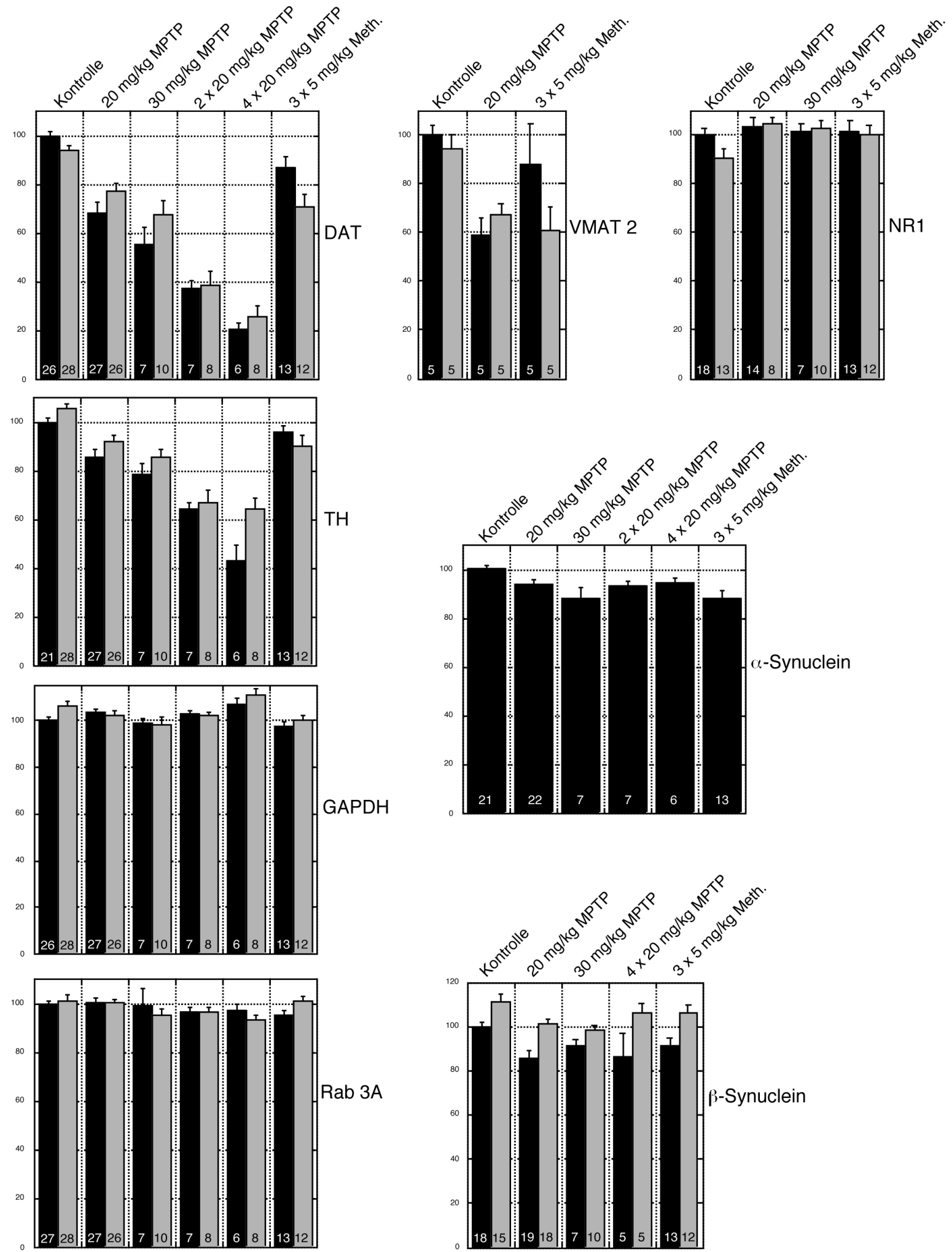

Abb. 13: Striatale Proteinmengen in $\alpha$-Synuclein-Nullmutanten und Wildtyp-Mäusen in Abhängigkeit von MPTP oder Methamphetamin. Die angegebenen Dosen MPTP, Methamphetamin oder physiologische Kochsalzlösung in Kontrolltieren wurden im Abstand von je zwei Stunden i.p. injiziert. Die Proteinmengen in PNS-Überständen aus Striatum-Homogenaten wurden fünf Tage nach Applikation über Immunoblotanalyse mit radioaktiver Quantifizierung bestimmt. Die Ergebnisse aus vier unabhängigen Experimenten wurden kumuliert und die Werte relativ zu 
Wildtyp-Kontrolltieren (Mittelwert \pm Standardfehler) dargestellt. Die Anzahl der analysierten Tiere ist jeweils am

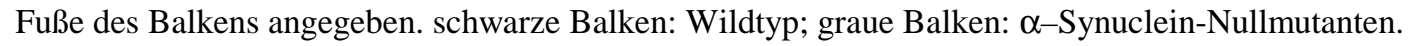
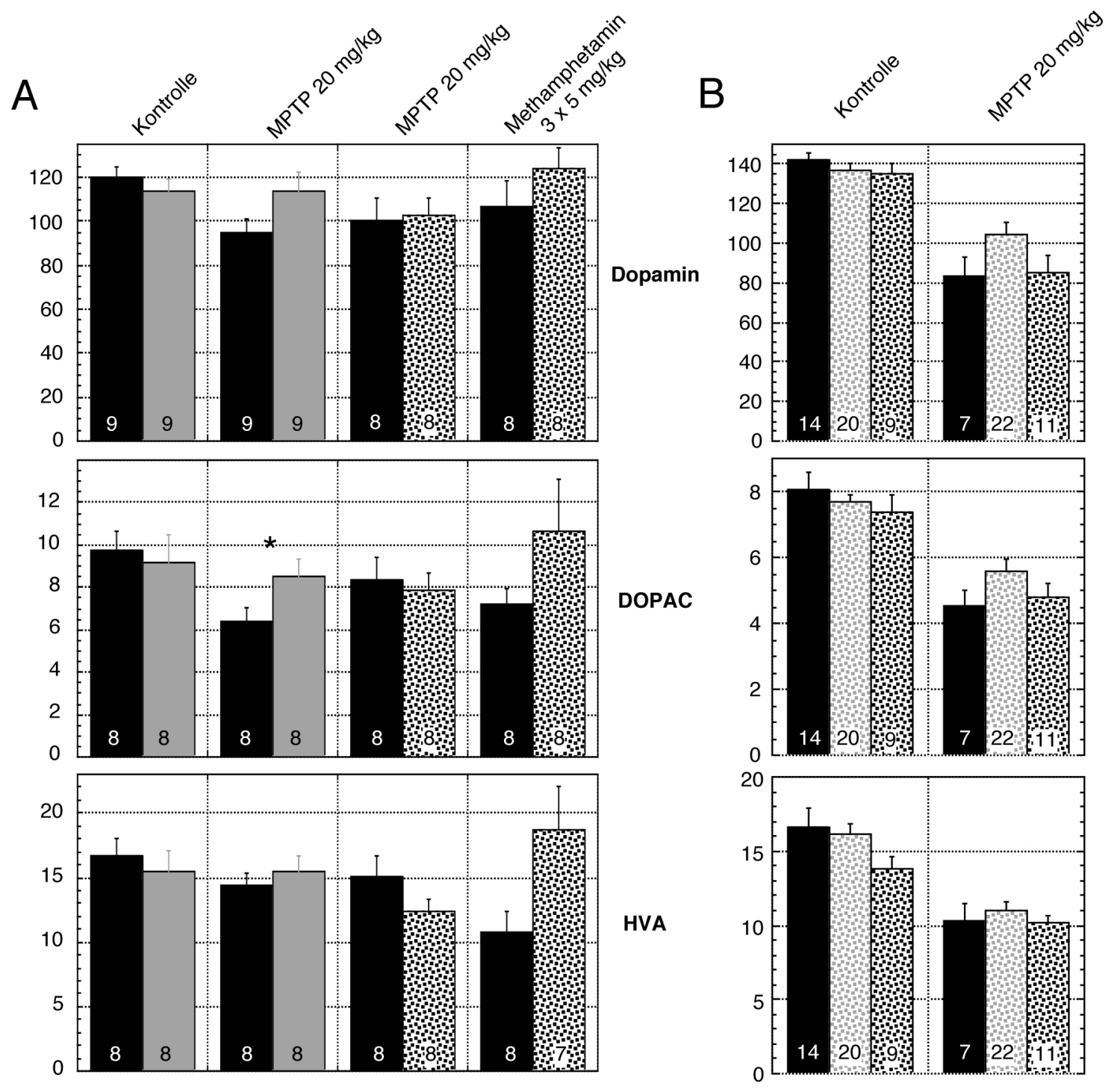

Abb. 14:Striatale Dopamin-, DOPAC- und Homovanillinsäure-Mengen in Wildtyp-Mäusen, $\alpha$-Synuclein-Nullmutanten und der $\alpha$-Synuclein Deletionsmauslinie C57B16/J/ola/hsd in Abhängigkeit von MPTP oder Methamphetamin. Mäusen wurde $20 \mathrm{mg} / \mathrm{kg}$ MPTP oder dreimal $5 \mathrm{mg} / \mathrm{kg}$ Methamphetamin im Abstand von je zwei Stunden i.p. injiziert. Kontrolltiere erhielten das gleiche Volumen der Trägersubstanz. Die Neurotransmitter-Mengen wurden fünf Tage (B) oder 10 Tage (A) nach Applikation aus deproteinierten Striatumextrakten über HPLC ermittelt. Die Anzahl der analysierten Tiere ist am Fuß jedes Balkens dargestellt. Die Dopaminmetaboliten in ng/mg Protein sind als Mittelwerte \pm Standardfehler dargestellt. Statistisch signifikante Unterschiede (ANOVA: $p<0,05)$ sind mit einem Sternchen markiert. schwarze Balken: Wildtyp; graue Balken: $\alpha$-Synuclein-Nullmutanten; grau gemusterte Balken: heterozygote C57B16/J/ola/hsd-Mäuse; schwarz gemusterte Balken: homozygote C57B16/J/ola/hsd-Mäuse.

Überraschend war der entgegengesetzte Effekt bei der Methamphetamin-Behandlung. Hier zeigten die $\alpha$-Synuclein-Nullmutanten eine doppelt so starke Empfindlichkeit verglichen mit den Wildtyp-Geschwistertieren. Die Mengen an Dopamin und seiner Metaboliten in den WildtypMäusen waren nur moderat um ca. $15 \%$ reduziert, wohingegen die Reduktion bei den Nullmutanten ca. $40 \%$ betrug. Wiederum hatte die Behandlung in beiden Gruppen keinen chronischen Effekt auf den striatalen Serotoningehalt. 
Die immunhistochemische Analyse der dopaminergen Terminalen im Striatum hatte eine Reduzierung durch MPTP gezeigt. Um diesen Effekt zwischen den beiden Mausgruppen quantitativ vergleichen zu können, wurden Markerproteine dopaminerger Terminalen als Funktion der MPTP- und Methamphetamin-Behandlung quantifiziert (Abb. 13). Aufgrund eines einzelnen Aminosäurenaustausches im C-Terminus des Maus-VMAT 2-Sequenz waren viele gegen die Rattensequenz gerichtete, kommerziell erhältliche Antikörper nicht verwendbar. Mit einem von Prof. Weihe (Marburg) freundlicherweise zur Verfügung gestellten Antikörper, gerichtet gegen die Maussequenz, konnten einige Tiere analysiert werden. Die starke Reduktion dieses Proteins deutete auf eine verminderte Menge dopaminerger synaptischer Vesikel hin, die in der Größenordnung des Dopaminverlustes lagen. Die Protektion in den $\alpha$-Synuclein-Nullmutanten war auf Proteinebene nur andeutungsweise detektierbar, jedoch nicht statistisch signifikant. Interessant war die Reduktion der VMAT 2-Mengen in den mit Methamphetamin behandelten Tieren, da sich in diesem Falle keine sichtbare Reduktion der immunzytochemisch gefärbten Terminalen abgezeichnet hatte. Der Plasmamembranmarker dopaminerger Neuronen, DAT, war in den mit MPTP behandelten Tieren ebenfalls vermindert. Hier war die Protektion in den Nullmutanten nur angedeutet und nicht statistisch signifikant. Das Ausmaß der Reduktion von TH, einem zytosolischen Protein, war nach MPTP-Behandlung relativ gering. Bei der Methamphetamin-Behandlung ergab sich jedoch eine signifikante Überempfindlichkeit in den Nullmutanten. Im Gegensatz zu VMAT 2, das in den präsynaptischen Terminalen angereichert ist (Dr. S. Takamoori, persönliche Mitteilung), kommen TH wie auch DAT im gesamten Neuron verteilt vor. Daher könnte die zu den DAT-Mengen vergleichsweise milde Reduktion der THMengen durch MPTP auf eine kompensatorische Heraufregulation des Schrittmacherenzyms der Dopaminsynthese hindeuten.

Für $\alpha$ - und $\beta$-Synuclein wurde ebenfalls eine von der MPTP-Behandlung abhängige Abnahme festgestellt. Beide Proteine wurden auch in den nicht dopaminergen Synapsen des Striatums nachgewiesen (Abb. 11). Die Mengen des ubiquitär vorkommenden präsynaptischen Proteins Rab3A waren bei den hohen MPTP-Dosen leicht verringert, wohingegen GAPDH- und NR1Mengen behandlungsunabhängig waren.

\subsection{Untersuchung der C57BI6/J/ola/hsd-Mauslinie}

Bei der Rückkreuzung der erzeugten $\alpha$-Synuclein-Mausnullmutanten in kommerziell erhältliche C57B16-Linien wurde bei der Linie C57B16/J/ola/hsd eine Mutation im $\alpha$-Synuclein-Gen entdeckt, die ebenfalls zu einem Verlust des Proteins führte (Abb. 9). Um die Ergebnisse in den $\alpha$-Synuclein-Nullmutanten an einer unabhängigen $\alpha$-Synuclein-defizienten Linie zu überprüfen, wurde das pharmakologisch induzierte Parkinson-Modell an C57B16/J/ola/hsd-Mäusen getestet. Als Wildtyp-Kontrolle wurde die Inzuchtlinie C57B16/J von Cerj verwendet. Zehn Tage nach Injektion wurden wie für die Nullmutanten beschrieben die striatalen Dopamin-Mengen bestimmt. In diesen Versuchen konnte kein signifikanter Unterschied zwischen beiden Mauslinien gegenüber der Behandlung mit $20 \mathrm{mg} / \mathrm{kg}$ MPTP oder 3 x $5 \mathrm{mg} / \mathrm{kg}$ Methamphetamin gefunden werden (Abb. 14). Ein parallel durchgeführtes Experiment mit den erzeugten $\alpha-$ Synuclein-Nullmutanten zeigte wiederum eine Protektion gegenüber der MPTP-Behandlung an, obwohl sie geringer ausfiel als bei der Analyse nach fünf Tagen. Inzuchtlinien sind bekannt für eine unterschiedliche Empfindlichkeit gegenüber MPTP, die dominant vererbt wird (Hamre et al. 1999). Um mögliche genetische Hintergrundeffekte weiter einzuschränken wurden die 
$\alpha$-Synuclein-defizienten C57B16/J/ola/hsd-Mäuse mit Wildtyp-Mäusen aus der $\alpha$-SynucleinNullmutanten-Linie gekreuzt und die F2-Nachkommen analysiert. Die Größe der spontanen chromosomalen Deletion war nicht bekannt, so daß keine Sonde für dieses Allel konstruiert werden konnte. Um zwischen Wildtyp-Tieren und den für die spontane Deletion heterozytogen Tieren unterscheiden zu können, wurden die striatalen $\alpha$-Synuclein-Mengen nach dem Experiment quantifiziert. Heterozygote Mäuse wiesen $\sim 60 \%$ der Wildtyp-Mengen auf. Bei Wildtyp- und $\alpha$-Synuclein-defizienten Mäusen war der Dopamingehalt nach $20 \mathrm{mg} / \mathrm{kg}$ MPTP nicht signifikant unterschiedlich und betrug nach fünf Tagen $56 \%$ des Kontrollwertes. In heterozygoten Mäusen war die Reduktion geringer und fiel um 27 \% gegenüber den Kontrolltieren ab. Vergleichbar waren auch die Ergebnisse der Dopamin-Metaboliten DOPAC und HVA.

Überraschenderweise bestätigten diese Versuche nicht die Ergebenisse der $\alpha$-SynucleinNullmutanten, so daß zusammengenommen eine Beteiligung von $\alpha$-Synuclein an der MPTP- und Methamphetamin-Toxizität unwahrscheinlich erscheint. Die Effekte waren wahrscheinlich durch ein mit dem $\alpha$-Synuclein-Gen zusammen vererbten Gen verursacht, da die analysierten Mäuse einen C57B16/J-129Sv-Hybridstamm bildeten.

\subsection{Untersuchung der Modulation des synaptischen Dopamin- transports durch $\alpha$-Synuclein}

Sowohl MPTP als auch Methamphetamin bewirken eine akute Freisetzung von Dopamin, auch wenn ihre pharmakologische Wirkung stark unterschiedlich ist (Miller et al. 1999; Sirinathsinghji et al. 1988; Sonsalla et al. 1992; Sulzer und Rayport 1990). Sowohl MPTP als auch Methamphetamin führten zu einem Verlust von nigrostriatalem Dopamin, eine Veränderung der Tyrosinhydroxylase-Mengen und -aktivität und einer Inhibition der synaptosomalen und vesikulären Dopaminaufnahme (Hogan et al. 2000). In den $\alpha$-Synuclein-Nullmutanten war die Sensitivität gegenüber beiden Komponenten verändert. Veränderungen des synaptischen Dompamin-Transportes zeigen einen Einfluß auf die Empfindlichkeit von MPTP und Methamphetamin (Fon et al. 1997; Fumagalli et al. 1998; Fumagalli et al. 1999; Gainetdinov et al. 1997; Gainetdinov et al. 1998). Es besteht somit die Möglichkeit, daß die veränderte Toxinempfindlichkeit durch einen veränderten synaptischen Dopamintransport verursacht wurde.

Um einen Einfluß der Mutation auf den Transport von Dopamin über die Plasmamembran zu untersuchen, wurde die Dopaminaufnahme in striatalen Synaptosomen gemessen (Abb. 15). In beiden Gruppen (Wildtyp und Nullmutanten) wurde die Aufnahme durch $1 \mu \mathrm{M}$ Methamphetamin um 50\% inhibiert. Auch die Absolutwerte mit $140 \mathrm{pmol} / \mathrm{mg}$ Protein/min für die Wildtyp-Mäuse und $161 \mathrm{pmol} / \mathrm{mg}$ Protein/min für die $\alpha$-Synuclein-Nullmutanten waren nicht signifikant unterschiedlich.

Die vesikuläre Dopaminaufnahme wurde mit Hilfe von partiell gereinigten synatischen Vesikeln untersucht. Auch hier ergab sich kein wesentlicher Unterschied zwischen Wildtyp- und $\alpha$-Synuclein defizienten Mäusen (Abb. 15). Methamphetamin inhibierte die Aufnahme in beiden Gruppen gleichermaßen, wenn auch mit geringerer Potenz, als sie für die synaptosomale Aufnahme beobachtet wurde. Da $\alpha$ - oder $\beta$-Synuclein nicht auf dieser Art von Vesikeln nachweisbar waren, untersuchten wir die vesikuläre Aufnahme nach Zugabe von rekombinant hergestellten Proteinen. Hierzu wurden die entsprechenden Fusionsproteine exprimiert und über Glutathion-Agarose gereinigt. GST wurde über die TEV-Protease abgespalten und das Produkt 
gegen Wasser dialysiert. Die Reinheit der rekombinanten Proteinen wurde über gefärbte SDSPAGE-Gele bestimmt und betrug mehr als $95 \%$.

Dopamin-Transport in Synaptosomen

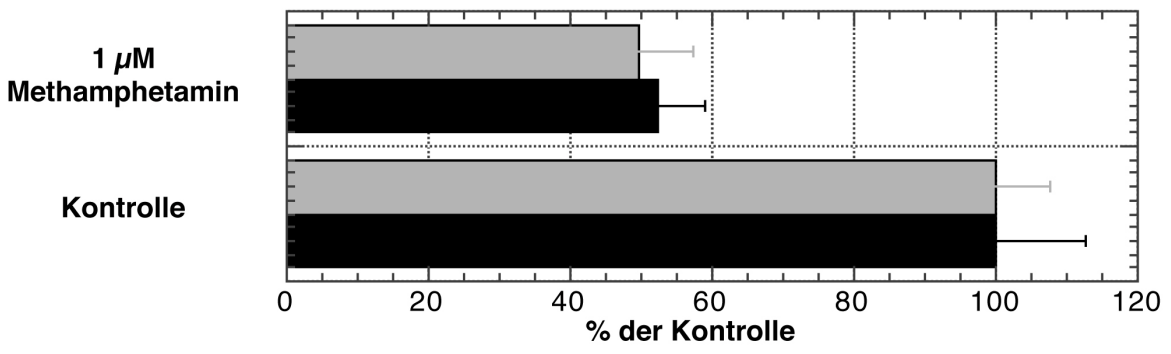

Vesikuläre Dopamin-Aufnahme

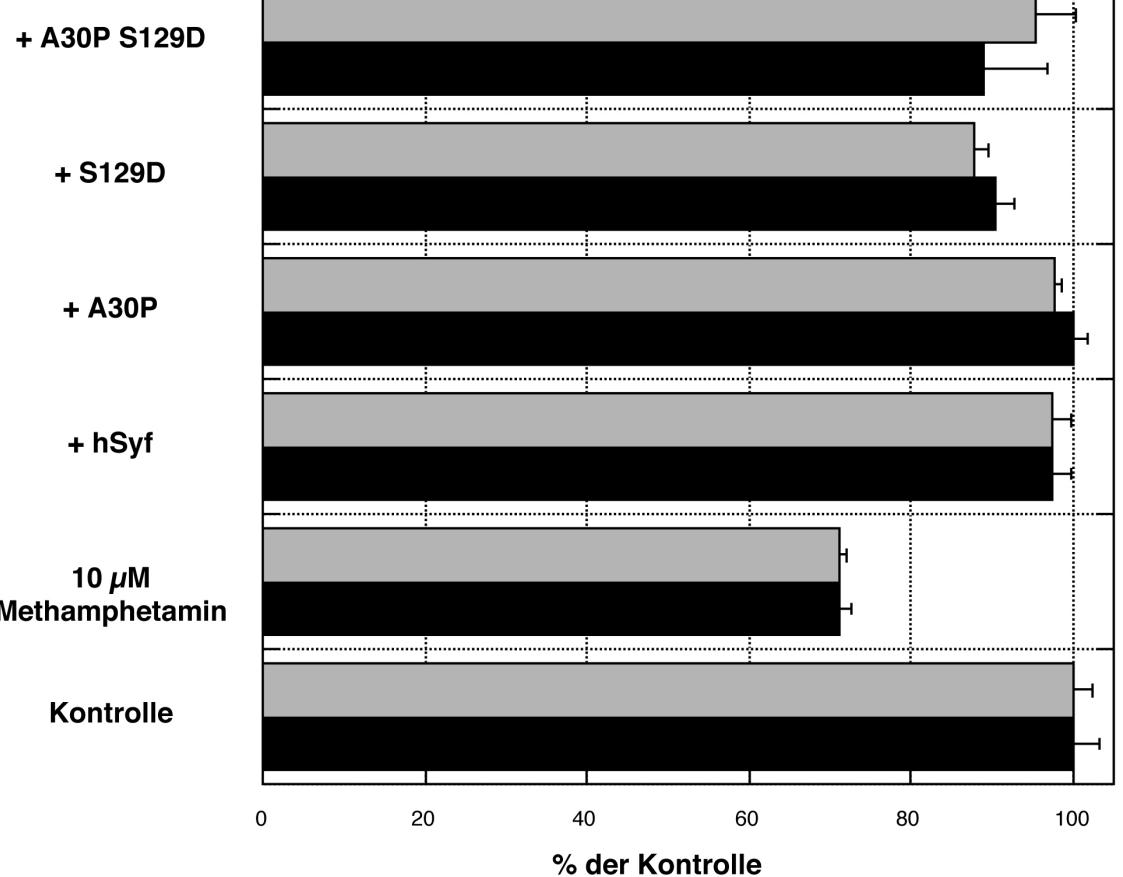

Abb. 15: Synaptischer Dopamintransport in $\alpha$-Synuclein-Nullmutanten und Wildtyp-Mäusen. Die Aufnahme von Dopamin in die rohe Synaptosomenfraktion (P2) von Wildtyp-Mäusen (wt; schwarze Balken; N=3) und Nullmutanten (KO; graue Balken; N=3) ist im oberen Diagramm dargestellt. Werte als Dublikate gemessen wurden um die unspezifische Aufnahme, gemessen in der Anwesenheit von 0,1 mM GBR12909 (wt: 9,5 pmol/mg Protein/min; ko: 10,4 pmol/mg Protein/min), korrigiert. Die Dopaminaufnahme unter Kontrollbedingungen (wt: $140 \mathrm{pmol} / \mathrm{mg}$ Protein/min; ko: $161 \mathrm{pmol} / \mathrm{mg}$ Protein/min) wurde gleich $100 \%$ gesetzt und die Werte \pm des Standardfehlers dargestellt. Die Aufnahme von Dopamin in die rohe synaptische Vesikelfraktion (LP2) ist im unteren Diagramm dargestellt (wt: schwarze Balken; KO: graue Balken). Hintergrundwerte wurden in der Anwesenheit von $50 \mu \mathrm{M}$ Reserpin gemessen (wt: 0,17 pmol/mg Protein/min; ko: 0,17 pmol/mg Protein $/ \mathrm{min}$ ). Werte als Dublikate gemessen sind dargestellt wie oben beschrieben (Kontrolle wt: 3,3 pmol/mg Protein/min; Kontrolle ko: $3,4 \mathrm{pmol} / \mathrm{mg}$ Protein/min). Die Aufnahme wurde in Anwesenheit von rekombinantem humanen Wildtyp- $\alpha$-Synuclein (hSyf), humanem $\alpha$-Synuclein mit den Mutationen A30P (A30P), S129D (S129D), A30P und S129D (A30P S129D) oder Methamphetamin gemessen.

Weder $\alpha$-Synuclein noch die mutierten Formen hatten einen signifikanten Einfluß auf den vesikulären Dopamintransport. Da die $\alpha$-Synuclein-Funktion möglicherweise durch Phosphorylierung an der Position Serin-129 reguliert wird, wurde diese Aminosäure durch Aspartat 
ersetzt, um ein konstitutiv phosphoryliertes Protein zu imitieren. Auch dieses entsprechend mutierte rekombinante Protein beeinflußte die vesikuläre Dopaminaufnahme nicht.

Zusammengenommen zeigten diese Versuche, daß eine Regulation weder des synaptischen noch des vesikulären Dopamintransports durch $\alpha$-Synuclein wahrscheinlich ist und die unterschiedliche Empfindlichkeit gegenüber MPTP und Methamphetamin in den $\alpha$-Synuclein-Nullmutanten nicht erklären kann.

\subsection{Herstellung und Analyse transgener, $\alpha$-Synuclein überexpri- mierender Mäuse}

Im Gegensatz zu Menschen und Primaten sind in Mäusen keine Parkinson-ähnlichen Krankheitsbilder bekannt. Um zu untersuchen, ob das humane $\alpha$-Synuclein-Ortholog oder verschiedene Mutanten ein solches in Mäusen induzieren können, wurden verschiedene $\alpha$-SynucleinKonstrukte transgen in Mäusen exprimiert.

Das Vektorrückgrat wurde aus den transgenen Konstrukten mit PvuI und NotI ausgeschnitten und die transgene Expressionskassette, gesteuert vom Thy1-Promotor, in Vorkerne befruchteter Oozyten von FVB-Mäusen injiziert (Abb. 16). Die in NMRI-Mäusen ausgetragenen Ur-Transgenen wurden über PCR mit den Primerpaaren 2475/2476 für die Linie des humanen $\alpha$-Synuclein (hSyf) und 1333/1334 für alle weiteren Linien auf chromosomale Insertion getestet. Insgesamt vier verschiedene transgene Konstrukte, die das humane $\alpha$-Synuclein-Ortholog, ohne und mit den Mutationen A30P, A53T und A30P S87D exprimierten, wurden erstellt. $18 \%$ der injizierten Oozyten mit dem A30P-, $16 \%$ mit dem A53T- und 19\% mit dem A30P S87DKonstrukt enthielten eine chromosomale Insertion. Von humanen Wildtyp-Konstrukten waren noch keine Mäuse erhalten worden. 54 \% der A30P-Linien, 64 \% der A53T-Linien und 36 \% der A30P S87D-Linien vererbten die Insertion. Diese Mäuse wurden mit $\alpha$-Synuclein-Nullmutanten gekreuzt, um individuelle Linien zu erhalten, die nur das humane Ortholog exprimierten. Drei Ur-Transgene der Linie A30P S87D waren gegenüber Geschwistertieren in der Größe vermindert und zeugten auch keine Nachkommen. Im Gegensatz dazu waren die anderen Ur-Transgene unauffällig und entwickelten auch im Alter von mehr als einem Jahr keine Symptome. Erst nach Kreuzung mit $\alpha$-Synuclein-Nullmutanten entwickelten $\sim 40 \%$ der A30Pund A30P S87D- und $~ 90 \%$ der A53T-Linien neurologische Symptome (Tab. 3). 


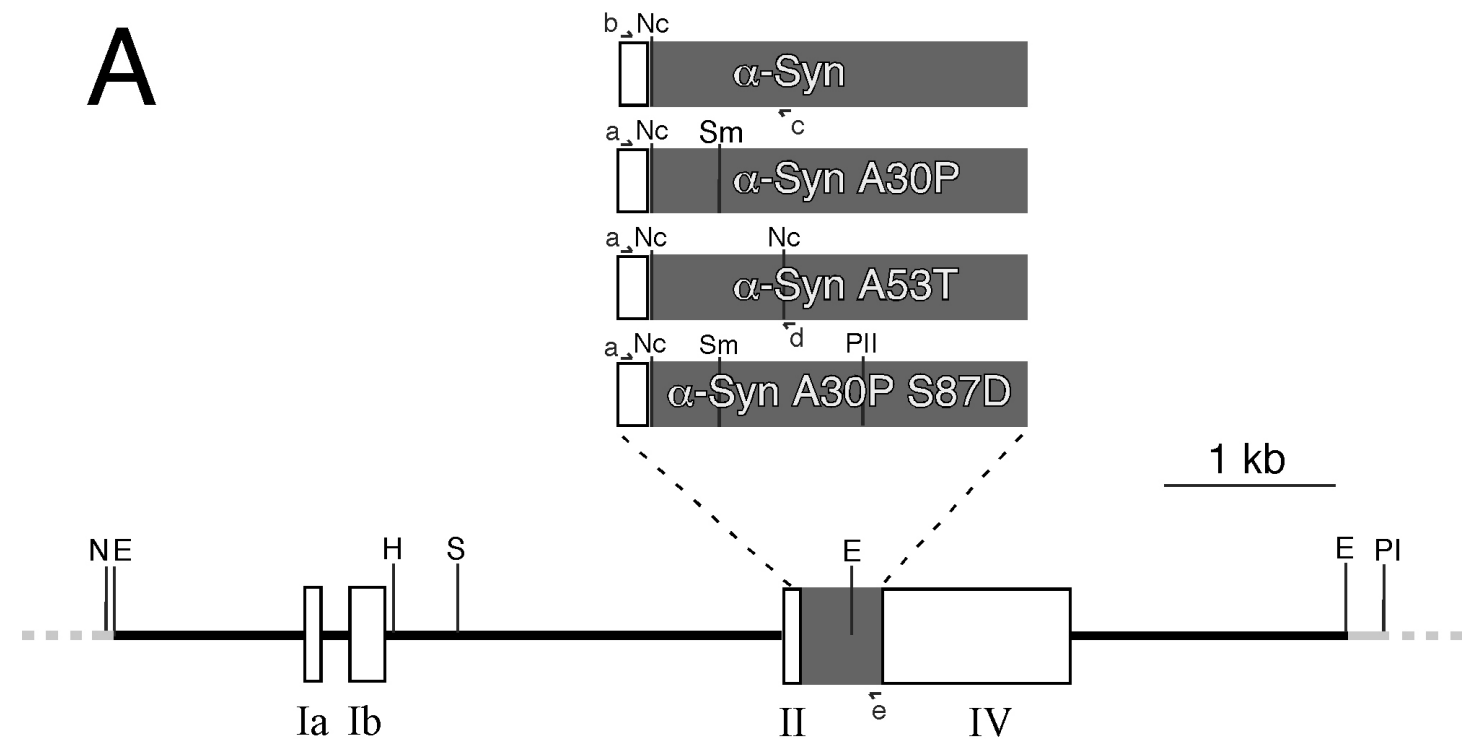

B

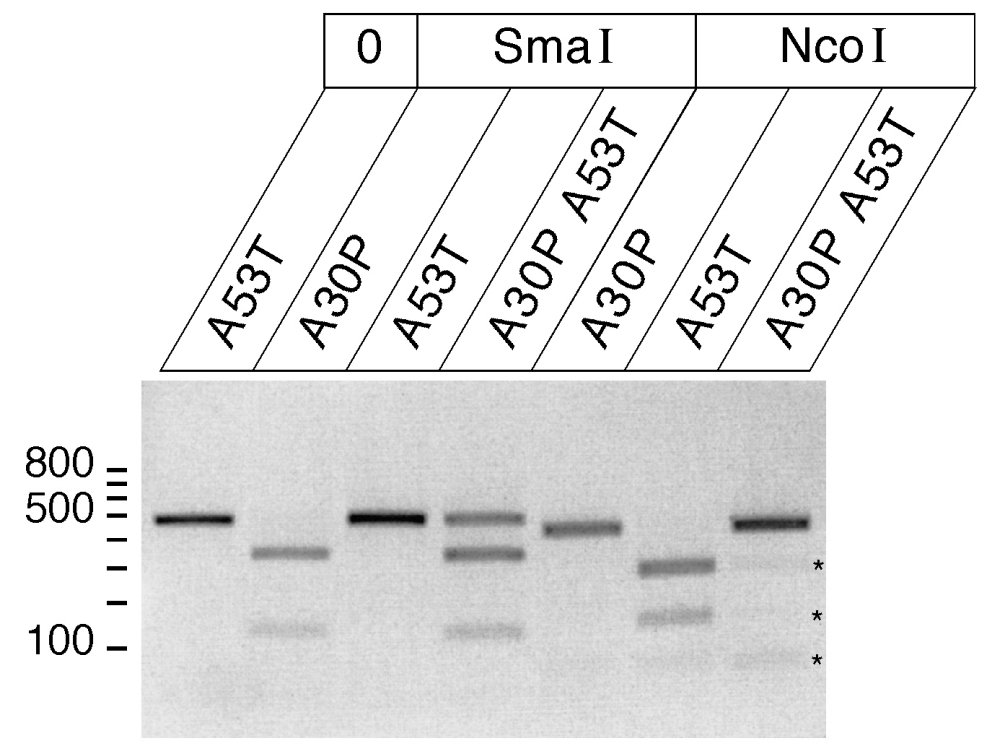

Abb. 16: Transgene Konstrukte gesteuert vom Thy1-Promotor und deren Identifizierung in transgenen Mäusen. A: Schematische Darstellung der verwendeten transgenen Konstrukte. Nicht translatierte Exone des Thy1-Gens sind als offene Boxen eingezeichnet. Die kodierenden Exone sind durch die $\alpha-$ Synuclein cDNA (graue Box) ersetzt. Oben: Ausschnittsvergrößerung und Darstellung der verwendeten humanen $\alpha$-Synuclein cDNA mit den entsprechenden Mutationen. Erkennungsstellen für die Restriktionsenzyme NotI (N), EcoRI (E), HinDIII (H), SpeI (S), NcoI (Nc), SmaI (Sm), PvuI (PI) und PvuII (PII) in den verschiedenen cDNAs, dem Thy1-Gen (schwarze Linie mit Boxen) und flankierend in der Vektorsequenz (grau) sind markiert. Die Positionen der Primer für die Amplifikation der $\alpha$-Synuclein-cDNAs sind eingezeichnet (a: 1333/2474, b: 2475, c: 2476, d: 2473, e:1334). B: Repräsentatives 1,5\% Agarosegel zur Identifizierung der doppelt-transgenen Mäuse. Die cDNA wurde über das Primerpaar 1333/1334 aus isolierter Mausgewebe-DNA amplifiziert und mit den Restriktionsenzymen SmaI oder NcoI geschnitten. Die untersuchten Mauslinien sind bezeichnet und wurden durch das charakteristische Bandenmuster identifiziert. Die schwachen Banden nach Verdau des PCR-Produktes doppelt-transgener Mäuse mit NcoI sind durch Sternchen markiert. Das unverdaute PCR-Produkt hat eine Größe von 480 bp. In der A30P-Linie wird dieses durch SmaI in zwei Fragmente der Größe 120 und 360 bp gespalten. Der NcoI-Verdau spaltet in allen PCR-Produkten ein 40 bp großes Fragment ab und teilt es zusätzlich noch in der A53T-Linie in 270 und 170 bp große DNA-Stücke. 


\begin{tabular}{|c|c|c|c|c|c|c|c|}
\hline Mauslinie & $\alpha-\operatorname{Syn}$ & $\begin{array}{c}\text { Symptom- } \\
\text { beginn }\end{array}$ & $\begin{array}{l}\text { Leitsymp- } \\
\text { tome }\end{array}$ & Mauslinie & $\alpha$-Syn & $\begin{array}{l}\text { Symptom- } \\
\text { beginn }\end{array}$ & $\begin{array}{c}\text { Leitsymp- } \\
\text { tome }\end{array}$ \\
\hline wt & $\begin{array}{c}100 \pm 1 \\
(8)\end{array}$ & - & - & M58A53T & $\begin{array}{c}255 \pm 22 \\
\text { (3) }\end{array}$ & $\begin{array}{c}336 \pm 56 \\
(4)\end{array}$ & Bs, mU, P \\
\hline M48A30P & $\begin{array}{c}145 \pm 18 \\
(5)\end{array}$ & & & M70A53T & $\begin{array}{c}219 \pm 20 \\
(4)\end{array}$ & $\begin{array}{c}237 \pm 47 \\
(10)\end{array}$ & P hE, Gs \\
\hline M49A30P & $\begin{array}{c}322 \pm 42 \\
(4)\end{array}$ & $\begin{array}{c}216 \pm 21 \\
(13)\end{array}$ & $\mathrm{P}$ hE, (Gs) & M78A53T & $\begin{array}{c}55 \pm 3 \\
(3)\end{array}$ & $\begin{array}{c}372 \pm 17 \\
(2)\end{array}$ & $\mathrm{PhE}$ \\
\hline M57A30P & & $\begin{array}{c}244 \pm 82 \\
(3)\end{array}$ & $\mathrm{mU},(\mathrm{P} h \mathrm{hE})$ & M87A53T & $\begin{array}{c}152 \pm 9 \\
(2)\end{array}$ & $\begin{array}{c}445 \pm 30 \\
(3)\end{array}$ & \\
\hline M82A30P & $\begin{array}{c}108 \pm 13 \\
(3)\end{array}$ & $\begin{array}{c}348 \\
(1) \\
\end{array}$ & & F89A53T & $\begin{array}{c}65 \pm 2 \\
(2) \\
\end{array}$ & & \\
\hline M83A30P & $\begin{array}{c}141 \pm 12 \\
(3)\end{array}$ & & & F3A30PS87D & $\begin{array}{c}67 \pm 4 \\
(2)\end{array}$ & & \\
\hline M87A30P & $\begin{array}{c}123 \pm 9 \\
(3) \\
\end{array}$ & & & F5A30PS87D & $\begin{array}{c}75 \pm 7 \\
(3) \\
\end{array}$ & & \\
\hline F106A30P & $\begin{array}{c}112 \pm 9 \\
(3) \\
\end{array}$ & $\begin{array}{c}165 \\
(1) \\
\end{array}$ & & M6A30PS87D & $\begin{array}{c}106 \pm 26 \\
(3)\end{array}$ & & \\
\hline $\begin{array}{l}\text { M49A30P } \\
\text { M70A53T }\end{array}$ & $\begin{array}{c}276 \\
(1) \\
\end{array}$ & $33 \pm 4$ & $\mathrm{Wr}, \mathrm{ksG}$ & F11A30PS87D & & $\begin{array}{l}24 \\
(1) \\
\end{array}$ & \\
\hline M4A53T & $\begin{array}{c}112 \pm 4 \\
(4)\end{array}$ & $\begin{array}{c}345 \pm 35 \\
(6)\end{array}$ & & M12A30PS87D & $\begin{array}{c}237 \pm 2 \\
(2)\end{array}$ & $\begin{array}{c}54 \pm 2 \\
(3)\end{array}$ & $\mathrm{mU}, \mathrm{At}, \mathrm{Bs}$ \\
\hline F12A53T & $\begin{array}{c}208 \pm 6 \\
(3)\end{array}$ & $\begin{array}{c}313 \pm 47 \\
(12)\end{array}$ & $\begin{array}{c}\text { Bs, Fl, } \\
(\mathrm{mU})\end{array}$ & M20A30PS87D & $\begin{array}{c}194 \\
(1)\end{array}$ & k.K.T. & $\mathrm{Wr}$ \\
\hline M13A53T & $\begin{array}{c}142 \pm 68 \\
(3)\end{array}$ & $\begin{array}{c}704 \pm 31 \\
(2)\end{array}$ & $\mathrm{mU}, \mathrm{Bs}$ & F33A30PS87D & $\begin{array}{c}283 \\
(1) \\
\end{array}$ & k.K.T. & $\mathrm{Wr}$ \\
\hline M28A53T & $\begin{array}{c}188 \pm 20 \\
(5)\end{array}$ & $\begin{array}{c}272 \pm 66 \\
(4)\end{array}$ & $\mathrm{mU}, \mathrm{eA}$ & & & & \\
\hline
\end{tabular}

Tab. 3: Expressionsmengen des transgenen $\alpha$-Synuclein der einzelnen transgenen Linien relativ zur Menge in Wildtyp-Mäusen. Rohe Synaptosomenfraktionen (P2) aus über sechs Monate alten und vorwiegend symptomatischen Mäusen wurden über SDS-PAGE aufgetrennt und über Immunoblotanalyse mit dem Antikörper $\alpha$ Syf und radioaktive Detektion quantifiziert. Aufgetragen sind die Mittelwerte \pm Standardfehler. In Klammern ist die Anzahl der analysierten Tiere angegeben. Der mittlere Erkrankungsbeginn in Tagen \pm Standardfehler und in Klammern die Anzahl der erkrankten Tiere mit den beobachteten Symptomen ist in den anderen Spalten angegeben (At: Ataxie; Fl: Flexion der Wirbelsäule; hE: hintere Extremität; P: Parese; eA: epileptogene Anfälle; mU: motorische Unruhe; Bs: Bewegungsstarre/Akinese; Gs: Gleichgewichtsstörung; ksG: kleinschrittiger Gang; Wr: Wachstumsretardierung). Zusätzlich zeigten sechs Linien der A30P-Mutation, fünf Linien der A53T-Mutation und sieben Linien der A30P S87D-Mutation keine Keimbahntransmission (k.K.T.). 

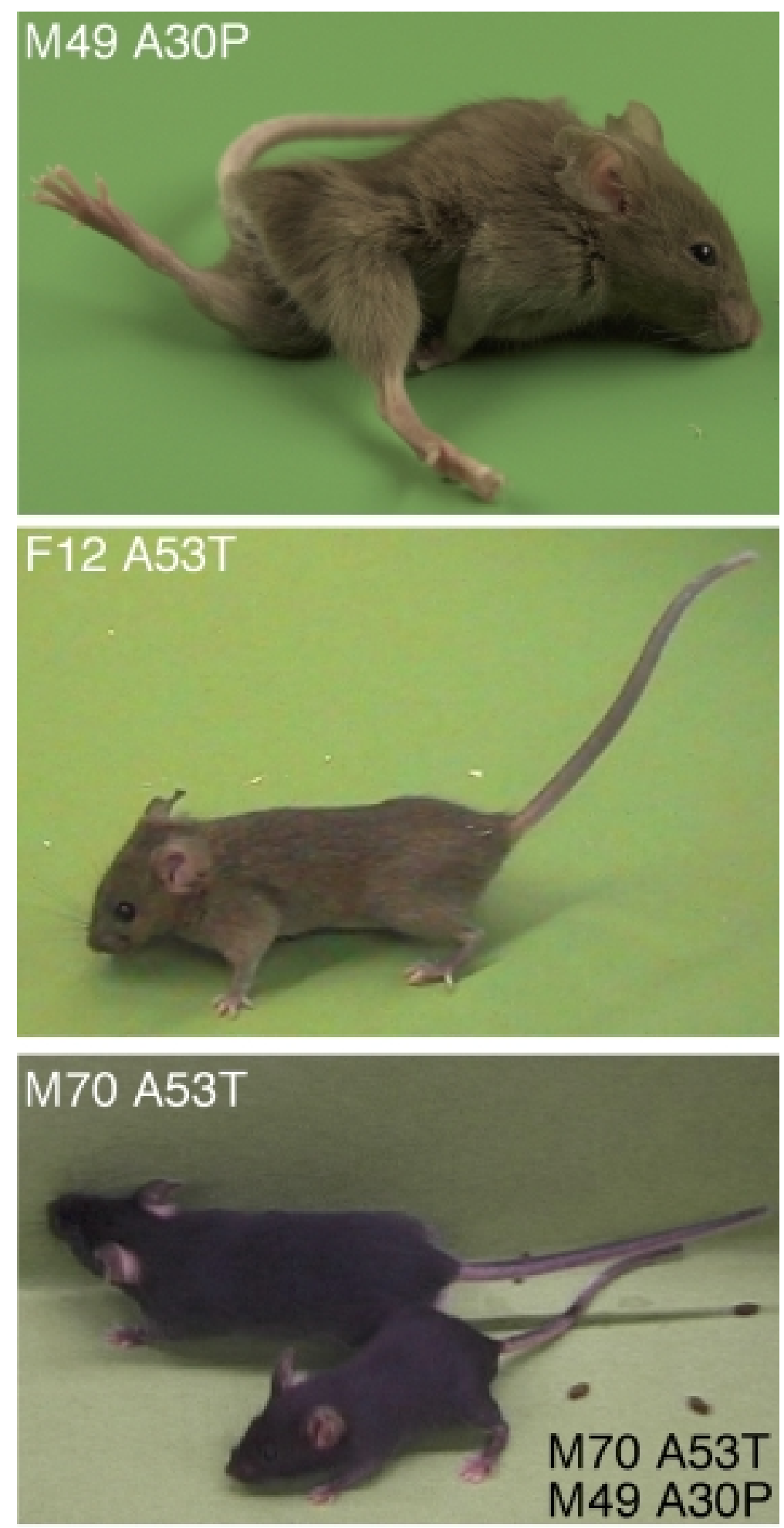

Abb. 17:Fortgeschrittene Stadien der Erkrankung $\alpha$-Synuclein transgener Mäuse. Mäuse der Linien M49A30P (oben) und F12A53T (Mitte) wurden im Alter von sechs bzw. neun Monaten photographiert. Die Maus M49A30P verschlechterte sich innerhalb weniger Tage bis zu einem Zustand, in dem sie sich nicht mehr fortbewegen konnte. Im Vordergrund stand die Parese der hinteren Extremitäten bei erhöhtem Muskeltonus und Streckstellung. Zusätzlich viel eine Flexion der Wirbelsäule auf. Die Maus der Linie F12A53T entwickelte über Wochen immer wieder Phasen der Bewegungsstarre, in der sie bis zu eine Minute verharrte, um danach wieder normal herumzulaufen. Geschwistertiere der Verpaarung der Linien M70A53T und M49A30P wurden im Alter von 8 Wochen photographiert (unteres Bild). Die doppelt-transgene Maus (unteres Bild, unten) ist im Vergleich zu der einzel-transgenen Maus (unteres Bild, oben) im Wachstum verlangsamt. Weiterhin ist ihr Gangbild kleinschrittig und mit verbreiterter Basis der hinteren Extremitäten. 


\subsection{Untersuchung neurologischer Ausfälle durch Mutationen der familiären Parkinson-Syndrome}

Das Symptommuster und auch der Beginn der neurologischen Symptome war bei den einzelnen Linien verschieden. Innerhalb einer Linie war die Symptomatik relativ konstant. In den Linien A30P- und A53T- war der mittlere Beginn im Zeitraum von 5 bis 14 Monaten (Tab. 3). Dabei sind von den meisten Linien erst einzelne Tiere erhalten worden und auch nicht alle über diesen langen Zeitraum beobachtet worden, so daß noch keine sicheren Aussagen über die Penetranz gemacht werden können. In Linien mit den schwersten Symptomen, wie M49A30P oder F12A53T, schienen bis zu $100 \%$ der Mäuse zu erkranken, wohingegen in Linien mit eher milden Symptomen, z.B. M28A53T, nur eine Penetranz von etwa $10 \%$ beobachtet wurde. Das Symptommuster war in den einzelnen Linien sehr unterschiedlich. Die Linie M49A30P entwickelte als Leitsymptom eine Parese der hinteren Extremitäten (Abb. 17). Die Muskeln waren atrophisch und im Tonus erhöht. Die Progredienz war bei dieser Linie schnell und mit lethalem Ausgang, so daß die Mäuse in der Regel nach ein bis zwei Wochen so beeinträchtigt waren, daß sie sich nicht mehr fortbewegen konnten. In diesem Stadium waren die hinteren Extremitäten maximal extendiert.

Die Linie M57A30P fiel insbesondere durch motorische Unruhe auf, so daß sie unkontrolliert über den Tisch rannten und sprangen ohne auf Hindernisse zu achten. Später im Verlauf wurde auch eine Parese und Atrophie der hinteren Extremitäten deutlich. Die Linien F12A53T und M58A53T hatten als Leitsymptom eine Bewegungsstarre, die insbesondere bei ersterer deutlich ausgeprägt war (Abb. 17). Die Mäuse verharrten bis zu einer Minute in einer unergonomischen Haltung, in der sie über den Tisch geschoben werden konnten. Löste sich diese Starre, so fielen sie durch einen gesteigerten Bewegungsdrang auf. Bei der Linie F12A53T entwickelte sich später eine Flexion der Wirbelsäule. Die Progredienz der Symptome war eher langsam, so daß über Wochen keine Verschlechterung feststellbar war. Die Linien M13A53T und M28A53T waren insbesondere in ihrer Bewegung gesteigert, so daß sie beim Öffnen der Käfige aus diesen sprangen. Bei den Linien M70A53T und M78A53T fiel als erstes eine Parese der hinteren Extremität auf, wobei die Progredienz im Vergleich zur Linie M49A30P wesentlich langsamer war.

\subsection{Symptomverstärkung in doppelt-transgenen Mäusen}

Um die Wirkung einer gleichzeitigen Expression beider Parkinson-Mutationen zu untersuchen, wurden doppelt-transgene Mäuse erstellt. Hierzu wurden die beiden Linien, die die höchsten transgenen Proteinmengen exprimierten, M49A30P und M70A53T, miteinander gekreuzt. Um den Genotyp der Nachkommen zu bestimmen, wurde die mit der Punktmutation eingefügte Markersequenz verwendet. Das A53T-Allel konnte spezifisch mit dem Primerpaar 2474/2473 amplifiziert werden. Nach Amplifikation mit dem Primerpaar 1333/1334 konnte das PCRProdukt vom A30P-Allel mit SmaI und vom A53T-Allel mit NcoI geschnitten werden. NcoI schnitt in beiden Allelen zusätzlich am Startcodon, so daß das NcoI-verdaute PCR-Produkt kleiner war als das unverdaute. Die möglichen Genotypen konnten somit durch die spezifischen Restriktionsmuster identifiziert werden (Abb. 16). Bei den doppelt transgenen Mäusen ergab die PCR mit dem Primerpaar 1333/1334 ein Mischprodukt, von denen ein Teil mit SmaI und der andere mit NcoI geschnitten werden konnte. Die PCR-Produktmenge vom A30P-Allel war 
wesentlich höher als die vom A53T-Allel, was wahrscheinlich durch eine höhere Kopienzahl bedingt war.

Die doppelt-transgenen Mäuse entwickelten wesentlich früher (nach ca. 30 Tagen) neurologische Ausfallserscheinungen (Tab. 3; Abb. 17). Die bisher erzeugten drei Mäuse zeigten eine Wachstumsretardierung und ein kleinschrittiges tippelndes und breitbasiges Gangbild. Insgesamt waren die Veränderungen wie schon in den einzel-transgenen Linien in den hinteren Extremitäten betont.

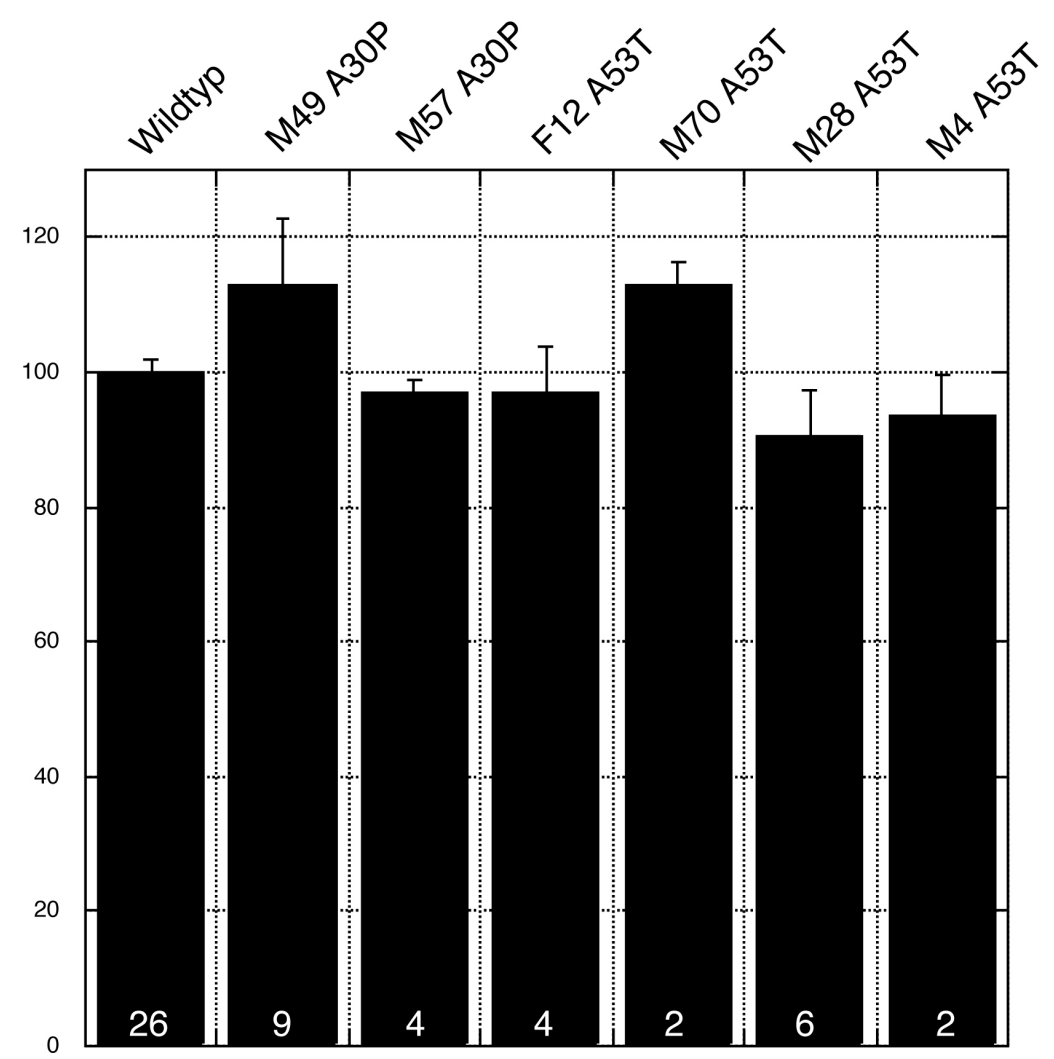

Abb. 18:Dopamingehalt im Striatum $\alpha$-Synuclein-transgener Mäuse. Deproteinierte Extrakte aus dem Striatum symptomatischer transgener Mäuse wurden gewonnen und die Dopaminmengen und seine Metaboliten DOPAC und Homovanillinsäure über HPLC bestimmt. Kumulierte Werte sind relativ zu Wildtyp-Kontrolltieren aufgetragen. Die Anzahl der untersuchten Tiere ist im Fuß der Balken angegeben.

\subsection{Symptomatik bei Imitierung eines konstitutiv phosphorylierten Serin-87}

$\mathrm{Da}$ in den Maus- und Ratten-Orthologen von $\alpha$-Synuclein als auch im $\beta$ - und $\gamma$-Synuclein an dieser Position ein Asparagin enthalten ist, wurde getestet, ob eine Phosphorylierung einen Einfluß auf die Pathogenese haben könnte. Mit der Mutation S87D wurde ein konstitutiv phosphoryliertes Serin imitiert.

Interessanterweise entwickelten drei der Ur-Transgenen Symptome in Form einer Wachstumsretardierung. In den etablierten Linien war der Symptombeginn in zweien im Vergleich zu den A30P- und A53T-Linien früher. So waren die Mäuse nach Kreuzung in die $\alpha$-SynucleinNullmutanten-Linie bereits nach 24 bzw. 54 Tagen neurologisch auffällig. Bei der Linie M12A30P S87D stand eine Bewegungsunruhe im Vordergrund. Als weitere Symptome fielen eine Ataxie und eine leichte Bewegungsstarre auf, die jedoch nicht so ausgeprägt war wie bei der 
Linie F12A53T. Die symptomatische Maus der Linie F11A30PS87D verstarb bereits am Tag der Symptomfeststellung und weitere transgene Nachkommen wurden bisher nicht erhalten.

\subsection{Vergleich der Expressionsstärke mit der Schwere der neurologischen Ausfälle}

Um die Symptomschwere und deren Beginn mit der Expressionsstärke des transgenen Konstruktes $\mathrm{zu}$ vergleichen, wurden die $\alpha$-Synuclein-Mengen in den transgenen Linien quantifiziert (Tab. 3). Die Bestimmung erfolgte vorwiegend an symptomatischen und alten (mehr als 6 Monate) Tieren. Im Vordergrund stand die Untersuchung des dopaminergen Systems, das überwiegend in frontale Gehirnabschnitte projiziert. Ungereinigte Synaptosomenfraktionen (P2) aus dem Frontalhirn (Cortex und Zwischenhirn) wurden gewonnen und die $\alpha$-Synuclein-Mengen durch quantitative Immunoblotanalyse bestimmt. Im Vergleich zu den $\alpha$-Synuclein-Mengen in Wildtyp-Mäusen waren die transgenen Expressionsmengen bis zu mehr als dreimal so hoch. Bei den einzel-transgenen Linien mit den Parkinson-Mutationen zeigte die Mauslinie M49A30P mit der schnellsten Progression der neurologischen Symptomatik auch die höchsten Expressionsraten. Die doppelt transgenen Mäuse wurden schon nach wenigen Wochen symptomatisch. Es fiel auf, daß die Expressionsmengen in ihnen geringer waren als die in der M49A30P-Linie, aus der sie generiert wurden. Wurden noch nicht symptomatische einzel-transgene Geschwistertiere untersucht, so betrug die Menge in den doppelt-transgenen Tieren soviel wie die Summe der Mengen in den einzel-transgenen. Die Expression der beiden $\alpha$-Synuclein-Mutanten erfolgte somit unabhängig voneinander, so daß die erhöhte transgene Proteinmenge für den frühen Symptombeginn verantwortlich schien. Die erhöhten Proteinmengen in alten Tieren deuteten entweder auf Proteinakkumulation oder -ablagerungen oder eine Erhöhung der Expressionsraten des transgenen Konstruktes mit zunehmendem Alter hin.

Die Linien mit den schwersten Verläufen der neurologischen Ausfälle waren auch die Linien mit den höchsten Expressionsraten der Parkinson-Mutationen. Die Expressionsraten des transgenen $\alpha$-Synuclein der Linien M78A53T und F89A53T betrugen nur ca. die Hälfte der Wildtyp$\alpha$-Synuclein-Mengen. Eine dieser beiden Linien entwickelte erst sehr spät leichte neurologische Veränderungen. Für die Entwicklung neurologischer Ausfälle war eine Überexpression der mutierten $\alpha$-Synuclein-Formen insofern nicht essentiell.

Die Linie F11A30P S87D entwickelte sehr früh Symptome, deren Progredienz vergleichbar schnell wie bei der Linie M49A30P war. Die Expressionsrate der Linie M12A30P S87D und auch der symptomatischen Ur-Transgene lag deutlich unterhalb der Linie M49A30P, so daß die zusätzliche Mutation S87D eine Beschleunigung der transgen hervorgerufenen Pathogenese bewirkte.

\subsection{Einfluß der $\alpha$-Synuclein-Mutanten auf das dopaminerge System}

Um zu untersuchen, ob die neurologischen Symptome durch Veränderungen im dopaminergen System hervorgerufen wurden, wurden Mäuse im späten Stadium der Ausfallserscheinungen morphologisch, neurochemisch und biochemisch untersucht. Die bisherigen immunhistochemischen Ergebnisse, die in der Abteilung für Neuropathologie der Southwestern Medical Center in Dallas (USA) durchgeführt wurden, zeigten keine wesentlichen Zell- und Synapsen- 
verluste im Striatum und der Substantia nigra. Auch Einschlußkörperchen konnten bisher nicht nachgewiesen werden.

Für eine quantitative Analyse wurde der Dopamingehalt im Striatum chromatographisch und die Menge verschiedener Proteine über Immunoblotanalyse bestimmt. Der Dopamingehalt in zwei der A30P- und vier der A53T-Linien war nicht signifikant gegenüber Wildtyp-Mäusen verändert (Abb. 18). Die doppelt-transgenen Mäuse und die A30P S87D-Linien konnten diesbezüglich noch nicht untersucht werden. Neben $\alpha$-Synuclein wurden im Striatum dopaminerge Markerproteine, $\beta$-Synuclein und weitere Kontrollproteine untersucht (Tab. 4). Die striatalen $\alpha$-Synuclein-Mengen in den A53T-Linien glichen denen, die in Synaptosomen des Frontalhirns bestimmt wurden. In den untersuchten A30P-Linien waren die transgenen Proteinmengen im Striatum jedoch wesentlich höher. So enthielten die transgenen Mäuse der Linie M49A30P $5,5 \mathrm{mal}$ so viel $\alpha$-Synuclein im Striatum als Wildtyp-Kontrolltiere, wohingegen die $\alpha$-SynucleinMengen im gesamten Frontalhirn nur 3,3mal so hoch waren. Da dieses Phänomen in mehreren Linien beobachtet und für beide Konstrukte die gleichen Promotorsequenzen verwendet wurden, könnte eine spezifische Akkumulation der A30P-Mutante im Striatum zu den erhöhten Werten geführt haben. Auch in den doppelt-transgenen Mäusen waren die striatalen Werte gegenüber den Werten des gesamten Frontalhirns erhöht. In der Linie M12A30P S87D waren die Mengen im Striatum und Frontalhirn vergleichbar, wohingegen in den beiden untersuchten symptomatischen Urtransgenen M20A30P S87D und M33A30P S87D die striatalen $\alpha$-SynucleinMengen 70 bis $80 \%$ höher waren als im gesamten Frontalhirn.

\begin{tabular}{|c|c|c|c|c|c|c|c|}
\hline & wt & M4A53T & F12A53T & M28A53T & M70A53T & M87A53T & F89A53T \\
\hline$\alpha$-Synuclein & $\begin{array}{c}100 \pm 5 \\
(23)\end{array}$ & $\begin{array}{c}123 \pm 7 \\
(7)\end{array}$ & $\begin{array}{l}\mathbf{2 6 2} \pm \mathbf{8} \\
\text { (4) }\end{array}$ & $\begin{array}{c}122 \pm 14 \\
(11)\end{array}$ & $\begin{array}{c}260 \pm 26 \\
(5)\end{array}$ & $\begin{array}{c}155 \pm 8 \\
\text { (2) }\end{array}$ & $\begin{array}{c}54 \pm 1 \\
(2)\end{array}$ \\
\hline$\beta$-Synuclein & $\begin{array}{c}100 \pm 3 \\
(19)\end{array}$ & $\begin{array}{c}95 \pm 4 \\
(6)\end{array}$ & $\begin{array}{c}86 \pm 10 \\
(4)\end{array}$ & $\begin{array}{c}81 \pm \mathbf{4} \\
(7)\end{array}$ & $\begin{array}{c}70 \pm 6 \\
(5)\end{array}$ & $\begin{array}{c}99 \pm 8 \\
(2)\end{array}$ & $\begin{array}{c}136 \pm 10 \\
(2)\end{array}$ \\
\hline GAPDH & $\begin{array}{c}100 \pm 2 \\
(23)\end{array}$ & $\begin{array}{c}109 \pm 3 \\
(7)\end{array}$ & $\begin{array}{c}99 \pm 2 \\
(4)\end{array}$ & $\begin{array}{c}112 \pm 6 \\
(11)\end{array}$ & $\begin{array}{c}101 \pm 5 \\
(5)\end{array}$ & $\begin{array}{c}103 \pm 0 \\
(2)\end{array}$ & $\begin{array}{c}98 \pm 3 \\
(2)\end{array}$ \\
\hline VMAT 2 & $\begin{array}{c}100 \pm 2 \\
(23)\end{array}$ & $\begin{array}{c}138 \pm 10 \\
(6)\end{array}$ & $\begin{array}{c}88 \pm 8 \\
(4)\end{array}$ & $\begin{array}{c}100 \pm 6 \\
(7)\end{array}$ & $\begin{array}{c}101 \pm 8 \\
(5)\end{array}$ & $\begin{array}{c}103 \pm 2 \\
(2)\end{array}$ & $\begin{array}{c}90 \pm 5 \\
(2)\end{array}$ \\
\hline DAT & $\begin{array}{c}100 \pm 3 \\
(19)\end{array}$ & & $\begin{array}{c}99 \pm 10 \\
(4)\end{array}$ & $\begin{array}{c}97 \pm 4 \\
(5)\end{array}$ & $\begin{array}{c}104 \pm 1 \\
(3)\end{array}$ & $\begin{array}{c}105 \pm 1 \\
(2)\end{array}$ & $\begin{array}{c}107 \pm 7 \\
(2)\end{array}$ \\
\hline TH & $\begin{array}{c}100 \pm 2 \\
(19)\end{array}$ & $\begin{array}{c}113 \pm 7 \\
(2)\end{array}$ & $\begin{array}{c}100 \pm 3 \\
(4)\end{array}$ & $\begin{array}{c}107 \pm 4 \\
(5)\end{array}$ & $\begin{array}{c}100 \pm 4 \\
(5)\end{array}$ & $\begin{array}{c}115 \pm 3 \\
(2)\end{array}$ & $\begin{array}{c}100 \pm 4 \\
(2)\end{array}$ \\
\hline NR1 & $\begin{array}{c}100 \pm 2 \\
(23)\end{array}$ & $\begin{array}{c}100 \pm 6 \\
(6)\end{array}$ & $\begin{array}{c}92 \pm 6 \\
(4)\end{array}$ & $\begin{array}{c}101 \pm 6 \\
(7)\end{array}$ & $\begin{array}{c}102 \pm 2 \\
(5)\end{array}$ & $\begin{array}{c}133 \pm 5 \\
(2)\end{array}$ & $\begin{array}{c}83 \pm 4 \\
(2)\end{array}$ \\
\hline Rab3A & $\begin{array}{c}100 \pm 2 \\
(11)\end{array}$ & & & $\begin{array}{c}103 \pm 2 \\
(2)\end{array}$ & $\begin{array}{c}96 \pm 5 \\
(2)\end{array}$ & & \\
\hline Rab3B & $\begin{array}{c}100 \pm 3 \\
(19)\end{array}$ & $\begin{array}{c}94 \pm 8 \\
(7)\end{array}$ & $\begin{array}{c}105 \pm 12 \\
(4)\end{array}$ & $\begin{array}{c}110 \pm 7 \\
(11)\end{array}$ & $\begin{array}{c}101 \pm 16 \\
(5)\end{array}$ & $\begin{array}{c}90 \pm 19 \\
(2)\end{array}$ & $\begin{array}{c}89 \pm 5 \\
(2)\end{array}$ \\
\hline Rab3C & $\begin{array}{c}100 \pm 2 \\
(12)\end{array}$ & $\begin{array}{c}96 \pm 6 \\
(6)\end{array}$ & $\begin{array}{c}106 \pm 5 \\
(4)\end{array}$ & $\begin{array}{c}91 \pm 3 \\
(5)\end{array}$ & $\begin{array}{c}99 \pm 6 \\
(3)\end{array}$ & $\begin{array}{c}109 \pm 1 \\
(2)\end{array}$ & $\begin{array}{c}93 \pm 10 \\
(2)\end{array}$ \\
\hline
\end{tabular}




\begin{tabular}{|c|c|c|c|c|c|c|}
\hline & wt & M48A30P & M49A30P & M57A30P & $\begin{array}{l}\text { M70A53T } \\
\text { M49A30P }\end{array}$ & $\begin{array}{c}\text { M12A30P } \\
\text { S87D }\end{array}$ \\
\hline$\alpha$-Synuclein & $\begin{array}{c}100 \pm 5 \\
(23)\end{array}$ & $\begin{array}{c}265 \pm 88 \\
\text { (2) }\end{array}$ & $\begin{array}{c}\mathbf{5 5 0} \pm \mathbf{3 1} \\
(10)\end{array}$ & $\begin{array}{c}491 \pm 63 \\
(4)\end{array}$ & $\begin{array}{c}511 \pm 39 \\
(3)\end{array}$ & $\begin{array}{c}277 \pm \mathbf{1 5} \\
(2)\end{array}$ \\
\hline$\beta$-Synuclein & $\begin{array}{c}100 \pm 3 \\
(19)\end{array}$ & $\begin{array}{c}165 \pm 7 \\
\text { (2) }\end{array}$ & $\begin{array}{c}94 \pm 5 \\
(9)\end{array}$ & $\begin{array}{c}105 \pm 6 \\
(4)\end{array}$ & $\begin{array}{c}55 \pm 17 \\
(3)\end{array}$ & $\begin{array}{c}82 \pm 4 \\
(2)\end{array}$ \\
\hline GAPDH & $\begin{array}{c}100 \pm 2 \\
(23)\end{array}$ & $\begin{array}{c}100 \pm 2 \\
(2)\end{array}$ & $\begin{array}{c}98 \pm 3 \\
(10)\end{array}$ & $\begin{array}{c}103 \pm 8 \\
(4)\end{array}$ & $\begin{array}{c}101 \pm 2 \\
(3)\end{array}$ & $\begin{array}{c}96 \pm 5 \\
(2)\end{array}$ \\
\hline VMAT 2 & $\begin{array}{c}100 \pm 2 \\
(23)\end{array}$ & $\begin{array}{c}94 \pm 1 \\
(2)\end{array}$ & $\begin{array}{c}91 \pm 6 \\
(9)\end{array}$ & $\begin{array}{c}97 \pm 6 \\
(3)\end{array}$ & $\begin{array}{c}84 \pm 12 \\
(3)\end{array}$ & $\begin{array}{c}106 \pm 8 \\
(2)\end{array}$ \\
\hline DAT & $\begin{array}{c}100 \pm 3 \\
(19)\end{array}$ & & $\begin{array}{c}112 \pm 7 \\
(9)\end{array}$ & $\begin{array}{c}91 \pm 10 \\
(4)\end{array}$ & $\begin{array}{l}104 \\
(1)\end{array}$ & \\
\hline TH & $\begin{array}{c}100 \pm 2 \\
(19)\end{array}$ & $\begin{array}{c}103 \pm 6 \\
(2)\end{array}$ & $\begin{array}{c}105 \pm 3 \\
(9)\end{array}$ & $\begin{array}{c}114 \pm 2 \\
(4)\end{array}$ & $\begin{array}{l}100 \\
(1)\end{array}$ & $\begin{array}{c}105 \pm 2 \\
\text { (2) }\end{array}$ \\
\hline NR1 & $\begin{array}{c}100 \pm 2 \\
(23)\end{array}$ & $\begin{array}{c}91 \pm 9 \\
(2)\end{array}$ & $\begin{array}{c}103 \pm 6 \\
(9)\end{array}$ & $\begin{array}{c}110 \pm 7 \\
(4)\end{array}$ & $\begin{array}{c}117 \pm 13 \\
\text { (3) }\end{array}$ & $\begin{array}{c}102 \pm 2 \\
(2)\end{array}$ \\
\hline Rab3A & $\begin{array}{c}100 \pm 2 \\
(11)\end{array}$ & & $\begin{array}{c}97 \pm 3 \\
(5)\end{array}$ & & & \\
\hline Rab3B & $\begin{array}{c}100 \pm 3 \\
(19)\end{array}$ & $\begin{array}{c}133 \pm \mathbf{3} \\
(2)\end{array}$ & $\begin{array}{c}129 \pm 4 \\
(10)\end{array}$ & $\begin{array}{c}89 \pm 10 \\
(3)\end{array}$ & $\begin{array}{c}118 \pm 14 \\
\text { (3) }\end{array}$ & $\begin{array}{c}112 \pm 6 \\
(2)\end{array}$ \\
\hline Rab3C & $\begin{array}{c}100 \pm 2 \\
(12)\end{array}$ & $\begin{array}{c}99 \pm 1 \\
(2)\end{array}$ & $\begin{array}{c}105 \pm 4 \\
(4)\end{array}$ & $\begin{array}{c}95 \pm 5 \\
(4)\end{array}$ & $\begin{array}{c}89 \pm 7 \\
(3)\end{array}$ & $\begin{array}{c}99 \pm 3 \\
(2)\end{array}$ \\
\hline
\end{tabular}

Tab. 4: Quantifizierung der Proteinlevel im Striatum in $\alpha$-Synuclein transgenen Linien. Postnukleäre Überstände wurden über SDS-PAGE aufgetrennt und Immunoblotanalyse radioaktiv quantifiziert. Mittelwerte \pm Standardfehler der analysierten Mäuse (Anzahl in Klammern) wurden relativ zu Wildtyp-Kontrolltieren bestimmt. Statistisch signifikante Unterschiede im Vergleich zu Wildtyp-Kontrollen (Ttest: $\mathrm{p}<0,05$ ) sind in Fett dargestellt.

In den $\alpha$-Synuclein-Nullmutanten hatte die Abwesenheit von $\alpha$-Synuclein zu einer leichten Erhöhung der $\beta$-Synuclein-Mengen geführt. In den transgenen Mäusen wurde nun untersucht, inwieweit die Überexpression der $\alpha$-Synuclein-Mutanten einen Einfluß auf die $\beta$-SynucleinMengen im Striatum hatte. Vier der sechs untersuchten A53T- und zwei der drei untersuchten A30P-Linien zeigten keine Veränderung der $\beta$-Synuclein-Mengen. Die Linien M28A53T und M70A53T zeigten eine Reduktion von 20 bis $30 \%$, wohingegen die $\beta$-Synuclein-Mengen in der Linie M48A30P um 65 \% erhöht waren. Auch in den doppelt-transgenen Mäusen zeigte sich eine deutliche Reduzierung der $\beta$-Synuclein-Mengen, die jedoch sehr variabel und insofern bei drei untersuchten Tieren nicht statistisch signifikant war. In der Linie M12A30P S87D war die Reduktion um $\sim 20 \%$ bei bisher zwei analysierten Tieren noch nicht gesichert. Überraschenderweise korrelierten die $\beta$-Synuclein-Veränderungen nicht mit den Überexpressionsraten von $\alpha$-Synuclein. Bei Überexpression wurden sowohl eine Steigerung, als auch eine Reduktion oder keine Veränderung der $\beta$-Synuclein-Mengen gefunden. Wie in Abb. 7 gezeigt exprimierten die meisten Synapsen $\alpha$ - und $\beta$-Synuclein gleichzeitig, andere jedoch nur eine beider Isoformen. Insofern könnte das Expressionsmuster des transgenen $\alpha$-Synuclein einen Einfluß auf die $\beta$-Synuclein-Mengen haben. Dies wird noch mit Hilfe der Immunhistochemie untersucht werden. Die dopaminergen Marker VMAT 2, DAT und TH waren nur in vier Linien deutlich verändert. In der Linie M4A53T, die nur eine moderate Überexpression des mutierten $\alpha$-Synuclein zeigte, waren die VMAT 2 Mengen um $40 \%$ gesteigert. In den doppelt-transgenen Mäusen und der F12A53T-Linie waren diese im Gegensatz dazu um 12 bis $16 \%$ reduziert, wobei dieser Wert wiederum durch mehr analysierte Tiere abgesichert werden müßte. Tyrosinhydroxylase war nur 
in der Linie M57A30P signifikant um $14 \%$ erhöht und DAT war in allen untersuchten Linien unverändert. Insbesondere war eine Reduktion der VMAT 2-Mengen nicht mit einer Reduktion der DAT-Mengen korreliert. In der Linie F12A53T bewirkte die Reduktion des dopaminergen Vesikelmarkers keine Reduktion des striatalen Dopamingehaltes, so daß eventuell die zytoplasmatische Konzentration erhöht war. In diesem Fall wäre eine Reduktion der vesikulären Dopaminaufnahme zu erwarten, die noch untersucht wird. Zusammengenommen zeigten diese Ergebnisse, daß weder die morphologischen, noch die neurochemischen oder biochemischen Paramter des nigrostriatalen Systems wesentlich verändert waren und daher keine Erklärung für die beobachteten neurologischen Veränderungen liefern.

Als Kontrolle wurden die Mengen von GAPDH, NR1 und drei Rab3-Isoformen bestimmt. GAPDH, NR1, Rab3A und $\mathrm{C}$ waren in den einzelnen Linien nicht signifikant verändert. Überraschenderweise waren in zwei A30P-Linien die Rab3B-Mengen um $30 \%$ erhöht. Die Rab3-Isoformen weisen ein unterschiedliches synaptisches Expressionsmuster auf (Schlüter 2000). Somit könnte die selektive Erhöhung von Rab3B auf eine Beeinflussung nur eines Subtyps von Synapsen durch die Überexpression von $\alpha$-Synuclein A30P hindeuten.

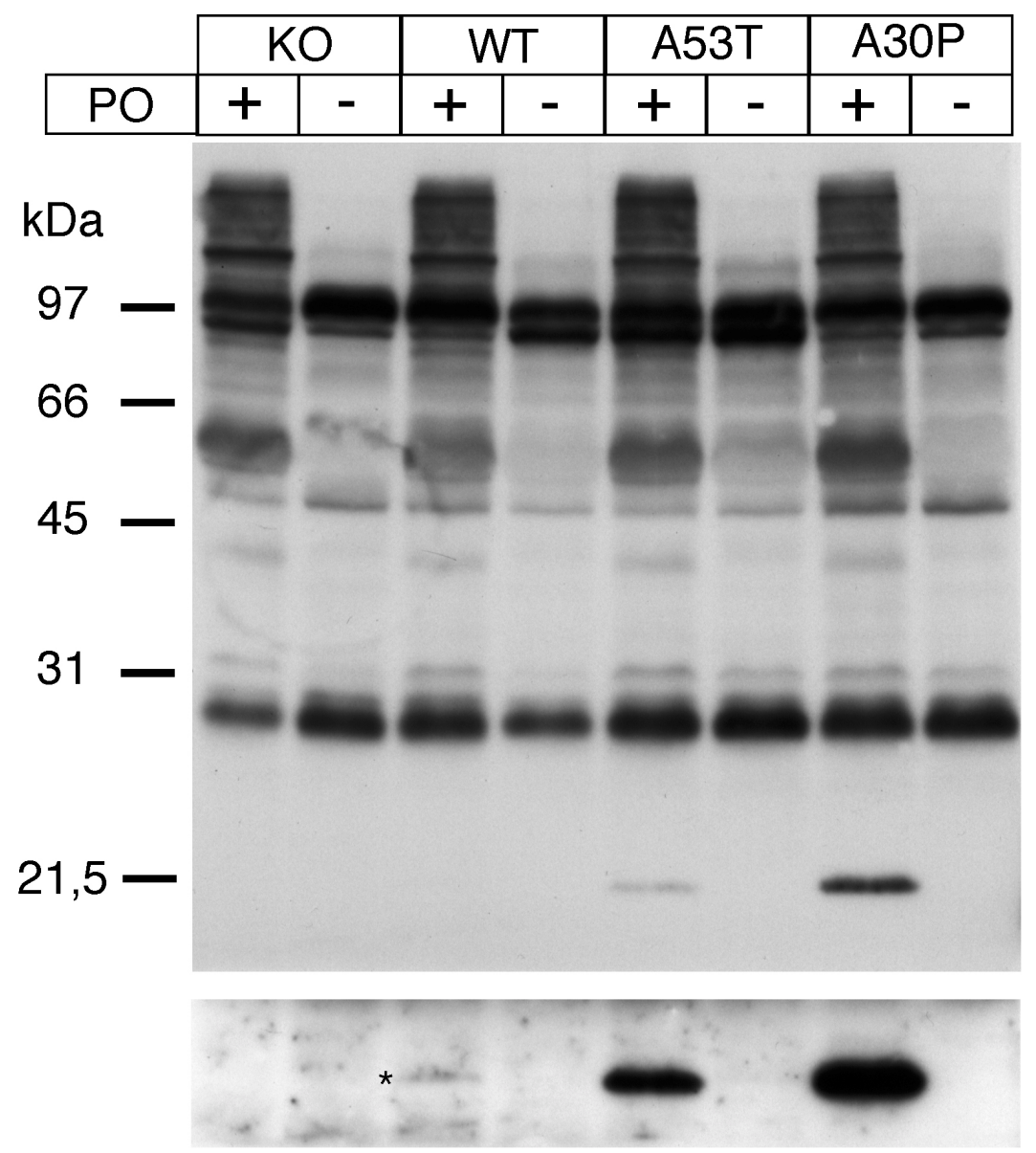

Abb. 19:Immunoblotanalyse von nitrosylierten Tyrosinresten in postnukleären Überständen. Proben von Q-Synuclein-Nullmutanten (KO), Wildtyp-Mäusen, der transgenen Linien M49A30P und M70A53T wurden mit Peroxynitrit $(\mathrm{PO}+)$ oder als Kontrolle mit der Trägersubstanz Natronlauge (PO -) inkubiert. $80 \mu \mathrm{g}$ Gesamtprotein wurden auf einem $12 \%$ igem Gel aufgetrennt und über Immunoblotanalyse mit einem Nitrotyrosin-spezifischen Antikörper (HM11) und ECL-Detektion analysiert. Unten ist eine längere Exposition dargestellt, um die mit einem Sternchen markierte schwache Bande in Wildtyp-Mäusen darzustellen. 


\subsection{In-vitro-Nitrosylierung von $\alpha$-Synuclein}

In Lewy-Körpern konnte eine Nitrosylierung von Tyrosinresten von $\alpha$-Synuclein nachgewiesen werden (Giasson et al. 2000). MPTP-Administration führt akut ebenfalls zur Nitrosylierung von Tyrosinhydroxylase und $\alpha$-Synuclein (Ara et al. 1998; Przedborski et al. 2001). Um zu testen, ob $\alpha$-Synuclein in den am stärksten symptomatischen transgenen Mäusen auf diese Art modifiziert ist, wurden Gewebehomogenate mit einem Nitrotyrosin-spezifischen Antikörper analysiert (Abb. 19). Als Positivkontrolle wurden die Proben mit Peroxynitrit behandelt. In den beiden analysierten transgenen Linien konnten Nitrotyrosinreste nur nach Peroxynitritbehandlung nachgewiesen werden. Nur nach langer Exposition konnte auch in behandelten Proben von Wildtyp-Mäusen ein schwaches Signal detektiert werden, welches auf modifiziertes $\alpha$-Synuclein zurückzuführen war, da es nicht in der unbehandelten Probe und auch nicht in den $\alpha$-SynucleinNullmutanten auftrat. Die $\alpha$-Synuclein-Expressionsmengen lagen in den transgenen Mäusen drei bis fünffach über den Wildtyp-Mäusen. Daher liegt zumindest der Großteil des transgen exprimierten $\alpha$-Synuclein nicht nitrosyliert vor. 


\section{Diskussion}

Die Identifizierung von Punktmutationen im $\alpha$-Synuclein-Gen in familiären Formen der Parkinson-Syndrome demonstrierte eine molekulare Beteiligung von $\alpha$-Synuclein an der Pathogenese einer Gruppe von autosomal dominanten Formen der Parkinson-Erkrankung (Polymeropoulos et al. 1997; Krüger et al. 1998). Da $\alpha$-Synuclein ein Hauptbestandteil der Lewy-Körper, den charakteristischen pathomorphologischen Veränderungen der Parkinson-Erkrankung, bildet, ist eine Beteiligung auch an der idiopathischen Form wahrscheinlich (Spillantini et al. 1998; Spillantini et al. 1997). In dieser Arbeit wurde die synaptische und pathogenetische Funktion von $\alpha-$ Synuclein untersucht.

\subsection{Physiologische Funktion von $\alpha$-Synuclein}

$\alpha$-Synuclein ist ein abundantes lösliches Protein der Präsynapse. In vitro bindet es an Vesikel mit einem hohen Anteil von sauren Phospholipiden (Davidson et al. 1998). Die Bindung wird von einer drastischen Konformationsänderung begleitet, während der das ungefaltete Protein eine überwiegend $\alpha$-helikale Struktur annimmt (Davidson et al. 1998; Weinreb et al. 1996). An welche Membranen $\alpha$-Synuclein in Neuronen bindet ist nicht geklärt. So zeigten Untersuchungen eine Assoziation mit synaptischen Vesikeln, Endozytosevesikeln aber auch der Plasmamembran (Clayton und George 1999; George et al. 1995; Leng et al. 2001). In der in dieser Arbeit durchgeführten subzellulären Fraktionierung wurden $\alpha$ - und $\beta$-Synuclein eindeutig in der Zytoplasmafraktion der Synapse nachgewiesen. Eine Membranbindung ist daher entweder transienter Natur oder auf eine Subpopulation des Proteins beschränkt, so daß der Großteil des Proteins gelöst vorliegt. Eine zytosolische Lokalisation wird auch durch die Interaktion mit Synphilin-1 gestüzt (Engelender et al. 1999). Synphilin-1 ist ebenfalls ein lösliches Protein und neben $\alpha$-Synuclein Bestandteil von Lewy-Körpern (Wakabayashi et al. 2000). Die Funktion von Synphilin-1 ist unbekannt, so daß sich auch keine Anhaltspunkte für die Funktion von $\alpha$-Synuclein ergeben. Ein weiterer Interaktionspartner von $\alpha$-Synuclein ist Phospholipase D2 (PLD2) (Jenco et al. 1998). Dieses Enzym ist an die Plasmamebran gebunden und hydrolysiert Phosphatidylcholin in Cholin und Phosphatidsäure (Exton 1997). Diese Funktion kann in vitro effizient durch $\alpha$ - und $\beta$-Synuclein inhibiert werden. Eine erhöhte Phospholipaseaktivität stimuliert die Endozytose, so daß $\alpha$-Synuclein als Regulator der enzymatischen Aktivität von PLD2 an der Endozytose beteiligt sein könnte. Die Endozytose ist ein integraler Schritt des synaptischen Vesikelzyklus. Ihre Veränderung bzw. Störung führt daher ultimativ zu Veränderungen der Anzahl synaptischer Vesikel. Diese wurde in neuronalen Primärkulturen untersucht, wobei eine Reduzierung der $\alpha$-Synuclein-Expression zu einer Abnahme des synaptischen Vesikelpools führte (Murphy et al. 2000). Dieses Ergebnis war überraschend, da die durch $\alpha$-Synucleinreduzierung aufgehobene Inhibition der Phospholipase D2 zu einer erhöhten Endozytoserate führen sollte.

Um die in vitro charakterisierten Funktionen von $\alpha$-Synuclein im lebenden Organismus zu validieren, wurden im Rahmen dieser Arbeit $\alpha$-Synuclein-Mausnullmutanten erzeugt und charakterisiert. In einer detaillierten Analyse der synaptischen Proteinkomposition und Gehirnmorphologie konnten in den $\alpha$-Synuclein-Nullmutanten keine signifikanten Veränderungen festgestellt werden. Somit wird $\alpha$-Synuclein nicht für die Entwicklung und Aufrechterhaltung 
einer normalen Gehirnfunktion und -zusammensetzung benötigt. In einer unabhängigen Studie, die mit Hilfe anderer Methoden ebenfalls keine wesentlichen Veränderungen in ihren $\alpha$ Synuclein-Nullmutanten aufzeigen konnten, wurden diese Ergebnisse bestätigt (Abeliovich et al. 2000). $\alpha$-Synuclein ist für die normale Funktion des Gehirns somit nicht essentiell. Dies wird auch durch die Tatsache verdeutlicht, daß die in dieser Arbeit entdeckte spontane Deletion des $\alpha$-Synuclein-Gens in einer von vielen Forschungseinrichtungen genutzten und analysierten Mausinzuchtlinie bisher verborgen geblieben war.

Synuclein tritt phylogenetisch erst spät in Erscheinung. So fehlen in Invertebraten SynucleinOrthologe und erst in Vertebraten ist das Protein erstmals vorhanden. Daher scheint es wahrscheinlich, daß neuronale Verschaltungen prinzipiell ohne Synuclein funktionieren können. Die Funktion des Proteins hängt wahrscheinlich mit den spezifischen Anforderungen an die neuronalen Netzwerke höherentwickelter Lebewesen zusammen.

In Mäusen werden vier Synuclein-Paraloge exprimiert. $\alpha$ - und $\beta$-Synuclein werden in einem Großteil der Synapsen koexprimiert. Aufgrund der hohen Sequenzübereinstimmung ist es möglich, daß $\beta$-Synuclein eine essentielle Funktion von $\alpha$-Synuclein in Mäusen maskiert. Funktionelle Redundanz ist ein generelles Problem bei der Erstellung von Maus-Nullmutanten. So wurde z.B. die essentielle Funktion des synaptischen Proteins Rab3 in Mäusen erst durch die Deletion aller vier Isoformen deutlich (Schlüter 2000). Im Wurm Caenorabditis elegans führte die Ausschaltung des entsprechenden Paralogen nur zu vergleichsweise milden Veränderungen (Nonet et al. 1997). Letzte Sicherheit gäbe somit nur die parallele Ausschaltung aller SynucleinGene.

Leichte Veränderungen in $\alpha$-Synuclein-Mausnullmutanten wurden im dopaminergen System gefunden (Abeliovich et al. 2000). Durch die Deletion dieses Proteins ist die Dopaminfreisetzung im Striatum erhöht, wohingegen keine Unterschiede im Hippokampus gefunden wurden. Diese selektive Beeinflussung des dopaminergen Systems ist insofern überraschend, als im Striatum die $\alpha$-Synuclein-Mengen vergleichsweise gering sind. Andererseits sind die nigrostiratalen Neurone beim Morbus Parkinson als erstes betroffen, so daß diese Neuronen besonders sensibel auf Veränderungen der Synucleinfunktion reagieren könnten. Ein direkter Einfluß von $\alpha$ Synuclein auf den Dopamintransport konnte in der vorliegenden Arbeit weder auf Ebene des Plasmamembrantransports noch des vesikulären Transports nachgewiesen werden. Somit ist die erhöhte Dopaminfreisetzung am ehesten auf einen veränderten Vesikeltransport zurückzuführen. Auf eine regulatorische Funktion von $\alpha$ - und $\beta$-Synuclein deutet die direkte Wechselwirkung mit Signaltransduktionskaskaden über die Phospholipase D2 und die phosphorylierungsabhängige Modulation dieser Funktion durch G-Protein-gekoppelte Rezeptorkinasen hin (Jenco et al. 1998; Pronin et al. 2000). Inwieweit auch die Serin-Phosphorylierung über Casein-Kinase oder die Tyrosin-Phosphorylierung über Src-Kinase physiologisch bedeutsam sind und eine reversible Membranassoziation bewirken, bleibt zu zeigen (Okochi et al. 2000; Ellis et al. 2001; Leng et al. 2001). Die Funktion von $\alpha$-Synuclein ist nicht nur auf ein Transmittersystem beschränkt, wie die breite Verteilung in verschiedenen Hirnregionen zeigt. Prinzipiell sollten Veränderungen daher in allen involvierten Synapsen evident werden. 


\subsection{Pharmakologisch induziertes Parkinson-Syndrom}

MPTP induziert einen selektiven Untergang dopaminerger Nervenendigungen und Neurone. Diese Wirkung ist bei Menschen irreversibel und die verursachten Symptome gleichen der beim Morbus Parkinson. Aufgrund dieser Tatsache wurde MPTP bevorzugt verwendet, um ein tierexperimentelles Parkinson-Syndrom zu erzeugen und untersuchen zu können. Zwischen Tierspezies gibt es jedoch bezüglich der MPTP-Sensitivität dramatische Unterschiede. Im Gegensatz zu Menschen und Affen sind bei Mäusen zehnfach höhere Dosen notwendig, um eine vergleichbare Reduktion des Dopamingehalts des nigrostriatalen Systems zu erreichen (Fornai et al. 1997b). Die Veränderungen sind in Mäusen reversibel, so daß sich das System nach mehreren Wochen wieder erholt.

Die Gemeinsamkeiten der Parkinson-Erkrankung und des durch MPTP-induzierten Syndroms sind neben der klinischen Symptomatik folgende: 1. Dopaminerge Neurone der SNC sind bevorzugt betroffen. 2. Dieses führt in beiden Fällen zu einer Reduktion der nigrostriatalen Dopaminkonzentration. 3. Die Komplex I-Aktivität der mitochondrialen Atmungskette in der SNC ist reduziert (Nicklas et al. 1985; Schapira et al. 1990). 4. Oxidative Entgleisungen sind in beiden Fällen an der Pathogenese beteiligt (Zhang et al. 2000b). So sind die Glutathion- und FerritinSpiegel in der SNC von Parkinson-Patienten reduziert und es kann eine erhöhte Lipidperoxidation nachgewiesen werden (Dexter et al. 1986; Dexter et al. 1992; Dexter et al. 1989; Dexter et al. 1990; Jellinger et al. 1993; Smith et al. 1987). Eine Auslösung oxidativer Entgleisungen durch MPTP wurde tierexperimentell nachgewiesen. Reaktive Sauerstoffspezies entstehen durch die inhibierende Wirkung von MPP+, dem aktiven MPTP-Metaboliten, auf die mitochondriale NADH-Dehydrogenase und die intrazelluläre Oxidation von Dopamin (Chan et al. 1991; Lotharius und O'Malley 2000; Lotharius et al. 1999; Nicklas et al. 1985; Ramsay et al. 1986; Ramsay et al. 1991). Mäuse, die transgen Cu/Zn-SOD oder Mn-SOD überexprimieren, zeigen eine verminderte Empfindlichkeit gegenüber MPTP, wohingegen diese in Glutathionperoxidase-, Cu/Zn-SOD und Mn-SOD-Nullmutanten gesteigert ist (Andreassen et al. 2001; Klivenyi et al. 1998; Przedborski et al. 1992; Zhang et al. 2000a).

Das entscheidende Oxidationsmittel scheint Peroxynitrit zu sein, welches durch die chemische Reaktion von Stickstoffmonoxid- und Sauerstoffradikalen gebildet wird (Good et al. 1998; Pennathur et al. 1999; Schulz et al. 1995). Ein Marker für durch Peroxynitrit verursachte Schäden ist 3-Nitrotyrosin (Beckman et al. 1990). Neueste in vitro Befunde zeigen, daß $\alpha$ Synuclein in vivo durch MPTP-Behandlung nitrotyrosyliert wird (Przedborski et al. 2001). Die Tyrosin-Nitrosylierung durch MPTP modizifiert nur wenige Proteine, unter anderem auch Tyrosinhydroxylase, deren enzymatische Aktivität so blockiert wird (Ara et al. 1998). Den Einfluß von Stickstoffmonooxid zumindest am MPTP-induzierten Parkinson-Syndrom zeigt die Verminderung der Sensitivität gegenüber MPTP durch Inhibitoren der neuronalen Stickstoffmonooxid-Synthetase (nNOS) in Primaten und die Deletion des Gens in Mäusen (Hantraye et al. 1996; Przedborski et al. 1996). Bei Ausschaltung der induzierbaren NOS (iNOS) in Gliazellen beschränkt sich die protektive Wirkung auf den verminderten Zellverlust in der SNC, nicht jedoch auf die Reduktion der dopaminergen Terminalen und Dopamin im Striatum (Dehmer et al. 2000; Liberatore et al. 1999). Oxidative Veränderungen an der DNA aktivieren das ReparaturEnzym Poly-ADP-Ribose-Polymerase (PARP). Da PARP-Inhibitoren und Nullmutationen gegenüber MPTP-Toxizität schützen, scheint der durch PARP-Aktivierung zusätzliche ATP- 
Verbrauch fatale Folgen für dopaminerge Neuronen zu haben (Cosi und Marien 1998; Mandir et al. 1999; Schulz et al. 1995).

Auch bei der Pathogenese der Parkinson-Erkrankung führen die oxidativen Entgleisungen zu einer Nitrotyrosylierung von $\alpha$-Synuclein. Diese Modifikation konnte in Lewy-Körpern immunhistochemisch nachgewiesen werden (Giasson et al. 2000). $\alpha$-Synuclein ist bisher das einzige Protein, dem eine pathogenetische Rolle beim idiopathischen Parkinson-Syndrom zugeschrieben wird.

In dieser Arbeit wurde die Annahme gemacht, daß die molekulare Pathogenese des MPTPinduzierten Parkinson-Syndroms über die oxidativen Entgleisungen in wesentlichen Aspekten der idiopathischen Form gleicht. Es wurde die Wirkung von MPTP auf $\alpha$-Synuclein-Mausnullmutanten untersucht. Die über homologe Rekombination hergestellten Nullmutanten zeigten eine deutliche Protektion gegenüber der Behandlung. Diese konnte jedoch nicht in der Mauslinie HW mit einer spontanen Deletion des $\alpha$-Synuclein-Gens bestätigt werden. Die Deletion ist kleiner als $2 \mathrm{cM}$ und betrifft höchstwahrscheinlich nur das $\alpha$-Synuclein-Gen (Specht und Schoepfer 2001). Daher fallen mögliche kompensatorische Effekte weiterer Gendeletionen außer Betracht. Im ersten Versuch wurde die HW-Linie mit C57B16/J-Mäusen verglichen, der sie ursprünglich abstammt. Die Mäuse der Linie HW sind jedoch als eigene Inzuchtlinie über Jahre bei Züchtern in England und Holland gehalten worden und weisen somit wahrscheinlich genetische Unterschiede im Vergleich zur Ursprunglinie von Jackson-Laboratories auf. Die verwendeten genetischen Tests der Züchter zeigten keine Unterschiede zu der Linie C57B16/J und so wurde sie auch als C57B16/J-Linie vertrieben, lediglich mit dem Züchterzusatz /ola/hsd. Die in dieser Arbeit identifizierte Gendeletion ist über Jahre nicht bemerkt worden. Die verwendeten Vergleichsmäuse der Linie C57B16/J entstammten dem Zuchtbetrieb CERJ und wurden regelmäßig durch Mäuse vom Zuchtbetrieb Jackson Laboratories aufgefrischt. Um auzuschließen, daß die protektive Wirkung der $\alpha$-Synuclein-Gendeletion durch weitere genetische Unterschiede in den zwei Inzuchtlinien maskiert wurden, wurde die Linie HW in Wildtyp-Mäuse zurückgekreuzt und die Nachkommen der für das $\alpha$-Synuclein heterozygoten Tiere erneut getestet. Die Gendeletion von $\alpha$-Synuclein führte auch in diesen Mäusen nicht zu einer veränderten Empfindlichkeit gegenüber MPTP oder Methamphetamin.

Wie oben beschrieben führten Veränderungen der Genexpression von Proteinen, die an der Regulation oxidativer Entgleisungen beteiligt sind, $\mathrm{zu}$ einer veränderten Empfindlichkeit gegenüber MPTP. Die Gendeletion von $\alpha$-Synuclein, dem Protein, das als einziges nachweislich an der idiopathischen Form der Parkinson-Syndrome beteiligt ist, blieb jedoch wie hier gezeigt ohne Einfluß auf die MPTP-Empfindlichkeit. Dies legt nahe, daß die molekularen Mechanismen, die einerseits zur Parkinson-Erkrankung und andererseits zum MPTP-induzierten ParkinsonSyndrom führen, unterschiedlich sind. Obwohl $\alpha$-Synuclein auch im MPTP-Modell nitrotyrosyliert wird, ist diese Veränderung nicht kausal im Zusammenhang mit den neurochemischen Veränderungen zu sehen. Dies wird auch durch das kurze Zeitfenster von nur wenigen Stunden deutlich, in der die oxidative Modifikation zu beobachten ist (Przedborski et al. 2001). Das Endresultat, die Verminderung des nigrostriatalen Dopamingehaltes, ist nicht nur diesen beiden Formen der Parkinson-Syndrome gemeinsam. Auch die Encephalitis lethargica, deren Ätiologie eine Viruserkrankung ist, und Infarkte in den Basalganglien können zu einem ParkinsonSyndrom führen (Lang und Lozano 1998). Nur in der idiopathischen und den familiären Formen mit Mutationen im $\alpha$-Synuclein Gen entstehen Lewy-Körper, so daß diese ein Charakteristikum 
der $\alpha$-Synuclein-abhängigen Syndrome zu sein scheinen. So konnten bisher auch nur in Affen Lewy-Körper-ähnliche eosinophile Einschlußkörperchen induziert werden, die $\alpha$-Synuclein und Ubiquitin enthielten, nicht jedoch die elektronenmikroskopischen Charakteristika der LewyKörper aufwiesen (Forno et al. 1993; Kowall et al. 2000). Dies schließt nicht aus, daß auch gemeinsame Aspekte zwischen den verschiedenen Syndromen vorhanden sind, wie z.B. eine Gliose in der SNC nach Untergang der Neuronen. Ein fehlender Einfluß von $\alpha$-Synuclein an der MPTP-Toxizität wurde auch in trangenen Mäusen nachgewiesen, die humane $\alpha$-SynucleinOrthologe exprimierten (Rathke-Hartlieb et al. 2001). Interessant ist in diesem Zusammenhang die Entstehung von Lewy-Körpern durch die Verwendung eines anderen mitochondrialen Toxins, dem Rotenon, in Ratten (Betarbet et al. 2000). In diesem Parkinson-Modell wurde das Toxin über einen Zeitraum von vier Wochen appliziert. Im Gegensatz zum MPTP-Modell in Mäusen zeigten die so behandelten Ratten auch für die Parkinson-Erkrankung typische Verhaltensveränderungen. $\mathrm{Ob}$ in diesem Modell $\alpha$-Synuclein eine Rolle spielt und ob es in Mäusen reproduziert werden kann, wird momentan untersucht.

Warum zeigten die hergestellten $\alpha$-Synuclein-Nullmutanten eine Protektion gegenüber MPTP? Im Gegensatz zu den HW-Mäusen haben diese Mäuse einen hybriden genetischen Hintergrund. Bei der Verpaarung der aus den Stammzellen entstanden chimären Männchen mit C57B16/JMäusen entstehen Nachkommen, deren genetische Information zur Hälfte der Mauslinie 129/Sv/ola und zur anderen Hälfte der Linie C57B16/J entstammt. Durch Rückkreuzungen in die C57B16/J-Linie kann der genetische Anteil der Linie 129/Sv reduziert werden. Die unmittelbar benachbarten Gene zu der über homologe Rekombination eingeführten Neomycin-Resistenzkassette entstammen jedoch weiterhin der 129/Sv-Linie, wohingegen das $\alpha$-Synuclein-WildtypAllel seinen Ursprung aus der C57B16/J-Linie hat. Insofern besteht die Möglichkeit, daß eines oder mehrere der gekoppelten Gene für die Protektion gegenüber der MPTP-Toxizität verantwortlich ist und $\alpha$-Synuclein keine Rolle spielt. In der Tat zeigen verschiedene Mauslinien eine unterschiedliche Empfindlichkeit gegenüber MPTP (Hamre et al. 1999). Dieser Effekt zeigt, wie wichtig die Kontrolle des genetischen Hintergrundes von transgenen Tieren sein kann. Um die Hypothese der gekoppelten Gene zu überprüfen, könnte das $\alpha$-Synuclein Wildtyp-Allel aus der Linie 129/Sv/ola in die Nullmutanten gekreuzt werden.

Methamphetamin führt wie MPTP zu einer akuten Dopaminfreisetzung. Semichronische Effekte sind jedoch unterschiedlich. Um zwischen der Wirkung von $\alpha$-Synuclein auf akute und chronische Effekte unterscheiden zu können, wurden Mäuse als Kontrolle mit Methamphetamin behandelt. Interessanterweise zeigten hier die $\alpha$-Synuclein-Nullmutanten eine erhöhte Empfindlichkeit. Diese bestätigte sich jedoch nicht bei Mäusen mit der spontanen Gendeletion, so daß die Überempfindlichkeit wiederum durch die gleichen gekoppelten Gene auf dem 129/Sv-Allel bedingt sein könnten.

\subsection{Rolle von $\alpha$-Synuclein in der Pathogenese der Parkinson- Syndrome}

Die Parkinson-Erkrankung ist eine chronisch degenerative Erkrankung insbesondere der dopaminergen Neurone der SNC. $\alpha$-Synuclein ist ein Hauptbestandteil von Lewy-Körpern, den charakteristischen pathomorphologischen Veränderungen dieser Erkrankung (Spillantini et al. 1997). Zwei Aminosäurenaustausche im $\alpha$-Synuclein führen zu familiären Formen der 
Parkinson-Syndrome, die durch einen frühen Erkrankungsbeginn gekennzeichnet sind (Polymeropoulos et al. 1997; Krüger et al. 1998). Die Ausschaltung des $\alpha$-Synuclein-Gens in Mäusen führt nicht zu einem Parkinson-Syndrom. Dies wird eindrucksvoll von der natürlich entstandenen Mauslinie HW, der das Gen fehlt, belegt. Auch in den hier hergestellten $\alpha$-Synuclein-Mausnullmutanten führte die Ausschaltung des Gens insbesondere im Alter nicht zu ParkinsonSyndromen. Die neurochemische Analyse ergab keine Hinweise auf subklinische Veränderungen des nigrostriatalen Systems. Dies legt nahe, daß es sich bei den $\alpha$-Synuclein-Mutationen A30P und A53T um gain of function-Mutationen handelt und sie nicht zu einem Funktionsverlust führen. Die dominanten Vererbungsmuster bestätigen diese Schlußfolgerung.

Um insbesondere dem chronischen Aspekt der Entstehung der Parkinson-Erkrankung Rechnung zu tragen und die pathogenetische Rolle von $\alpha$-Synuclein zu untersuchen, wurden transgene Mäuse hergestellt, die humane $\alpha$-Synuclein-Isoformen exprimieren. Die Expression der $\alpha$-Synuclein-Polymorphismen A30P und A53T führte zu neurologischen Ausfällen. Dabei zeigten sich folgende Charakteristika: 1. Die Ursprungstransgene aus der Linie FVB erkrankten nicht. Erst nach Rückkreuzung in die Hybridlinie C57B16/J x 129Sv/ola der $\alpha$-Synuclein-Nullmutanten zeigten die Mäuse Symptome. Dabei spielte der Maus- $\alpha-S y n u c l e i n-G e n o t y p$ keine Rolle. 2. Die transgenen Mäuse erkrankten erst im fortgeschrittenen Alter frühestens nach einem halben Jahr. 3. Die Schwere der Erkrankung nahm mit der Expressionsstärke zu. 4. Das Symptommuster war heterogen. Im Vordergrund standen Veränderungen des motorischen Systems mit Paresen und Muskelatrophien insbesondere der hinteren Extremität. Weitere Symptome waren Akinese, Bewegungsunruhe und Krampfanfälle.

Neurochemisch, biochemisch wie auch morphologisch ergaben sich keine Veränderungen im Striatum und der SNC, die auf ein Parkinson-Syndrom hingedeutet hätten. $\alpha$-SynucleinEinschlußkörperchen wurden auch nicht in anderen Hirnarealen gefunden. Die $\alpha-S y n u c l e i n-$ Mengen nahmen in den phänotypisch stärksten Mauslinien mit dem Alter zu. Dies legt nahe, daß die Akkumulation des humanen $\alpha$-Synuclein für die neurologischen Ausfälle verantwortlich ist. Von anderen Gruppen hergestellte transgene Mäuse, die $\alpha$-Synuclein aus Mensch exprimierten, zeigten ebenfalls motorische Störungen (Masliah et al. 2000; van der Putten et al. 2000). Die Überexpression der humanen Wildtyp-Isoform führte zur Bildung von Einschlußkörperchen, die jedoch nicht Lewy-Körpern glichen (Masliah et al. 2000). Diese enthielten ausschließlich das humane und nicht das murine $\alpha$-Synuclein. Die Symptome der erkrankten Tiere waren im Vergleich zu den in dieser Arbeit erzeugten milder. Dies legt den Schluß nahe, daß Einschlußkörperchen nicht ursächlich an der Entstehung der Erkrankung mitwirken. Möglicherweise werden durch die Überexpression von $\alpha$-Synuclein Interaktionspartner gebunden und dadurch ihre Funktion blockiert. Die Blockierung könnte dabei durch die familiären Polymorphismen A30P und A53T verstärkt sein. In der Tat wurde eine erhöhte Affinität für die humane A53TIsoform zu Synphilin-1 gemessen (Engelender et al. 1999). Synphilin-1 ist ebenfalls Bestandteil der Lewy-Körper, so daß eventuell das blockierte Protein zusammen mit $\alpha$-Synuclein in diesen abgelagert wird (Wakabayashi et al. 2000). Die Affinität der A30P-Isoform an Synphilin-1 ist vergleichbar mit der der humanen Wildtyp-Isoform. Insofern ist auch die Beeinflußung anderer Interaktionspartner wahrscheinlich.

Die juvenile rezessive Form der Parkinson-Erkrankung wird durch Mutationen im Parkin-Gen verursacht, die dieses Protein inaktivieren (Kitada et al. 1998). Wie neueste Befunde zeigen, ist dieses Protein für die Ubiquitinierung von $\alpha$-Synuclein verantwortlich (Shimura et al. 2001). 
Patienten mit der juvenilen rezessiven Form der Parkinson-Erkrankung haben keine LewyKörper. Dies legt den Schluß nahe, daß die Ubiquitinierung von $\alpha$-Synuclein für die Entstehung von Lewy-Körpern entscheidend ist. Möglicherweise beeinflußt die Überexpression von $\alpha$-Synuclein und insbesondere die von den mutierten Formen die Effizienz der Ubiquitinierung und des folgenden Abbaus durch Proteasomen, so daß der Abbau anderer Proteine gehemmt wird. In der Tat akkumulieren in Patienten mit einem Defekt im Parkin neben $\alpha$-Synuclein auch andere Proteine (Imai et al. 2001). Die Überexpression von Parkin kann in der Zellkultur den durch ungefaltete Proteine ausgelösten Zelltod inhibieren (Imai et al. 2000). Eine mögliche Wirkung der Überexpression von $\alpha$-Synuclein-Isoformen könnte daher die Ansammlung toxischer ungefalteter Proteine sein. Unterstützt wird diese Hypothese auch durch die Beobachtung, daß die $\alpha$-Synuclein-Mengen selbst mit dem Alter der transgenen Mäuse zunehmen, diese jedoch nicht in Einschlußkörperchen abgelagert sind.

Interessanterweise erkrankten auch transgene Mäuse, die nur 50-60\% der in Wildtyp-Tieren gemessenen $\alpha$-Synuclein-Mengen exprimierten. Dies könnte zweierlei Ursachen haben. 1. Die Mutation A53T inhibiert das Parkinsystem so effizient, daß auch die geringen Mengen ausreichen, um die Akkumulation toxischer Produkte zu begünstigen. 2. Die transgene Expression wird durch den Thy1-Promotor gesteuert, so daß $\alpha$-Synuclein auch in Neuronen exprimiert wird, in denen es physiologischerweise nicht vorkommt. Daher könnten diese Neuronen besonders empfindlich gegenüber den zerstörenden Effekten der humanen A53T-Isoform sein.

Eine wichtige Frage bleibt, warum die Überexpression der humanen $\alpha$-Synuclein-Isoformen zu neurologischen Ausfällen führt, die jedoch nicht einem Parkinson-Syndrom entsprechen. Die Paresen und insbesondere die Atrophie der betroffenen Muskeln spricht für einen Funktionsverlust der Motorneurone. In diesen ist $\alpha$-Synuclein normalerweise nicht enthalten, so daß diese Neuronen empfindlicher auf die Überexpression der mutierten Isoformen reagieren könnten. Veränderungen in den motorischen Endplatten wurden in einer unabhängigen Studie nachgewiesen, die das humane $\alpha$-Synuclein A53T exprimierten (van der Putten et al. 2000). Auch in diesen Mäusen waren Paresen das Leitsymptom.

$\alpha$-Synuclein ist bei mehreren neurologischen Erkrankungen in Einschlußkörperchen zu finden, so daß diese unter dem Oberbegriff der Synucleopathien zusammengefaßt wurden. Die Parkinson-Erkrankung, Demenzen mit Lewy-Körpern, Hallervorden-Spatz-Syndrom und Varianten der Alzheimer-Erkrankung haben Lewy-Körper in verschiedenen Hirnarealen, die $\alpha$ Synuclein enthalten. Unterformen der multiplen Systematrophien weisen hingegen Einschlußkörperchen (Sichelkörper) auf, die in Oligodendrozyten vorkommen. Dies zeigt, daß $\alpha$-Synuclein in sehr verschiedenen Zellen an deren Untergang beteiligt sein kann. Inwieweit sich die pathogenetischen Mechanismen gleichen ist noch offen. Es wird der Eindruck gewonnen, daß für die Etwicklung eines Parkinson-Syndroms in Mäusen noch andere ätiologische Faktoren neben den mutierten $\alpha$-Synuclein-Isoformen gleichzeitig vorhanden sein müßten. Die Penetranz der domiant vererbten Parkinson-Syndrome liegt unter $100 \%$, so daß auch im Menschen weitere ätiologische Faktoren eine Rolle spielen müssen, und das mutierte $\alpha$-Synuclein nicht alleine unweigerlich zur Entstehung eines Parkinsons-Syndroms führt (Polymeropoulos et al. 1997). Ob es sich dabei um Umweltfaktoren oder um genetische Prädisposition handelt, ist noch offen. Ein genetischer Faktor wurde auch in der vorliegenden Arbeit deutlich, da die Urtransgenen im FVBHintergrund nicht erkrankten. Insofern waren für die Entstehung der beschriebenen neurologischen Ausfälle in Mäusen zum einen die Überexpression der mutierten $\alpha$-Synuclein- 
Isoformen und zum anderen der genetische Hintergrund der C57B16/J x 129Sv/ola-Hybridmäuse entscheidend.

Eine alternative Erklärung für das Fehlen der charakteristischen neruochemischen und pathomorphologischen Veränderungen eines Parkinson-Syndroms in Mäusen könnte die im Vergleich zum Menschen kurze Lebensspanne der Mäuse sein. Dies scheint jedoch unwahrscheinlich, da anscheinend auch transgene Fliegen (Drosophila melanogaster) ein Parkinson-Syndrom entwickeln können (Feany und Bender 2000). In diesen wurde die humane $\alpha$-Synuclein-A53T-Isoform überexprimiert, welche zum Untergang von dopaminergen Neuronen und der Entstehung von Lewy-Körpern führte. Im Fliegen-Genom konnten bisher keine Hinweise auf ein $\alpha$-Synuclein-Ortholog gefunden werden. Die Lewy-Körper entstehen in Fliegen relativ schnell, so daß sich möglicherweise in Vertebraten Schutzmechanismen gegen die Aggregation von $\alpha$-Synuclein gebildet haben. Erst wenn diese aussetzen kann sich eine Parkinson-Erkrankung entwickeln. In Fliegen wäre dann dieser Schutzmechanismus nicht vorhanden, so daß sie relativ leicht erkranken könnten.

Der Polymorphismus A53T führt im Menschen zum Parkinson-Syndrom. Die Orthologe aus Mäusen, Ratten und Vögeln haben an dieser Position bereits ein Threonin. In diesen Tieren ist jedoch kein Parkinson-Syndrom bekannt. Daher wurde in dieser Arbeit die Hypothese aufgestellt, daß eventuell eine weitere Aminosäure im humanen $\alpha$-Synuclein für die Entstehung der Parkinson-Erkrankung notwendig ist. Als möglicher Kandidat wurde das Serin an der Position 87 identifiziert. Alle anderen bisher sequenzierten $\alpha$-Synuclein-Orthologe, aber auch die Paraloge Synoretin, $\beta$ - und $\gamma$-Synuclein tragen an dieser Position ein Asparagin. Analog zur Hyperphosphorylierung bei den Tauopathien wurde vermutet, daß das Serin-87 phosphoryliert werden und diese zusätzliche Modifikation die Entstehung eines Parkinson-Syndroms beschleunigen könnte. In vitro kann diese Aminosäure über Caseinkinase phosphoryliert werden, obwohl das Serin an der Position 129 bevorzugt modifiziert wird (Okochi et al. 2000; Pronin et al. 2000). Um die Signifikanz dieser Phosphorylierung in vivo zu testen, wurden transgene Mäuse erstellt, die die Mutation S87D enthielten. Das Aspartat ist negativ geladen und kann zur Imitierung einer Serin-Phosphorylierung verwendet werden. Interessanterweise waren bereits mehrere der Ursprungstransgenen im FVB-Hintergrund phänotypisch auffällig. In zwei der Linien, die in den bereits erwähnten Hybridhintergrund gekreuzt werden konnten, verstärkte sich die Symptomatik, so daß diese Mäuse bereits nach wenigen Wochen neurologische Ausfälle zeigten. Eine detaillierte Analyse dieser Mäuse wird zeigen, ob in ihnen Einschlußkörperchen oder neurochemische Veränderungen in der Substanzia nigra bzw. im Striatum gefunden werden können, und so eine Rolle der Phosphorylierung von $\alpha$-Synuclein in der Pathogenese der ParkinsonErkrankung nachgewiesen werden kann. 


\section{$6 \quad$ Zusammenfassung}

Die Synuclein-Proteinfamilie besteht aus den vier Paralogen $\alpha-, \beta-, \gamma$-Synuclein und Synoretin. $\alpha$ - und $\beta$-Synuclein werden hauptsächlich im Gehirn, $\gamma$-Synuclein im peripheren Nervensystem und Synoretin in der Retina exprimiert. Subzelluläre Fraktionierungen und immunzytochemische Untersuchungen zeigten eine Lokalisation von $\alpha$ - und $\beta$-Synuclein im synaptischen Zytoplasma. In neuronalen Primärkulturen und auch im Mausgehirn ist ein Großteil des $\alpha$ - und $\beta$-Synucleins in Synapsen kolokalisiert.

Insbesondere wegen seiner Beteiligung an der Parkinson-Erkrankung hat $\alpha$-Synuclein große Aufmerksamkeit erhalten. Dieses Protein wird bevorzugt in rostralen Hirnabschnitten exprimiert, doch ist die Konzentration im Striatum vergleichsweise gering. Die Ausschaltung der $\alpha$-Synuclein-Expression in Mäusen veränderte die molekulare synaptische Architektur und auch die mikroskopische Gehirnstruktur nicht meßbar. Alte $\alpha$-Synuclein-Mausnullmutanten zeigten keine pathomorphologischen oder neurochemischen Veränderungen im nigrostriatalen System. Diese Befunde zeigen, daß $\alpha$-Synuclein weder essentiell für eine normale Funktion des Gehirns ist noch ein Verlust eine erhöhte Anfälligkeit gegenüber Parkinson-Syndromen bewirkt.

Zur Untersuchung der Pathogenese der Parkinson-Erkrankung im Tierexperiment wird in der Regel MPTP benutzt, da es wesentliche Symptome der idiopathischen Erkrankung kopiert. Wie an Mäusen mit einer spontanen $\alpha$-Synuclein-Gendeletion gezeigt, ist $\alpha$-Synuclein nicht an der Pathogenese des durch MPTP induzierten Parkinson-Syndroms in Mäusen beteiligt. Eine unterschiedliche Empfindlichkeit der hergestellten $\alpha$-Synuclein-Nullmutanten und WildtypGeschwistertiere war höchst wahrscheinlich durch die mit dem Resistenzgen kosegregierten Genen der Mauslinie 129/Sv/ola bedingt. Dies zeigt zum einen, wie wichtig die Kontrolle des genetischen Hintergrundes in der Analyse von transgenen Tieren sein kann und zum anderen, daß noch weitere, bisher noch nicht identifizierte Proteine an der Pathogenese der MPTPinduzierten Parkinson-Syndrome beteiligt sind. Proteine sowohl des Dopamintransports als auch der Regulation von Redoxvorgängen in Neuronen haben in vivo einen Einfluß auf pharmakologisch induzierte Parkinson-Modelle. Im Gegensatz $\mathrm{zu}$ diesen Proteinen wurde für $\alpha$-Synuclein eine wesentliche Rolle in der Entstehung familiärer als auch der idiopathischen Parkinson-Erkrankung nachgewiesen. Diese Arbeit zeigt, daß sich die Pathogenese der toxischen Syndrome und der idiopathischen Parkinson-Erkrankung in einem wesentlichen molekularen Aspekt unterscheiden, und unterstützt die Annahme, daß es mehrere Mechanismen gibt, die zum Ausfall des nigrostriatalen Systems führen können. In dieser Hinsicht müssen die bisher aus pharmakologisch induzierten Parkinson-Syndromen abgeleiteten Mechanismen in einem neuen Kontext interpretiert werden.

Die transgene Expression der familiären Parkinson-Mutationen in Mäusen führte expressions- und zeitabhängig zu neurologischen Ausfällen, die nicht durch Veränderungen des nigrostriatalen Systems verusacht waren. Diese Ergebnisse zeigen, daß $\alpha$-Synuclein multiple neurologische Erkrankungen verursachen kann und daß weitere ätiologische Faktoren für die Entstehung der Parkinson-Erkrankung wahrscheinlich sind.

Stichwörter: $\quad \alpha$-Synuclein; MPTP; Parkinson-Symdrom; Maus-Nullmutanten 


\section{Summary}

The Synuclein protein family comprises the paralogs $\alpha-, \beta-, \gamma$-Synuclein and Synoretin. $\alpha$ - and $\beta$-Synuclein are predominantly expressed in the brain, whereas $\gamma$-Synuclein is expressed in the peripheral nervous system and Synoretin in the retina. Subcellular fractionations and immunocytochemistry showed a localisation of $\alpha$ - and $\beta$-Synuclein in the synaptic cytosol. In neuronal primary cultures and the mouse brain, the majority of $\alpha$ - and $\beta$-Synuclein are colocalized in the synapses.

In the past, $\alpha$-Synuclein has received considerable attention because of its contribution to Parkinson's disease. This protein is predominantly expressed in rostral brain areas, although the concentration in the striatum is comparatively low. The deletion of the $\alpha$-Synuclein expression in mice did not change the molecular synaptic architecture or the microscopic brain structure. Old $\alpha$-Synuclein deficient mice did not show any pathomorphological or neurochemical changes in the nigrostriatal system. These findings show, that $\alpha$-Synuclein is neither essential for normal brain function nor does the deletion cause an elevated susceptibility for parkinsonism.

MPTP is used commonly to investigate the pathogenesis of Parkinson's disease in animal models as it mimics fundamental changes of the idiopathic disease. As shown among mice with a spontaneous $\alpha$-Synuclein gene deletion, $\alpha$-Synuclein is not involved in the pathogenesis of MPTP-induced parkinsonism in mice. A difference in the sensitivity of the $\alpha$-Synuclein deficient mice generated in the present study as compared to wildtype littermates was most likely caused by cosegregated genes of the mouse line 129/Sv/ola with the marker gene for antibiotic resistance. This demostrates the importance of genetic background effects in the analysis of transgenic mice and suggests that additional yet unidentified proteins are involved in the pathogenesis of MPTP-induced parkinsonism. Proteins involved both, in dopamine transport and the regulation of redox processes in neurons, have an influence on pharmacologically induced models of parkinsonism in vivo. In contrast to these proteins, however, only $\alpha$-Synuclein was shown to have an essential role in the development of both, familial and idiopathic Parkinson's syndromes. The present thesis shows, that the pathogenesis of toxic syndromes and the idiopathic Parkinson's disease are different in a substantial molecular aspect, and supports the assumption that multiple mechanisms exist which lead to a loss of the nigrostriatal system. As a consequence, current molecular models of pharmacologically induced parkinsonism mechanisms must be reinterpreted on the background of the present study.

The transgenic expression in mice of $\alpha$-Synucleins with the familial Parkinson mutations led to the expression and time dependent onset of neurological deficits which were not caused by changes in the nigrostriatal system. These results show, that $\alpha$-Synuclein can cause multiple neurological diseases and additional etiological factors are likely to contribute to the development of Parkinson's disease.

keywords: $\quad \alpha$-Synuclein; MPTP; Parkinson syndrome; targeted deletion in mice 


\title{
8 Literaturverzeichnis
}

\author{
Abeliovich A, Schmitz Y, Farinas I, Choi-Lundberg D, Ho WH, Castillo PE, Shinsky N, \\ Verdugo JM, Armanini M, Ryan A, Hynes M, Phillips H, Sulzer D und Rosenthal A (2000): \\ Mice lacking alpha-synuclein display functional deficits in the nigrostriatal dopamine system. \\ Neuron 25, 239-252.
}

Akopian AN und Wood JN (1995): Peripheral nervous system-specific genes identified by subtractive cDNA cloning. J Biol Chem 270, 21264-21270.

Andreassen OA, Ferrante RJ, Dedeoglu A, Albers DW, Klivenyi P, Carlson EJ, Epstein CJ und Beal MF (2001): Mice with a partial deficiency of manganese superoxide dismutase show increased vulnerability to the mitochondrial toxins malonate, 3- nitropropionic acid, and MPTP. Exp Neurol 167, 189-195.

Ara J, Przedborski S, Naini AB, Jackson-Lewis V, Trifiletti RR, Horwitz J und

Ischiropoulos H (1998): Inactivation of tyrosine hydroxylase by nitration following exposure to peroxynitrite and 1-methyl-4-phenyl-1,2,3,6-tetrahydropyridine (MPTP). Proc Natl Acad Sci U S A $\underline{95}, 7659-7663$.

Beckman JS, Beckman TW, Chen J, Marshall PA und Freeman BA (1990): Apparent hydroxyl radical production by peroxynitrite: implications for endothelial injury from nitric oxide and superoxide. Proc Natl Acad Sci U S A $\underline{87}$, 1620-1624.

Bernheimer H, Birkmayer W, Hornykiewicz O, Jellinger K und Seitelberger F (1973): Brain dopamine and the syndromes of Parkinson and Huntington. Clinical, morphological and neurochemical correlations. J Neurol Sci $\underline{20}$, 415-455.

Betarbet R, Sherer TB, MacKenzie G, Garcia-Osuna M, Panov AV und Greenamyre JT (2000): Chronic systemic pesticide exposure reproduces features of Parkinson's disease. Nat Neurosci $\underline{3}, 1301-1306$.

Betz A, Ashery U, Rickmann M, Augustin I, Neher E, Südhof TC, Rettig J und Brose N (1998): Munc13-1 is a presynaptic phorbol ester receptor that enhances neurotransmitter release. Neuron 21, 123-136.

Blanchard MM, Taillon-Miller P, Nowotny P und Nowotny V (1993): PCR buffer optimization with uniform temperature regimen to facilitate automation. PCR Methods Appl $\underline{2}$, 234-240.

Brose N, Huntley GW, Stern-Bach Y, Sharma G, Morrison JH und Heinemann SF (1994): Differential assembly of coexpressed glutamate receptor subunits in neurons of rat cerebral cortex. J Biol Chem 269, 16780-16784.

Buchman VL, Adu J, Pinon LG, Ninkina NN und Davies AM (1998a): Persyn, a member of the synuclein family, influences neurofilament network integrity. Nat Neurosci $1,101-103$.

Buchman VL, Hunter HJ, Pinon LG, Thompson J, Privalova EM, Ninkina NN und Davies AM (1998b): Persyn, a member of the synuclein family, has a distinct pattern of expression in the developing nervous system. J Neurosci 18, 9335-9341.

Capecchi MR (1989): Altering the genome by homologous recombination. Science 244, 12881292.

Castillo PE, Janz R, Südhof TC, Tzounopoulos T, Malenka RC und Nicoll RA (1997):

Rab3A is essential for mossy fibre long-term potentiation in the hippocampus. Nature $\underline{388}, 590$ 593. 
Chan P, DeLanney LE, Irwin I, Langston JW und Di Monte D (1991): Rapid ATP loss caused by 1-methyl-4-phenyl-1,2,3,6-tetrahydropyridine in mouse brain. J Neurochem $\underline{57}$, 348351.

Chen C und Okayama H (1987): High-efficiency transformation of mammalian cells by plasmid DNA. Mol Cell Biol 7, 2745-2752.

Chou JH und Jahn R (2000): Binding of Rab3A to synaptic vesicles. J Biol Chem 275, 94339440 .

Clayton DF und George JM (1998): The synucleins: a family of proteins involved in synaptic function, plasticity, neurodegeneration and disease. Trends Neurosci 21, 249-254.

Clayton DF und George JM (1999): Synucleins in synaptic plasticity and neurodegenerative

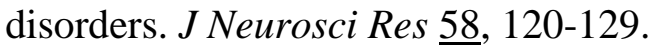

Colley WC, Sung TC, Roll R, Jenco J, Hammond SM, Altshuller Y, Bar-Sagi D, Morris AJ und Frohman MA (1997): Phospholipase D2, a distinct phospholipase D isoform with novel regulatory properties that provokes cytoskeletal reorganization. Curr Biol 7, 191-201.

Conway KA, Harper JD und Lansbury PT, Jr. (2000): Fibrils formed in vitro from alphasynuclein and two mutant forms linked to Parkinson's disease are typical amyloid. Biochemistry $\underline{39}, 2552-2563$.

Cosi C und Marien M (1998): Decreases in mouse brain NAD+ and ATP induced by 1-methyl4-phenyl-1, 2,3,6-tetrahydropyridine (MPTP): prevention by the poly(ADP-ribose) polymerase inhibitor, benzamide. Brain Res 809, 58-67.

Davidson WS, Jonas A, Clayton DF und George JM (1998): Stabilization of alpha-synuclein secondary structure upon binding to synthetic membranes. J Biol Chem $\underline{273}$, 9443-9449.

Dehmer T, Lindenau J, Haid S, Dichgans J und Schulz JB (2000): Deficiency of inducible nitric oxide synthase protects against MPTP toxicity in vivo. J Neurochem $\underline{74}$, 2213-2216.

Del Sal G, Manfioletti G und Schneider C (1988): A one-tube plasmid DNA mini-preparation suitable for sequencing. Nucleic Acids Res $\underline{16}, 9878$.

Dexter D, Carter C, Agid F, Agid Y, Lees AJ, Jenner P und Marsden CD (1986): Lipid peroxidation as cause of nigral cell death in Parkinson's disease. Lancet 1986, 2, 639-640.

Dexter DT, Carter CJ, Wells FR, Javoy-Agid F, Agid Y, Lees A, Jenner P und Marsden CD (1989): Basal lipid peroxidation in substantia nigra is increased in Parkinson's disease. $J$ Neurochem 52, 381-389.

Dexter DT, Carayon A, Vidailhet M, Ruberg M, Agid F, Agid Y, Lees AJ, Wells FR, Jenner P und Marsden CD (1990): Decreased ferritin levels in brain in Parkinson's disease. $J$ Neurochem 55, 16-20.

Dexter DT, Jenner P, Schapira AH und Marsden CD (1992): Alterations in levels of iron, ferritin, and other trace metals in neurodegenerative diseases affecting the basal ganglia. The Royal Kings and Queens Parkinson's Disease Research Group. Ann Neurol 32, S94-100.

Dougherty WG, Carrington JC, Cary SM und Parks TD (1988): Biochemical and mutational analysis of a plant virus polyprotein cleavage site. Embo J $\underline{7}, 1281-1287$.

Edelmann L, Hanson PI, Chapman ER und Jahn R (1995): Synaptobrevin binding to synaptophysin: a potential mechanism for controlling the exocytotic fusion machine. Embo J $\underline{14}$, 224-231.

Ellis CE, Schwartzberg PL, Grider TL, Fink DW und Nussbaum RL (2001): alphasynuclein is phosphorylated by members of the Src family of protein-tyrosine kinases. $J$ Biol Chem 276, 3879-3884. 
Engelender S, Kaminsky Z, Guo X, Sharp AH, Amaravi RK, Kleiderlein JJ, Margolis RL, Troncoso JC, Lanahan AA, Worley PF, Dawson VL, Dawson TM und Ross CA (1999):

Synphilin-1 associates with alpha-synuclein and promotes the formation of cytosolic inclusions. Nat Genet 22, 110-114.

Exton JH (1997): Phospholipase D: enzymology, mechanisms of regulation, and function. Physiol Rev 77, 303-320.

Farrer M, Gwinn-Hardy K, Muenter M, DeVrieze FW, Crook R, Perez-Tur J, Lincoln S, Maraganore D, Adler C, Newman S, MacElwee K, McCarthy P, Miller C, Waters C und Hardy J (1999): A chromosome 4p haplotype segregating with Parkinson's disease and postural tremor. Hum Mol Genet $\underline{8}$, 81-85.

Feany MB und Bender WW (2000): A Drosophila model of Parkinson's disease. Nature $\underline{404}$, 394-398.

Fearnley JM und Lees AJ (1991): Ageing and Parkinson's disease: substantia nigra regional selectivity. Brain 114 ( Pt 5), 2283-2301.

Feinberg AP und Vogelstein B (1983): A technique for radiolabeling DNA restriction endonuclease fragments to high specific activity. Anal Biochem 132, 6-13.

Fon EA, Pothos EN, Sun BC, Killeen N, Sulzer D und Edwards RH (1997): Vesicular transport regulates monoamine storage and release but is not essential for amphetamine action. Neuron 19, 1271-1283.

Fornai F, Alessandri MG, Torracca MT, Bassi L und Corsini GU (1997a): Effects of noradrenergic lesions on MPTP/MPP+ kinetics and MPTP-induced nigrostriatal dopamine depletions. J Pharmacol Exp Ther 283, 100-107.

Fornai F, Vaglini F, Maggio R, Bonuccelli U und Corsini GU (1997b): Species differences in the role of excitatory amino acids in experimental parkinsonism. Neurosci Biobehav Rev 21 , 401-415.

Fornai F, Giorgi FS, Alessandri MG, Giusiani M und Corsini GU (1999): Effects of pretreatment with N-(2-chloroethyl)-N-ethyl-2- bromobenzylamine (DSP-4) on methamphetamine pharmacokinetics and striatal dopamine losses. J Neurochem $\underline{72}$, 777-784.

Forno LS, DeLanney LE, Irwin I und Langston JW (1993): Similarities and differences between MPTP-induced parkinsonsim and Parkinson's disease. Neuropathologic considerations. Adv Neurol 60, 600-608.

Franken SM, Scheidig AJ, Krengel U, Rensland H, Lautwein A, Geyer M, Scheffzek K, Goody RS, Kalbitzer HR, Pai EF und Wittinghofer A (1993): Three-dimensional structures and properties of a transforming and a nontransforming glycine-12 mutant of p21H-ras.

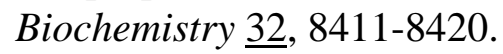

Fumagalli F, Gainetdinov RR, Valenzano KJ und Caron MG (1998): Role of dopamine transporter in methamphetamine-induced neurotoxicity: evidence from mice lacking the transporter. J Neurosci $\underline{18}, 4861-4869$.

Fumagalli F, Gainetdinov RR, Wang YM, Valenzano KJ, Miller GW und Caron MG (1999): Increased methamphetamine neurotoxicity in heterozygous vesicular monoamine transporter 2 knock-out mice. J Neurosci 19, 2424-2431.

Fykse EM, Takei K, Walch-Solimena C, Geppert M, Jahn R, De Camilli P und Südhof TC (1993): Relative properties and localizations of synaptic vesicle protein isoforms: the case of the synaptophysins. J Neurosci $\underline{13}, 4997-5007$. 
Gainetdinov RR, Fumagalli F, Jones SR und Caron MG (1997): Dopamine transporter is required for in vivo MPTP neurotoxicity: evidence from mice lacking the transporter. $J$ Neurochem 69, 1322-1325.

Gainetdinov RR, Fumagalli F, Wang YM, Jones SR, Levey AI, Miller GW und Caron MG (1998): Increased MPTP neurotoxicity in vesicular monoamine transporter 2 heterozygote knockout mice. J Neurochem $\underline{70}$, 1973-1978.

Gasser T, Muller-Myhsok B, Wszolek ZK, Oehlmann R, Calne DB, Bonifati V, Bereznai B, Fabrizio E, Vieregge P und Horstmann RD (1998): A susceptibility locus for Parkinson's disease maps to chromosome 2p13. Nat Genet 18 , 262-265.

George JM, Jin H, Woods WS und Clayton DF (1995): Characterization of a novel protein regulated during the critical period for song learning in the zebra finch. Neuron 15, 361-372.

Giasson BI, Duda JE, Murray IV, Chen Q, Souza JM, Hurtig HI, Ischiropoulos H, Trojanowski JQ und Lee VM (2000): Oxidative damage linked to neurodegeneration by selective alpha- synuclein nitration in synucleinopathy lesions. Science 290, 985-989.

Giovanni A, Sonsalla PK und Heikkila RE (1994a): Studies on species sensitivity to the dopaminergic neurotoxin 1-methyl- 4-phenyl-1,2,3,6-tetrahydropyridine. Part 2: Central administration of 1-methyl-4-phenylpyridinium. J Pharmacol Exp Ther 270, 1008-1014.

Giovanni A, Sieber BA, Heikkila RE und Sonsalla PK (1994b): Studies on species sensitivity to the dopaminergic neurotoxin 1-methyl- 4-phenyl-1,2,3,6-tetrahydropyridine. Part 1: Systemic administration. J Pharmacol Exp Ther 270, 1000-1007.

Goedert M (2001): The significance of tau and alpha-synuclein inclusions in neurodegenerative diseases. Curr Opin Genet Dev 11, 343-351.

Good PF, Hsu A, Werner P, Perl DP und Olanow CW (1998): Protein nitration in Parkinson's disease. J Neuropathol Exp Neurol 57, 338-342.

Graham FL, Smiley J, Russell WC und Nairn R (1977): Characteristics of a human cell line transformed by DNA from human adenovirus type 5. J Gen Virol 36, 59-74.

Guan KL und Dixon JE (1991): Eukaryotic proteins expressed in Escherichia coli: an improved thrombin cleavage and purification procedure of fusion proteins with glutathione S-transferase. Anal Biochem 192, 262-267.

Hamre K, Tharp R, Poon K, Xiong X und Smeyne RJ (1999): Differential strain susceptibility following 1-methyl-4-phenyl-1,2,3,6- tetrahydropyridine (MPTP) administration acts in an autosomal dominant fashion: quantitative analysis in seven strains of Mus musculus. Brain Res $\underline{828}$, 91-103.

Hantraye P, Brouillet E, Ferrante R, Palfi S, Dolan R, Matthews RT und Beal MF (1996): Inhibition of neuronal nitric oxide synthase prevents MPTP-induced parkinsonism in baboons. Nat Med 2, 1017-1021.

Heikkila RE, Hess A und Duvoisin RC (1984): Dopaminergic neurotoxicity of 1-methyl-4phenyl-1,2,5,6- tetrahydropyridine in mice. Science 224, 1451-1453.

Hell JW, Maycox PR, Stadler H und Jahn R (1988): Uptake of GABA by rat brain synaptic vesicles isolated by a new procedure. Embo J $\underline{7}, 3023-3029$.

Higuchi R. Site directed mutagenesis. In: PCR Protocols: A Guide to Methods and Applications; hrsg. v. Innis D, Gelfand H, Snisnky JJ, und White TJ. Academic Press New York 1990, 177 183.

Hogan KA, Staal RG und Sonsalla PK (2000): Analysis of VMAT2 binding after methamphetamine or MPTP treatment: disparity between homogenates and vesicle preparations. J Neurochem 74, 2217-2220. 
Hooper M, Hardy K, Handyside A, Hunter S und Monk M (1987): HPRT-deficient (LeschNyhan) mouse embryos derived from germline colonization by cultured cells. Nature $\underline{326}$, 292295.

Hörtnagl H, Berger ML, Sperk G und Pifl C (1991): Regional heterogeneity in the distribution of neurotransmitter markers in the rat hippocampus. Neuroscience 45, 261-272.

Huttner WB, Schiebler W, Greengard P und De Camilli P (1983): Synapsin I (protein I), a nerve terminal-specific phosphoprotein. III. Its association with synaptic vesicles studied in a highly purified synaptic vesicle preparation. J Cell Biol $\underline{96}$, 1374-1388.

Imai Y, Soda M und Takahashi R (2000): Parkin suppresses unfolded protein stress-induced cell death through its E3 ubiquitin-protein ligase activity. J Biol Chem 275, 35661-35664.

Imai Y, Soda M, Inoue H, Hattori N, Mizuno Y und Takahashi R (2001): An unfolded putative transmembrane polypeptide, which can lead to endoplasmic reticulum stress, is a substrate of Parkin. Cell 105, 891-902.

Irizarry MC, Kim TW, McNamara M, Tanzi RE, George JM, Clayton DF und Hyman BT (1996): Characterization of the precursor protein of the non-A beta component of senile plaques (NACP) in the human central nervous system. J Neuropathol Exp Neurol 55, 889-895.

Iwai A, Masliah E, Yoshimoto M, Ge N, Flanagan L, de Silva HA, Kittel A und Saitoh T (1995): The precursor protein of non-A beta component of Alzheimer's disease amyloid is a presynaptic protein of the central nervous system. Neuron $\underline{14}$, 467-475.

Jakes R, Spillantini MG und Goedert M (1994): Identification of two distinct synucleins from human brain. FEBS Lett 345, 27-32.

Javitch JA, D'Amato RJ, Strittmatter SM und Snyder SH (1985): Parkinsonism-inducing neurotoxin, N-methyl-4-phenyl-1,2,3,6 -tetrahydropyridine: uptake of the metabolite N-methyl-4phenylpyridine by dopamine neurons explains selective toxicity. Proc Natl Acad Sci U S A $\underline{82}$, 2173-2177.

Jellinger KA, Kienzl E, Rumpelmaier G, Paulus W, Riederer P, Stachelberger H, Youdim MB und Ben-Shachar D (1993): Iron and ferritin in substantia nigra in Parkinson's disease. Adv Neurol $\underline{60}$, 267-272.

Jenco JM, Rawlingson A, Daniels B und Morris AJ (1998): Regulation of phospholipase D2: selective inhibition of mammalian phospholipase $\mathrm{D}$ isoenzymes by alpha- and beta-synucleins.

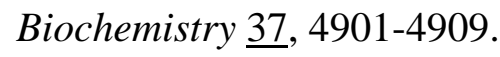

Jones DH und Matus AI (1974): Isolation of synaptic plasma membrane from brain by combined flotation-sedimentation density gradient centrifugation. Biochim Biophys Acta $\underline{356}$, 276-287.

Kahle PJ, Neumann M, Ozmen L, Muller V, Jacobsen H, Schindzielorz A, Okochi M, Leimer U, van Der Putten H, Probst A, Kremmer E, Kretzschmar HA und Haass C (2000): Subcellular localization of wild-type and Parkinson's disease- associated mutant alpha -synuclein in human and transgenic mouse brain. $J$ Neurosci $\underline{20}$, 6365-6373.

Kitada T, Asakawa S, Hattori N, Matsumine H, Yamamura Y, Minoshima S, Yokochi M, Mizuno Y und Shimizu N (1998): Mutations in the parkin gene cause autosomal recessive juvenile parkinsonism. Nature $\underline{392}$, 605-608.

Klivenyi P, St Clair D, Wermer M, Yen HC, Oberley T, Yang L und Flint Beal M (1998): Manganese superoxide dismutase overexpression attenuates MPTP toxicity. Neurobiol Dis $\underline{5}$, 253-258. 
Kowall NW, Hantraye P, Brouillet E, Beal MF, McKee AC und Ferrante RJ (2000): MPTP induces alpha-synuclein aggregation in the substantia nigra of baboons. Neuroreport 11,211 213.

Krüger R, Kuhn W, Muller T, Woitalla D, Graeber M, Kosel S, Przuntek H, Epplen JT, Schols L und Riess O (1998): Ala30Pro mutation in the gene encoding alpha-synuclein in Parkinson's disease. Nat Genet $\underline{18}, 106-108$.

Laemmli UK (1970): Cleavage of structural proteins during the assembly of the head of bacteriophage T4. Nature 227, 680-685.

Lang AE und Lozano AM (1998): Parkinson's disease. First of two parts. N Engl J Med $\underline{339}$, 1044-1053.

Langston JW, Ballard P, Tetrud JW und Irwin I (1983): Chronic Parkinsonism in humans due to a product of meperidine-analog synthesis. Science 219, 979-980.

Lavedan C, Leroy E, Dehejia A, Buchholtz S, Dutra A, Nussbaum RL und Polymeropoulos MH (1998): Identification, localization and characterization of the human gamma-synuclein gene. Hum Genet $\underline{103}$, 106-112.

Leng Y, Chase TN und Bennett MC (2001): Muscarinic receptor stimulation induces translocation of an \{alpha\}- synuclein oligomer from plasma membrane to a light vesicle fraction in cytoplasm. J Biol Chem $\underline{3}, 3$.

Leroy E, Boyer R, Auburger G, Leube B, Ulm G, Mezey E, Harta G, Brownstein MJ, Jonnalagada S, Chernova T, Dehejia A, Lavedan C, Gasser T, Steinbach PJ, Wilkinson KD und Polymeropoulos MH (1998): The ubiquitin pathway in Parkinson's disease. Nature $\underline{395}$, 451-452.

Li C, Takei K, Geppert M, Daniell L, Stenius K, Chapman ER, Jahn R, De Camilli P und Süidhof TC (1994): Synaptic targeting of rabphilin-3A, a synaptic vesicle Ca2+/phospholipidbinding protein, depends on rab3A/3C [published erratum appears in Neuron 1995 Jul;15(1):following 239]. Neuron 13, 885-898.

Liberatore GT, Jackson-Lewis V, Vukosavic S, Mandir AS, Vila M, McAuliffe WG, Dawson VL, Dawson TM und Przedborski S (1999): Inducible nitric oxide synthase stimulates dopaminergic neurodegeneration in the MPTP model of Parkinson disease. Nat Med 5, 1403-1409.

Lotharius J und O'Malley KL (2000): The parkinsonism-inducing drug 1-methyl-4phenylpyridinium triggers intracellular dopamine oxidation. A novel mechanism of toxicity. $J$ Biol Chem 275, 38581-38588.

Lotharius J, Dugan LL und O'Malley KL (1999): Distinct mechanisms underlie neurotoxinmediated cell death in cultured dopaminergic neurons. J Neurosci 19, 1284-1293.

Lowe J, McDermott H, Landon M, Mayer RJ und Wilkinson KD (1990): Ubiquitin carboxyl-terminal hydrolase (PGP 9.5) is selectively present in ubiquitinated inclusion bodies characteristic of human neurodegenerative diseases. J Pathol 161, 153-160.

Lowry OH, Rosebrough NJ, Farr AL und Randall RJ (1951): Protein measurement with the Folin phenol reagent. J Biol Chem 193, 265-275.

Mandell JW, Townes-Anderson E, Czernik AJ, Cameron R, Greengard P und De Camilli $\mathbf{P}$ (1990): Synapsins in the vertebrate retina: absence from ribbon synapses and heterogeneous distribution among conventional synapses. Neuron $\underline{5}, 19-33$.

Mandir AS, Przedborski S, Jackson-Lewis V, Wang ZQ, Simbulan-Rosenthal CM, Smulson ME, Hoffman BE, Guastella DB, Dawson VL und Dawson TM (1999): Poly(ADP- 
ribose) polymerase activation mediates 1-methyl-4-phenyl-1, 2,3,6-tetrahydropyridine (MPTP)induced parkinsonism. Proc Natl Acad Sci U S A $\underline{96}$, 5774-5779.

Markey SP, Johannessen JN, Chiueh CC, Burns RS und Herkenham MA (1984):

Intraneuronal generation of a pyridinium metabolite may cause drug-induced parkinsonism. Nature 311, 464-467.

Maroteaux L und Scheller RH (1991): The rat brain synucleins; family of proteins transiently associated with neuronal membrane. Brain Res Mol Brain Res 11, 335-343.

Maroteaux L, Campanelli JT und Scheller RH (1988): Synuclein: a neuron-specific protein localized to the nucleus and presynaptic nerve terminal. J Neurosci $\underline{8}$, 2804-2815.

Masliah E, Rockenstein E, Veinbergs I, Mallory M, Hashimoto M, Takeda A, Sagara Y, Sisk A und Mucke L (2000): Dopaminergic loss and inclusion body formation in alphasynuclein mice: implications for neurodegenerative disorders. Science $\underline{287}$, 1265-1269.

Matsumine H, Yamamura Y, Kobayashi T, Nakamura S, Kuzuhara S und Mizuno Y (1998): Early onset parkinsonism with diurnal fluctuation maps to a locus for juvenile parkinsonism. Neurology 50, 1340-1345.

Matteoli M, Takei K, Cameron R, Hurlbut P, Johnston PA, Südhof TC, Jahn R und De Camilli P (1991): Association of Rab3A with synaptic vesicles at late stages of the secretory pathway. J Cell Biol 115, 625-633.

McGeer PL, Itagaki S, Akiyama H und McGeer EG (1988): Rate of cell death in parkinsonism indicates active neuropathological process. Ann Neurol 24, 574-576.

McMahon HT und Südhof TC (1995): Synaptic core complex of synaptobrevin, syntaxin, and SNAP25 forms high affinity alpha-SNAP binding site. J Biol Chem 270, 2213-2217.

Miller GW, Gainetdinov RR, Levey AI und Caron MG (1999): Dopamine transporters and neuronal injury. Trends Pharmacol Sci 20, 424-429.

Murphy DD, Rueter SM, Trojanowski JQ und Lee VM (2000): Synucleins are developmentally expressed, and alpha-synuclein regulates the size of the presynaptic vesicular pool in primary hippocampal neurons. J Neurosci 20, 3214-3220.

Nakajo S, Omata K, Aiuchi T, Shibayama T, Okahashi I, Ochiai H, Nakai Y, Nakaya K und Nakamura Y (1990): Purification and characterization of a novel brain-specific 14-kDa protein. J Neurochem 55, 2031-2038.

Nakajo S, Tsukada K, Omata K, Nakamura Y und Nakaya K (1993): A new brain-specific $14-\mathrm{kDa}$ protein is a phosphoprotein. Its complete amino acid sequence and evidence for phosphorylation. Eur J Biochem 217, 1057-1063.

Nakajo S, Shioda S, Nakai Y und Nakaya K (1994): Localization of phosphoneuroprotein 14 (PNP 14) and its mRNA expression in rat brain determined by immunocytochemistry and in situ hybridization. Brain Res Mol Brain Res 27, 81-86.

Nicklas WJ, Vyas I und Heikkila RE (1985): Inhibition of NADH-linked oxidation in brain mitochondria by 1-methyl-4- phenyl-pyridine, a metabolite of the neurotoxin, 1-methyl-4-phenyl1,2,5,6-tetrahydropyridine. Life Sci 36, 2503-2508.

Nonet ML, Staunton JE, Kilgard MP, Fergestad T, Hartwieg E, Horvitz HR, Jorgensen EM und Meyer BJ (1997): Caenorhabditis elegans rab-3 mutant synapses exhibit impaired function and are partially depleted of vesicles. J Neurosci 17, 8061-8073.

O'Dell SJ, Weihmuller FB und Marshall JF (1993): Methamphetamine-induced dopamine overflow and injury to striatal dopamine terminals: attenuation by dopamine D1 or D2 antagonists. J Neurochem $\underline{60}, 1792-1799$. 
Okochi M, Walter J, Koyama A, Nakajo S, Baba M, Iwatsubo T, Meijer L, Kahle PJ und Haass C (2000): Constitutive phosphorylation of the Parkinson's disease associated alphasynuclein. J Biol Chem 275, 390-397.

Pennathur S, Jackson-Lewis V, Przedborski S und Heinecke JW (1999): Mass spectrometric quantification of 3-nitrotyrosine, ortho-tyrosine, and o,o'-dityrosine in brain tissue of 1-methyl-4phenyl-1,2,3, 6- tetrahydropyridine-treated mice, a model of oxidative stress in Parkinson's disease. J Biol Chem 274, 34621-34628.

Perin MS, Fried VA, Mignery GA, Jahn R und Südhof TC (1990): Phospholipid binding by a synaptic vesicle protein homologous to the regulatory region of protein kinase C. Nature $\underline{345}$, 260-263.

Piccini P, Burn DJ, Ceravolo R, Maraganore D und Brooks DJ (1999): The role of inheritance in sporadic Parkinson's disease: evidence from a longitudinal study of dopaminergic function in twins. Ann Neurol $\underline{45}$, 577-582.

Polymeropoulos MH, Lavedan C, Leroy E, Ide SE, Dehejia A, Dutra A, Pike B, Root H, Rubenstein J, Boyer R, Stenroos ES, Chandrasekharappa S, Athanassiadou A, Papapetropoulos T, Johnson WG, Lazzarini AM, Duvoisin RC, Di Iorio G, Golbe LI und Nussbaum RL (1997): Mutation in the alpha-synuclein gene identified in families with Parkinson's disease. Science 276, 2045-2047.

Pronin AN, Morris AJ, Surguchov A und Benovic JL (2000): Synucleins are a novel class of substrates for G protein-coupled receptor kinases. J Biol Chem 275, 26515-26522.

Przedborski S, Jackson-Lewis V, Yokoyama R, Shibata T, Dawson VL und Dawson TM (1996): Role of neuronal nitric oxide in 1-methyl-4-phenyl-1,2,3,6- tetrahydropyridine (MPTP)induced dopaminergic neurotoxicity. Proc Natl Acad Sci U S A $\underline{93}$, 4565-4571.

Przedborski S, Kostic V, Jackson-Lewis V, Naini AB, Simonetti S, Fahn S, Carlson E, Epstein CJ und Cadet JL (1992): Transgenic mice with increased Cu/Zn-superoxide dismutase activity are resistant to $\mathrm{N}$-methyl-4-phenyl-1,2,3,6-tetrahydropyridine-induced neurotoxicity. $J$ Neurosci $\underline{12}$, 1658-1667.

Przedborski S, Chen Q, Vila M, Giasson BI, Djaldatti R, Vukosavic S, Souza JM, JacksonLewis VV, Lee VM und Ischiropoulos H (2001): Oxidative post-translational modifications of alpha-synuclein in the 1- methyl-4-phenyl-1,2,3,6-tetrahydropyridine (MPTP) mouse model of Parkinson's disease. J Neurochem $\underline{76}, 637-640$.

Ramsay RR, Salach JI, Dadgar J und Singer TP (1986): Inhibition of mitochondrial NADH dehydrogenase by pyridine derivatives and its possible relation to experimental and idiopathic parkinsonism. Biochem Biophys Res Commun 135, 269-275.

Ramsay RR, Krueger MJ, Youngster SK, Gluck MR, Casida JE und Singer TP (1991): Interaction of 1-methyl-4-phenylpyridinium ion (MPP+) and its analogs with the rotenone/piericidin binding site of NADH dehydrogenase. J Neurochem $\underline{56}, 1184-1190$.

Rathke-Hartlieb S, Kahle PJ, Neumann M, Ozmen L, Haid S, Okochi M, Haass C und Schulz JB (2001): Sensitivity to MPTP is not increased in Parkinson's disease-associated mutant alpha-synuclein transgenic mice. J Neurochem $\underline{77}$, 1181-1184.

Robinson PJ, Sontag JM, Liu JP, Fykse EM, Slaughter C, McMahon H und Südhof TC (1993): Dynamin GTPase regulated by protein kinase C phosphorylation in nerve terminals [see comments]. Nature $\underline{365}, 163-166$.

Rosahl TW, Geppert M, Spillane D, Herz J, Hammer RE, Malenka RC und Südhof TC (1993): Short-term synaptic plasticity is altered in mice lacking synapsin I. Cell $\underline{75}$, 661-670. 
Rosahl TW, Spillane D, Missler M, Herz J, Selig DK, Wolff JR, Hammer RE, Malenka RC und Südhof TC (1995): Essential functions of synapsins I and II in synaptic vesicle regulation. Nature 375, 488-493.

Saiki RK, Gelfand DH, Stoffel S, Scharf SJ, Higuchi R, Horn GT, Mullis KB und Erlich HA (1988): Primer-directed enzymatic amplification of DNA with a thermostable DNA polymerase. Science 239, 487-491.

Sanger F, Nicklen S und Coulson AR (1977): DNA sequencing with chain-terminating inhibitors. Proc Natl Acad Sci U S A $\underline{74}$, 5463-5467.

Schapira AH, Cooper JM, Dexter D, Clark JB, Jenner P und Marsden CD (1990):

Mitochondrial complex I deficiency in Parkinson's disease. J Neurochem 54, 823-827.

Schlüter OM: Funktionelle Analyse des Rab3/Rabphilin-Zyklus in Maus-Nullmutanten. Nat. Diss. Hannover 2000.

Schulz JB, Matthews RT, Muqit MM, Browne SE und Beal MF (1995): Inhibition of neuronal nitric oxide synthase by 7-nitroindazole protects against MPTP-induced neurotoxicity in mice. J Neurochem $\underline{64}$, 936-939.

Serpell LC, Berriman J, Jakes R, Goedert M und Crowther RA (2000): Fiber diffraction of synthetic alpha-synuclein filaments shows amyloid-like cross-beta conformation. Proc Natl Acad Sci U S A $\underline{97}$, 4897-4902.

Shibayama-Imazu T, Okahashi I, Omata K, Nakajo S, Ochiai H, Nakai Y, Hama T, Nakamura Y und Nakaya K (1993): Cell and tissue distribution and developmental change of neuron specific $14 \mathrm{kDa}$ protein (phosphoneuroprotein 14). Brain Res $\underline{622}, 17-25$.

Shimura H, Schlossmacher MG, Hattori N, Frosch MP, Trockenbacher A, Schneider R, Mizuno Y, Kosik KS und Selkoe DJ (2001): Ubiquitination of a new form of alpha-synuclein by parkin from human brain: implications for Parkinson's disease. Science 293, 263-269.

Sian J, Dexter DT, Lees AJ, Daniel S, Agid Y, Javoy-Agid F, Jenner P und Marsden CD (1994): Alterations in glutathione levels in Parkinson's disease and other neurodegenerative disorders affecting basal ganglia. Ann Neurol $\underline{36}$, 348-355.

Sirinathsinghji DJ, Heavens RP und McBride CS (1988): Dopamine-releasing action of 1methyl-4-phenyl-1,2,3,6- tetrahydropyridine (MPTP) and 1-methyl-4-phenylpyridine (MPP+) in the neostriatum of the rat as demonstrated in vivo by the push-pull perfusion technique: dependence on sodium but not calcium ions. Brain Res $\underline{443}$, 101-116.

Smith MT, Sandy MS und Di Monte D (1987): Free radicals, lipid peroxidation, and Parkinson's disease. Lancet 1987, 1, 38.

Song JY, Ichtchenko K, Südhof TC und Brose N (1999): Neuroligin 1 is a postsynaptic celladhesion molecule of excitatory synapses. Proc Natl Acad Sci U S A 96, 1100-1105.

Sonsalla PK, Nicklas WJ und Heikkila RE (1989): Role for excitatory amino acids in methamphetamine-induced nigrostriatal dopaminergic toxicity. Science $\underline{243}$, 398-400.

Sonsalla PK, Giovanni A, Sieber BA, Donne KD und Manzino L (1992): Characteristics of dopaminergic neurotoxicity produced by MPTP and methamphetamine. Ann N Y Acad Sci $\underline{648}$, 229-238.

Southern EM (1975): Detection of specific sequences among DNA fragments separated by gel electrophoresis. J Mol Biol $\underline{98}$, 503-517.

Specht CG und Schoepfer R (2001): Deletion of the alpha-synuclein locus in a subpopulation of C57BL/6J inbred mice. BMC Neurosci $\underline{2}, 11$.

Spillantini MG, Schmidt ML, Lee VM, Trojanowski JQ, Jakes R und Goedert M (1997): Alpha-synuclein in Lewy bodies. Nature $\underline{388}, 839-840$. 
Spillantini MG, Crowther RA, Jakes R, Hasegawa M und Goedert M (1998): alphaSynuclein in filamentous inclusions of Lewy bodies from Parkinson's disease and dementia with lewy bodies. Proc Natl Acad Sci U S A 95, 6469-6473.

Sulzer D und Rayport S (1990): Amphetamine and other psychostimulants reduce $\mathrm{pH}$ gradients in midbrain dopaminergic neurons and chromaffin granules: a mechanism of action. Neuron $\underline{5}$, 797-808.

Surguchov A, Surgucheva I, Solessio E und Baehr W (1999): Synoretin--A new protein belonging to the synuclein family. Mol Cell Neurosci 13, 95-103.

Teng L, Crooks PA, Sonsalla PK und Dwoskin LP (1997): Lobeline and nicotine evoke $[3 \mathrm{H}]$ overflow from rat striatal slices preloaded with $[3 \mathrm{H}]$ dopamine: differential inhibition of synaptosomal and vesicular [3H]dopamine uptake. J Pharmacol Exp Ther 280, 1432-1444.

Towbin H, Staehelin T und Gordon J (1979): Electrophoretic transfer of proteins from polyacrylamide gels to nitrocellulose sheets: procedure and some applications. Proc Natl Acad Sci U S A $\underline{76}$, 4350-4354.

Ueda K, Fukushima H, Masliah E, Xia Y, Iwai A, Yoshimoto M, Otero DA, Kondo J, Ihara Y und Saitoh T (1993): Molecular cloning of cDNA encoding an unrecognized component of amyloid in Alzheimer disease. Proc Natl Acad Sci U S A 90, 11282-11286.

van der Putten H, Wiederhold KH, Probst A, Barbieri S, Mistl C, Danner S, Kauffmann S, Hofele K, Spooren WP, Ruegg MA, Lin S, Caroni P, Sommer B, Tolnay M und Bilbe G (2000): Neuropathology in mice expressing human alpha-synuclein. J Neurosci 20, 6021-6029.

Wakabayashi K, Engelender S, Yoshimoto M, Tsuji S, Ross CA und Takahashi H (2000): Synphilin-1 is present in Lewy bodies in Parkinson's disease. Ann Neurol 47, 521-523.

Wei Y, Zhang Y, Derewenda U, Liu X, Minor W, Nakamoto RK, Somlyo AV, Somlyo AP und Derewenda ZS (1997): Crystal structure of RhoA-GDP and its functional implications. Nat Struct Biol $\underline{4}$, 699-703.

Weinreb PH, Zhen W, Poon AW, Conway KA und Lansbury PT, Jr. (1996): NACP, a protein implicated in Alzheimer's disease and learning, is natively unfolded. Biochemistry $\underline{35}$, 13709-13715.

Wilkinson KD, Lee KM, Deshpande S, Duerksen-Hughes P, Boss JM und Pohl J (1989): The neuron-specific protein PGP 9.5 is a ubiquitin carboxyl-terminal hydrolase. Science 246 , 670-673.

Wilkinson KD, Deshpande S und Larsen CN (1992): Comparisons of neuronal (PGP 9.5) and non-neuronal ubiquitin C-terminal hydrolases. Biochem Soc Trans 20, 631-637.

Zhang J, Graham DG, Montine TJ und Ho YS (2000a): Enhanced N-methyl-4-phenyl1,2,3,6-tetrahydropyridine toxicity in mice deficient in $\mathrm{CuZn}$-superoxide dismutase or glutathione peroxidase. J Neuropathol Exp Neurol 59, 53-61.

Zhang Y, Dawson VL und Dawson TM (2000b): Oxidative stress and genetics in the pathogenesis of Parkinson's disease. Neurobiol Dis $\underline{7}, 240-250$. 


\section{Danksagung}

Herrn Prof. Dr. med. T. C. Südhof und Herrn Dr. med. M. Geppert danke ich für die Anregung und Betreuung der Arbeit.

Herrn Prof. Dr. med. T. C. Südhof, Herrn PD Dr. rer. nat. N. Brose und Herrn Prof. Dr. rer. nat. R. Jahn danke ich für ihre Unterstützung und viele anregende Diskussionen.

Herrn PD Brose, Herrn Prof. Dr. rer. nat. K.-A. Nave und Herrn Prof. Dr. rer. nat. T. A. Trautner danke ich für die finanzielle Unterstützung, die Aufrechterhaltung des Laborplatzes und den Zugang zu Abteilungsressourcen für die Durchführung dieser Arbeit.

Auch bedanke ich mich bei Herrn F. Benseler und Frau I. Thannhäuser für die DNASequenzierungen und -synthesen, bei Herrn Dr. S. Takamori für die Unterstützung bei der Durchführung der Dopamintransportmessungen und bei meinen Kollegen für die interessanten Diskussionen und den Zugang zu Antikörperressourcen.

Mein besonderer Dank gilt Herrn Dr. F. Fornai für die fruchtbare Zusammenarbeit und die Einführung in tierexperimentelle Parkinson-Syndrome und Herrn Dr. med. vet. Riedesel und seinen Mitarbeitern, insbesondere Frau S. Schmidt und Frau U. Bornemann, für die Unterstützung bei der Herstellung und Zucht transgener Mäuse. 


\section{Lebenslauf}

Am 24.07.1969 wurde ich in Göttingen geboren. Ich bin verheiratet und Vater einer Tochter.

Nach Besuch des Reismann-Gymnasium in Paderborn erhielt ich die Allgemeine Hochschulreife am 11.05.1989.

Das Biochemiestudium begann ich zum Wintersemester 1989/1990 an der Universität Bayreuth und schloß es nach Wechsel an die Universität Hannover am 31.10.1994 erfolgreich ab. Die Arbeiten für die naturwissenschaftliche Promotion führte ich unter Anleitung von Herrn Prof. Dr. med. T. C. Südhof am Max-Planck-Institut für Experimentelle Medizin in Göttingen durch und bekam die Doktorwürde am 06.12.2000 von der Universität Hannover verliehen.

Das Medizinstudium begann ich zum Wintersemester 1992/1993 an der Medizinischen Hochschule Hannover und schloß es nach Wechsel an die Universität Göttingen am 25.05.2000 erfolgreich ab.

Die medizinische Promotion begann ich am 01.01.1997 in der Abteilung Molekulare Neurobiologie am Max-Planck-Institut für Experimentelle Medizin. 